
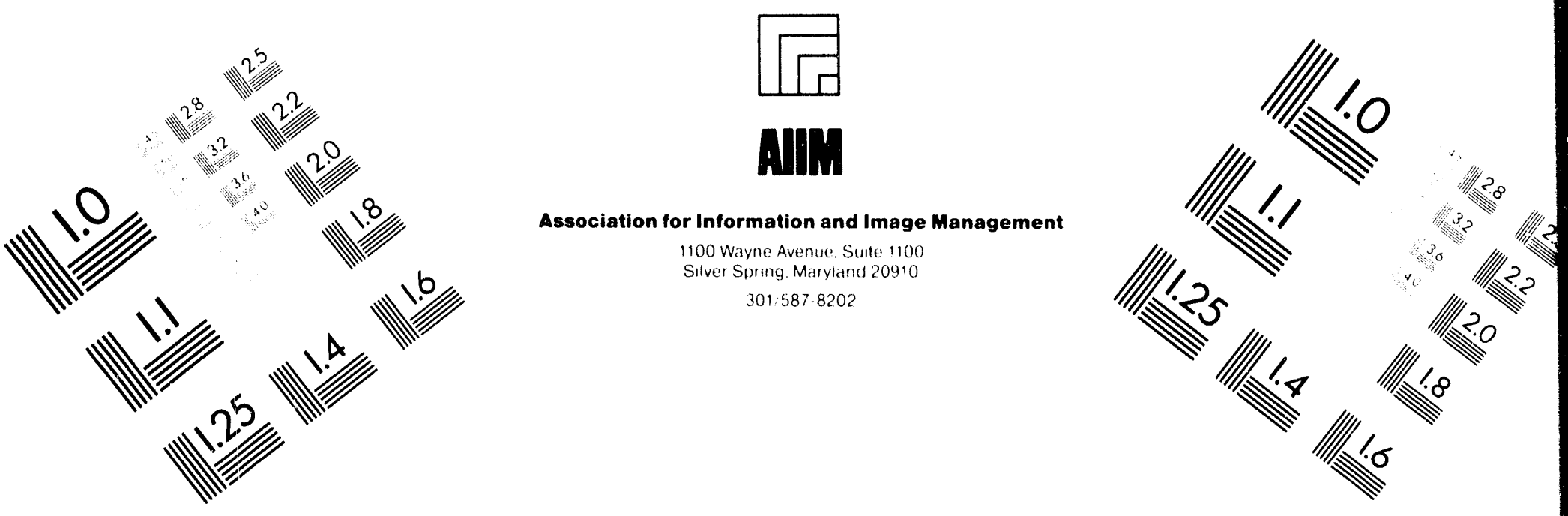

\title{
Centimeter
}

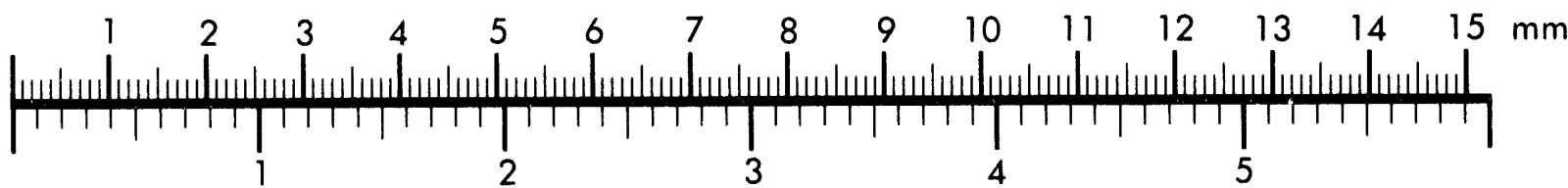

Inches
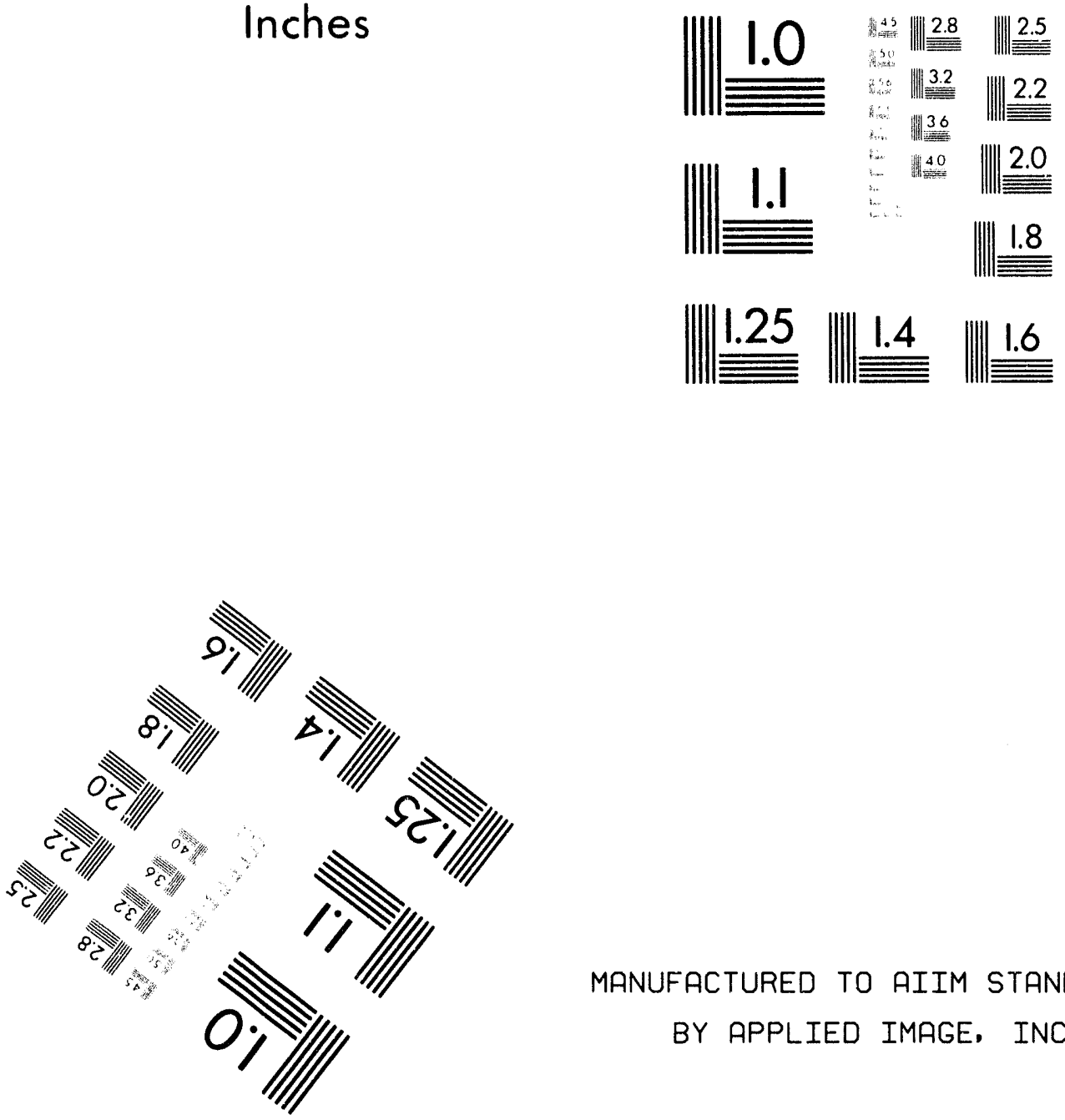

MANUFACTURED TO AIIM STANDARDS

BY APPLIED IMAGE, INC.

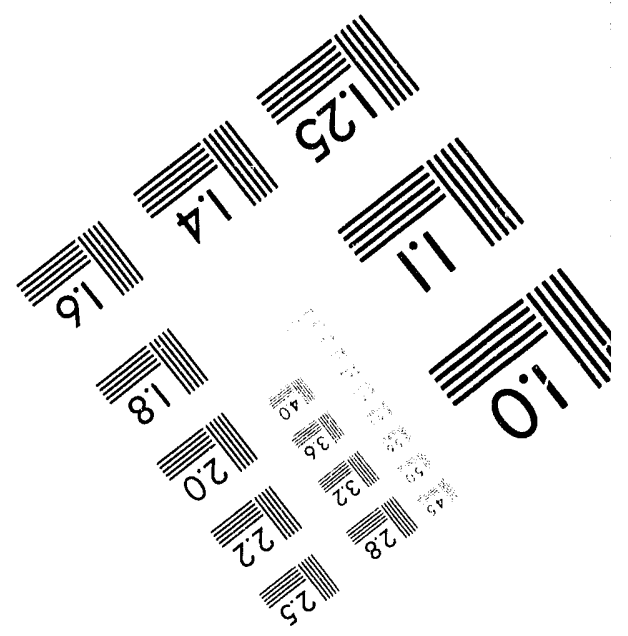



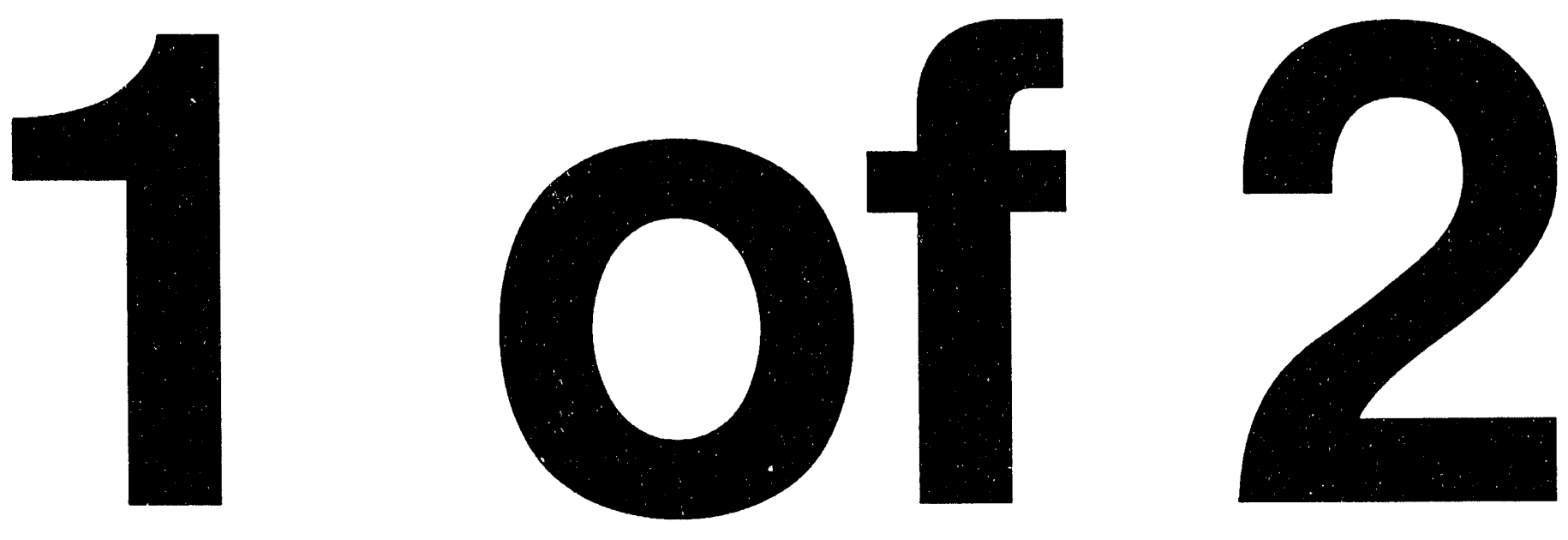
OAK RIDGE
NATIONAL
LABORATORY

MARTIN MAGRETRA

\section{Catalog of Data Bases and Reports}

\author{
Environmental Sciences Division
}

Publication No. 4244
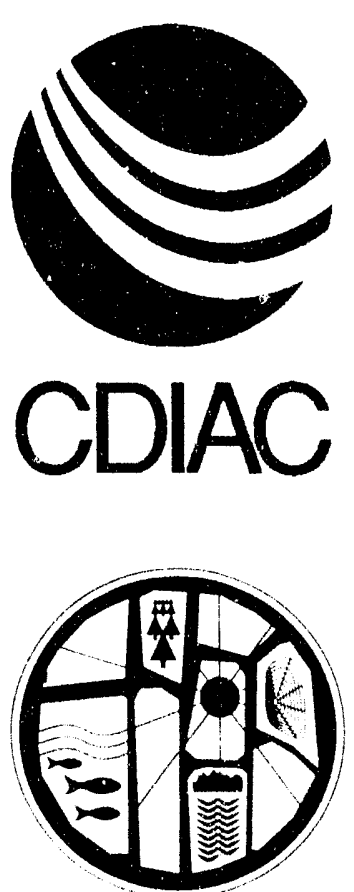

MANAGED BY

MARTIN MARIETTA ENERGY SYSTEMS, INC.

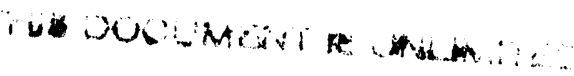


This report has been reproduced directly from the best available copy.

Available to DOE and DOE contractors from the Office of Scientific and Technical Information, P.O. Box 62, Oak Ridge, TN 37831; prices available from (615) 576-8401, FTS 626-8401.

Available to the public from the National Technical Information Service. U.S. Department of Commerce, 5285 Port Royal Rd., Springfield, VA 22161.

This report was prepared as an account of work sponsored by an agency of the United States Government. Neither the United States Government nor any agency thereot, nor any of their employees, makes any warranty, express or implied, or assumes any legal liability or responsibility for the accuracy, completeness, or usefulness of any information, apparatus, product, or process disclosed, or represents that its use would not infringe privately owned rights. Reference herein to any specific commercial product, process, or service by trade name, trademark, manufacturer, or otherwise, does not necessarily constitute or imply its endorsement, recommendation, or favoring by the United States Government or any agency thereof. The views and opinions of authors expressed herein do not necessarily state or reflect those of the United States Government or any agency thereof. 


\title{
Carbon Dioxide Information Analysis Center World Data Center-A for Atmospheric Trace Gases
}

\section{Catalog of Data Bases and Reports}

\author{
Environmental Sciences Division
}

Publication No. 4244

April 1994

Prepared for the

Global Change Research Program

Environmental Sciences Division

Office of Health and Fnvironmental Research

U.S. Department of Energy

Budget Activity Number KP 0500000

Prepared by the

Carbon Dioxide Information Analysis Center

Oak Ridge National Laboratory

Oak Ridge, Tennessee 37831-6335

managed by

Martin Marietta Energy Systems, Inc.

for the

U.S. Department of Energy

under Contract No. DE-AC05-84OR2 1400 


\section{Introduction}

This document, Catalog of Data Bases and Reports, provides information about the many reports and other materials made available by the U.S. Department of Energy's (DOE's) Global Change Research Program (GCRP). It is divided into nine sections plus author and title indexes:

Section A--U.S. Department of Energy Global Change Research Program Research Plans and Summaries

Section B-U.S. Department of Energy Global Change Research Program Technical Reports

Section C-U.S. Department of Energy Atmospheric Radiation Measurements (ARM) Program Reports

Section D-Other U.S. Department of Energy Reports

Section E-CDIAC Reports

Section F-CDIAC Numeric Data and Computer Model Distribution

Section G-Other Data Sets Distributed by CDIAC

Section H-USDA Reports on Response of Vegetation to Carbon Dioxide

Section I-Other Publications

The reports in Sect. A provide information about the scope, activities, and direction of the GCRP. Sections B, $C, D$, and $E$ contain information about research that has been sponsored by GCRP, including those produced by CDIAC.

The numeric data packages (NDPs) and computer model packages (CMPs) (described in Sect. F) have been compiled by GCRP's Carbon Dioxide Information Analysis Center (CDIAC). NDPs and CMPs include documents and transfer media [i.e., 9-track magnetic tape(s), IBM-formatted floppy diskettes, or CD-ROM]. The data may also be obtained by accessing CDIAC's anonymous FTP area. The documentation provides complete descriptions of the data set, describes limitations and restrictions of the data, suggests data applications, provides tabular listings and graphical displays of the data, and includes reprints of pertinent literature. The transfer media provide machine-readable data files, FORTRAN and SAS retrieval codes to read and print the data files, and descriptive files that explain the contents and format of each data file. Section $G$ describes additional data bases distributed by CDIAC.

Section $\mathrm{H}$ describes reports about research in the joint program of the U.S. Department of Agriculture and GCRP, and Sect. I contains reports from various workshops, symposia, and reviews.

CDIAC operates the World Data Center-A (WDC-A) for Atmospheric Trace Gases, a component of the World Data Center System coordinated by the International Council of Scientific Unions. CDIAC publications that are also WDC-A reports are denoted by (WDC-A) beneath the publication number.

Reports and materials listed herein are distributed free of charge by CDIAC while supplies last. Documents in Sects. A, B, C, D, and F (document only, no magnetic media) can also be purchased from the National Technical Information Service or DOE's Office of Scientific and Technical Information.

Other materials and services are available, including a semiannual newsletter, CDIAC Communications, which provides information about current global change research, CDIAC services, and new publications and upcoming meetings related to global change.

To request any of the materials listed in this booklet call or write:

Carbon Dioxide Information Analysis Center

Oak Ridge National Laboratory

P.O. Box 2008

Oak Ridge, TN $37831-6335$

(615) 574-0390; FAX (615) 574-2232

Bitnet: CDP@ORNLSTC; Internet: CDP@ORNL.GOV; Omnet: CDIAC 
Section A

\section{U.S. Department of Energy Global Change Research Program Research Plans and Summaries}


The Carbon Dioxide Research Plan: A Summary

(November 1983)

DOE/ER-

0178

Carbon Dioxide Research Division, U.S. Department of Energy

The purpose of this plan is to provide all present and potential participants in evaluating the carbon dioxide issue with a clear picture of the current scope and activities of the Department of Energy's Carbon Dioxide Research Program and the direction it is likely to take in the near future. The plan summarizes the goals, objectives, and approaches used in research on the carbon cycle. climate and first detection, vegetation responses, and indirect effects.

\section{$\mathrm{CO}_{2}$ Climate Research Plan}

DOE/ER-

(December 1983)

0186

\section{R. Riches, Carbon Dioxide Research Division}

This research plan, which is part of the U.S. Department of Energy's Carbon Dioxide Research Program, addresses the questions related to the global and regional rate of $\mathrm{CO}_{2}$-induced climate change. The objective of the plan is to define the key questions in such a way that research is directed at experiments where answers are needed, rather than at experiments where answers can be easily obtained.

\section{Vegetation Response to Carbon Dioxide Research Plan (January 1984)}

\section{R. C. Dahiman, Carbon Dioxide Research Division}

This report summarizes the U.S. Department of Energy Carbon Dioxide Research Program's research plan on vegetation response to carbon dioxide. The plan includes a short history of the effects of $\mathrm{CO}_{2}$ on vegetation followed by a description of the structure of the vegetation response system. The main part of the plan describes the research tasks within the system, and the final section summarizes the program priorities and scheduling.

\section{Carbon Cycle Research Plan} (January 1984)

\section{R. C. Dahlman, Carbon Dioxide Research Division}

This report summarizes the carbon cycle research plan of the Carbon Dioxide Research Program of the U.S. Department of Energy. It includes a short history of atmospheric $\mathrm{CO}_{2}$ levels and what is known about global carbon cycle exchanges. The main part of the plan describes the research tasks and the relationship and priorities of the components. 
DOE/ER-

0202

DOE/ER-

0202/1

DOE/ER-

0299

DOE/ER0347

\section{Carbon Dioxide and Climate: Summaries of Research in} FY 1983 and FY 1984

(September 1984)

Carbon Dioxide Research Division, U.S. Department of Energy

This Program Summary documents the activities and products of the (arbon Dioxide Research Program in Fiscal Years 1983 and 1984. It includes descriptions of all projects funded annually in these years or under multiple year contracts from liscal Year 1982. Also, a brief summary of the Program's goals, objectives, and organization is provided.

\section{Carbon Dioxide and Climate: Summaries of Research in FY 1985}

(September 1985)

Carbon Dioxide Research Division, U.S. Department of Energy

This Program Summary documents the activities and products of the Carbon loioxide Research Program in Fiscal Year 1985. It includes descriptions of all projects funded and a brief summary of the CDR Program's goals, objectives, and organization.

\section{Carbon Dioxide and Climate: Summaries of Research in FY 1986}

(October 1986)

Carbon Dioxide Research Division, U.S. Department of Energy

This Program Summary documents the activities and products of the Carbon Dioxide Research Program in Fiscal Year 1986. It includes descriptions of all projects funded and a brief summary of the CDR Program's goals, objectives, and organization.

\section{Carbon Dioxide and Climate: Summaries of Research in FY 1987}

(October 1987)

Carbon Dioxide Research Division, U.S. Department of Energy

This Program Summary documents the activities and products of the Carbon Dioxide Research Program in Fiscal Year 1987. It includes descriptions of all projects funded and a brief summary of the CDR Program's goals, objectives, and organization. 
Carbon Dioxide and Climate: Summaries of Research in FY 1988

DOE/ER(October 1988)

Carbon Dioxide Research Division, U.S. Department of Energy

This Program Summary documents the activities and products of the Carbon Dioxide Research Program in Fiscal Year 1988. It includes descriptions of all projects funded and a brief sumnary of the CDR Program's goals, objectives, and organization.

Carbon Dioxide and Climate: Summaries of Research in FY 1989 (October 1989)

Carbon Dioxide Research Program, U.S. Department of Energy

This Program Summary documents the activities and products of the Carbon Dioxide Research Program in Fiscal Year 1989. It includes descriptions of all projects funded and a brief summary of the CDR Program's goals, objectives, and organization.

\section{Carbon Dioxide and Climate: Summaries of Research in FY 1990} (October 1990)

Carbon Dioxide Research Program, U.S. Department of Energy

This Program Summary documents ine activities and products of the Carbon Dioxide Research Program in Fiscal Year 1990. It includes descriptions of all projects funded and a brief summary of the CDR Program's goals, objectives, and organization.

Carbon Dioxide and Climate: Summaries of Research in FY 1991 (October 1991)

\section{Carbon Dioxide Research Program, U.S. Department of Energy}

This Program Summary describes the activities and products of the Carbon Dioxide Research Program in FY 1991. It includes descriptions of all projects funded and a brief summary of the CDR program's goals, objectives, and organization.

\section{Multi-Year Strategic Plan for the Atmospheric Studies in Complex Terrain (ASCOT) Program} (June 1992)

\section{Environmental Sciences Division, U.S. Department of Energy}

The effects of topographical forcing on the atmosphere's planetary boundary layer encompass a broad range of phenomena, an understanding of which is essential for a variety of theoretical and practical applications in the atmospheric sciences. In particular, the transport and diffusion of airborne pollutants in regions of complex terrain are strongly affected by the properties of 
the boundary layer. The ability to describe and predict the fate of airborne contaminants, from either routine or accidental releases, is a crucial issue in air quality and emergency preparedness and response studies. In many instances, however, the relevant boundary layer processes have not yet been well-characterized, let alone understood. The effects on boundary layer properties arising from inhomogeneous surface fluxes of heat and moisture into the atmosphere over mountainous regions have received relatively little attention but are expected to be significant. Such effects, as well as the interactions of local and regional atmospheric circulations with large scales of flow, are a central problem in the development of regional- and global-scale computational models used to predict climate change and its possible effects on smaller scales.

The U.S. Department of Energy's (DOE) Atmospheric Studies in Complex Terrain (ASCOT) program addresses these issues through an integrated program of measurements, modeling and analysis. Specifically, ASCOT is a basic research program studying the properties of atmospheric boundary layers over nonuniform terrain and the interactions among various scales of motion that influence those properties. ASCOT has two principal goals: (1) to characterize, understand, and predict boundary layer structure and evolution over inhomogeneous terrain, with scales of motion of order $1 \mathrm{~km} \mathrm{to} 100 \mathrm{~km}$, and (2) to develop methodologies needed to apply this knowledge to DOE mission needs, both sitespecific and generic, including site safety, air quality, and climate change.

The current foci of ASCOT activities are the Tennessee Valley, particularly near Oak Ridge National Laboratory and the Front Range of the Colorado Rocky Mountains in the vicinity of DOE-s Rocky Flats Plant. The first site is a broad valley between two mountain chains, whereas the second forms the interface between a large mountain range and an adjacent plain. Both sites develop boundary layers whose properties are strongly affected by local terrain features as well as by larger-scale terrain and synoptic influences. Within these areas, ASCOT's objectives are to characterize and analyze the structure of the planetary boundary layer and its principal thermally driven circulations on scales on the order 1 to $100 \mathrm{~km}$ and to develop, test, and validate models describing the resultant transport and diffusion of atmospheric pollutants that may be released there.

Technological advances developed through this research will be made available to scientists at the two DOE sites. As the ASCOT program acquires additional instrumentation, particularly remote-sensing profilers for measuring winds and temperatures aloft, it will include more detailed studies of the properties of the boundary layer over mountains themselves. These objectives are closely aligned not only with mission requirements of DOE but also with initiatives of the National Energy Strategy.

DOE/ER0565T

\section{Global Change Research: Summaries of Research in FY 1992 (October 1992)}

\section{Environmental Sciences Division, U.S. Department of Energy}

This document describes the ac: vities and products of the Global Change Research Program in FY 1992 and is organized into four main sections:

\section{Introduction}

- provides a mission statement, need, and mandate for a global-climate-change program

- describes program relationships within the Department of Energy and the current situation regarding the global-climate-change issue 
- lists a prioritization framework and specific activities

- $\quad$ shows level of effort

\section{Research Areas and Project Descriptions}

- describes scientific questions in each research area

- $\quad$ provides descriptions of individual research projects

- lists the expected product for each project

- $\quad$ shows the research approach or method used in each project and

- provides results to date when applicable

\section{Appendix}

- $\quad$ provides locator information on principal investigators for the overall report

\section{Indexes}

- $\quad$ provides indexes of keywords, principal investigators, and research instituitions for easy reference

Questions concerning DOE's Global Change Research Program or specific projects may be addressed to the Environmental Sciences Division, U.S. Department of Energy, ER-74, Washington. D.C. 20585. The Program's telephone number is (301) 903-3281.

\section{Atmospheric Sciences Program Summaries of Research in FY 1992}

(November 1992)

\section{Environmental Sciences Division, U.S. Department of Energy}

This document describes the activities and products of the Atmospheric Science Program of the Environmental Sciences Division, Office of Health and Environmental Research, Office of Energy Research, in FY 1992. The report is organized into four main sections:

\section{Introduction}

- provides a mission statement, need, and mandate for an atmospheric science program

- ties atmospheric science issues to the research approach, program goals, and objectives

- relates each specific research area to the overall goals of the program

- $\quad$ shows the level of effort

\section{Research Areas and Project Descriptions}

- describes scientific questions in each research area

- $\quad$ provides descriptions of individual research projects

- lists the expected product for each project

- shows the research approach or methodology used in each project

- provides results to date when applicable 
Appendixes

- provides addresses of principal investigators and defines acronyms used in the text

Indexes

- provides locator information on subjects, principal investigators, and research institutions for the overall report

Questions concerning the Atmospheric Sciences Program or specific projects may be addressed to the Environmental Sciences Division, U.S. Department of Energy. ER-74. Washington, D.C. 20585. The Program's telephone number is (301) 903-3281.

DOE/ER0575T

DOE/ER0586T

\section{Overview of the DOE Atmospheric Chemistry Program's Ozone Project (January 1993)}

\section{Environmental Sciences Division, U.S. Department of Energy}

This document, which describes the background and initial design for the DOE Ozone Project, defines initial DOE plans.

\section{Atmospheric Chemistry Program. Program Operation Plan (April 1993)}

\section{Environmental Sciences Division, U.S. Department of Energy}

The Department of Energy's Atmospheric Chemistry Program (ACP) was initiated in 1991 to coordinate DOE's university and federal-laboratory atmospheric-chemistry research and to focus these efforts on national and international information requirements in the atmospheric-chemistry field.

This Program Operations Plan describes the structure and vision of the effort designed to fulfill these needs, and is divided into two major components. The first of these is a Strategic Plan, which outlines the ACP's rationale, objectives, and vision and describes the products that are anticipated over a future 10 -year period.

The second component of the Program Operations Plan, the Implementation Plan, deals directly with resource considerations. As such, it focuses on practical implementation of Strategic-Plan elements at the individual research institutions, the anticipated scientific contributions of these groups, and their coordination within the ACP. In contrast to the Strategic Plan, the Implementation Plan extends only 5 years into the future. 


\section{Atmospheric Sciences Program. Summaries of Research in FY 1993 DOE/ER- (November 1993)

Environmental Sciences Division, U.S. Department of Energy

This document describes the activities and products of the Atmospheric Sciences Program of the Environmental Sciences Division, Office of Health and Environmental Research, Office of Energy Research, in FY 1993. The report is organized into four main sections.

\section{Introduction}

- provides a mission statement, need, and mandate for an atmospheric science program

- ties atmospheric science issues to the research approach, program goals, and objectives

- relates each specific research area to the overall goals of the program

- $\quad$ shows the level of effort

\section{Research Areas and Project Descriptions}

- describes scientific questions in each research area

- $\quad$ provides descriptions of individual research projects

- lists the expected product for each project

- $\quad$ shows the research approach or methodology used in each project

- $\quad$ provides results to date when applicable

\section{Appendixes}

- $\quad$ provides addresses of principal investigators and defines acronyms used in the text

\section{Indexes}

- $\quad$ provides locator information on subjects, principal investigators, and research institutions for the overall report

Questions concerning the Atmospheric Sciences Program or specific projects may be addressed to the Environmental Sciences Division, U.S. Department of Energy, ER-74, Washington, D.C. 20585. The Program's telephone number is (301) 903-3281.

\section{Global Change Research: Summaries of Research in FY 1993 (October 1993)}

\section{Environmental Sciences Division, U.S. Department of Energy}

This document describes the activities and products of the Global Change Research Program in FY 1993. The report is organized into four main sections.

\section{Introduction}

- $\quad$ provides a mission statement, need, and mandate for an global-climate-change program

- describes program relationships within the Department of Energy and the current situation regarding the global-climate-change issue

- lists the program objectives and specific activities

- $\quad$ shows the distribution of research and the level of effort 


\section{Research Areas and Project Descriptions}

- describes scientific questions in each research area

- provides descriptions of individual research projects

- provides in-depth information on the research approach

- lists the expected product for each project

- shows the research approach or method used in each project

- provides results to date when applicable

\section{Appendixes}

- provides locator information on principal investigators for the overall report and defines acronyms used in the text

\section{Indexes}

- provides indexes of keywords, principal investigators, and research institutions for easy reference

Questions concerning the Global Change Research Program or specific projects may be addressed to the Environmental Sciences Division, U.S. Department of Energy, ER-74, Washington, D.C. 20585. The Program's telephone number is (301) 903-3281. 
Section B

\section{U.S. Department of Energy Global Change Research Program Technical Reports}




\section{On Possible Changes in Global Sea Level and Their Potential Causes (DOE/NBB-0022, November 1982, 49 pp.)}

\section{T. P. Barnett, Scripps Institution of Oceanography}

The purpose of this paper is to review the hehavior of global sea level over the last century. This analysis of global sea level avoids the space and time bias of previous works. Between 1903-1969, a coherent pattern of increasing relative sea level (RSL) was found to exist on average at all stations analyzed. Subject to numerous assumptions, RSL increase associated with this pattern was $15 \mathrm{~cm} /$ century. A similar analysis of the period 1930.1975 again showed RSL. increasing everywhere except in the western half of the North Pacific Ocean in which a decrease was found. This decrease in RSL is substantiated further by hydrographic data. Thus, in recent years, the concept of a global sea level rise is not supported. The temporal behavior of the near global signals from both time periods was approximated well by a simple linear trend. There was no evidence of a more rapid rise in RSL in recent years.

In this analysis, potential causes of the above RSL change were investigated. Changes in the position of the earth's axis of rotation support the idea that the RSL change was caused by approximately equal melting of Greenland/Antarctica ice. Changes in the length of day only marginally support this idea. However, other attractive geophysical explanations for variations in both these astronomical parameters exist. Observed change in sea surface temperature (SST), if representative of reasonable changes in vertical thermal structure, could give the observed RSL change. However, the SST data are likely biased instrumentally toward an increasing trend. Also, thermal expansion of the oceans would not significantly affect the rotational parameters although changes in these parameters could be the result of non-RSL, related processes. Changes in ocean circulation and subsidence along all the coastal margins seem unlikely causes of the observed change in RSL. In summary, it is not possible at this time to explain reliably the apparent increase in RSL.

\section{Effects of Approximate Radiation Treatments Used in the Climate Models on the Clear Sky Thermal Radiation Flux and Its Perturbation Due to $\mathrm{CO}_{2}$ Increase (DOE/ER/60023-1, January 1983, 41 pp.)}

\section{W-C. Wang, Atmospheric and Environmental Research, Inc.}

This report presents an assessment of the effects of approximate radiation treatments, which are commonly adopted in climate models, on the calculated thermal radiation flux, and of the effect of the approximations on the flux's perturbation due to $\mathrm{CO}_{2}$ increase.

In this assessment, the uncertainties in the calculated clear sky thermal flux associated with the approximations (Curtis-Godson and correlated-k methods) for inhomogeneous atmosphere, the use of exponential kernel (diffusivity factor) approximation, the treatment of model layer temperature (constant and linear Planck function), and the representation (narrow and wide band) for the correlation of spectral features between the overlapping gases and the Planck function are examined. 
The results indicate that for an inhomogeneous atmosphere the correlated-k method calculates nearly identical flux and flux perturbation as those computed using the curtis-(iodson method. The results also suggest that the use of a diffusivity factor (1.66) to represent the zenith angle integration is appropriate for $\mathrm{CO}_{2}$ thermal radiation calculations.

However, the narrow band representation which accounts for the correlation of spectral features tends to calculate a smaller atmospheric opacity than the wide band representation which neglects such a correlation. As a result, the latter computes a much larger downward flux at surface as well as its increase due to $\mathrm{CO}_{2}$ increase. It is also found that the calculated thermal hux is very sensitive to the treatment of model layer temperature.

\title{
TR003 Carbon Dioxide Emissions from Fossil Fuels: A Procedure for Estimation and Results for 1950-1981 (DOE/NBB-0036, June 1983, 75 pp.)
}

\author{
G. Marland, and R. M. Rotty, Oak Ridge Associated Universities, Institute for Energy \\ Analysis
}

The purpose of this report is to provide detailed documentation for a procedure to estimate $\mathrm{CO}$ emissions from fossil fuels and to make independent and updated estimates of the rate at which fossil fuel combustion has released carbon dioxide into the atmosphere.

With new data and revised methods, an attempt is made to reduce the uncertainties. For each type of fuel, the annual global $\mathrm{CO}_{2}$ emissions are the product of three terms: the amount of fuel produced, the fraction of the fuel that becomes oxidized, and a factor for the carbon content of the fuel.

An important outcome of this independent examination of the full computation of $\mathrm{CO}_{2}$ emissions from fossil fuels is that no fundamental oversights in the earlier methods of keeling and of Rotty were discovered. An additional result of this examination is estimates of the uncertainties in the final numbers. The largest absolute uncertainty enters the computation with the United Nations data set for fuel production but even here global fuel production is dominated by a small number of countries, most of which are believed to maintain and publish good statistical records. Although the estimated uncertainty in the $\mathrm{CO}_{2}$ emissions is about 10 percent, the trend of increasing emissions from fossil fuels is tirmly established.

\section{TR004 Carbon in Live Vegetation of Major World Ecosystems} (DOE/NBB-0037, June 1983, 152 pp.)

\section{J. S. Olson, J. A. Watts, and L. J. Allison, Oak Ridge National Laboratory}

The objectives of this research were to make a computer generated world map of vegetation and carbon density for natural and modified ecosystem complexes and to illustrate some human influences on the global carbon cycle. A data base was compiled to make a seven color 
ecology map (1:30,000,000 near the equator) of 44 land ecosystem mosaics or subdivisions in seven broad groups: Forest and Woodland: Interrupted Woods; Mainly Cropped. Residential. Commercial. and Park; Grass and Shrub Complexes; Tundra and Desert; Major Wetlands; and Other Coastal. Aquatic, and Miscellaneous.

The map provides a basis for making improved estimates of vegetation areas and carbon quantities, natural biological exchanges of $\mathrm{CO}_{2}$, and net historic shifts of carbon between the biosphere and the atmosphere. It is derived from the patterns of preagricultural vegetition or potential vegetation types and their relation to carbon content and from modern acrial surveys and intensive biomass data from research sites. Ecoșstem complexes are defined and located (with a $0.5^{\prime \prime} \times 0.5^{\circ}$ grid) to reflect the major climatic, topographic. and land-use patterns.

Estimates of biomass in trees and total carbon in live plants per unit are tabulated. The results help define the role of the terrestrial biosphere in the global carbon cycle. Results also imply major historic reductions of global carbon for broad regions and most vegetation types. Lowered estimates of carbon caused by forest harvest or clearing for crops in the last century imply lowered estimates of input of nonfossil $\mathrm{CO}_{2}$ to the atmosphere. The map of Major World Ecosystem Complexes indicates where some of the recent and future changes of organic carbon are most likely: in tree formations and wetlands where wood or peat reserves are still high in some of the interrupted woods where recent land-use transition rates have been high.

Refinement and use of the map and its associated data bases continue in research, for example. on flux estimates for fire, forest clearing, and other carbon exchanges in models of the global carbon cycle.

\section{Deforestation Measured by LANDSAT: Steps Toward a Method (DOE/EV/10468-1, June 1983, 62 pp.)}

G. M. Woodwell, J. E. Hobbie, R. A. Houghton, J. M. Melillo, B. J. Peterson, G. R. Shaver, and T. A. Stone, The Ecosystems Center, Marine Biological Laboratory

\section{B. Moore, Complex Systems Research Center, University of New Hampshire}

\section{A. B. Park, The Space Systems Division, General Eiectric Company}

The increase in atmospheric $\mathrm{CO}_{2}$ over the past century is due in part to deforestation. The LANDSAT system appears to have the potential for providing objective, synoptic and repetitive information on rates of clearing of forests globally. The purpose of this work was development of a method for using the LANDSAT system to determine net change in the area of forests, and thercfuic in the amount of carbon held in terrestrial systems, globally. Three approaches to the lise of LANDSAT data for this purpose seemed possible. First, if a sufficiently detailed clissification of a vegetation can be made from a single LANDSAT image, an estimate of net flux is possible through use of the model. This is the single image approach. Second, LANDSAT imagery might be used to construct two classification inventories of the amount of carbon in the vegetation at different dates. Finally, the technique of change detection using satellite imagery might be applied by subtracting the digital information in a later image from a former image to produce a third data set that records only the changes. It is, of course, these changes that are the objective. 
The change detection method holds the greatest promise heciuse it reduces the problems of misclassitication evident in the single and double inventory methods. The method was simplitied further by establishing the criteria of change as two gross changes, that from forest to non-forest. and that from non-forest to forest. The problems of classification of imagery have thereby been reduced to little more than detection.

A system of sampling was suggested for a global survey. Sampling would be stratified to favor areas where changes are abundant. Thirty-nine countries or states within countries account for $900^{\circ}$, of published estimates of deforestation in the tropics and subtropics. To cover these countries once by 1 ANDSAT requires about 1,200 scenes. Further stratificalion within countries can be based on zones or fronts of intense deforestation. I.ANDSAI imagery required to cover these anes is about 500 scenes. Since current estimates of deforestation in the tropies may vary by $6000^{0}$, a reduction of the uncertainty to,$-10^{\prime \prime}$ o may be a greater improvement than is appropriate. If an uncertainty of $-25 \%$ were aceptable, the required sample for the important tropical countries and for the fronts of deforestation would be 360 and 75 scenes, respectively. The cost of a live year program designed to reduce the uncertainty to $-25^{\circ}$, was estimated as 4 to 7 million dollars for datat and imagery analysis.

TR006 Response of the North American Corn Belt to Climate Warming (DOE/NBB-(0040, August 1983, $27 \mathrm{pp}$.)

\section{T. J. Blasing, and A. M. Solomon, Oak Ridge National Laboratory}

This report explains the projections of the influence of a climatic change on the location of the North American corn belt. The climate of this corn belt was characterized to estimate the effects of climatic change on that agricultural region. Heat and moisture characteristics of the current corm belt were identilied and mapped based on a simulated climate for a doubling of atmospheric ( $\left.{ }^{\circ}\right)_{2}$ concentrations. The result was a map of the projected corn belt corresponding to the simulated climatic change. Such projections were made with and without an allowance for carlier planting dates that could occur under a (O)-indued climatic warming. Because the direct effects of ( ()$^{\prime}$. increases on plants, improvements in farm technology, and plant breeding are not considered, the resulting projections represent an extreme or "worst" catse.

The results indicate that even for such a "worst" case, climatic conditions favoring corn production would not extend very far into Canada. Climatic "buffering" effects of the (ireat lakes would apparently retard northeastward shifts in com-belt location.

Changes in timing of annual climatological events are important to crop responses, but little is currently known about these phenomena. Timing is thus a major source of uncertainty in specifying agricultural responsiss to climatic change. 


\section{An Analysis of Concepts for Controlling Atmospheric Carbon Dioxide (DOE/CH/00016-1, December 1983, 66 pp.)}

\section{Steinberg, Brookhaven National Laboratory}

This report reviews and analyzes possible mitigating technologies and processes for the control of the $\mathrm{CO}_{2}$ effect. This analysis addresses the mitigation of the $\mathrm{CO}_{2}$ effect mainly by controlling the $\mathrm{CO}_{2}$ content in the atmosphere. As such, the steps involve either restriction of emission, or the removal, recovery, disposal, and reuse of $\mathrm{CO}_{2}$.

\section{Carbonate Chemistry of the Weddell Sea (DOE/EV/10611-4, March 1984, 118 pp.)}

\section{C.-T. A. Chen, College of Oceanography, Oregon State University}

Concurrent pH, calcium, and total alkalinity data were obtained in the eastern Weddell Sea during the winter of 1981 . These data represent the initial concentrations of calcium, alkalinity, and total $\mathrm{CO}$, in the most important source region of world ocean bottom waters at the time they were formed. For the first time, an evaluation of the variation of calcium and carbon cycles in the deep oceans referenced to the source water were made. The data were analyzed together with data from the literature, and the results indicated that: (1) the October pll values south of the Polar Front are indistinguishable from the November values, but the seasonal effect is large north of the front: (2) a large change in pH occurs at the ice edge; (3) partial pressure of $\mathrm{CO}_{2}$ in the Weddell Sea surface water is only slightly lower than the atmospheric value; (4) alkalinity does not show cross-ice-edge or seasonal variations, but the values seem to increase at a slower rate with decreasing temperature south of the Polar Front; (5) sea ice is relatively high in calcium and alkalinity concentrations; (6) mixing dominates the distribution of chemical properties; (7) pH is useful in identifying the sources of waters in the Weddell Sea, whereas calcium and alkalinity are not; (8) the surface water is deficient in $\mathrm{CO}_{2}$ from human activities because the pack ice blocks the air-sea exchange of gases; and (9) little excess $\mathrm{CO}_{2}$ can be found in the Antarctic Bottom Water. The situation may change, however, if the Weddell Sea ice coverage is reduced because of $\mathrm{CO}_{2}$-induced global warming.

[The data set is available on tape (NDP-028) from the Carbon Dioxide Information Analysis Center at Oak Ridge National Laboratory.|

\section{Response of Unmanaged Forests to $\mathrm{CO}_{2}$-Induced Climate Change: Available Information, Initial Tests, and Data Requirements (DOE/NBB-0053, April 1984, 93 pp.)}

\footnotetext{
A. M. Solomon, M. L. Tharp, D. C. West, G. E. Taylor, J. W. Webb, and J. L. Trimble, Oak Ridge National Laboratory

In this report, the scientific literature is reviewed to determine how tree recruitment, growth, and mortality are related to climate directly and indirectly through climate's modulation of plant competition, succession, and migration. The resulting potential responses of forest communities to climate changes expected under increased atmospheric $\mathrm{CO}_{2}$ concentrations are described. Empirical data sets, containing measurements of climate variables and tree
} 
densities in the eastern United States, are evaluated for their potential use in statistical projections of forest responses to climate change. $A$ sso evaluated for projection purposes is a forest-stand simulation model based on many of the processes that determine forest dymanics. The ability of the model to reproduce extant forests at 21 sites in eastern North America was first veritied. Then, a model experiment simulated responses of forests at those 21 locations 10 a scenario in which climate responds to doubling and quadrupling of ( $1 \mathrm{O}_{2}$. The implications of the forest simulations are discussed in terms of internal forest dymamics and requirements for specified information from climate projections, as well as for additional model developments that could address remaining ecological uncertainties.

\title{
Computer Implementation of a Globally Averaged Model of th: World Carbon Cycle (DOE/NBB-0062, July 1984, 79 pp.)
}

\author{
W. R. Emanuel, G. G. Killough, W. M. Post, and H. H. Shugart, ()ak Ridge National \\ Laboratory
}

M. P. Stevenson, Science Applications, Inc.

A model of the global carbon cycle and its computer implementation are described in this report. Three major components of the cycle - the atmosphere oceans, and terrestrial ecosystems - are represented. The dynamics of total carbon (i.e., mass of ${ }^{2} \mathrm{C}^{\circ}+{ }^{16} \mathrm{C}$ and ${ }^{1.1} \mathrm{C}^{\circ}$ ), and lle two less abundant isotopes, " $\mathrm{C}$ and ${ }^{14} \mathrm{C}$, are treated. The model equations are derived from a compartment diagram of the cycle by expressing mass balance for each compartment as a first-order differential equation. The atmosphere is represented by a single compartment and the oceans by 19 globally-averaged layers with depth. Carbon in terrestrial ecosystems is divided among tive compartments. The model simulates phenomena on time scales from several years to several centuries. Carbon dioxide released to the atmosphere by fossil fuel combustion and " produced naturally in the atmosphere or by nuclear weapons tests are incorporated as exogenous inpuls. Forest clearing results in a direct transter of carbon to the atmosphere to "trees" and "ground vegetation" are altered as a result of land-use change.

The model is implemented in FORTRAN. Readily available routines are used for standard numerical procedures. The model does not aceess exogenous data sets: parameter values and control variables are set in data intialization statements. Tabulated results are provided als printed output.

\section{TR011 Historical Carbon Dioxide: Abundances Derived from the Smithsonian Spectrobolograms (DOE/NBB-0063, August 1984, $11+\mathrm{pp}$. )}

\section{G. M. Stokes, J. C. Barnard, and E. W. Pearson, Pacific Northwest Laboratory}

This report describes results of the analysis of the Smithsonian Solar Comstant Program spectroscopic data to determine atmospheric $\mathrm{CO}$, concentrations before 1958. A representative sample of Smithsonian Spectrobolograms were analyzed for 1935, 1941, and 1948. The resulting carbon dioxide concentrations for those years were $297.7+-5.6,298.4+6.3$, and 
$308.3+-4.6 \mathrm{ppm}$, respectively. These results also yield an anmual increase of $0.59+27 \mathrm{ppm}$ for the average trend for the period of 1935 through 1948.

The method of analysis used to obtain these results is described in detail. It appears to be much less sensitive to the sources of error that have plagued earlier analyses of the same data. The results also offer obvious guidance on steps that may be taken to improve the analysis of the data.

\section{Seasonal Climate Scenarios for Europe and North America in a High- $\mathrm{CO}_{2}$, Warmer World (DOE/EV/10098-5, August 1984, 70 pp.)}

\section{J. P. Palutikof, T. M. L. Wigley, and J. M. Lough, University of East Anglia, Norwich, United Kingdom}

This report presents work done to determine possible patterns of climate change in firope and North America associated with a global $\mathrm{CO}_{2}$-induced warming. The scenarios presented are based on warm and cold periods from the twentieth-century instrumental record. Four sets of scenarios were prepared, each using different criteria for the selection of data used in the construction process. One of these sets is based on twenty-year time-scale data from the period of warming that occurred during the early twentieth century. Since this warming may be partly attributed to increasing $\mathrm{CO}_{2}$, and since the warming effect of $\mathrm{CO}_{2}$ is a medium to long time scale phetiomenon, this particular scenario is preferred over the others.

The regional patterns of three surface parameters are discussed for the different scenarios: sea level pressure, temperature, and precipitation. Contrasts that arise between the scenarios because of differences in the construction method are critically examined. Where the construction process allows, maps are also presented of the change in temperature and rainfall variability.

A.though contrasts do occur between the patterns of the four scenarios for Europe, there are also some notable similarities. Winters are expected to become colder (and more variable) over large parts of the continent. This cold zone is associated with an increase in blocking frequency. Rainfall should decrease overall in spring and summer, whereas autumn and winter should be wetter in a warm world. The changes for both temperature and rainfall can be related to the scenario pressure patterns.

The North American scenarios for temperature and pressure exhibit much less inter-seasonal contrast than is the case for Europe. Temperatures are shown to be generally higher throughout the year in a warm world. Of the three scenarios for which temperature maps are presented, only that based on long time scale changes during the early twentieth century warming shows any extensive development of cooler conditions over continental areas. Temperature variability should be lower. North America shares with Europe indications that winters will be wetter, but autumns are expected to be mainly drier. 


\section{TR013 An Analysis of Possible Future Atmospheric Retention of Fossil Fuel $\mathrm{CO}_{2}$ (DOE/OR/21400-1, September 1984, 109 PV.)}

\section{J. A. Edmonds, and J. Reilly, Institute for Fnergy Analysis}

\section{J. R. Trabalka, and D. E. Reichle, Oak Ridge National Laboratory}

This report discusses the probable rates and potential range of future ('), emissions and estimates a range of future atmospheric $\mathrm{CO}_{2}$ concentrations through the year 2075. Ilistoric fossil fuel usage to the present, increasing at a rate of $4.5^{\circ}$ o per year until 1973 and all a slower ratc of $1.9^{\circ}$ o alter 1973, was combined with thee semarios of projected emissions growth ranging from about 0.2 to $2.8 \%$ per year to provide annual ( 0 , emissions data for 1 wo different carbon cycle models. The emissions scenarios were constructed using an energy-economic model and by varying key parameters within the bounds of eurently expected future values. The extreme values for ( ()$_{2}$ emissions in the year 2075 of about 500101500 ppm. with a median of about 700 ppm. The time at which atmospheric $\mathrm{CO}_{2}$ would potentially double from the preindustrial level ranges from year 2025 to 2075 . The practical programmatic value of this forecast exercise is that it forces quantitative detintion of the assumptions and the uncertainties, which are the basis for understanding the natural hiogechemical eycle of carbon and both historic and future human influences on the dynamics of the global eycle. Assumptions about the possible range of future atmospheric $(\mathrm{C})$, levels provide a basis on which to evaluate the implications of these changes on climate and the biosphere.

\section{TR014 The Changing Pattern of Fossil Fuel $\mathrm{CO}_{2}$ Emissions} (I)(OE/(OR/21400-2, September 1984, 24 pp.)

\section{R. M. Rotty, G. Marland, and N. Treat, Institute for Energy Analysis}

This report analyes the fossil fuel (o), emissions from developing nations of the world compared with emissions from developed nations during the past three decades. The world was divided into six fuel-consuming regions (North America; Western Larope; U.S.S.R. and castern liurope; Japan, Australia, and ()ceania; Asian countries with centrally planned economies; and developing countries) and ( () , emissions were calculated from U.N. data on fuel consumption.

Emissions from developing nations have been increasing at a higher rate than those from the developed world. Developing nations do not show the reduction in growth rate of (C), emissions that occurred for North America, western Lurope, and Japan alter 1973. Discontinuities evident for the People's Republic of (hina appear to coincide with times of major change in govermmental policies.

For the next few decades, increases in atmospheric ( ()$_{2}$ concentrations will be largely determined by fiel policies in the developed nations of the world. However, before the middle of the next century, fiel policies of the rapidly growing nations will become extremely important, if not dominant, in the world ( $(1)$ picture. 


\title{
A Proposed Reference Set of Scenarios for Radiatively Active Atmospheric Constituents \\ (DOE/NBB-0066, October 1984, 51 pp.)
}

\author{
D. J. Wuebbles, M. C. MacCracken, and F. M. Luther, Lawrence Livermore National \\ Laboratory
}

The development of reference scenarios for coordinated scientific investigations of the effects of man-made trace species emissions necessary both for model intercomparisons and governmental decision-making is needed. The species that should be considered include; $\mathrm{CO}_{2}$, chlorocarbons, stratospheric ozone. tropospheric ozone, methane. nitrogen oxides, nitrous oxide, tropospheric acrosols, carbonaceous and other light-absorbing aerosols, stratospheric aerosols, carbon monoxide, hydrocarbons, and water vapor.

This report proposes a set of scenarios for past and future concentrations of radiatively active atmospheric constituents. The following concentrations may be reached in the next century: $\mathrm{CO}_{2}, 340$ to $680 \mathrm{ppmv} ; \mathrm{CH}_{4}, 1.7$ to $3.4 \mathrm{ppmv} ; \mathrm{N}_{2} \mathrm{O}, 302 \mathrm{ppbv}$ to $375.5 \mathrm{ppbv} ; \mathrm{CFC}-11,0$ to $744.8 \mathrm{pptv}$; and $\mathrm{CFC}-12,0$ to $1789.5 \mathrm{pptv}$. The report stresses the major uncertainties underlying our understanding of the budgets of the species and the uncertainties in projecting future changes in societal and economic actions. The scenarios are intended to promote discussion leading to generally accepted sets of scenarios that can serve not as a forecast, but as a reference for all research groups using the continental and global-scale chemical interactions and climatic effects of these concentrations.

\section{A Systems Study for the Removal, Recovery and Disposal of Carbon Dioxide from Fossil Fuel Power Plants in the U.S. (DOE/CH/00016-2, December 1984, 76 pp.)}

\section{Steinberg, H. C. Cheng, and F. Horn, Brookhaven National Laboratory}

The U.S. contributes about $30 \%$ of the world's total man-made $\mathrm{CO}_{2}$ emissions; utilities are responsible for about $30 \%$ of the U.S. total. This report summarizes research on the removal, recovery, and disposal of $\mathrm{CO}_{2}$ from U.S. utilities as one option for preventing the "global greenhouse effect."

The removal and recovery system evaluated in this report is based on an absorption/stripping system using an improved stack gas scrubbing solvent. The recovered $\mathrm{CO}_{2}$ is then liquefied for transmission to the ultimate disposal site. The $\mathrm{CO}_{2}$ control process is integrated with the power plant operation in that low-pressure steam from the power-generating turbines is used to regenerate the solvent. For $90 \%$ removal of $\mathrm{CO}_{2}$, the efficiency of the power plant is reduced from the conventional $38 \%$ to a value of $35 \%$. Three methods of disposal are discussed: (1) injection into the 500-m-deep ocean below the thermocline, about 100 miles off the U.S. coastal waters; (2) storage in depleted oil and gas wells; and (3) storage in excavated salt caverns.

The report recommends evaluating this type of control system in other nations that are major $\mathrm{CO}_{2}$ contributors. It is estimated that the worldwide application of a $\mathrm{CO}_{2}$ control system could reduce the annual incremental $\mathrm{CO}_{2}$ concentration by as much as $32 \%$. 
TR017 A Climatic Data Bank for Northern Hemisphere Land Areas, 1851-1980 (DOE/EV/10739-2, January 1985, 335 pp.)

\title{
R. S. Bradley, University of Massachusetts
}

\author{
P. M. Kelly, P. D. Jones, and C. M. Goodess, University of East Anglia, Norwich, UK
}

\section{H. F. Diaz, NOAA/ERL}

A necessary prerequisite for studies of climatic fluctuations and the causes of climatic variability is a comprehensive set of long-term climatic data for as wide an area as possible. This report documents a new compilation of long-term temperature and precipitation station data for the Northern Hemisphere. The authors surveyed libraries, archives, and data centers to obtain climate data to supplement and improve existing data banks. While the authors report long-term data on mean monthly temperatures and monthly precipitation totals, the primary focus is on the former.

More than 700 temperature and 120 precipitation records extending back into the 19 th Century have been incorporated into the data bank. Problems that contribute to potential inconsistencies in the records are discussed (particularly changes in methods of computing mean daily temperature). The temperature data have been used in producing a gridded set of departures from a reference period (1946 1960). The authors discuss problems associated with changes in spatial data coverage with reference to the computation of the "hemispheric" average temperature through time.

[The data set is available on tape (NDP-012) from the Carbon Dioxide Information Analysis Center at Oak Ridge National Laboratory.]

TR018 A Global Paleoclimatic Data Base for 6000 Year B.P. (DOE/EV/10097-6, February 1985, 155 pp.)

\section{T. Webb, III, Brown University}

The testing of climate-model simulations for past climates requires subcontinental to global maps of paleoclimatic data. Such maps reveal the magnitude and pattern of climatic variables at enough model grid-points that useful comparisons are possible. This report documents a global data base of pollen, lake-level, and marine plankton data for 6000 year B.P. (the mid-llolocenc period); a total of 797 stations are included. This data base provides a core of paleoclimatic information for 6000 year B.P. to which other sources such as ice cores, paleodunes, paleosols, and lluvial geomorphology data can be added.

Pollen data record the broad-scale vegetational patterns that are related to climate. Lake-level data record the relative water depth in lakes and thus provide records of past changes in moisture. Marine plankton data contain information about the geographic distribution of plankton, which (like vegetation) reflect climatic patterns.

Pollen data are available from eastern North America, Alaska, Europe, the Soviet Union, South America, and New Zealand. Lake-level data exist for Australia, Africa, southwestern Asia, western North America, eastern North America, and South America. 
Marine plankton data are mainly available from the North Atlantic and northwestern Indian Oceans, but isolated samples exist for the Pacific and Southern Oceans.

Estimated temperature values are presented for eastern North America, Europe, and the ocean samples. Precipitation is estimated for central North America and isolated sites in India and Africa. The data are displayed on maps, and the site locations and other descriptive information are tabulated.

[The data set is available on tape (NDP-011) from the Carbon Dioxide Information Analysis Center at Oak Ridge National Laboratory.]

\section{Carbon Dynamics of Northern Hardwood Forests: Gas Exchange Characteristics (DOE/EV/10091-1, February 1985, 70 pp.)}

\section{T. W. Jurik, G. M. Briggs, and D. M. Gates, University of Michigan}

There is considerable interest in the response of plants to increased mole fractions of $\mathrm{CO}_{2}$ in the atmosphere. The objective of the research reported in this document is to quantify the carbon dynamics of northern hardwood forests and to predict the response of these forests to changing environmental conditions in the future, particularly to increases in $\mathrm{CO}_{2}$ levels. This report presents studies of physiological responses in relation to environment, based on field studies at five sites at the University of Michigan Biological Station near Pellston, Michigan. Leaf $\mathrm{CO}_{2}$ exchange and conductance for water vapor were measured in situ using a mobile laboratory. Measurements of leaf conductance for water vapor were also made with a portable porometer. Leaf water potential was measured in the field with a Scholander-type pressure bomb. Photosynthesis; leaf $\mathrm{CO}_{2}$ exchange rate (CER); leaf conductance; transpiration; water use efficiency (WUE); leaf water potential; gas exchange of leaves, stems, and twigs; and soil respiration were studied.

The optimal temperature for CER was 23 to $25 \mathrm{C}$ for leaves growing in the sun and 20 to $24 \mathrm{C}$ for those growing in the shade. In saturating $\mathrm{CO}_{2}$ and saturating light, the temper-ature optimum for CER shifted upward to 33 to $38 \mathrm{C}$, and maximum CER was more than doubled. Red oak, red maple, and big-tooth aspen have increased WUE in high $\mathrm{CO}_{2}$.

There is now considerable information on variation in CER and photosynthetic capacity of a single leaf with environmental conditions. Variation among leaves in a given microenvironment and among different microenvironments is known for several physiological characteristics. Variation as a function of habitat (e.g., site fertility) is less understood. 


\title{
TR020 Reconstruction of Past Atmospheric $\mathrm{CO}_{2}$ Contents from the Chemistry of the Contemporary Ocean: An Evaluation (DOE/OR-857, March 1985, 79 pp.)
}

\author{
W. S. Broecker, and T. Takahashi, Lamont-Doherty Geological Observatory

\section{T.-H. Peng, Oak Ridge National Laboratory}

This report summarizes attempts to reconstruct the $\mathrm{CO}_{2}$ using contemporary ocean data. Although a beautiful idea, this approach becomes a geochemical nightmare because the uncertainties in the reconstructions will always be larger than the uncertainties ultimately available from other approaches (e.g., ice cores and carbon 13 records). Thus, the value of the ocean data lies in understanding oceanic processes rather than in reconstructing past atmospheric $\mathrm{CO}_{2}$ contents. When the history of atmospheric $\mathrm{CO}_{2}$ has been reconstructed from ice core $\mathrm{CO}_{2}$ and carbon 13 records, then the ocean distribution of $\mathrm{CO}_{2}$ can be used to constrain some of the current uncertainties in models of the uptake of fossil fuel $\mathrm{CO}_{2}$ by the ocean.

\section{TR021 A Two Dimensional $\mathrm{CO}_{2}$-Ocean Model Including the Biological Processes (DOE/NBB-0070, May 1985, 33 pp.)}

\section{F. Baes, Jr., and G. G. Killough, Oak Ridge National I aboratory}

The purpose of the research reported in this document was to develop a 2-dimensional ocean model that includes biologically controlled processes (photosynthesis and calcium carbonate precipitation) to (1) determine if these processes can be represented with sufficient simplicity to permit rapid computation of the steady-state distribution of carbon in a many-box model, and (2) to conduct various time-integrations from the steady-state initial condition to examine how the response to increasing atmospheric $\mathrm{CO}_{2}$ depends on the forcing of the model. The authors approach differs from previous approaches in that (1) they model half a world ocean as a single water volume extending from the equator toward one pole and (2) they describe the flow of water between boxes in the idealized ocean in terms of a small number of parameters with the dimension of diffusivities.

Atmospheric carbon content depends on photosynthesis and the concentration of nutrients, a finding consistent with earlier estimates from one-dimensional models. The effects of circulation rate and warming are secondary. The rate of uptake by the model ocean at any given time in the past is found to vary linearly with the excess carbon in the ocean and in the atmosphere; this suggests that the current rate of carbon uptake by the real oceans may be strongly affected by the forcing that occurred over the previous century or so, and that a model cannot be tested against the current response of the oceans unless the excess carbon taken up in past years can be determined. While the airborne fraction (AF) of excess carbon (airborne + oceanic) in the years just after 1980 depends on previous history, integrating to the year 2100 shows that AF becomes more dependent on total excess carbon and its rate of growth. For the rapid-release scenario, AF reaches values greater than 0.8 by the year 2100 . 


\section{A Grid Point Surface Air Temperature Data Set for the Northern Hemisphere \\ (DOE/EV-10098-2, July 1985, 251 pp.)}

P. D. Jones, S. C. B. Raper, B. Santer, B. S. G. Cherry, C. Goodess, P. M. Keliy, and

T. M. L. Wigley, University of East Anglia, Norwich, UK

R. S. Bradley, University of Massachusetts

H. F. Diaz, NOAA/ERL

This report consists of a compilation of 2,666 station records of monthly surface-air temperatures for the Northern Hemisphere. To use these data to form a gridded dataset for the Northern Hemisphere the homogeneity of each of these records, where provided, was assessed. The results of this assessment are presented in the report and stations are classed as immediately usable, corrected, or uncorrectable. Full details of how this was achieved for each station are presented in tabular form. Of the 2,666 station records, 1,584 were used to produce the gridded temperature data set. Temperature anomalies were calculated for monthly means for the reference period 1951-70 using the homogenized data. Anomalies at each point of a $5^{\circ}$ latitude by $10^{\circ}$ longitude grid were interpolated from the station data for each month for the period 1851 to 1984.

[The data set is available on tape (NDP-020) from the Carbon Dioxide Information Analysis Center at Oak Ridge National Laboratory.]

\section{The Effect of Elevated Atmospheric $\mathrm{CO}_{2}$ on Plant Communities (DOE/EV/04329-5, July 1985, 39 pp.)}

\section{F. A. Bazzaz, K. Garbutt, and W. E. Williams, Harvard University}

This report summarizes exploratory research on the effects of elevated carbon dioxide concentrations on the growth of a variety of ecologically important plants. Although the plant responses were subtle and complex, the following broad conclusions could be drawn from the study:

1. Different species showed different degrees of growth enhancement, suggesting that competition relationships may have changed.

2. Flowering and fruiting did not always change to the same degree, or even in the same direction, as total plant weight. Thus, experiments not carried through to fruit maturity can lead to incorrect conclusions.

3. Because of fruiting and flowering changes, some effects from exposure to increased carbon dioxide concentrations were not completed for several generations. Thus, evolutionary changes in the characteristics of the individual species may be expected.

4. Elevated carbon dioxide can have a slight protective effect against other pollutants. 
TR024 Methods of Uncertainty Analysis for a Global Carbon Dioxide Model (DOE/OR/21400-4, July 1985, 41 pp.)

\section{R. H. Gardner, and J. R. Trabalka, Oak Ridge National Laboratory}

This report describes the results of applying Monte Carlo methods of uncertainty analysis to Oak Ridge National Laboratory's World Carbon Cycle Model to examine the time-dependent variability of predicted values of atmospheric carbon dioxide and relate them to uncertainties associated with model parameters. The report presents the details of the statistical methods used to reveal significant relationships between model parameters and predictions. When emission rates of carbon from fossil fuel combustion were considered a part of the $\mathrm{CO}_{2}$ release scenario (e.g., fixed for all model simulations) then, (1) predicted atmospheric concentrations of carbon dioxide showed relatively low levels of variability through time, (2) parameter importance levels were time dependent, and (3) model parameters associated with absorption of carbon in the ocean and release rates of carbon from forest clearing accounted for over $90 \%$ of the uncertainty of predicted atmospheric $\mathrm{CO}_{2}$ in the year 2075. The implementation and refinement of these techniques for the carbon cycle model now make it possible to examine, in a manner consistent with available data, the uncertainties associated with other scenarios of carbon emission rates and to compare the results in a quantitative manner with those of other models.

\section{TR025 The Stability of Low-Latitude Sea Surface Temperatures: An} Evaluation of the CLIMAP Reconstruction With Emphasis on the
Positive SST Anomalies
(DOE/ER/60167-1, October 1985, 57 pp.)

\section{W. L. Prell, Brown University}

This report examines the stability of low-altitude sea surface temperatures over the past 18,000 years and evaluates the evidence for positive sea surface temperature anomalies (i.e., warmer than present) in the CLIMAP 1981 reconstruction of the oceans during the last glacial maximum about 18,000 years ago. A global array of planktonic foraminiferal population data were compiled and then applied both to CLIMAP temperature equations and to the modern analog technique of temperature estimation. The modern analog technique of estimating temperature is substantially different from the CLIMAP method and gives equal or high correlation with observed data and lower standard estimates of error than comparable CLIMAP equations. The comparison indicates that the estimates of relatively stable low-latitude temperatures and, in some cases, warmer sea surface temperatures are inherent in the planktonic foraminiferal populations and are not a function of CLIMAP's 1981 method of temperature estimation. 


\title{
Carbonate Chemistry of the Bering Sea (DOE/EV/10611-5, September 1985, 79 pp.)
}

\section{C.-T. A. Chen, C.-L. Wei, and M. R. Rodman, Oregon State University}

The dynamics of atmospheric-ocean exchanges of carbon dioxide. and of carbon dioxide fluxes with the oceans, are important, but largely unquantified factors in understanding the global carbon cycle. This report has the following goals with respect to defining the carbonate chemistry of the Bering Sea: (1) to obtain the first winter oxygen and carbonate data in the Bering Sea; (2) to evaluate seasonal, cross-frontal, and cross-ice-edge variations of oxygen and carbonate chemistry; (3) to estimate the effect of pack ice on air-sea exchange of gases; (4) to estimate the penetration depth of the excess, anthropogenic $\mathrm{CO}_{2}$ in the Bering Sea; and (5) to compare the results with data reported in the literature and to estimate the importance of the Bering Sea in removing the excess $\mathrm{CO}_{2}$ from the atmosphere.

The analyses in this report are based on data collected aboard the U.S. Coast Guard icebreaker Polar Sea in the late winter of 1983 (part of the outer Continental Shelf Environmental Assessment Program) and on summer data available in the literature. Wintertime oxygen, $\mathrm{pH}$, alkalinity, and calcium data across the marginal ice zone of the central and southeastern Bering Sea shelf are analyzed and compared with summer data.

The Bering Sea pack ice impedes but does not stop the air-sea exchange of gases. Mixing dominates the distribution of chemical properties on the shelf. Excess $\mathrm{CO}_{2}$ has probably saturated the Bering Sea shelf water but does not penetrate more than $1000 \mathrm{~m}$ in the Aleutian Basin. No excess $\mathrm{CO}_{2}$ was detected in the bottom waters. Overall, the Bering Sea contains $0.19+/-0.05 \times 10 \mathrm{E}^{15} \mathrm{~g}$ excess carbon.

\section{A Grid-Point Surface Air Temperature Data Set for the Southern Hemisphere (DOE/EV/10098-6, February 1986, 73 pp.)}

\author{
P. D. Jones, S. C. B. Raper, C. M. Goodess, B. S. G. Cherry, and T. M. L. Wigley, \\ University of East Anglia
}

A truly representative time series of average temperatures for Earth can only be achieved by incorporation of data from both the land and marine areas of both hemispheres (most studies to date have been representative of conditions over only the Northern Hemisphere land masses). In this study, a compilation of 610 station records of monthly surface air temperature has been assembled for the Southern Hemisphere, north of $62.5^{\circ} \mathrm{S}$. The basic source of data was the digitized form of the World Weather Records; additional data were incorporated for Indonesia, Australia, some Pacific islands (particularly Tahiti), New Zealand, Peru, and Antarctica.

To use these data to reconstruct the first grid-point temperature data set for the Southern Hemisphere, the homogeneity of each of the station records has been assessed. Each station has been classed into one of three groups: immediately usable, corrected, or uncorrectable. The results are presented in tabular form.

Of the 610 station records, 293 were used to produce a gridded data set on a $5^{\circ}$ latitude by $10^{\circ}$ longitude grid between $5^{\circ} \mathrm{S}$ and $60^{\circ} \mathrm{S}$, inclusive. Grid-point anomalies for 1851-1984, with 
respect to the reference period 1951-1970, were interpolated from station data using a simple inverse-distance weighting algorithm. To produce a best-possible data set, Antarctic data were included after they became available in 1957.

The time series of the Southern Hemisphere area average shows little overall trend during the nineteenth century. After 1900, the series shows a warming trend to the mid 1940s. Between about 1945 and 1970 no trend can be seen. Since 1970 a strong warming trend has set in. The three warmest years of the entire record are 1980, 1981, and 1983. The overall warming trend since 1900 is about $0.5^{\circ} \mathrm{C}$, of which roughly $0.3^{\prime \prime} \mathrm{C}$ occurred between 1900 and 1945 and $0.2^{\circ} \mathrm{C}$ since 1970. The history of the land-based Southern Hemisphere temperature series is, therefore, not dissimilar to that for the Northern Hemisphere. However, the early twentieth-century warming up to $: 940$ is smaller in magnitude, and the cooling evident in the Northern Hemisphere between 1940 and 1965 appears only as a hiatus in the longer-term warming trend.

[The data set is available on tape (NDP-020) from the Carbon Dioxide Information Analysis Center at Oak Ridge National Laboratory.]

\title{
TR028 Definition and Characterization of Data Needs to Describe the Potential Effects of Increased Atmospheric $\mathrm{CO}_{2}$ on Marine Fisheries from the Northeast Pacific Ocean (DOE/NBB/0075, December 1985, 139 pp.)
}

\author{
R. M. Strickland, D. J. Grosse, A. I. Stubin, G. K. Ostrander, and T. H. Sibley, University of \\ Washington
}

Increased concentrations of atmospheric $\mathrm{CO}_{2}$ will have direct effects on climate and on dissolved $\mathrm{CO}_{2}$ in the oceans and indirect effects on abiotic (physical and chemical) properties of the oceans. Effects of increased concentrations of dissolved $\mathrm{CO}_{2}$ are expected to be minimal, except for the possible effects of increased availability of trace metals. The abiotic effects that are most important for marine fisheries are changes in temperature, ice cover, turbulence, and current patterns in the upper layer of the ocean. Equally important fishery impacts may be transmitted via biotic effects on prey and predators of immature tish. The most promising avenue for both general and specific climate-related fishery research at this time is the effects of the abiotic environment on the planktonic food supplies of larval and juvenile fish, especially as mediated by primary production. Global warming will shift the present latitudinal domains of most fish species poleward, but the magnitudes of this shift and of possible associated changes in fishery yiold are unknown. Uncertainty is related to lack of knowledge of the ways that temperature and other factors regulate fish populations, as well as to uncertainties in the rate and magnitude of changes in the environment. Uncertainty also arises because of differing species characteristics and local factors such as rivers, bathymetry, and ice that makes it difficult to generalize among fisheries. Four northeast Pacific region case-study species were studied to determine individual fishery responses to climate change (Alaska pollock. Theragra chalcogramma; Pacific herring. Clupea harengus pallasi; pink shrimp, Pandalus borealis; and yellowfin sole, Limanda aspera). Because unique properties of individual fisheries are as important as the general properties of all fisheries for determining climatic effects, the ability to project the effects of climate change on fisheries without performing detailed case studies is limited. Likewise, it is difficult to extrapolate from the results of the present case studies to other fisheries. These results are particularly inapplicable to other 
major categories of fisheries, including open-ocean, upwelling, and tropical and subtropical shelf fisheries. Such fisheries should be the focus of additional case studies. Possible temperature effects on the incidence of disease and parasitism in fish also should be investigated.

Ultimately, greater understanding of the effects of climate on fisheries will depend on improvements in coordinated large-scale data gathering in the field. In the interim, useful supporting studies can be performed on the small-scale laboratory responses of fish larvae and plankton to abiotic changes (especially $\mathrm{CO}_{2}$, temperature, and turbulence) and on developing quantitative relationships using these results and other existing field and laboratory data. In particular, there is sufficient theoretical and empirical knowledge to justify beginning the development of a global marine primary-production model, which would have the corollary benefit of complementing global carbon cycle models.

\section{Preliminary Data Report for the INDIVAT Number 1 and INDIGO $1 /$ INDIVAT 3 Cruises in the Indian Ocean (DOE/NBB/0074, January 1986, 106 pp.)}

\section{C.-T. A. Chen, College of Oceanography, Oregon State University}

\section{A. Poisson, and C. Goyet, Universite Pierre et Marie Curie, Paris}

The main objective of this research was to quantify the oceanic penetration of excess $\mathrm{CO}_{2}$ by using carbonate data directly. The specific objectives were (1) to obtain the first winter carbonate data in the South Indian Ocean, which is near the major point of origin for the bottom waters in the world oceans; (2) to evaluate seasonal and cross-frontal (Subtropical and Antarctic Front) variations of carbonate chemistry; (3) to estimate the depth of penetration of the excess man-derived $\mathrm{CO}_{2}$ in the Indian Ocean from both carbonate and transient tracer data; and (4) to compare the results with reported literature data.

This report summarizes the experimental data and a limited preliminary analysis from the first two of a series of cruises scheduled for the Indian Qcean for the period 1984 to 1987. When the tracer data become available, a full report will be published.

Preliminary results of this study are:

1. The surface $\mathrm{pH}$ and normalized nitrate, alkalinity, and total $\mathrm{CO}_{2}$ values correlated linearly with temperature.

2. Small deviations from the linearity are related to the Subtropical Front and the equatorial upwelling.

3. Large nitrate variations occurred in surface waters collected at the same station but in different seasons; however, there was less variation between normalized nitrate concentrations in waters with the same temperature.

4. There appeared to be a seasonal difference in alkalinity and total $\mathrm{CO}_{2}$. 
5. The decrease in alkalinity and total $\mathrm{CO}_{2}$ between the Antarctic Waters and the Indian Central Waters from north of the Subtropical Front may be caused by the decrease in nitrate and the increase in temperature.

6. The remnant North Atlantic Deep Water, which has a weak salinity signal, can be identified by $\mathrm{pH}$ and total $\mathrm{CO}_{2}$ data, but nutrient, oxygen, and calcium data also help in tracing this water.

7. The alkalinity and total $\mathrm{CO}_{2}$ data for subsurface waters agree well with GEOSECS data for GS 427 and 428 but not for GS 429 .

These results permit for the first time an evaluation of the variations in the carbon and nitrogen cycles in the Antarctic Intermediate Water in the Indian Ocean with reference to the source water in winter.

TR030 Effects of Energy Technology on Global $\mathrm{CO}_{2}$ Emissions (DOE/NBB/0076, April 1986, 92 pp.)

\section{H. C. Cheng, M. Steinberg, and M. Beller, Brookhaven National Laboratory}

This study was done to investigate the effects on global energy consumption and $\mathrm{CO}_{2}$ emissions of end-use and electricity-generation technologies, with emphasis on efficiency improvement. The following are the conclusions of the study.

1. The large margins of efficiencies between present and future improved energy technologies, and the wide variations in efficiency levels among countries, indicate considerable room for major long-term reductions in energy consumption through technological improvements.

2. Savings achievable by more efficient end-use and electricity-generation technologies, if effectively implemented, are estimated as about 145 exajoules ( $10^{18}$ joules) of liquids fuels, 118 exajoules of gas fuels, and 236 exajoules of solid fuels, with an overall fossil-fuel savings of 500 exajoules, which is about $58 \%$ of the fossil-fuel demand without technology improvements for year 2050 .

3. The distribution of these fossil-fuel savings by end-users is 175 exajoules $(39 \%)$ for residential and commercial users, 227 exajoules $(46 \%)$ for industrial users, and 76 exajoules (15\%) for transportation users. Breakdown by fuel type for each type of user shows that technologies could produce savings in solid fuels for industrial users and in liquid fuels for transportation users.

4. The regional breakdown of the overall fossil-fuel savings of 500 exajoules, is 97 exajoules $(19.5 \%)$ from the U.S., 101 exajoules $(20 \%)$ from Canada and Western Europe, 56 exajoules ( $11 \%$ ) from OECD Pacific, and the remaining 245 exajoules $(49 \%)$ from the Soviet Union, China, and all the other developing countries. Except for the USA, the general global structure of fuel savings is $50 \%$ from solid fuels, $26 \%$ from liquids, and $24 \%$ from gases. Because the USA has a larger demand for liquid fuels, especially by transportation users, than all the other regions, it has a higher potential for liquid fuel savings through technology improvement. 
5. The associated overall reduction of carbon emission in year 2050 is 10 petagrams $\left(10^{19} \mathrm{~g}\right)$, i.e., carbon emissions could be reduced from 17 petagrams without efficiency improvements to 7 petagrams with the efficiency improvements discussed in this study a $59 \%$ reduction. The largest share of the reduction is from solids, 5.6 petagrams carbon, with liquids contributing 2.8 and gases $1.6 \mathrm{Pg} \mathrm{C}$.

6. The distribution of the overall reduction of $\mathrm{CO}_{2}$ emissions by end-users is $3.8 \mathrm{Pg} \mathrm{C}$ $(38 \%)$ for residential and commercial users, $4.7(47 \%)$ for industrial users, and $1.5(1.5 \%)$ for transportation users.

7. The regional breakdown of the overall reduction of 10 petagrams of carbon emissions is $1.9 \mathrm{Pg} \mathrm{C}(19 \%)$ from the U.S., $2.0(20 \%)$ from Canada and Western Europe, $1.1(11 \%)$ from the OECD Pacific, and the remaining $5.0 \mathrm{Pg} \mathrm{C}(50 \%)$ from the Soviet Union, China, and all the other developing countries. Hence, the developing regions have the same potential for reducing $\mathrm{CO}_{2}$ emissions as do the developing regions in year 2050 through technology efficiency improvements.

8. The largest share of energy savings by residential and commercial users is from space conditioning technologies, about $75 \%$ of the fossil-fuel savings and $35 \%$ of the electricity savings, with water-heating technologies accounting for most of the remaining fossil-fuel savings $(20 \%)$ and about $15 \%$ of the electricity savings. For industrial users, about $80 \%$ of the fossil-fuel savings are from improvements of efficiencies in process heat, and about $80 \%$ of the savings in electricity are from improvements in electric drives. Automobiles and trucks account for about $80 \%$ of the liquid-fuel savings by transportation users.

Overall $\mathrm{CO}_{2}$ emission in year 2050 could be reduced by $46 \%$ compared with that without technology improvement, through improvements of these technologies; this is about $80 \%$ of the reduction due to general technology improvements.

9. Use of the savings in electricity generated from non-fossil energy (i.e., nuclear, solar, and hydro) due to technology improvement to replace demand for electricity generated from fossil fuels produces additional savings of 13 exajoules of liquids, 14 exajoules of gases, and 56 exajoules of solids. Combining the improvements in end-use and electricity-generation technologies with such replacement raises the total fossil-fuel savings in year 2050 to 580 exajoules, which is $68 \%$ of the fuel demand without the technology improvements. The associated reduction of $\mathrm{CO}_{2}$ emission is 11.8 petagrams of carbon. This means that $\mathrm{CO}_{2}$ emissions in year 2050 could be reduced by $68 \%$, compared with $59 \%$ without such replacement.

10. The actual savings of fossil fuels should be larger than the estimates given if account is taken of the energy needed for producing and transporting the saved energy, and the actual reduction of $\mathrm{CO}_{2}$ emission should be correspondingly larger.

11. The total capital costs for technology implementation for year 2050 are about 6.0 and 24.0 trillion 1980 USA dollars, resulting in total returns on investment based purely on fuel savings of about $8 \%$ and $10 \%$ for the USA and the world, respectively. The industrial sector has more potential than the other users for reducing $\mathrm{CO}_{2}$ emissions $(50 \%$ of the overall reduction) with low capital requirements for technology implementation ( $6 \%$ of overall capital requirements) and high return on investment $(40 \%)$. 


\title{
TR031 The Impact of Climate Change from Increased Atmospheric Carbon Dioxide on American Agriculture (DOE/NBB/0077, May 1986, 100 pp.)
}

\author{
W. L. Decker, V. K. Jones, and R. Achutuni, University of Missouri
}

This report summarizes the current knowledge of potential effects of $\mathrm{CO}_{2}$-induced climate change on agriculture in the United States. Emphasis is placed on the fourteen-state midwestern region (Illinois, Indiana, lowa, Kansas, Michigan, Minnesota, Missouri, Nebraska, North Dakota, Ohio, Oklahoma, South Dakota, Texas, and Wisconsin) and on four crops (corn, soybeans, wheat, and sorghum) and animal production. The report begins with a review of American agriculture by describing developments in the twentieth century, natural and institutional resources that support the farm enterprise, and the magnitude of production of crops and livestock. The report then discusses the effects of climate change on crop production (with a summary of the direct effects of $\mathrm{CO}_{2}$ on plants); topics include changes in growing-degree days, cropping patterns, genetic selection, farm management alternatives, and pest management. Next the report covers the effects of climate change on animal production in relation to the following topics: effects of temperature, rainfall, humidity, and day length; animal management; genetics; and effects of climate on forages such as grasses and legumes. In the summary chapter, knowns, unknowns, and required research are presented for each of eight issues or concerns (for example, water availability, genetic development).

\section{TR032 A Comparison of Tropical Forest Surveys} (DOE/NBB/0078, June 1986, 66 pp.)

\section{J. Molofsky, Butler University}

\section{A. S. Hall, Cornell University}

\section{N. Myers, Consultant, Oxford, England}

Over the years several assessments of tropical forest areas have been made. This report examines the two most recent studies of tropical forest areas and rates of forest loss: Norman Myers' Conversion of Tropical Moist Forests (1980), and the FAO/UNEP Tropical Forest Resources Assessment Project $(198 / \mathrm{a}, \mathrm{b}, \mathrm{c})$ to identify and clarify discrepancies between them. These reports were chosen for comparison because the apparent discrepancy between their respective estimates of deforestation rates has been the basis of a continuing controversy. Myers' report, prepared under the auspices of the National Academy of Sciences, was concerned principally with the conversion of virgin forests to other land use and the resulting extinction of tropical species. His report concluded that tropical moist forests are being converted from a primary state to various human-impacted categories at a rate of $200,000 \mathrm{~km}^{2}$ per year, but only about one-half of this amount is permanently deforested. The remainder is cleared, cultivated for a few years, and allowed to recover in a process called shifting cultivation. Although shifting cultivation allows a forest to recover, the regrowth may exhibit reduced biological diversity and biomass. The FAO/UNEP (1981a,b,c) report emphasized the availability of forest resources to meet the future fuelwood, housing, and economic needs of UN member states. The report concluded that conversion of forest to nonforest land is occurring at a rate of $73,000 \mathrm{~km}^{2}$ per year. 
Different definitions apparently have caused a misinterpretation of the results of the two reports. The present paper attempts to identify more precisely the differences between the two studies to integrate the large tropical forest data base from these two sources into a cohesive whole. Specifically, those countries covered in both surveys where the largest differences occur are identified. Then, further research can be directed where it will be most useful. The present study does not assess all discrepancies between the reports of Myers and FAO but only those for countries where both investigators have given specific numbers.

\title{
High Accuracy Standards and Reference Methodology for Carbon Dioxide in Air (DOE/PR-06010-31, June 1986, 101 pp.)
}

\author{
W. L. Zielinski, Jr., E. E. Hughes, I. L. Barnes, J. W. Elkins, and H. L. Rook, National \\ Bureau of Standards
}

This report summarizes the activities and accomplishments of a three-year NBS program for the development of standards and reference methodology for carbon dioxide in air that was designed to:

- Develop defined Standard Reference Materials (SRMs) for $\mathrm{CO}_{2}$ in air at atmospheric concentrations having a total uncertainty (95\% confidence level) not exceeding 0.1 percent relative;

- $\quad$ Assess the equivalency of absolute gravimetry employed by the National Bureau of Standards (NBS) and absolute manometry employed by the Scripps Institution of Oceanography (SIO) for the development of accurate standards for $\mathrm{CO}_{2}$ in air at atmospheric concentrations; and

- Develop a state-of-the-art isotope dilution mass spectrometer (ID-MS) system and associated methodology to serve as an NBS-based reference method for absolute independent confirmation of $\mathrm{CO}_{2}$ concentrations in $\mathrm{CO}_{2}$ in air standards.

The first of these objectives has been realized in the issuance of seven $\mathrm{CO}_{2}$ in air SRMs in the 300-400 parts-per-million (ppm) range of interest. Each SRM cylinder in these seven SRMs contains a $\mathrm{CO}_{2}$ in air concentration that is individually certified to be stable for a period of at least two years within a total uncertainty of $0.2 \mathrm{ppm}$ with $95 \%$ confidence. The first three of these were issued in 1983, covering nominal concentrations of 330,340 , and $350 \mathrm{ppm}$. Four additional SRM's were issued in 1985, covering nominal concentrations of 340 and $380 \mathrm{ppm}$. Two of these four SRMs were certified in size 150 cubic foot cylinders to address the higher volume needs of investigators, while the remaining two were certified in standard SRM size cylinders (30 cubic foot). All four of the latest SRMs also were certified for nitrous oxide levels in the part-per-billion ( $\mathrm{ppb}$ ) range and have information (non-certified) values for methane (1.7-1.8), and for halocarbons F-11 and F-12 in the part-per-trillion (ppt) range. Five additional $\mathrm{CO}_{2}$ in air SRMs are planned for certification in 1986 at nominal concentrations of 200, 300 (two SRMs), 360, and 1000 ppm. 
The second of these objectives was to assess the equivalency between absolute gravimetry (NBS) and absolute manometry $(\mathrm{SIO})$, in order to ensure a scientific basis for the transfer of responsibility for $\mathrm{CO}_{2}$ in air standards from SIO to NBS. The differences that were observed between $\mathrm{CO}_{2}$ concentrations assigned by gravimetry by NBS and those measured by SIO using the constant volume manometer (CVM) for multiple intercomparisons were within the limits of experimental error of the two systems. Hence, standards from one system (NBS) can be used interchangeably with standards from the other system (SIO). This achieves one of the primary goals of the program: namely, that NBS standards may be used for calibrating measurements of atmospheric $\mathrm{CO}_{2}$ without compromising the existing data record, and, further, that the institutionalization at NBS of the availability of standards will ensure the long-term continuity and integrity of this data record for the indefinite future. These intercomparisons represent the completion of a convergence plan prepared at the outset of this program by principal scientists of SIO (C. D. Keeling) and NBS (E. E. Hughes).

The third objective has involved the design, construction, testing, and evaluation of a computercontrolled ID-MS system to serve as an independent reference method for the analysis of $\mathrm{CO}_{2}$ in air SRMs. In practice, this method would be used to independently verify the accuracy of randomly-selected, gravimetrically-certified $\mathrm{CO}_{2}$ in air calibrations covering a range of $\mathrm{CO}_{2}$ concentrations within 300-400 ppm and extensions above and below this range. A separate report detailing the characteristics of this system and its performance will be issued. NBS plans to use this system and its associated methodology as a confirmatory reference method for $\mathrm{CO}_{2}$ in air SRMs.

Current research extensions to this program include the development of an NBS master calibration curve incorporating numerous primary gravimetric standards covering the $300-400 \mathrm{ppm}$ range and an assessment of the absolute minimum error associated with the preparation of such standards and the development of SRMs. Specifically, this continuing research is directed at (1) the development of a global calibration curve interrelating all NBS primary gravimetric standards within a predictable uncertainty, and (2) a detailed evaluation of the feasibility of further reducing the total uncertainty at $95 \%$ confidence for certified SRM concentrations, below its current level of $0.2 \mathrm{ppm}$ ( $0.6 \%$ relative). A separate report describing the results of this extended research will be issued.

\section{TR034 Carbonate Chemistry of the North Pacific Ocean (DOE/NBB-0079, October 1986, 176 pp.)}

\section{C.-T. A. Chen, M. R. Rodman, C.-L. Wei, and E. J. Olson, Oregon State University \\ R. A. Feely, and J. F. Gendron, Pacific Marine Environmental Laboratory, NOAA}

The objective of this research was to quantify the oceanic penetration of excess $\mathrm{CO}_{2}$ by using carbonate data directly, and to understand better the oceanic carbon cycle. Data collected along two longitudinal cruises serve as the main data sources, and supplementary data sets in the literature are selected for delineating the distribution of physical and chemical properties in a wide area of the North Pacific Ocean.

Oxygen, $\mathrm{pH}$, alkalinity, total $\mathrm{CO}_{2}$, and nutrients are interrelated parameters. Along two longitudinal sections these parameters show a core structure underlying the salinity minimum layer. From these oxidation-related parameters, the researchers concluded that the subsurface water of the eastern North Pacific Ocean is older than that of the western North Pacific Ocean. 
Alkalinity data can be used as a water mass tracer. Different water masses reveal their own mixing trends which can be identified when examining the correlation of normalized alkalinity with temperature. The vertical distribution of the normalized alkalinity shows a maximum core at a depth of about $2500 \mathrm{~m}$ in the North Pacific Ocean. Calcium carbonate dissolution and circulation in the deep and bottom layers contribute to the formation of the normalized $\mathrm{CaCO}_{1}$ dissolution rate of 0.060 and $0.053 \mathrm{umol} / \mathrm{kg} / \mathrm{yr}$, respectively, referenced to the Weddell Sea Deep Water for waters deeper than $2000 \mathrm{~m}$.

This analysis of carbonate data shows that about $25 \%$ of the increase in total inorganic $\mathrm{CO}_{2}$ in deep water, in its journey from the surface of the Southern Ocean to the depth of the North Pacific, results from inorganic $\mathrm{CaCO}_{3}$ dissolution. No significant difference in the inorganic carbon/organic carbon ratio exists between the two longitudinal sections. However, the eastern section has a higher total $\mathrm{TCO}_{2}$ input than that of the western section.

The degree of saturation of calcite and aragonite was calculated from all available data sets. Four selected cross-sections, three longitudinal and one latitudinal, and two three-dimensional graphs show that a large volume of the North Pacific is undersaturated with $\mathrm{CaCO}_{3}$. The saturation horizon generally shows a shoaling from west to east and from south to north in the North Pacific Ocean. It was found that the lysocline falls at a depth much deeper (about $2500 \mathrm{~m}$ deeper) than the saturation horizon of calcite and several hundred meters shallower than the calcium carbonate compensation depth. Results appear to support the kinetic point of view on the $\mathrm{CaCO}_{3}$ dissolution mechanisms.

Calculations on the excess $\mathrm{CO}_{2}$ show that its penetration depth is strongly related to circulation. The shallowest penetration depth is less than $300 \mathrm{~m}$ found in the eastern equatorial region where upwelling prevails and the deepest penetration depth is deeper than $2000 \mathrm{~m}$ off Japan where an interaction of Oyashio and Kuroshio currents is found. These results agree with conclusions drawn based on Freons, tritium, and carbon-14 data. Overall the North Pacific contains $14,7+/-4 \times 10^{15} \mathrm{~g}$ excess carbon.

[The data set is available on tape (NDP-029) from the Carbon Dioxide Information Analysis Center at Oak Ridge National Laboratory.]

\section{An Annotated Inventory of Climatic Indices and Data Sets (DOE/NBB-0080, November 1986, 195 pp.)}

\section{H. A. Hattemer-Frey, Oak Ridge National Laboratory}

\section{T. R. Karl, and F. T. Quinlan, National Climatic Data Center}

This publication describes 34 prominent climatic indices and provides an annotated listing and bibliography of additional indices to help meet the information needs of researchers who are evaluating the effects of increased atmospheric $\mathrm{CO}_{2}$ levels. The goal was to discuss a wide range of indices that would be useful to scientists working directly in diverse areas of $\mathrm{CO}_{2}$ climate research and those individuals interested in climate research results for other applied studies. 
This publication is a source to consider first to determine what information is available and how knowledge of climatic indices may help investigators meet their research goals.

To ensure that a broad spectrum of indices was considered, indices from the following ten subject areas are included:

(1) Global/Hemispheres, (2) Marine Data Sets, (3) Long-Term Regional and Local Temperature and Precipitation Data Sets, (4) Atmospheric Constituents Data Sets, (5) Upper Air Data Sets, (6) Southern Oscillation/El Nino Data Sets, (7) Solar Data Sets, (8) Proxy Data Sets, (9) Lake Levels and River Flows Data Sets, and (10) Snowcover and Sea Ice Extent Data Sets.

Each description provides a brief but detailed summary of the index's relevance, importance, and derivation. Seventeen descriptor fields were used to describe each index, including primary references, relevant background information, calculation of the index, temporal resolution, spatial coverage, unit of measurement, period of record, reliability, relationship to other indices, application, and citation information.

\section{TR036 Uncertainty in Future Global Energy Use and Fossil Fuel $\mathrm{CO}_{2}$ - Emissions 1975 to 2075 (DOE/NBB/0081, December 1986, 95 pp.)}

\section{J. A. Edmonds, and J. M. Reilly, Pacific Northwest Laboratory}

\section{R. H. Gardner, Oak Ridge National Laboratory}

\section{A. Brenkert, Science Applications International Corporation}

This report summarizes the results of work with the IEA/ORAU Long-Term Global Energy- $\mathrm{CO}_{2}$ model to analyze model predictions of future global carbon emissions from fossil fuel use and the uncertainty surrounding such forecasts.

The methods used were the latest techniques of uncertainty analysis along with review and revision of the IEA/ORAU model structure, and review and description of uncertainty surrounding model assumptions and parameters to explore uncertainty in fossil fuel $\mathrm{CO}_{2}$ emissions over the period 1975-2075. Possible interrelationships among assumptions and parameters, and their effects on overall forecast uncertainty are explored.

The major findings include:

1. The median rate of $\mathrm{CO}_{2}$ emissions grow at an average annual rate of 1.0 percent per year. This rate is substantially lower than the post World War II experience and lower than that found by earlier studies.

2. Overall uncertainty in the emission rate was found to be considerable. A range of 3.0 percent per year growth in emissions and a decline of 1.4 percent per year are needed to bracket 90 percent of the 400 randomly generated scenarios. 
3. Low and declining $\mathrm{CO}_{2}$ emissions rates appear more likely than past research has indicated. Roughly one quarter of the scenarios show global emissions falling from current levels.

4. The three most important determinants of variation in $\mathrm{CO}_{2}$ emissions were labor productivity, rate of improvement in end-use energy efficiency, and the income elasticity of demand for energy in the developing world.

5. Based on the analysis of potential correlation among assumptions, model structure plays a key role in the determination of median estimates of fossil fuel $\mathrm{CO}_{2}$ for energy emissions.

6. Conspicuously absent from the list of key variables were the rate of interfuel substitution and the fossil fuel resource base by fuel type.

\section{Monthly Mean Pressure Reconstructions for Europe (Back to 1780) and North America (to 1858) (DOE/ER/60397-H1, February 1987, 99 pp.)}

\section{P. D. Jones, T. M. L. Wigley, and K. R. Briffa, Climatic Research Unit, University of East Anglia}

Monthly grid-point pressure data are reconstructed from station records of air temperature, precipitation and pressure for Europe, back to 1780, and North America, back to 1858. The reconstructions are based on a principal components regression technique which relates surface pressure patterns to those of the temperature, precipitation and station pressure data. The relationships are derived over a calibration period and the results are tested with independent data from another period. To illustrate the results, examples are given of pressure anomalies over Europe during 1816 (the "year without a summer"), anomalies over both Europe and North America for January and November 1862 (months with particularly strong anomalies), and anomalies over North America during 1884 (the year after Krakatau).

The reconstructions are compared with other monthly mean pressure maps produced by Lamb and Johnson (1966) for Europe for 1780 to 1872 and for North America for 1858 to 1898, and by Kington (1980) for Europe for 1781 to 1785 . Both of these map series show systematic biases relative to the present reconstructions. The reconstructed data are available on a magnetic tape.

[The data set is available on tape (NDP-025) from the Carbon Dioxide Information Analysis Center at Oak Ridge National Laboratory.] 
TR038 A Data Bank of Antarctic Surface Temperature and Pressure Data (DOE/ER/60397-H2, June 1987, 52 pp.)

\section{P. D. Jones, University of East Anglia}

\section{W. S. Limbert, British Antarctic Survey}

A data bank of monthly-mean surface air temperature and sea-level or station-level pressures is presented for 29 stations over the Antarctic region south of $60^{\circ} \mathrm{S}$. Considerable attempts have been made to locate missing data in nationally published sources and in World Weather Records. By cross-checking neighboring station data, suspect values have been either verified or corrected.

At four sites in the Antarctic Peninsula region, composite records were produced by amalgamating records from a number of short and longer length records at or near the key sites. The four sites were Bellingshausen, Faraday, Esperenza, and Rothera.

The mean Antarctic temperature series produced by Raper et al. (1984) is updated using the same method of calculation.

\section{TR039 The Prospect of Solving the $\mathrm{CO}_{2}$ Problem Through Global Reforestation (DOE/NBB-0082, February 1988, 66 pp.)}

\section{G. Marland, Oak Ridge Associated Universities and Oak Ridge National Laboratory}

We are confronted with the possibility that it may become necessary to try to limit the increase in atmospheric $\mathrm{CO}_{2}$ in order to avert adverse changes in the global climate. One short-term approach would be to stimulate the growth of forests to take up in woody matter enough carbon to balance the discharge of $\mathrm{CO}_{2}$ from fossil fuel burning. This study evaluated the extent to which the area and/or net growth rate (mean annual increment) of global forests would need to be enhanced in order to remove an additional $5 \times 10^{9}$ tons of carbon per year from the atmosphere.

Although it is physically possible to plant large areas of new plantation and/or to stimulate tree growth via advanced silviculture techniques, conflicts in land use and resource aliocation are quickly encountered in efforts of sufficient magnitude. The scale of the effort required is approximately equal to doubling the new annual yield of all of the world's closed forests or planting new fast growing forests over an area equivalent to the total of global forest clearing to date. The cost of such a scheme is immense but it needs to be compared with the costs of other approaches to dealing with atmospheric $\mathrm{CO}_{2}$ or of coping with the attendant changes in climate. It is clear that although it is impractical to think in terms of solving the $\mathrm{CO}_{2}$ problem through forestry alone, forestry could play a significant role. 


\section{A Primer on Greenhouse Gases (DOE/NBB-0083, March 1988, 100 pp.)}

\section{J. Wuebbles, Lawrence Livermore National Laboratory}

\section{J. Edmonds, Pacific Northwest Laboratory}

The purpose of this document is to provide a reference summarizing current understanding of basic information for important greenhouse gases. Each of the gases included is recognized to be important to the future state of global atmospheric chemistry and climate. Included as greenhouse gases are those of direct radiative importance to climate, those that act as radiative precursors, and those of importance as intermediate constituents because of their chemical activities. Knowns, unknowns, and uncertainties for each gas are described. This document focuses on information relevant to understanding the role of energy and atmospheric chemical and radiative processes in the determination of atmospheric concentrations of greenhouse gases.

The document takes the form of a large table. Two summary tables highlight the contents. One outlines the basic information given in the main document table, and the other gives an indication of the relative potential importance of the gases to chemistry and climatic effects on the global atmosphere.

In the course of the development of this document several conclusions became clear. The most important of these conclusions are:

1. There are major uncertainties regarding the source budgets for key gases including $\mathrm{CH}_{4}$, $\mathrm{CO}, \mathrm{N}_{2} \mathrm{O}$, and $\mathrm{NO}_{x}$. These uncertainties greatly exceed those for the sources of $\mathrm{CO}_{2}$ emissions.

2. Of particular concern is the relatively primitive evaluation of the relationship between energy activities and emissions of these gases, despite the fact that these gases are estimated to have energy sources amounting to between 32 and $75 \%$ of all man-made sources.

3. The relationship between energy and emissions sources for the gases evaluated in this study is stronger than had been anticipated before the study began.

4. Chemical processes in the atmosphere represent an important link between energy and other emissions sources and the composition of the atmosphere. Understanding atmospheric composition is essential to detecting and quantifying the role of energy and $\mathrm{CO}_{2}$ in climate change.

5. More definitive studies of the interactions between chemical and climatic processes are necessary to facilitate an early detection of a $\mathrm{CO}_{2}$ /climate-change signal. This is intended to be a living document to be updated as additional information in important greenhouse gases becomes available. The reader is invited to contribute to the updating process. This version of the report did not consider several currently minor but potentially important greenhouse gases. Namely, non-methane hydrocarbons and additional chlorocarbons, particularly $\mathrm{CFC}-113, \mathrm{CCl}_{4}$, and $\mathrm{CH}_{3} \mathrm{CCl}_{3}$, deserve consideration. 


\section{TR041 Regional Intercomparisons of General Circulation Model Predictions and Historical Climate Data (DOE/NBB-0084, April 1988, 291 pp.)}

\section{Stanley L. Grotch, Lawrence Livermore National Laboratory}

This study is a detailed intercomparison of the results produced by four different General Circulation Models (GCMs) that have been used to project the climatic consequences of a doubling of the atmospheric $\mathrm{CO}_{2}$ concentration. The results for the models developed by groups at the National Center for Atmospheric Research (NCAR/CCM, Washington and Meehl, 1984), the Geophysical Fluid Dynamics Laboratory of NOAA (GFDL, Manabe and Wetherald, 1987), and the Goddard Institute for Space Studies of NASA (GISS, Hansen, et al., 1984) have been described by Schlesinger and Mitchell (1985) in the DOE state-of-the-art (SOA) report, "Projecting the Climatic Effects of Increasing Carbon Dioxide." The fourth model examined here is the Oregon State University GCM (OSU, Schlesinger, 1986), results for which did not become available until after publication of the SOA.

We have chosen to examine only two model variables here: (1) surface air temperature, and (2) precipitation. We consider these variables for both seasonally and annually averaged periods, for both the current climatic conditions and the predicted equilibrium changes after a doubling of the $\mathrm{CO}_{2}$ concentration. For the current climate $\left(1 \times \mathrm{CO}_{2}\right)$, the model results for these two variables were compared with each other and with several data sets representing observed climate conditions over recent 15 to 30 year periods; the domain covered is global, although the adequacy of data over many regions is very limited. The grid resolution of the different models varies from $4^{\circ}$ latitude by $5^{\circ}$ longitude to $8^{\circ}$ latitude by $10^{\circ}$ longitude; the data are typically available with similar resolution. Thus, each data point (on the model or observation grid) represents a region of about $400 \mathrm{~km}$ by $400 \mathrm{~km}$ or larger, or roughly the size of Colorado, even though regions of this size may have very diverse local climates.

In Schlesinger and Mitchell (1985), the analyses emphasized the global scale nature of the models. Here, the major focus is the intercomparison of models and data over a range of scales: global, hemispheric, zonal, continental, and regional (typically representing 5 to 20 model gridpoints). The fundamental question addressed is: "How well do the predictions from different GCMs agree with each other and with historical climatology over different areal extents, from the global scale down to the range of only several gridpoints?"

The major conclusion of this study is that, although the models often agree well when comparing seasonal or annual averages over large areas, substantial disagreements become apparent as the spatial extent is reduced, particularly when detailed regional distributions are examined. Tabulations are provided to document these differences quantitatively. At scales below continental, the correlations observed between different model predictions are often very poor, particularly for land gridpoints during Northern Hemisphere $(\mathrm{NH})$ summer, with differences of as much as $5^{\circ} \mathrm{C}$ between models and observations and between one model and another over relatively large areas.

A more limited analysis, using the results from only two GCMs, examines the seasonal variability of surface air temperature for the control climates. These results suggest that both models exhibit serious differences with historical climatology in at least one of the two meteorological seasons which are analyzed [December-January-February (DJF) or June-July-August (JJA)]. The implications of this work for investigation of climatic impacts on a regional scale are profound. 
For these two very important variables, at least, the poor agreement between model simulations of the current climate on the regional scale calls into question the ability of these models to project the amplitude of future climatic change on anything approaching the scale of only a few $(<10)$ gridpoints, which is essential if useful resource assessment studies are to be conducted. Much work remains to be done by the modelling community to better resolve the sources of disagreements among models and between models and observations so that model improvements can be made which will improve the climatic projections produced by these models. A stronger cooperative effort among the different modelling groups, including such recent initiatives as calculating results with a common set of boundary conditions, will be necessary so that we are sure that we are getting model agreement for the right reasons, a prerequisite for improving confidence in model projections.

\title{
Surface Energy Balance of Three General Circulation Models: Current Climate and Response to Increasing Atmospheric $\mathrm{CO}_{2}$ (DOE/ER-60422-H1, MAY 1988, 119 pp.)
}

\author{
W. J. Gutowski, D. S. Gutzler, D. Portman, and W.-C. Wang, Atmospheric and \\ Environmental Research, Inc.
}

We examine the surface energy balance simulated by state-of-the-art general circulation models at GFDL, GISS and NCAR for climates with current levels of atmospheric $\mathrm{CO}_{2}$ concentration (control climate) and with twice the current levels. The work is part of an effort sponsored by the U.S. Department of Energy to assess climate simulations produced by these models. The surface energy balance enables us to diagnose differences between models in surface temperature climatology and sensitivity to doubling $\mathrm{CO}_{2}$ in terms of the processes that control surface temperature. Our analysis compares the simulated balances by averaging the fields of interest over a hierarchy of spatial domains ranging from the entire globe down to regions a few hundred kilometers across.

Principal Findings

1. For the global average control climate, individual surface fluxes of sensible heat (SH), latent heat $(\mathrm{LH})$, shortwave radiation (SW) and upward (LW $\uparrow$ ) and downward (LW longwave radiation agree between the models to within $25 \mathrm{Wm}^{-2}$. In all three models the surface energy balance is dominated by longwave radiation (the "greenhouse" effect). Other surface fluxes are smaller, but the models also agree on their relative magnitudes. The $25 \mathrm{Wm}^{-2}$ difference is only a small fraction of the magnitudes of the largest fluxes, $\mathrm{LW} \downarrow$ and $\mathrm{LW} \uparrow$. However, the difference is a large fraction of the net longwave radiation at the surface $\left(-60 \mathrm{Wm}^{-2}\right)$, and it is as large as any of the global-average seasonal changes in these fluxes. From this perspective, differences between surface fluxes in these stateof-the-art models are substantial even for the global average.

2. Global average changes in surface fluxes when $\mathrm{CO}_{2}$ doubles agree between models to within $3 \mathrm{Wm}^{-2}$; intermodel discrepancies are only small fractions of the flux changes from $\mathrm{CO}_{2}$ doubling. However, the apparent agreement between models in Figure E-2 should be viewed with caution because flux changes associated with doubled $\mathrm{CO}_{2}$ are about the same size as the differences between models in their control climates: $25 \mathrm{Wm}^{-2}$.

Furthermore, averaging over the globe obscures much larger differences occurring on smaller scales (cf. points 4 and 6 below). 
3. Spatial variation of net longwave radiation at the surface is small compared to the spatial variability of near-surface air temperature and moisture, both of which exert significant control on the new surface longwave flux. The relatively small variability of $L_{\text {net }}$ appears to be a consequence of compensation among variations of temperature, atmospheric moisture and clouds.

4. Intermodel differences in doubled- $\mathrm{CO}_{2}$ surface flux changes of up to $100 \mathrm{Wm}^{-2}$ occur near the limits of polar ice caps. Differences in ice modeling approach contribute strongly to the flux differences. Differences in control climate sea ice limits also help produce the strong differences in flux changes.

5. Differences between models for surface fluxes in regions a few hundred $\mathrm{km}$ across are often closely linked to differences in zonal mean climatology.

6. Intermodel surface flux discrepancies in the regional averages are as large as $50 \mathrm{Wm}^{-2}$, which is twice the difference found for the global average. Furthermore, models often disagree over the sign of regional flux changes when $\mathrm{CO}_{2}$ doubles. Such differences appear to be closely associated with differences in model hydrology.

7. Fields that are subject to orographic control show relatively small intermodel discrepancy, i.e., differences between models for the same region tend to be smaller than interregional differences. A most notable example is precipitation, examined here because of its indirect relation to the surface energy balance through the hydrological cycle.

\section{Recommendations}

1. Effort should be given to developing a better understanding of the hydrological cycle and how to simulate it. Progress in this area appears to be especially important for improving regional climate modeling (point 6 above). Relatively large flux discrepancies on the global scale (points 1 and 2) may also be reduced by such progress because the hydrological cycle, through water vapor and cloud cover, strongly influences the longwave radiation transmitted from the atmosphere to the surface. Examples of the work needed are Manabe and Wetherald (1987) and Meehl and Washington (1987) who have analyzed soil moisture sensitivity in NCAR and GFDL model simulations of current and doubled $\mathrm{CO}_{2}$ simulations.

2. Better agreement in zonal mean climatology between models is needed, since much of the intermodel difference in regional climatology is attributable to zonal mean differences between models.

3. Effects of increased resolution on regional simulation should be studied. Our results suggest that improvements in orographically dependent fields are possible simply by increasing resolution. Grid nesting needs to be explored as a means of improving regional modeling over land areas where orographic control may be important for regional climatology. 
The Use of Statistical Climate-Crop Models for Simulating Yield to Project the Impacts of $\mathrm{CO}_{2}$ Induced Climate Change (DOE/ER/60444-HI, July 1988, 42 pp.)

\author{
W. L. Decker, and R. Achutuni, University of Missouri-Columbia
}

Climate change has been projected to result from increased levels of greenhouse gasses. Obviously, significant changes in climate will influence agricultural production. Analysis techniques are needed to determine the consequences of climate change on agriculture production and food supply.

This report discusses (1) the historical perspective for the development of statistical models, (2) statistical models for assessing the impacts of $\mathrm{CO}_{2}$-induced climate change, (3) production transformations resulting from climate change and $\mathrm{CO}_{2}$ fertilization, (4) integration of direct effects of $\mathrm{CO}_{2}$ fertilization with the indirect effects caused by climate change, and (5) the value of statistical modeling for estimating crop production for large areas having increased $\mathrm{CO}_{2}$ concentrations.

The report recommends development in three areas important in modeling crop production: (1) a technique that results in a more reasonable adjustment than a fixed percentage increase by $\mathrm{CO}_{2}$ fertilization and incorporates interactions between climate anomalies and $\mathrm{CO}_{2}$ concentrations, (2) refinement of the relationship between yield and transpiration to provide a more rational approach to the estimation of production for large areas, and (3) comparison of estimations obtained from a process model and a statistical model for a large area (crop reporting district or state) and simulation of the variabilities of these two techniques using historical climatic records.

\title{
Documentation of IAP Two-Level Atmospheric General Circulation Model (DOE/ER/60314-HI, February 1989, 383 pp.)
}

\author{
Q.-C. Zeng, X.-H. Zhang, X.-Z. Liang, C.-G. Yuan, and S.-F. Chen, Institute of \\ Atmospheric Physics, Beijing, People's Republic of China
}

Since 1980, a group directed by Qing-Cun Zeng at the Institute of Atmospheric Physics (IAP) of the Chinese Academy of Science has been developing grid-point general circulation models (GCMs) for climate simulations. Unique characteristics make the dynamic framework of the models different from other GCMs.

1. Departures of temperature, geopotential, and surface pressure from their "standards" are introduced to cancel the large truncation errors in the mountain regions.

2. New coordinates and variables are introduced, leading the energy equation to a very compact form and the grid to a more flexible arrangement.

3. The computation scheme conserves the "available" energy conservation exactly (it the dissipation is omitted), and is free from computational modes. 
4. No false source exists because the formulation and calculation of boundary terms or boundary conditions at the atmosphere-ocean and atmosphere-land interfaces are physically consistent.

Taking these characteristics into consideration, the authors have designed several schemes using spherical grids. One of the schemes, on C-grid system, was first designed and reported by Zeng and then extended to the atmosphere-ocean-coupled model. Most recently the authors also designed a B-grid scheme. Both schemes conserve the "available" energy of dissipative and adiabatic atmosphere under the "standard stratification approximation" or provide a bounded norm of the predicted variables in $L_{2}$ space if the implicit and split methods are applied, without using the standard stratification approximation. The B-grid scheme is used to compute wind vector directly at gridpoints, without using interpolations of wind components, and can easily be used in conjunction with implicit or semi-implicit methods. However, the C-grid scheme is economical in computation and suitable to stepwise topography. It is this scheme that has been thoroughly and systematically' tested and applied to climate simulations. Based upon the C-grid scheme, a two-level global atmospheric GCM (AGCM) and a four-level world ocean GCM (OGCM) have been completed with $4^{\circ} \times 5^{\circ}$ horizontal resolution and have been applied to climate simulations. The report documents the control version of the IAP two-level AGCM.

The physical parameterization schemes such as longwave radiation, cloud prediction, convective processes, boundary layer treatment and the ground surface hydrology developed by OSU are adopted with appropriate modifications in the current version of IAP two-level AGCM. However, in IAP AGCM, some nonlinear horizontal diffusion is included and the solar radiation is calculated using the delta-Eddington model, which accommodates the inclusion of atmospheric smoke and dust in addition to atmospheric Rayleigh scattering and absorptions of ozone and water vapor. The IAP AGCM emphasizes the prediction of water vapor transport because the condensation process is extremely important not only in causing precipitation, which is a main variable characterizing the regional climate, but also in controlling the internal energy source in atmospheric motions. The scheme presented can avoid drastic variations in water vapor distribution.

A full presentation of the model's dynamic framework; the calculations of the physics (source and sink terms) and treatment of boundary conditions; the FORTRAN program, including a directory of purpose, algorithm, and IO information for each subprogram; the FORTRAN symbols in the named common blocks, together with a brief description or definition, the mathematical equivalent, the units, and location in the code listing; a physics dictionary summarizing the treatment of numerous variables and giving their location in the code and references; and a guide to model use and operation, including a complete collection of 10 information in a model integration are included. 


\title{
A Preliminary Analysis of U.S. $\mathrm{CO}_{2}$ Emissions Reduction Potential from Energy Conservation and the Substitution of Natural Gas for Coal in the Period to 2010 (DOE/NBB-0085, February 1989, s6 pp.)
}

\author{
J. A. Edmonds, and W. B. Ashton, Pacific Northwest Laboratory \\ H. C. Cheng, and M. Steinberg, Brookhaven National Laboratory
}

This report sheds light on the issue of U.S. $\mathrm{CO}_{2}$ emissions reduction potential from the present to the year 2010 from energy conservation and the substitution of natural gas for coal. $A$ preliminary assessment of the technical feasibility and consequences of reducing U.S. $\mathrm{CO}_{2}$ emissions from 1985 levels by 10,25 , or $50 \%$ by either the year 1995 or 2010 . Conservation potential studies were also examined to see what energy and conservation efficiency improvements are feasible at current and anticipated energy technologies and prices.

\section{Global Lake-Level Variations from 18,000 to 0 Years Ago: A Palaeoclimatic Analysis (DOE/ER/60304-H1, SEPTEMBER 1989, 213 pp.)}

\section{F. A. Street-Perrott, D. S. Marchand, N. Roberts, and S. P. Harrison, Oxford University}

Fluctuations in the water levels of lakes can are an important source of information about past climates and can be used to validate the palaeoclimatic simulations made with atmospheric general-circulation models. The Oxford Lake-Level Data Bank contains information about variations in the water levels of about 360 lake basins during the past 30,000 years. This data set was compiled as part of the Climates of the Holocene Mapping Project (COHMAP). In this report, regional and global maps of lake status (coded as high, intermediate, or low) at 18, 15 , $12,9,6,3$, and 0 thousands of years Before Present are presented and compared with numerical simulations for the same time slices carried out with the National Center for Atmospheric Research (NCAR) Community Climate Model. Although agreement between the data and the model is generally excellent, significant discrepancies occur. These may reflect the effects of changes in boundary conditions that were not included in the experiments, for example increased glacial-age aerosol loadings, as well as the inability of the model to portray some of the complexities of the climate system such as oceanic circulation and orographic effects.

\section{An Evaluation of the Relationship Between the Production and Use of Energy and Atmospheric Methane Emissions (DOE/NBB-0088P, April 1990, 234 pp.)}

\section{W. Barns, and J. A. Edmonds, Pacific Northwest Laboratory}

Methane is the most abundant hydrocarbon in the atmosphere. It has an assumed lifetime of about 10 years, and its atmospheric concentration is increasing about $1 \%$ per year. It is also one of the most potent of the greenhouse gases, with more than 30 times the warming potential of carbon dioxide on a per molecule basis. 
Much of the atmosphere's methane comes from natural sources like wetlands. But a significant portion comes from human activities; probably $201030 \%$ of the overall total comes from the production, distribution, and use of energy. Unlike carbon dioxide, only a small fraction of the methane in the atmosphere is produced by combustion. Rather, it comes from coal mining, natural gas production and distribution, automotive exhausts, biomass burning, and landfill decay.

Moreover, the quantitative relationships are much more ambiguous with methane than they are with carbon dioxide.

Those relationships were estimated and emission coefficients were determined to extend the Edmonds-Reilly Long-Term Energy- $\mathrm{CO}_{2}$ Model to include the effects of methane emissions. This report discusses the sources of information on emissions, the difficulties in assessing coefficients, and the final values chosen for the expanded model.

Methane emissions from coal mining are essentially a function of coal rank and depth; a weighted average of 250 cubic feet per short ton of production was used. Natural gas is mostly methane, and a $2 \%$ loss to the atmosphere was assessed. Venting and flaring data are available for most countries, but much of that data is of questionable accuracy, so the fraction vented was assessed at one-fifth. The range of methane emissions from automobiles and trucks is very wide; the global total emission was estimated to be 1 to 2 teragrams per year ( $\mathrm{Tg} / \mathrm{y}$ ). Traditional biomass (fuel wood and bagasse) burning was estimated to introduce 10 to $15 \mathrm{Tg} / \mathrm{y}$ into the air. Finally, landfill emissions were estimated to contribute 30 to $70 \mathrm{Tg} / \mathrm{y}$ to the atmosphere.

These estimated methane emissions total about $110 \mathrm{Tg} / \mathrm{y}$. In comparison with similar studies, this value is in the low end of the range. Use of these values in the model, therefore, provides an element of conservatism.

\section{TR048 Effects of Air Temperature on Atmospheric $\mathrm{CO}_{2}$-Plant Growth Relationships (DOE/ER-0450T, April 1990, 61 pp.)}

\section{S. G. Allen, S. B. Idso, and B. A. Kimball, U.S. Water Conservation Laboratory}

\section{J. T. Baker, and L. H. Allen, Jr., SDA-ARS and the University of Florida}

\section{J. R. Mauncy, and J. W. Radin, Western Cotton Research Laboratory}

\section{G. Anderson, Arizona State University}

In general, doubling the concentration of atmospheric $\mathrm{CO}_{2}$ increases the productivity of $\mathrm{C} 3$ plants by about one-third. Because temperature may influence this effect, the literature on this topic was searched and is summarized in this report.

The enhancement in plant growth and photosynthesis of $\mathrm{C} 3$ species brought about by greater $\mathrm{CO}_{2}$ concentration increases with air temperature. Increased temperature and a doubling of $\mathrm{CO}_{2}$ concentration produced a maximum increase in growth of $300 \%$ and in net photosynthesis of $170 \%$ in $\mathrm{C} 3$ plants. The interaction between temperature and $\mathrm{CO}_{2}$ concentration differs considerably among species. This interspecies variation may explain much of the wide range in plant responses to $\mathrm{CO}_{2}$ concentration reported in the literature. Crop species' responses to increased $\mathrm{CO}_{2}$ concentration and temperature should therefore be studied individually. In addition, $\mathrm{CO}_{2}$ concentration appears to interact with other climatic variables, such as solar radiation, in its 
effect on plant productivity. Growth and productivity effects are nowhere near as pronounced with $\mathrm{C} 4$ species as they are with $\mathrm{C} 3$ species because of the more efficient photosynthetic mechanism of $\mathrm{C} 4$ plants.

Stomatal conductance of $\mathrm{C} 4$ species did, however, respond to combined increases in $\mathrm{CO}_{2}$ concentration and temperature; the decrease in stomatal conductance produced by enriched $\mathrm{CO}_{2}$ was enhanced by increasing temperature. As a result, a significant increase in water-use efficiency of $\mathrm{C} 4$ crops can be expected in a high- $\mathrm{CO}_{2}$ environment.

Simulating Climate With Two Different Numerical Schemes (DOE/34-0459T, JUNE 1990, 57 pp.)

W. J. Gutowski, and M. J. Iacono, Atmospheric and Environmental Research, Inc.

\author{
Xin-Zhong Liang, State University of New York, Stony Brook
}

Wei-Chyung Wang, State University of New York, Albany

To determine the dependence of climate simulation on model numerics, two simulations of a perpetual July were run on the Oregon State University two-layer atmospheric-physics model, one that used gridpoint techniques for the numeric treatment of atmospheric dynamics and one that used spectral techniques.

The gridpoint model produced a stronger circulation. The differences in atmospheric transport predicted by the two models have a significant influence on the atmospheric portion of the hydrologic cycle. The gridpoint model produces more frequent precipitation, especially in the tropics, and higher amounts of atmospheric moisture. Consequently, it indicates greater cloud cover, producing differences in other fluxes, such as solar and terrestrial radiation. Substantial regional differences in the models' simulations were found, but differences in zonal averages typically dominate differences appearing in spatial distributions of climatological fields.

Removing certain feedbacks in the climate syster. underscored the differences produced by the choice of numeric technique. For example, diabatic heating tends to amplify differences resulting from the choice. Varying horizontal resolution also alters the model climatology. To a certain degree, these differences are tempered when a model is tuned to account for and reflect current climate. However, the choice of numeric technique should be made carefully because it may still influence a model's sensitivity to forcing changes.

\title{
Modeling $\mathrm{pCO}_{2}$ in the Upper Ocean: A Review of Relevant Physical, Chemical, and Biological Processes (DOE/RL-01830T-H5, December 1990, 63 pp.) \\ D. Archer, University of Washington
}

The $\mathrm{pCO}_{2}$ of the surface ocean is controlled by a combination of physical, chemical, and biological processes. Modeling surface ocean $\mathrm{pCO}_{2}$ is analogous to modeling sea surface temperature (SST), in that sea surface $\mathrm{pCO}_{2}$ is affected by fluxes across the air-sea interface and by exchange with deeper water. However, $\mathrm{pCO}_{2}$ is also affected by chemical and 
biological processes which have no analog in SST. Seawater $\mathrm{pCO}_{2}$ is buffered by pH equilibrium reactions between the species $\mathrm{CO}_{2}, \mathrm{HCO}_{1}$, and $\mathrm{CO}_{3}$. This effect provides an effective reservoir for $\mathrm{CO}_{2}$ in seawater that is 10 times larget than it would be for an unbuffered gas. The equilibrium between dissolved and atmospheric $\mathrm{CO}_{2}$ is sensitive to temperature, tending to higher $\mathrm{pCO}_{2}$ in warmer water.

Biological export of carbon as sinking particles maintains a gradient of $\mathrm{pCO}_{2}$, with lower values near the surface (this process is called the "biological pump"). In most of the ocean, biological activity removes all of the available nutrients from the surface water; that is, the rate of carbon export in these locations is limited by the rate of nutrient supply to the euphotic zone. However, in much of the high-latitude oceans, primary production does not deplete the euphotic zone of nutrients, a fact to which the atmospheric $\mathrm{pCO}_{2}$ is extraordinarily sensitive. Understanding the limits to phytoplankton growth in the high latitudes, and how these limits might change under different climatic regimes, is essential to prediction of future ocean uptake of fossil fuel $\mathrm{CO}_{2}$.

Because many of the processes controlling sea surface $\mathrm{pCO}_{2}$ are driven by mixing in the upper ocean, fluctuations in the depth of the mixed layer are of primary importance to modeling sea surface $\mathrm{pCO}_{2}$. The depth of the mixed layer can be predicted using a numerical model of the upper ocean. Fluxes of heat, momentum, and dissolved gases provide the boundary conditions for such a model. A major limitation on the precision of calculated heat fluxes is the effect of clouds on the atmospheric radiative heat fluxes.

Three families of mixed layer models have been developed, and although the physical mechanisms by which mixing occurs differ among the model groups, all are successful at predicting the observed ocean mixed layer depth. The "integrated turbulent kinetic energy" (TKE) models construct a budget for surface ocean TKE, using the wind stress as source and dissipation as sink for TKE. Excess kinetic energy is converted to potential energy by mixing denser water up into the surface mixed layer. The "shear instability" models maintain profiles of current velocity resulting from the wind stress; when the current shear becomes too large relative to density stratification, the model mixes (entrains) deep water into the surface layer. "Turbulence closure" models are the most general and the most complicated of the three types, and are based on laboratory studies of fluid turbulence. This paper explores behavioral distinctions between the three types of models, and summarizes previously published comparisons of the generality, accuracy, and computational requirements of the three models. The application of mixed layer models to treatment of sea ice is also reviewed.

Simulation of the upper ocean on a global scale is limited by finite computation resources and by imperfect meteorological forcing data. The air-sea heat fluxes can either be calculated as described above or imposed using an "SST restoring" strategy which pushes the model SST toward observations within some relaxation time constant. Simulation of free convection driven by surface cooling, particularly deep convection in high-latitude winter, is essential to modeling formation of deep water and is therefore an integral part of virtually all circulation models. Convection driven by the wind (forced convection) requires higher spatial resolution and more detailed meteorological forcing data. One strategy for reducing overhead associated with the mixed layer is to "embed" the mixed layer into a surface box of variable thickness, within a deeper surface box. All three mixed layer model types have been incorporated into global-scale simulations. 


\section{A Comprehensive Precipitation Data Set for Global Land Areas (DOE/ER-69017T-HI, April 1991, 82 pp.)}

\section{J. K. Eischeid, and H. F. Diaz, NOAA/ERL}

\section{R. S. Bradley, University of Massachusetts}

\section{P. D. Jones, University of East Anglia}

An expanded and updated compilation of long-term station precipitation data, together with a new set of gridded monthly mean fields for global land areas, are described. The present data set contains 5328 station records of monthly total precipitation, covering the period from the mid-1800s to the late 1980s. The station data were individually tested and visually inspected for the presence of spurious trends, jumps, and other measurement biases. The quality control procedure which was used to check the station records for nonclimatic discontinuities and other biases is detailed. We also discuss some of the problems which typically contribute to potential inhomogeneities in precipitation records.

The station data were interpolated onto a $4^{\circ}$ latitude by $5^{\circ}$ longitude uniform grid. Comparisons of these data with two other global-scale precipitation climatologies are presented. We find good agreement among the three global-scale climatologies over the common areas in each set. Three different indices of long-term precipitation variations over the global land areas all indicate a general increase of annual precipitation since the $1940 \mathrm{~s}$, although a decline is evident over the last decade. There is some indication that the last few decades of the 19th century may have been as wet as the recent ones. An interesting feature of this study is the presence of relatively large differences in seasonal trends, with March-May and September-November becoming wetter in the last few decades. The December-February and June-August seasons exhibit smaller overall trends, although the northern winter season does exhibit large decadalscale fluctuations.

\section{Processes for Identifying Regional Influences of and Responses to Increasing Atmospheric $\mathrm{CO}_{2}$ and Climate Change-The MINK Project. An Overview (DOE/RL/01830T-H5, August 1991, 35 pp.)}

\section{N. J. Rosenberg, and P. R. Crosson, Resources for the Future, Washington, D.C.}

This overview report explains the rationale for and the methodology used in conduct of the study "Processes for Identifying Regional Influences of and Responses to Increasing Atmospheric $\mathrm{CO}_{2}$ and Climate Change-The MINK Project," commissioned by the U.S. Department of Energy. The major findings of the study are also presented in this overview, which accompanies a series of six reports in which the requisite technical details on methodology, sectoral analyses, and integrated analysis of climate change impacts and responses are provided in detail. 
TR052B Processes for Identifying Regional Influences of and Responses to Increasing Atmospheric $\mathrm{CO}_{2}$ and Climate Change-The MINK Project. Report I. Background and Baselines (DOE/RL/01830T-H6, August 1991, 113 pp.)

N. J. Rosenberg, P. R. Crosson, K. D. Frederick, W. E. Easterling, III, M. S. McKenney, R. A. Sedjo, M. D. Bowes, J. Darmstadter, L. A. Katz, and K. M. Lemon, Resources for the Future, Washington, D.C.

This report (No. I) is intended to provide background information on project organization and methodology (Sec. 1). In Sec. 2 and 3 the region chosen for study and the scenario of climate change applied to it are described. The remainder of the paper provides information on the current functioning of the region-its demography and macroeconomic characteristics, its major natural resource sectors, the way these sectors interlink among themselves and with other industries and the region's economic base. In the final section projections are made of the demographics and macroeconomic characteristics of the region 20 and 40 years into the future.

TR052C Processes for Identifying Regional Influences of and Responses to Increasing Atmospheric $\mathrm{CO}_{2}$ and Climate Change-The MINK Project. Report IIA. Agricultural Production and Resource Use in the MINK Region Without and With Climate Change (DOE/RL/01830T-H7, August 1991, 123 pp.)

P. R. Crosson, L. A. Katz, and J. Wingard, Resources for the Future, Washington, D.C.

This report (IIA) treats agriculture in MINK in terms of state and region-wide production and resource use for the main crops and animals in the baseline periods of 1984-87 and 2030. The effects of the analog climate on the industry at this level of aggregation are considered in both baseline periods.

TR052D Processes for Identifying Regional Influences of and Responses to Increasing Atmospheric $\mathrm{CO}_{2}$ and Climate Change-The MINK Project. Report IIB. A Farm-Level Simulation of the Effects of Climate Change on Crop Production in the MINK Region (DOE/RL/01830T-H8, August 1991, 222 pp.)

W. E. Easterling, III, M. S. McKenney, N. J. Rosenberg, and K. M. Lemon, Resources for the Future, Washington, D.C.

This report (IIB) deals with agriculture at the level of farms and Major Land Resource Areas (MLRAs). The Erosion Productivity Impact Calculator (EPIC), a crop growth simulation model developed by scientists at the U.S. Department of Agriculture, is used to study the impacts of the analog climate on yieids of main crops in both the 1984-87 and the 2030 baselines. The results of this work with EPIC are the basis for the analysis of the climate change impacts on agriculture at the region-wide level undertaken in the report. 
Processes for Identifying Regional Influences of and Responses to Increasing Atmospheric $\mathrm{CO}_{2}$ and Climate Change-The MINK Project. Report III. Forest Resources (DOE/RL/01830T-H9, August 1991, 123 pp.)

M. D. Bowes, and R. A. Sedjo, Resources for the Future, Washington, D.C.

This report is directed to an analysis of the possible impacts of climatic change on forest resources in the Missouri-lowa-Nebraska-Kansas region. It follows a uniform methodological strategy that is applied to the four resource sectors most likely to be impacted by climate change (i.e., agriculture, forestry, water resources, and energy). The methodological strategy is fully explained in report I of this series.

Processes for Identifying Regional Influences of and Responses to Increasing Atmospheric $\mathrm{CO}_{2}$ and Climate Change-The MINK Project. Report IV. Water Resources (DOE/RL/01830T-H10, August 1991, 153 pp.)

K. D. Frederick, Resources for the Future, Washington, D.C.

This report is directed to an analysis of the possible impacts of climatic change on water resources in the Missouri-lowa-Nebraska-Kansas region. It follows a uniform methodological strategy that is applied to the four resource sectors most likely to be impacted by climate change (i.e., agriculture, forestry, water resources, and energy). The methodological strategy is fully explained in report I of this series.

\section{Processes for Identifying Regional Influences of and Responses to Increasing Atmospheric $\mathrm{CO}_{2}$ and Climate Change-The MINK} Project. Report V. Energy (DOE/RL/01830T-H11, August 1991, 60 pp.)

J. Darmstadter, Resources for the Future, Washington, D.C.

This report is directed to an analysis of the possible impacts of climatic change on energy in the Missouri-Iowa-Nebraska-Kansas region. It follows a uniform methodological strategy that is applied to the four resource sectors most likely to be impacted by climate change (i.e., agriculture, forestry, water resources, and energy). The methodological strategy is fully explained in report I of this series. 


\title{
TR052H Processes for Identifying Regional Influences of and Responses to Increasing Atmospheric $\mathrm{CO}_{2}$ and Climete Change-The MINK Project. Report VI. Consequences of Climate Change for the MINK Economy: Impacts and Responses (DOE/RL/01830T-H12, August 1991, 58 pp.)
}

\author{
M. D. Bowes, and P. R. Crosson, Resources for the Future, Washington, D.C.
}

This report is directed to providing an integrated analysis of the possible economic impacts of climatic change on resources in the Missouri-Iowa-Nebraska-Kansas region. It is based on a uniform methodological strategy that was applied to the four resource sectors most likely to be impacted by climate change (i.e., agriculture, forestry, water resources, and energy). The methodological strategy is fully explained in report I of this series.

\section{TR053 The Determination of Total Dissolved Inorganic Carbon in Sea Water Using Extraction/Coulometry: The First Stage of a Collaborative Study (DOE/RL/01830T-H14, February 1992, 43 pp.)}

\section{A. G. Dickson, Scripps Institution of Oceanography}

Samples of sterilized sea water were bottled and sent to a total of fifteen laboratories for analysis for total dissolved inorganic carbon. These were located in Canada (2), Germany (1), The Netherlands (1), Sweden (1), the United States (9), and the United Kingdom (1). All except one laboratory used their current implementation of an extraction/coulometric procedure to analyze the samples; the other laboratory, Dr. Keeling's laboratory at the Scripps Institution of Oceanography, analyzed the samples using their extraction/manometric procedure, which is considered a "definitive" method.

Each of the laboratories returned at least some results, and only two laboratories were clearly (on their own admission) having substantial difficulties in implementing the procedure. The results from the other twelve laboratories were extremely encouraging. The within-laboratory standard deviation of the results reported by the various laboratories (omitting the two that had substantial difficulties) ranged from $0.56-2.75 \mu \mathrm{mol} \mathrm{kg}^{-1}$ with a pooled standard deviation of $1.55 \mu \mathrm{mol} \mathrm{kg}^{-1}$. The weighted mean calculated from the results of these twelve laboratories was $1977.8 \mu \mathrm{mol} \mathrm{kg}^{-1}$; almost identical to the certified value obtained by extraction/manometry $\left(1978.8 \mu \mathrm{mol} \mathrm{kg}^{-1}\right)$. This indicates that the extraction/coulometric procedure is capable of making unbiased measurements. Unfortunately, the spread of the mean values from these twelve laboratories was substantial $\left(17.2 \mu \mathrm{mol} \mathrm{kg}^{-1}\right)$ and only five sets of results had a mean that was equivaient to the certified value (with $95 \%$ confidence).

Although the optimal procedure for this determination is still not clear (some recommendations for further study are contained in the body of this report), I believe the majority of these discrepancies results from the lack (at the time of this study) of a written standard operating procedure and of certified reference materials for total dissolved inorganic carbon in sea water.

This is no longer the case; both now exist and it remains to see if the expected improvements materialize. In April 1992, 1 intend to initiate a further study distributing blind samples to various laboratories for analysis to assess what, if any, changes have taken place. 


\title{
Modeling the Response of Plants and Ecosystems to Elevated $\mathrm{CO}_{2}$ and Climate Change \\ (DOE/ER-60490T-HI, March 1992, 190 pp.)
}

\author{
J. F. Reynolds, D. W. Hilbert, J. Chen, P. C. Harley, P. R. Kemp, and P. W. Leadley, \\ San Diego State University
}

In recognition of the role of plants in the bio-geosphere carbon cycle, the Carbon Dioxide Research Program of U.S./DOE initiated a research program on the Direct Effects of Increasing Carbon Dioxide on Vegetation (Stain and Cure 1985; Dahlman. 1985). This report describes continuing research that we are conducting as part of the $\mathrm{DOE} / \mathrm{CO}_{2}$ program to develop a general ecosystem model to investigate the potential responses of different terrestrial ecosystems to changes in the global environment over the next century. The Committee on Global Change (1988) notes that such "generic ecosystem models" can only be useful for predicting responses of ecosystems to future global changes if they are linked to population-community models. Our research approach incorporates such efforts as part of a multi-investigator, multi-university, long-term research strategy developed with the ultimate goal of providing experimental data, modeling methodology, and models for predicting long-term, large-scale ecosystem response to global change.

\section{Climate Data Bases of the People's Republic of China 1841-1988 (DOE/NBB-0091T, January 1993, 215 pp.)}

\section{Kaiser, University of Tennessee and Oak Ridge National Laboratory}

\author{
S. Tao, C. Fu, Z. Zeng, and Q. Zhang, Chinese Academy of Sciences
}

\section{W.-C. Wang, State University of New York, Albany}

\section{T. Karl, Nationai Climatic Data Center}

A data base containing meteorological observations from the People's Republic of China (PRC) is described. These data were compiled in accordance with a joint research agreement signed by the U.S. Department of Energy and the PRC Chinese Academy of Sciences (CAS) on August 19, 1987. CAS's Institute of Atmospheric Physics (Beijing, PRC) has provided records from 296 stations, organized into five data sets: (1) a 60-station data set containing monthly measurements of barometric pressure, surface air temperature, precipitation amount, relative humidity, sunshine duration, cloud amount, wind direction and speed, and number of days with snow cover; (2) a 205-station data set containing monthly mean temperatures and monthly precipitation totals; (3) a 40-station subset of the 205-station data set containing monthly mean maximum and minimum temperatures and monthly extreme maximum and minimum temperatures; (4) a 180-station data set containing daily precipitation totals; and (5) a 470station data set containing 10-day precipitation totals. Sixteen stations from these data sets ( 13 from the 60-station set and 3 from the 205-station set) have temperature and/or precipitation records that begin prior to 1900 , whereas the remaining stations began observing in the early to mid-1900s. Records from most stations extend through 1988. 
These data can be used in defining regional climate changes, establishing relationships between regional and large-scale climates, studying the climatic impacts of urbanization and increased concentrations of greenhouse gases, and assembling large-scale climate data bases. Additional uses could include examining impacts of periodic events such as volcanic eruptions or the El Niño/Southern Oscillation. These data sets represent the most comprehensive, long-term instrumental Chinese climate data currently available. 
Section C

\section{U.S. Department of Energy Atmospheric Radiation Measurements (ARM) Program Reports}




\title{
Atmospheric Radiation Measurement Program Plan
}

(February 1990)

\section{Atmospheric and Climate Research Division, U.S. Department of Energy}

Scientists from the DOE National Laboratory community contributed to the preparation of the ARM Program Plan with input from members of the academic community, the private sector, and from scientists from other Committee on Earth Sciences (CES) agencies. The Plan was subjected to an extensive peer review and the many helpful comments we have received have been incorporated into this document. We believe that ARM will serve the CES objectives in Global Change research and support the DOE mission of formulating a National Energy Strategy that takes into account the potential for global climate change.

\section{Atmospheric Radiation Measurement Program Plan, Executive Summary (February 1990)}

\section{Atmospheric and Climate Research Division, U.S. Department of Energy}

Scientists from the DOE National Laboratory community contributed to the preparation of the ARM Program Plan with input from members of the academic community, the private sector, and from scientists from other Committee on Earth Sciences (CES) agencies. The Plan was subjected to an extensive peer review and the many helpful comments we have received have been incorporated into this document. We believe that ARM will serve the CES objectives in Global Change research and support the DOE mission of formulating a National Energy Strategy that takes into account the poteniial for global climate change.

\section{Identification, Recommendation, and Justification of Potential Locales for ARM Sites, Executive Summary} (April 1991)

\author{
Atmospheric and Climate Research Division, U.S. Department of Energy \\ This report is an account of a study that was undertaken within the ARM program to \\ examine locations suitable for establishing and maintaining experimental sites that meet the \\ objectives of ARM and to recommend an ordered set of locales in which to locate sites, \\ thereby creating the framework for site selection. Selection of specific ARM sites will come \\ from further analysis based on the principles established in this report. The results of the \\ study have been reviewed by several entities within the ARM program and DOE, as well as \\ leading scientists in the meteorological and atmospheric radiation community. This report \\ incorporates the many helpful comments and suggested changes received from these \\ reviews.
}


DOE/ERO495T

CONF9110336

DOE/ER00585T

\author{
Identification, Recommendation, and Justification of Potential \\ Locales for ARM Sites \\ (April 1991)
}

Atmospheric and Climate Research Division, U.S. Department of Energy

This report is an account of a study that was undertaken within the ARM program to examine locations suitable for establishing and maintaining experimental sites that meet the objectives of ARM and to recommend an ordered set of locales in which to locate sites, thereby creating the framework for site selection. Selection of specific ARM sites will come from further analysis based on the principles established in this report. The results of the study have been reviewed by several entities within the ARM program and DOE, as well as leading scientists in the meteorological and atmospheric radiation community. This report incorporates the many helpful comments and suggested changes received from these reviews.

\section{Proceedings of the Second Atmospheric Radiation Measurement (ARM) Science Team Meeting} (December 1992)

\section{Environmental Sciences Division \\ U.S. Department of Energy}

The second Atmospheric Radiation Measurement (ARM) Science Team Meeting was held in Denver, Colorado, in October 1991. The 5 day meeting provided a forum for a technical exchange among the members of the ARM Science Team and a discussion of the technical aspects of the project infrastructure. The meeting included several activities: Science Team presentations, discussions of the first site occupation plan, experiment design sessions, and poster sessions. This proceedings document includes papers presented at the meeting. The papers included are those from the technical sessions, the experiment design sessions, the first site occupation, and descriptions of locales for future sites.

\section{The Possible Direct Use of Satellite Radiance Measurements by the Atmospheric Radiation Measurement Program} (March 1993)

\section{Environmental Sciences Division \\ U.S. Department of Energy}

The Atmospheric Radiation Measurement (ARM) Program is a major research program initiated by the U.S. Department of Energy to improve scientific understanding of radiative and cloud processes critical to predicting the Earth's climate and future climate changes. Central to this concept is the use of four to six intensively instrumented sites for long-term study and characterization of the processes of interest. The instrumentation sites will include ground-based, high-accuracy radiometers for measuring the short and longwave surface flux, as well as an extensive set of ground- and air-based instrumentation for characterizing the intervening atmospheric column. Satellite-based measurements are expected to play a very important role in providing top-of-atmosphere (TOA) measurements. 
In an earlier study, we assessed the current and planned satellite measurement capabilities as they relate to ARM. That study focused on the ability of satellites to provide such derived physical quantities as temperature and water-vapor profiles; cloud coverage, top height, and temperature; and earth radiation budgets. Although such derived products can be very useful, they often involve significant processing of the direct satellite data (e.g., inversion of radiance to obtain temperature and water-vapor profiles or the conversion of radiances to fluxes to obtain radiation budgets). This processing in turn often requires both modeling and auxiliary data sets (e.g., initial-guess profiles for the inversion). Thus, unless great care is taken, there is a very real danger that such "derived" satellite data would not be an independent data set against which to compare ARM outputs.

In this study, we examine the possibility of comparing ARM outputs directly with satellite measurements, thereby ensuring the independence of these two important data sets. Thus, we have focused on four questions: (1) What do satellites really measure and how well do they measure it? (2) What can we do about the general lack of adequate visible channel calibration?

(3) What is the best way for ARM to obtain near-real-time access to this unprocessed data?

(4) What is the optimum way for ARM to make use of satellite data? The answer to each of these questions is summarized in the detailed papers that follow.

\section{Quantifying and Minimizing Uncertainty of Climate Forcing by Anthropogenic Aerosols (March 1993)}

J. E. Penner

Lawrence Livermore National Laboratory

R. J. Charlson

University of Washington

J. M. Hales

ENVAIR

\section{N. Laulainen}

Pacific Northwest Laboratory

R. Leifer

Environmental Measurements Laboratory
T. Novakov

Lawrence Berkeley Laboratory

J. Ogren

NOAA Climate Monitoring and

Diagnostics Laboratory

L. F. Radke

National Center for Atmospheric Research

S. E. Schwartz

Brookhaven National Laboratory

L. Travis

NASA Goddard Institute for Space Studies 
Here, we estimate the uncertainty in the forcing by these aerosol types. Estimates of the clear-sky forcing by other anthropogenic aerosol types do not even exist although the forcing by these aerosol types is thought to be smaller than that by sulfate and biomass-burning aerosols.

The cloudy-sky forcing by anthropogenic aerosols, wherein aerosol cloud condensation nuclei concentrations are increased, thereby increasing cloud droplet concentrations and cloud albedo and possibility influencing cloud persistence, may also be significant. In contrast to the situation with the clear-sky forcing, estimates of the cloudy-sky forcing by an anthropogenic aerosols are little more than guesses, and it has not been possible to quantify the uncertainty of the estimates.

This situation dictates that considerable importance be attached to quantifying forcing by the anthropogenic aerosol and to defining and minimizing uncertainties in the calculated forcings. In this article, we define a research strategy for improving the estimates of the clear-sky forcing which, if implemented, should allow these effects to be incorporated into climate models within the next several years. The strategy encomipasses five major, but not necessarily coordinated, activities: surface-based observations of aerosol chemical and physical properties and the radiation field, aircraft-based observations of aerosol chemical and physical properties and the radiation field, aircraft-based observations of the same properties, process studies to refine model treatments, satellite observations of aerosol abundance and size distribution, and modeling studies to demonstrate consistency between the observations and to allow extension of the limited set of observations to the global scale. A similar strategy for defining the magnitude of the cloudy-sky forcing should also be possible, but our uncertain understanding of this forcing requires that research of a more exploratory nature be carried out prior to engaging in a large-scale experiment of the magnitude of that recommended for the clear-sky forcing.

\section{Intercomparison of Radiation Codes in Climate Models (May 1991)}

\section{Journal of Geophysical Research, American Geophysical Union}

This special section consists of a series of papers devoted to the scientific aspects of state-ofthe-art methods in radiative transfer computations relevant for investigations of the Earth's atmosphere. The results discussed in the papers constitute a portion of the Intercomparison of Radiation Codes in Climate Models (ICRCCM) project, which was developed under the auspices of the World Meteorological Organization (WMO) and the International Council of Scientific Unions as supported by the Carbon Dioxide Research Division (now called Atmospheric and Climatic Research Division) of the U.S. Department of Energy (DOE). A description of the initial phase of the ICRCCM project can be found in the work by luther et al. (Bulletin of the American Meteorological Society 69, 40 48, 1988). The principal objectives of ICRCCM were to develop an understanding of the various radiative transfer algorithms, to investigate the causes and the nature of the differences in the results among the various codes (including their accuracy with respect to benchmark computations), and to ascertain the sensitivity of the algorithms to a number of factors (including spectral parameters, constituent amounts, and meteorological conditions). 
Section D

Other U.S. Department of Energy Reports 
Four State-of-the-Art (S()A) volumes document what is known, unknown, and uncertain about $\mathrm{CO}_{2}$ data, analyses, and modeling capabilities. They also outline potential avenues of research for reducing critical uncertainties. The four volumes are:

\section{Detecting the Climatic Effects of Increasing Carbon Dioxide (December 1985)}

M. C. MacCracken, and F. M. Luther (eds.), Lawrence Livermore National Laboratory

The objective of this volume is to document what is known about detecting the $\mathrm{CO}_{2}$-induced changes in climate and to describe the uncertainties and unknowns associated with this monitoring and analysis effort.

\section{Characterization of Information Requirements for Studies of $\mathrm{CO}_{2}$ Effects: Water Resources, Agriculture, Fisheries, Forests and} Human Health

(December 1985)

\section{R. White, Lawrence Berkeley Laboratory}

This companion volume to the SOAs establishes a baseline of knowns and unknowns and delineates the data and improvements in methodology required to estimate the impacts on humankind from increased atmospheric $\mathrm{CO}_{2}$.

\section{Projecting the Climatic Effects of Increasing Carbon Dioxide} (December 1985)

M. C. MacCracken, and F. M. Luther (eds.), Lawrence Livermore National Laboratory

This volume summarizes what is known about projections of the climatic effects of the increasing $\mathrm{CO}_{2}$ concentration and describes the uncertainties and unknowns associated with such projections.

\section{Direct Effects of Increasing Carbon Dioxide on Vegetation}

(December 1985)

B. R. Strain, and J. D. Cure (eds.), Duke University

This volume summarizes the current knowledge of the direct effects of increasing atmospheric $\mathrm{CO}_{2}$ on vegetation and the subsequent effects on ecosystems. 
DOE/ER0239

DOE/ER0316

\section{Atmospheric Carbon Dioxide and the Global Carbon Cycle (December 1985)}

\section{J. R. Trabalka (ed.), Oak Ridge Nutional Laboratory}

This volume focuses on the global cycle of carbon, the dymamic balance among global atmospheric $\mathrm{CO}_{2}$ sources and sinks, which determines the rate of increase in the atmospheric $\mathrm{CO}_{2}$ concentration.

\section{Master Index for the Carbon Dioxide Research State-of-the-Art Report Series (March 1987)}

\section{P. Farrell (ed.), Oak Ridge National Laboratory}

This volume is a comprehensive citation and subject index for CDRD's four State-of-theArt reports and the two companion volumes. This comprehensive subject index has been formatted in a matrix arrangement to graphically show the distribution of subject treatment in the six reports. A glossary of terms, tables, conversion factors and other aids are also included in this volume.

\section{Global Distribution of Total Cloud Cover and Cloud Type Amounts Over Land (October 1986)}

\section{S. G. Warren, University of Washington}

\section{J. Hahn, and J. London, University of Colorado}

\section{R. M. Chervin, and R. L. Jenne, National Center for Atmospheric Research}

Clouds exert large influences on the earth's climate by virtue of their radiative properties both in the solar and thermal-infrared spectral regions and because of their role in the hydrological cycle. These effects depend on cloud thickness, height, and water content, and therefore, it is useful to distinguish clouds by type. Currently, the surface identification of clouds by type is more accurate than identification from satellites.

This is the third in a series of atlases resulting from a study of global cloud climatology from ground-based observations. This atlas describes, for the land areas of the earth, the average total cloud cover; the amounts of each cloud type and geographical, diurnal, seasonal, and interannual variations in these quantities; and the average base heights of the low clouds. This atlas presents a method for determining the average fractional coverage of each cloud type, taking into account the overlap of different cloud types present simultaneously in a single observation. The method is designed to derive the true average amounts rather than the amounts seen from below or above. The method separately obtains the average frequency of occurrence and the average amount-when-present and multiplies 
these to derive the average amount of each cloud type. These quantities are mapped for six cloud types, and the average total cloud cover is also mapped for each of four seasons at $5^{\prime \prime} \mathrm{x}$ $5^{\circ}$ latitude-longitude resolution (poleward of $50^{\circ}$ latitude, the size of the box is increases in longitude to maintain approximately equal area in each box). Biurnal and interannual variations of cloud type quantities are niapped at the same spatial resolution. The numbers plotted in this at las as well as more detailed information not included in this atlas, such as average frequencies and amounts for individual year/seasons and individual reporting hours, are available on magnetic tape from the Data Support Section at the National Center for Atmospheric Research and from CDIAC.

The first two atlases in this series described the frequency of occurrence of each cloud type and the simultaneous occurrence of different types but included no information about cloud amounts. A fourth atlas, in preparation, provides data on cloud amounts for the ocean areas of the earth.

\section{Antarctic Surges-A Clear and Present Danger?} (July 1987)

\section{U. Radok, CIRES, University of Colorado \\ D. Jenssen, and B. McInnes, University of Melbourne}

Antarctic ice streams typically move hundreds of meters in a year. The investigation here outlined for nonspecialists was carried out with the support of the U.S. Department of Energy at the University of Colorado at Boulder and at the University of Melbourne, Australia, in order to determine whether polar ice streams, like some mountain glaciers, can accelerate their motion from time to time by one or two orders of magnitude in the span of a few years, with appreciable effects on global sea level.

The necessary factual background can be derived from the fact that the mass gains and losses of the Antarctic ice sheet as a whole closely balance one another. The working hypothesis that they do so exactly was used to construct three-dimensional steady-state fields of ice velocity and temperature in broad agreement with the as yet very scant observational record for the ice sheet. Next, a numerical model (due to Budd and Mclnnes 1974 and Budd 1975), which links the sliding motion of the ice to the energy dissipated by the friction between the ice and the underlying rock, was used to simulate the time-dependent behavior of eight ice streams representing the full range of Antarctic conditions.

In contrast to the realistic alternation between fast advances and stagnating retreats which the model had produced for some mountain glaciers known to surge, the modeled ice streams instead went from steady to irregular continuous fast sliding when the prescribed ice deformability was reduced and/or the implied lubrication by frictional heating was increased. Substantial rapid advances did not develop, except as transient phases in two experiments.

The inability of the model in general to create surges in ice streams could be due solely to its over-simplified treatment of the complex hydraulic processes taking place below the ice. 
DOE/ER0406
More adequate treatments of these processes are being developed and, when expanded into new self-propelled models, could show ice stream surges to be feasible. However, it may be significant that along surging glaciers the accumulation decreases and becomes strongly negative ("ablation") in the lower reaches. By contrast, the accumulation on Antarctic ice streams increases all the way from their regions of formation to the regions of discharge into the ocean. It is then possible that ice stream surges are prevented by the strong downstream increase in mass flow and also by the flexible restraint exerted by terminal ice shelves.

\section{Global Distribution of Total Cloud Cover and Cloud Type Amounts Over the Ocean}

(December 1988)

\section{S. G. Warren, University of Washington}

C. J. Hahn, CIRES, University of Colorado

\section{J. London, University of Colorado}

\section{R. M. Chervin, and R. L. Jenne, National Center for Atmospheric Research}

These two oversized volumes $(11 \times 17 \mathrm{in.})$ are the third and fourth in a series of atlases that have resulted from a study of the global cloud distribution from ground-based observations. The first two atlases (NCAR/TN-201+STR and NCAR/ TN-241+STR) described the frequency of occurrence of each cloud type and the co-occurrence of different types. They did not include any information on cloud amounts. The volumes cited here describe the average total cloud cover; the amounts of each cloud type; the clouds' geographic, diurnal, seasonal, and interannual variations; and the average base heights of the low clouds. One volume does all this for the land areas of the Earth, and the other for the ocean areas. The great preponderance of each of these two volumes is made up of maps displaying the data gathered with a resolution of $5^{\circ} \times 5^{\circ}$. About $30 \mathrm{pp}$. of each volume is taken up with a narrative description, discussion, and analysis of the data and of the means used to gather the data. Graphs of data are also presented on microfiche cards. The data plotted on the maps and other data contained in these atlases are available on magnetic tape from CDIAC as Numeric Data Package NDP-026.

\section{Atmospheric Carbon Dioxide and the Greenhouse Effect (May 1989)}

\section{Carbon Dioxide Research Program, U.S. Department of Energy}

A popular guide to the greenhouse effect and its relation to atmospheric carbon dioxide concentrations. Discussions include comparison of the problems with the problems of acid rain and ozone loss, and the quantification of increases in atmospheric $\mathrm{CO}_{2}$ effects on climate, vegetation, and sea level. Potential responses to these effects are discussed, and further information on all these topics identified. 


\section{Building an Advanced Climate Model Program Plan for the CHAMMP Climate Modeling Program}

(December 1990)

\section{Atmospheric and Climate Research Division, U.S. Department of Energy}

The program has two aspects that are inescapably coupled and must be conducted in an increasingly comprehensive series of coordinated projects. First, advanced climate models must be developed that dramatically increase the computational throughput of climate model simulations by combining state-of-the-science supercomputing systems with advances in numerical methods and model physics. These new generation models must be used to address three critical problems: more accurate prediction of regional climatic changes that may occur over decadal to centennial periods, determination of the limits to climate predictability imposed by the inherent variability of climate as a dynamic system, and development of realistic schedules for achieving improved predictions of climatic change.

\section{Computer Hardware, Advanced Mathematics, and Model Physics (CHAMMP) Pilot Project Final Report}

(May 1992)

\section{J. Drake, Oak Ridge National Laboratory}

\section{Foster, Argonne National Laboratory}

\section{P. Swarztrauber, National Center for Atmospheric Research}

The collaborative relationship between researchers at NCAR, ORNL, and Argonne has continued in FY 1991 and been productive in a number of areas. From a broad definition of the issues involved in using massively parallel computers for climate modeling, the group has moved to providing solutions to some of the more difficult specific problems of the parallel computation of atmospheric dynamics. In particular, algorithms have been developed and applied for

- $\quad$ an efficient Legendre transform on MIMD and SIMD architectures

- parallel Fast Fourier Transforms tailored for global modeling on both MIMD and SIMD computers

- distributed semi-Lagrangian transport calculations on MIMD computers

Significant progress has also been made in understanding issues relevant to the design of massively parallel climate models. In particular, the group has completed studies of

- parallel scalability of the spectral transform and other numerical methods

- load balancing strategies and vertical parallelization for climate models 
This work provides both a technical basis for developing parallel spectral climate models on MIMD and SIMD machines and a scientific basis for the design of future parallel climate models. The algorithms are now being applied in preliminary parallel implementations of the NCAR Community Climate Model (CCM2). The status of the PCCM2 is discussed in this overview. Studies of alternative numerical methods, the special transform algorithm, load distribution issues, scalability analysis, and a set of test problems designed for evaluation of numerical methods are also described in accompanying papers.

\section{Glaciers, Ice Sheets, and Sea Level: Effect of a $\mathrm{CO}_{2}$-Induced Climatic Change \\ (September 1985)}

\section{Polar Research Board, National Research Council}

This report summarizes the consensus of the Workshop on the Interactions between Land Ice and the Oceans (in Seattle, Washington, September 13-15, 1984), mentions areas of uncertainty, and makes recommendations for research.

\section{International Carbon Dioxide-Related Activities: The International Organizations Involved and U.S. Bilateral Arrangements (July 1983)}

\section{R. Dougher, Oak Ridge Associated Universities}

This paper describes the international organizations and the type of $\mathrm{CO}_{2}$-related activities they conduct and outlines the $\mathrm{CO}_{2}$ research work conducted through bilateral arrangements.

\section{Review of Carbon Dioxide Research Staffing and Academic Support} (April 1985)

\section{S. B. Clark, L. Howard, W. Stevenson, and J. Trice, Oak Ridge Associated Universities}

The report summarizes the research staffing and academic support of the U.S. Department of Energy's Carbon Dioxide Research Division (CDRD) for 1983 and 1984. About $60 \%$ of CDRD's staff were university-affiliated and about $20 \%$ were students; however, carbon dioxide research will probably not affect the general labor market for scientists and engineers because it uses only a small part of the total labor pool. The report also discusses options for academic support by CDRD. These include: (1) modifying procurement procedures for research contracts to increase academic involvement; (2) sponsoring summer institutes on issues of interest to CDRD; and (3) supporting traveling lecture programs to inform technical and nontechnical audiences of CDRD's interests. 


\section{DOE/PE- Global Climate Trends and Greenhouse Gas Data: Federal 0094P Activities in Data Collection, Archiving, and Dissemination. A Report to the Congress of the United States (June 1990)}

\section{Office of Environmental Analysis, U.S. Department of Energy}

This report examines the current holdings of data related to greenhouse-gas emissions and climate trends that have been collected by federal agencies; the procedures for collecting, archiving, and disseminating those data; and the coordination of those information activities. It examines what procedures are necessary for improving the availability of the data and information needed to deal with greenhouse-gas and climate-change issues. It also considers what information is needed for the scientific understanding, estimation, and projection of emissions; for the modeling of climate-system processes; for the detection and characterization of trends; and for the support of assessment and policy studies. To explain the kinds of data needed and the special requirements for processing these kinds of data, the methods for estimating greenhouse-gas emissions and for detecting climate trends are summarized.

Particular gaps in data coverage and targets of opportunity for improved data (i.e., data collected but never encoded for computer use and prepared for distribution) are identified. Additional types of data that especially need collection for special purposes have also been pointed out.

The numerous and often extensive appendixes include lists and descriptions of data sources, descriptions of data needed for specific subject areas, the theory and philosophy of data management, and a bibliography.

\section{DOE/EP- 0001P}

\section{Policy Statements on Data Management for Global Change Research (July 1991)}

\section{U.S. Global Change Research Program, National Science Foundation}

The overall purpose of these policy statements is to facilitate full and open access to quality data for $\mathrm{g}$ 'obal change research. They were prepared in consonance with the goal of the U.S. Global Change Research Program and represent the U.S. Government's position on the access to global change research data.

- The Global Change Research Program requires an early and continuing commitment to the establishment, maintenance, validation, description, accessibility, and distribution of high-quality long-term data sets.

- Full and open sharing of the full suite of global data sets for all global change researchers is a fundamental objective.

- Preservation of all data needed for long-term global change research is required. For each and every global change data parameter, there should be at least one explicitly designated archive. Procedures and criteria for setting priorities for data acquisition, 
retention, and purging should be developed by participating agencies, both nationally and internationally. A clearinghouse process should be established to prevent the purging and loss of important data sets.

- Data archives must include easily accessible information about the data holdings, including quality assessments, supporting ancillary information, and guidance and aids for locating and obtaining the data.

- National and international standards should be used to the greatest extent possible for media and for processing and communication of global data sets.

- Data should be provided at the lowest possible cost to ylobal change researchers in the interest of full and open access to data. This cost should, as a first principle, be no more than the marginal cost of filling a specific user request. Agencies should act to streamline administrative arrangements for exchanging data among researchers.

- For those programs in which selected principal investigators have initial periods of exclusive data use, data should be made openly available as soon as they become widely useful. In each case, the funding agency should explicitly define the duration of any exclusive use period. 
Section E

\section{CDIAC Reports}


Graduate Student Theses Supported by Carbon Dioxide Research Division Office of Basic Energy Sciences, U.S. Department of Energy (September 1987)

\title{
R. E. Millemann, Oak Ridge National Laboratory
}

The U.S. Department of Energy's Carbon Dioxide Research Division (CDRD) has a strong commitment to support graduate education. Over the yuars, CDRD has funded graduate thesis research, the results of which have not been summarized. The purpose of this report is to summarize information on thesis research supported by CDRD and to make it available to carbon dioxide researchers and other interested persons. The file will be updated annually. Copies of theses can be obtained upon request from CDIAC.

The information used to prepare this report was obtained through a questionnaire sent to CDRD contractors in early 1987. The cutoff date for assembling this information was August 1987, so the actual number of theses completed during 1987 may be greater than that indicated on the summary page and in the figures.

To date, $25 \mathrm{Ph} . \mathrm{D}$. and 23 Master's theses, including 4 internship reports for the M.En. degree from Miami University (Ohio), have been written based on research supported wholly or in part by CDRD funds. Of these, 16 are in the carbon cycle area and 11 relate to climate, 17 to vegetation response, 3 to sea level, and 4 to CDIAC; a few theses are relevant to more than one program area. The number of universities involved in awarding degrees based on thesis research is 20, including one foreign university, the University of Melbourne. Of the contractors for the period 1981 through 1987, 82 responded to the questionnaire, and of these, 26 supported thesis research. Most of the contractors also served as the major professors for the students.

After the summary and figure pages, four lists appear in this report: an Author List containing the complete thesis citation, name(s) of the major professor(s), major department, contractor, and contract number; a Contractor List having the affiliation of and the thesis research supported by each contractor; a Program Area List in which the theses are grouped by subject area; and a University List in which the theses are grouped by the degree-granting institutions.

\section{Bibliography on Tropical Rain Forests and the Global Carbon Cycle. Vol. 1. An Introduction to the Literature (May 1988)}

\author{
C. A. S. Hall, State University of New York and University of Montana \\ S. Brown, University of Illinois
}

F. M. O'Hara Jr., Consultant, Oak Ridge National Laboratory

P. B. Bogdonoff, D. Barshaw, E. Kaufman, and S. Underhill, Cornell University

This bibliography is Part I of a two-part volume; the second part will be an ecological and land-use bibliography on South Asia by J. F. Richards. World literature on tropical rain 
forests, tropical deforestation, land-use change in the tropics, tropical forest conversion, and swidden agriculture as related to the global carbon cycle is covered in this bibliography. Historic papers and books are included, but comprehensive coverage was only sought for 1980 through 1987. This compendium of nearly 2000 entries forms the point of departure for a series of bibliographies on this topic. Other works in this series will be on the global carbon cycle and rain forests in specific geographic areas, whereas this volume includes references to literature about the global carbon cycle and rain forests anywhere in the world. The bibliography is ordered alphabetically by author and is indexed by subject and author.

This bibliography is the third in a series of up-to-date, specialized, and evaluated bibliographies that have been produced by the cooperative efforts of the U.S. Department of Energy's Carbon Dioxide Information Analysis Center (CDIAC) and carbon dioxide researchers.

\section{ORNLI CDIAC-24/V2 \\ Bibliography on Tropical Rain Forests and the Global Carbon Cycle. Vol. 2. South Asia (February 1989)}

\section{E. P. Flint, and J. F. Richards, Duke University}

Considerable debate has centered on the role of biotic carbon release and uptake in the global carbon cycle. Carbon release caused by deforestation may contribute significantly to increased global atmospheric $\mathrm{CO}_{2}$. The first bibliography in this series addressed worldwide tropical rain forests and the carbon cycle, emphasizing the most recent literature. The focus of this bibliography is South Asia, primarily India, Pakistan, and Bangladesh and including some references to Nepal, Bhutan, Sri Lanka, Burma, and other nations.

This bibliography covers a range of ecological, botanical, forestry, agricultural, geological, and geographical sources for the period from 1889 to the present. References include land-use change as it affects all South Asia vegetation types, from tropical rain forests to high mountain systems to deserts. This broad scope was chosen because forests are believed to have covered most of South Asia within the past few millennia and because massive human impact is believed to be responsible for the prevalence of grassland, semidesert, and thorn forests in the regional landscape today.

Major emphases include biomass and productivity of all natural and agricultural South Asian vegetation types, forest area and volume, deforestation and environmental degradation, official land-use statistics, descriptive and quantitative studies of vegetation and animals, forest history, and local and regional case studies of land-use.

This bibliography is the fourth in a series of up-to-date, specialized, and evaluated bibliographies that have been produced by the cooperative effort of the U.S. Department of Energy's Carbon Dioxide Information Analysis Center (CDIAC) and $\mathrm{CO}_{2}$ researchers. 


\section{Environmental Consequences of $\mathrm{CO}_{2}$-Climate Interactions: The Need for Integrated Resource Analysis} (January 1989)

\section{R. M. Cushman, J. C. Waterhouse, and M. P. Farrell, Oak Ridge National Laboratory}

The increasing concentration of atmospheric carbon dioxide is expected to alter the global climate and thereby affect agriculture, forestry, fisheries, and water resources. Resources such as these interact on a regional scale, and realistic projections of the effects on these resources must take into account the important interactions and feedbacks linking them. In addition, carbon dioxide directly affects the water use and growth of vegetation; therefore, the interactive effects of carbon dioxide and climate must also be considered. These interactions and feedbacks pose a significant challenge to any attempt to model the response of resources to changing carbon dioxide and climate. In particular, model linkage and the integration of processes that operate on different spatial and temporal scales are problems that must be addressed.

\section{A Plan for Intermodel Comparison of Atmospheric $\mathrm{CO}_{2}$ Projections with Uncertainty Analysis} (June 1990)

\section{A. W. King, and M. J. Sale, Oak Ridge National Laboratory}

Projecting future concentrations of atmospheric carbon dioxide $\left(\mathrm{CO}_{2}\right)$ is one of the principle objectives of the U.S. Department of Energy's Carbon Dioxide Research Program (CDRP). These projections are needed to assess the likelihood of significant global and regional change as a consequence of the continued use of fossil fuels and to determine whether alternative scenarios of future energy use can significantly alter this likelihood.

The projection of future atmospheric $\mathrm{CO}_{2}$ concentration requires (1) estimates of the anthropogenic release of $\mathrm{CO}_{2}$ to the atmosphere from the combustion of fossil fuels and changes in land use and (2) global carbon cycle models describing the atmospheric retention of that $\mathrm{CO}_{2}$. However, all model projections of future $\mathrm{CO}_{2}$ concentrations involve some degree of uncertainty. Much of this uncertainty can be attributed to (1) uncertainties in future energy and land-use emissions, (2) uncertainties about the global carbon cycle reflected in the structural and conceptual differences between models, and (3) measurement error and uncertainty in the parameters and variables within a particular model. Fortunately, methods for quantifying model uncertainty exist so that projects can be made with confidence limits that reflect the associated uncertainties.

This document is a plan for an intermodel comparison of atmospheric $\mathrm{CO}_{2}$ projections that includes uncertainty analysis of the global carbon cycle models used to make those projections. The plan includes a procedure for the documentation, support, and archiving of global carbon cycle models within the Carbon Dioxide Information Analysis Center (CDIAC) at Oak Ridge National Laboratory (ORNL). 
Incertainty analysis is the examination of uncertainties in predictions from simulation models. The analysis identifies the dependence of model predictions on inputs, initial conditions, and parameters. Incertainty analyșis of global carbon cycle models cinn identify carbon cycle components and processes with the greatest sensitivities and uncertainties. This information can then be used to determine which uncertainties have the greatest influence on future atmospheric $\left({ }^{\prime}()_{2}\right.$ concentrations and where further research and data collection could be most effectively applied to reduce uncertainties. An intermodel comparison of atmospheric $\mathrm{CO}_{2}$, projections with uncertainty analysis can help define research that will improve model performance.

ORNLI CDIAC-33

\section{ORNL/ CDIAC-34/R4 (WDC-A)}

\section{Environmental Atlas of the lowa-Kansas-Missouri-Nebraska Climate-Change Study Region}

\author{
L. J. Allison, C. T. Hunsaker, R. M. Cushman, T. W. White, and J. D. Draves \\ Oak Ridge National Laboratory
}

In 1988 the U.S. Department of Energy (DOE) began an integrated research project to study the potential effect of changing climate on environmental resources. The area of study chosen was the four-state midwestern region of lowa, Kansas, Missouri, and Nebraska. Baseline years are defined as 1984-1987 for agricultural crops and livestock and 1985 for water resources. Agriculture and water--resources that are sensitive to climate, interactive, and important to the study region and to the United States-were chosen for study.

Essential to an integrated regional study is a comprehensive data base of environmental resources in the region, both to characterize the regional resources as they exist today and to serve as input for modeling the response of the resources to climate change. This atlas contains 45 maps and corresponding tabulated data showing the baseline agricultural and water resource data for the lowa-Kansas-Missouri-Nebraska study region along with basic geographic reference data. This atlas may serve as input for modeling the response of resources to climate change and provides DOE project investigators with critical baseline agricultural and water resource data for the Iowa-Kansas-Missouri-Nebraska study region.

\section{Catalog of Data Bases and Reports (April 1994)}

\section{Carbon Dioxide Information Analysis Center, Oak Ridge National Laboratory}

This document provides information about the many reports and other materials made available by the U.S. Department of Energy's Global Change Research Program (GCRP). It is divided into eight sections plus an author and a title index.

The reports in Section $A$ provide information about the scope, activities, and direction of the GCRP. Sections B, C, D, and E contain information about research that has been sponsored by GCRP, including those produced by CDIAC. Section F describes numeric data packages (NDPs) and computer model packages (CMPs), Sec. G describes other data bases distributed by CDIAC, Sec. H. describes reports about research in the joint program of the U.S. Department of Agriculture and GCRP, and Sec. I contains reports from various workshops, symposia, and reviews. 


\title{
Documentation and Analysis of a Global $\mathrm{CO}_{2}$ Model Developed by Peng et al.
}

(July 1990)

\author{
H. I. Jager, T. H. Peng, A. W. King, and M. J. Sale, Oak Ridge National Laboratory
}

In 1983, Peng et al. developed a modification of the Oeschger et al. 1975 ocean model. Both the original and the modification are one-dimensional representations of the ocean, including (1) $\mathrm{CO}_{2}$ exchange between a well mixed atmosphere and a well mixed ocean surface layer and (2) diffusive mixing into the waters lying below the mixed layer. Peng et al. also added a representation of deep-water cycling from intermediate depths to the surface polar outcrop to the ocean bottom and then back to the surface. In addition, they incorporated oceanic primary productivity into the model and benchmarked the model against the penetration of bomb-produced tritium measured by the Geochemical Ocean Sections Study (GEOSECS) program.

This report documents that modified model and describes how the model was standardized to allow comparison with other models. Before being subjected to sensitivity analysis, the standardized version of the model was supplemented with a calibration routine to define reasonable combinations of initial conditions. This routine improved the model's ability to hold an initial equilibrium state. The subsequent sensitivity analysis showed that the model was sensitive to different parameters at different points in its run time. For short runs, the initial conditions selected were of greatest importance; the significance of the initial conditions declined in longer simulations. With the $\mathrm{pCO}_{2}$ excluded from the sensitivity analysis, ocean surface area was always second in importance. Next, the $\mathrm{CO}_{2}$ exchange rate was most important in short runs, but the alkalinity of the oceans was in all but the shortest runs.

\section{Glossary: Carbon Dioxide and Climate}

(August 1990)

\section{Carbon Dioxide Information Analysis Center, Oak Ridge National Laboratory}

The impact of increased concentrations of carbon dioxide $\left(\mathrm{CO}_{2}\right)$ and other trace gases in the atmosphere is of concern in both scientific and nontechnical fields. This glossary contains definitions of selected $\mathrm{CO}_{2}$-related terms and has been compiled to help fill the gaps in information related to climate-change terminology.

Terms in the glossary are defined with an emphasis on their relationship to $\mathrm{CO}_{2}$ and climate. Many of the definitions are then followed by a more comprehensive discussion of the terms and their use. References to the literature from which the definitions were taken are listed at the end of the glossary.

This is the third edition of Glossary: Carbon Dioxide and Climate. This new edition contains more than a hundred new terms, redefinitions of many of the original terms, and an expansion of a section of tables. 
ORNLI CDIAC-46 (WDC-A)
In addition to terminology associated with the $\mathrm{CO}_{2}$-climate issue, a variety of other types of nomenclature is required to fully understand crucial relations between emissions, atmospheric conditions, and changing climate. The (ilossary also contains seven tables of International System of Units Prefixes, common conversion factors, useful quantities found in $\mathrm{CO}_{2}$ research, geological time scales, and abbreviations and acronyms commonly used in atmospheric research.

\section{Trends '91: A Compendium of Data on Global Change (December 1991)}

\section{T. A. Boden, Oak Ridge National Laboratory}

\section{R. J. Sepanski, and F. W. Stoss, University of Tennessee and Oak Ridge National Laboratory}

This document is a source of frequently used global-change data including historical and modern records of atmospheric carbon dioxide $\left(\mathrm{CO}_{2}\right)$, methane $\left(\mathrm{CH}_{4}\right)$, and other trace gas species; $\mathrm{CO}_{2}$ emissions from fossil fuel burning; emissions of chlorofluorocarbons (CFC-1.1 and $\mathrm{CFC}-12$ ); and temperature records. This second issue of the Trends series expands the coverage of sites recording atmospheric concentrations of $\mathrm{CO}_{2}$ and $\mathrm{CH}_{4}$, and it updates records reported in the first issue. New data for other trace atmospheric gases have been included in this issue: historical data on nitrous oxide $\left(\mathrm{N}_{2} \mathrm{O}\right)$ from ice cores, modern records of atmospheric concentrations of CFC- 11 and $\mathrm{CFC}-12$ and $\mathrm{N}_{2} \mathrm{O}$, and estimates of global emissions of $\mathrm{CFC}-11$ and $\mathrm{CFC}-12$. The estimates for global and national $\mathrm{CO}_{2}$ emissions from the burning of fossil fuels, the production of cement, and gas flaring have been revised and updated. Regional $\mathrm{CO}_{2}$ emission estimates have been added, and long-term temperature records have been updated and expanded.

Data records are presented in four- to six-page formats, each dealing with a specific site, region, or emissions species. The data records include tables and graphs; discussion of methods for collecting, measuring, and reporting the data; trends in the data; and references to literature that provides further information.

All data appearing in the document are available on an IBM-formatted floppy diskette or via FTP from the Carbon Dioxide Information Analysis Center.

\section{ORNLI CDIAC-49}

\section{Trends '91: A Compendium of Data on Global Change- Highlights \\ (March 1992)}

\section{T. A. Boden, Oak Ridge National Laboratory}

R. J. Sepanski, and F. W. Stoss, University of Tennessee and Oak Ridge National Laboratory

This document highlights frequently used global-change data. The second issue of the Trends series expands the coverage of sites that record atmospheric concentrations of 
carbon dioxide $\mathrm{CO}_{2}$ and methane $\left(\mathrm{CH}_{4}\right)$, and it updates records reported in the first issue. New data for other trace atmospheric gases have been included in this issue: historical data on nitrous oxide $\left(\mathrm{N}_{2} \mathrm{O}\right)$ from ice cores, modern records of atmospheric concentrations of chlorofluorocarbons (CFC-11 and CFC-12) and $\mathrm{N}_{2}$, and estimates of global emissions of CFC: 11 and $\mathrm{CFC}-12$. The estimates for global and national $\mathrm{CO}_{2}$ emissions from the burning of fossil fuels, the production of cement, and gas flaring have been revised and updated. Regional $\mathrm{CO}_{2}$ emission estimates have been added, and long-term temperature records have been updated and expanded.

Data records are presented in four- to six-page formats, each dealing with a specific site, region, or emissions species. The data records include tables and graphs,; discussion of methods for collecting, measuring, and reporting the data; trends in the data; and references to literature that provide further information.

All data appearing in the document are available on digital media from the Carbon Dioxide Information Analysis Center.

\title{
Climate Change and Water Supply, Management and Use: Literature Review (May 1992)
}

\author{
L. H. Chang, J. D. Draves, and C. T. Hunsaker \\ Oak Ridge National Laboratory
}

There is evidence that concentrations of atmospheric $\mathrm{CO}_{2}$, tropospheric $\mathrm{O}_{3}$, and $\mathrm{CH}_{4}$, among other gases that contribute to the greenhouse effect, have increased in recent decades and that these changes may induce changes in global air temperatures and regional climate features in coming years. A literature review was conducted to sample the literature base on which our understanding of the water resource impacts of climate change rests. Water resource issues likely to be important include hydrologic response to climate change, the resilience of water supply systems to changing climatic and hydrologic conditions, and the effects of climate change on water quality and water uses (such as navigation and energy generation). A computer-assisted search of literature on the effects of climate change on these subjects was conducted. All studies were classified by type of paper (e.g., review, discussion, or case study), region, water resource variable studies, and source of climate scenario. The resulting bibliography containing more than 200 references was largely annotated. Case studies of potential hydrologic impacts have been more common than studies of impacts on water management or water use, but this apparent gap is closing. Case studies demonstrating methods of incorporating potential risks of climate change into water project planning and management have been performed. Considerable variability in regional coverage exists; the Great Lakes basin and California receive relatively more attention than such regions as New England and the Missouri River basin. General circulation mode-based and hypothetical climate scenarios have been the dominant sources of climate scenarios used in case studies, although a variety of other methods for developing climate scenarios have been developed. 


\section{Adapting to Sea-Level Rise in the U.S. Southeast: The Influence of Built Infrastructure and Biophysical Factors on the Inundation of Coastal Areas}

(November 1992)

\section{R. C. Daniels, The Iniversity of Tennessec and (Dak Ridge National Laboratory}

\section{M. Cornitz, Coddard Institute for Space Studies}

\section{A. J. Mehta, and S.-C. Lee, University of Florida}

\section{R. M. Cushman, Oak Ridge National Laboratory}

The Earth's mean surface air temperature has increased by $0.5^{\prime \prime} \mathrm{C}$ over the past 100 years. This warming trend has occurred concurrently with increases in the concentration and number of greenhouse gases in the atmosphere (e.g., $\mathrm{CO}_{2}, \mathrm{~N}_{2} \mathrm{O}, \mathrm{H}_{2} \mathrm{O}, \mathrm{CH}_{4}$, and $\mathrm{ClCs}$ ). These gases may be partially responsible for this temperature increase and may cause this trend to accelerate in the future because of the increased amount of thermal radiation that will be trapped in the troposphere by these gases. This trapping effect may result in a net increase in the earth's global mean surface air temperature of $1.5^{\prime \prime}$ to $4.5^{\prime \prime} \mathrm{C}$ by the year 2100. An increase in the mean surface air temperature of this magnitude could cause signiiicant increase. This increase in sea surface temperature will cause sea levels to rise--from thermal expansion of the sea and the addition of melt waters from alpine glaciers and continental ice sheets.

To allow for the cost-effective analysis of the impacts that sea-level rise may have on the U.S. Southeast, a method is needed that will allow sites potentially at risk to be identified for study. Previously, no objective method was available to identify such sites. This project addresses the problem of potential coastal damage by using a geographic data base that has information on both physical and climatological factors to identify areas of the U.S. Southeast at risk to inundation or accelerated erosion as a result of sea-level rise. The following six areas were selected for further study from the many identified as being at high risk: Galveston, Texas; Caminada Pass, Louisiana; Bradenton Beach. Florida; Daytona Beach, Florida; McClellanville, South Carolina; and Nags Head, North Carolina. These six areas are representative of three of the major stages of economic development on the East and Gulf coasts (i.e., urban/residential, undeveloped/rural, and resort/recreational), consequently any conclusion drawn from these case studies may be generalized to other high risk regions with similar geologic and economic histories.

For each study area the amount of land, by land-use type, in danger from inundation was calculated for three sea-level-rise scenarios. The calculated values were based on elevation alone. These studies were then extended by considering the effects that built infrastructure (e.g., seawalls) and biophysical factors (e.g., erosion/accretion rates) would have on the actual amount of land that would be inundated if the sea were allowed to advance unchecked. By considering these factors, a best-guess estimation of the amount of land that may be lost to the sea was derived for each study area and each scenario. These estimated values consider both natural (e.g., elevation and erosion/accretion) and anthropogenic (e.g., built infrastructure) effects when predicting the future location of the coastline in the years 2050 and 2100 for each study area, for each scenario. 


\title{
Selected Translated Abstracts of Russian-Language Climate-Change Publications. I. Surface Energy Budget
} (September 1992)

\section{H. Kavina, All-Kussian Research Institute of Hydrometeorological Information}

\author{
M. D. Burtis, Oak Ridge National Laboratory
}

This report presents abstracts (translated into English) of important Russian-language literature concerning the surface energy budget as it relates to climate change. In addition to the bibliographic citations and abstracts translated into English, this report presents the original citations and abstracts in Russian. Author and title indexes are included to assist the reader in locating abstracts of particular interest.

\section{CDIAC Catalog-Numeric Data Packages and Computer Model Packages \\ (May 1993)}

\section{Thomas A. Boden, Oak Ridge National Laboratory}

\section{Frederick M. O'Hara, Jr., Consultant, Oak Ridge National Laboratory}

\section{Frederick W. Stoss, University of Tennessee and Oak Ridge National Laboratory}

The Carbon Dioxide Information Analysis Center acquires, quality-assures, and distributes to the scientific community numeric data packages (NDPs) and computer model packages (CMPs) dealing with topics related to atmospheric trace-gas concentrations and global climate change. These packages include data on historic and present atmospheric $\mathrm{CO}_{2}$ and $\mathrm{CH}_{4}$ concentrations, historic and present oceanic $\mathrm{CO}_{2}$ concentrations, historic weather and climate around the world, sea-level rise, storm occurrences, volcanic dust in the atmosphere, sources of atmospheric $\mathrm{CO}_{2}$, the response of plants to elevated $\mathrm{CO}_{2}$ levels, sunspot occurrences, and many other indicators of, contributors to, or components of climate change. This catalog describes the packages presently offered by CDIAC, reviews the processes used by CDIAC to assure the quality of the data contained in these packages, notes the medium on which each package is available, describes the documentation that accompanies each package, and provides ordering information. Numeric data are available in the printed NDPs and CMPs, in CD-ROM format, and from an anonymous FTP area via Internet. All CDIAC information products are available at no cost. 
ORNL CDIAC-64

\section{Selected Translated Abstracts of Russian-Language Climate-} Change Publications. II. Clouds

(January 1994)

C. B. Ravina, All-Russian Research Institute of Hydrometeorological Information

\section{D. Burtis, Oak Ridge National Laboratory}

This report presents abstracts (translated into English) of important Russian-language literature concerning clouds as they relate to climate change. In addition to the bibliographic citations and abstracts translated into English, this report presents the original citations and abstracts in Russian. Author and title indexes are included to assist the reader in locating abstracts of particular interest. 
Section $\mathrm{F}$

CDIAC Numeric Data and Computer

Model Distribution 


\title{
Atmospheric $\mathrm{CO}_{2}$ Concentrations-Mauna Loa Observatory, Hawaii, 1958-1991
}

\section{D. Keeling (contributor)}

Since 1958, air samples have been continuously collected at Mauna Loa Observatory and analyzed by infrared spectroscopy for $\mathrm{CO}_{2}$ concentrations. Data are averaged to give monthly and annual atmospheric $\mathrm{CO}_{2}$ concentrations.

These data represent the longest continuous record of atmospheric $\mathrm{CO}_{2}$ concentrations in the world. This precise data record covers a single site (Mauna Loa Observatory, Hawaii). It is a reliable indicator of the regional trend in the concentration of atmospheric $\mathrm{CO}_{2}$ in the middle layers of the troposphere and is critical to $\mathrm{CO}_{2}$-related research. The data are in one file taking $2.5 \mathrm{kB}$.

\section{Tree Ring Chronology Indexes and Reconstructions of Precipitation in Central lowa, USA (1984)}

\section{T. J. Blasing, and D. N. Duvick (contributors)}

Tree core samples ( $4 \mathrm{~mm}$ in diameter) were extracted from the trunks of white oak (Quercus $a l b a$ ) at three sites in central Iowa (Duvick Back Woods, Ledges State Park, and Pammel). At least 60 trees were sampled at each site, and at least two cores were taken from each tree. The growth rings of each core were dated by calendar year and measured; the measurements were then transformed into dimensionless ring-width indices and correlated with annual precipitation. Data were collected for the years 1680 through 1979 . Each tree ring was characterized by the site, year, tree-ring-width index, number of core samples, decade year, and the annual reconstructed precipitation estimate. These data have more than $50 \%$ of their variance in common with the known annual statewide average precipitation for lowa and serve as useful indicators of the precipitation and drought history of the region for the past 300 years. The data are in two files: tree-ring-chronology data $(8 \mathrm{kB})$ and the annual reconstructed precipitation data for central lowa $(2 \mathrm{kB})$.

\section{Global Surface Air Temperature Variations: 1851-1984 (revised 1986)}

\author{
P. D. Jones, S. C. B. Raper, T. M. L. Wigley, R. S. Bradley, P. M. Kelly, \\ and H. F. Diaz (contributors)
}

Monthly and annual surface-air temperature anomalies relative to the 1951-1970 mean surface-air temperature were calculated for the periods of 1851-1984 for the Northern Hemisphere, 1858-1984 for the Southern Hemisphere exclusive of Antarctica, and 1958-1984 for the Southern Hemisphere inclusive of Antarctica. These estimates are derived from land-based meteorological station data and fixed-position weather-ship data interpolated onto a $5^{\circ}$ latitude by $10^{\circ}$ longitude grid. The data are in three files, one for the Northern Hemisphere 
temperature anomalies ( $10 \mathrm{kB}$ ) and two for the Southern Ilemisphere femperature anomalies

(9) $k(3,2 k(3)$.

NDP-004/R1 Transient Tracers in the Oceans (TTO)-Hydrographic Data and (WDC-A) Carbon Dioxide Systems with Revised Carbon Chemistry Data (revised 1986)

\author{
P. G. Brewer, T. Takahashi, and R. T. Williams (contributors)
}

The 1981 TTO North Atlantic experiment cruise consisted of seven legs and visited 250 hydrographic stations across the North Atlantic Ocean in 200 days. About 9000 water samples were taken for analysis of salinity, oxygen, and nutrients. More than 3000 samples were collected for tritium analysis, and more than 1000 samples for radiocarbon analysis. Samples were characterized hydrographically (e.g., sample depth, ocean depth, and water temperature) and chemically (e.g., alkalinity, salinity, silicate concentrations, and nitrate concentrations). They may be used for ocean-mixing studies, for testing models of ocean $\mathrm{CO}_{2}$ uptake, and for determining the exchange of carbon dioxide between the atmosphere and the ocean. The data are in two files [original TTO data $(0.67 \mathrm{MB})$ and revised TTO data $(0.86 \mathrm{MB})]$. NDP-005/R1
(WDC-A)

(WDC-A)

\section{Atmospheric $\mathrm{CO}_{2}$ Concentrations-The NOAA/GMCC Flask Sampling Network} (revised 1990)

\section{T. J. Conway, and P. Tans (contributors)}

Flask air samples are collected approximately once per week at 29 stations scattered around the globe. The earliest samples were taken in 1968, but the period of record varies from station to station. The samples are analyzed for atmospheric $\mathrm{CO}_{2}$ concentration on a nondispersive infrared gas analyzer apparatus at the NOAA/GMCC laboratory in Boulder, Colorado. The measurements are directly traceable to the World Meteorological Organization primary $\mathrm{CO}_{2}$ standards. Each sample is characterized by station, year, sampling date and time, flask identification number, $\mathrm{CO}_{2}$ concentration, date and time of analysis, and quality indicators. The data are in 30 files [one file that contains data through 1981 (946 kB), and one file for each site with data from 1981 through 1986 (ranging from 3.6 to $55.8 \mathrm{kB}$ )].

\section{Production of $\mathrm{CO}_{2}$ from Fossil Fuel Burning by Fuel Type, 1860-1982 (1984)}

\section{R. M. Rotty, and G. Marland (contributors)}

Global carbon dioxide emissions for 1950 through 1982 were estimated by Marland and Rotty (1984) from fuel production data from the U.N. Energy Statistics Yearbook (1983, 1984). Data before 1950 came from Keeling (1973). Fuel-production data were used in these calculations because they appeared to be more reliable on a global basis than fuel-consumption data. 
The data given are the year and annual global $\mathrm{CO}_{2}$ emissions (annual global total; cumulative global total since 1860; and annual global emissions from solid fuels, liquid fuels, natural gas, gas flaring, and cement manufacturing). These data provide the only pre-1950 estimates of the amount of carbon emitted to the atmosphere from fossil-fuel burning. The $\mathrm{CO}_{2}$ emission record since 1950 has been updated and revised several times with the most recent estimates being published by Marland et al. (1989). The data are in one file taking $7.5 \mathrm{kB}$.

\section{Atmospheric $\mathrm{CO}_{2}$ Concentrations-The CSIRO (Australia) Monitoring Program from Aircraft for 1972-1981 (1984)}

\section{J. Beardsmore, and G. I. Pearman (contributors)}

From 1972 through 1981, air samples were collected in glass flasks from aircraft at a variety of latitudes and altitudes over Australia, New Zealand, and Antarctica. The samples were analyzed for $\mathrm{CO}_{2}$ concentrations with nondispersive infrared gas analysis. The resulting data contain the sampling dates, type of aircraft, flight number, flask identification number, sampling time, geographic sector, distance in kilometers from the listed distance measuring equipment (DME) station, station number of the radio navigation distance measuring equipment, altitude of the aircraft above mean sea level, sample analysis date, flask pressure, tertiary standards used for the analysis, analyzer used, and $\mathrm{CO}_{2}$ concentration. These data represent the first published record of $\mathrm{CO}_{2}$ concentrations in the Southern Hemisphere expressed in the WMO $1981 \mathrm{CO}_{2}$ Calibration Scale and provide a precise record of atmospheric $\mathrm{CO}_{2}$ concentrations in the troposphere and lower stratosphere over Australia and New Zealand. The data are in one file taking $263 \mathrm{kB}$.

\section{Annual and Seasonal Global Temperature Anomalies in the Troposphere and Low Stratosphere, 1958-1992} (revised 1992)

\section{J. K. Angell, and J. Korshover (contributors)}

For 1958 through 1992, the annual and seasonal temperature anomalies relative to a 1958-1977 mean (expressed in degrees Celsius) were calculated for the surface, troposphere (850-300 mb), tropopause (300-100 mb), and low stratosphere (100-50 mb and 100-30 $\mathrm{n}$-h) layers on regiona!, hemispheric, and global bases. Most of the values are column-mean temperatures obtair ed from the differences in height between constant-pressure surfaces at individual radiosonde stations. The pressure-height data before 1980 were obtained from published values in Monthly Climatic Data for the World. These temperature anomalies may be used to analyze long-term temperature trends for a layer of the atmosphere (i.e., surface, troposphere, tropopause, and low stratosphere), a region (i.e., polar, temperate, subtropical, and equatorial), a hemisphere, or the globe. The data are in one file taking $64.5 \mathrm{kB}$. 
NDP-009

NDP-010 (WDC-A)

\section{Growth and Chemical Responses to $\mathrm{CO}_{2}$ Enrichment-Virginia Pine (Pinus Virginiana Mill.) (1985)}

\author{
R. J. Luxmoore, R. J. Norby, E. G. O'Neill, D. G. Weller, J. M. Ells, and \\ H. H. Rogers (contributors)
}

From June 28 to October 29 in 1982 , Virginia pine seedlings were exposed to elevated $\mathrm{CO}_{2}$ levels in open-top growth chambers at one of four concentrations $(75,150,300$, and $600 \mathrm{ppm}$ above ambient).

Plant dry weight; height; stem diameter; and chemical contents of leaf, stem, and root tissues were measured before and after exposure. Soil variables were also characterized.

These data illustrate the short-term physical and chemical response of Virginia pine seedlings to elevated levels of $\mathrm{CO}_{2}$. The data are in seven files: initial dry weights before exposure $(844 \mathrm{kB})$, dry weights after exposure $(4 \mathrm{kB})$, major nutrient concentrations after final harvest $(12 \mathrm{kB})$, minor nutrient concentrations after final harvest $(17 \mathrm{kB})$, soil nutrient concentrations after final harvest $(4 \mathrm{kB})$, soil leachate elements after final harvest $(5 \mathrm{kB})$, and soil leachate solutes after final harvest $(4 \mathrm{kB})$.

\section{Atmospheric $\mathrm{CO}_{2}$ Concentrations-The CSIRO Monitoring Program: Surface Data for Cape Grim, Tasmania (1985)}

\section{J. Beardsmore, G. I. Pearman, and R. C. O'Brien (contributors)}

From 1976 through 1983, air samples collected from a high-volume general intake $10 \mathrm{~m}$ above the roof of the laboratory at Cape Grim, Tasmania, were dried and analyzed for $\mathrm{CO}_{2}$ concentrations with a nondispersive infrared gas analyzer. This baseline $\mathrm{CO}_{2}$ record from Cape Grim indicates the $\mathrm{CO}_{2}$ concentrations in large, maritime air masses devoid of vegetative influences in this region of the Southern Hemisphere. The data available on each sample are sampling date; daily, monthly, and annual $\mathrm{CO}_{2}$ concentrations; standard deviation associated with each concentration; number of hours of data used to calculate the $\mathrm{CO}_{2}$ values; and the analyzer used. The data are in three files: daily $(17 \mathrm{kB})$, monthly $(3 \mathrm{kB})$, and annual (310 bytes).

\section{NDP-011 Global Paleoclimatic Data for 6000 Yr B.P.} (1985)

\section{T. Webb, III (contributor)}

To determine regional and global climatic variations during the past 6000 years, pollen, lake level, and marine plankton data from 797 stations were compiled to form a global data set. Radiocarbon dating and dated tephras were used to determine the ages of the specimens. The data available for the pollen data are site number, site name, latitude, longitude, elevation, 
and percentages of various taxa. For lake-level data, the data are site number, site name, latitude, longitude, and lake-level status. And for marine plankton, the data are site number, site name, latitude, longitude, water depth, date, dating control code, depth of sample, interpolated age of sample, estimated winter and summer sea-surface temperatures, and percentages of various taxa. The data are in 55 files: 5 files for each of 9 geographic-regions and 10 supplemental files. The files for each region include (1) a FORMAT file describing the format and contents of the data for that region, (2) an INDEX file containing descriptive information about each site and its data, (3) a DATA file containing the data and available climatic estimates, (4) a PUBINDEX file indexing the bibliographic references associated with each site, and (5) a REFERENCE file containing the bibliographic references. The files range in size from 2 to $66 \mathrm{kB}$.

\title{
Climatic Data for Northern Hemisphere Land Areas, 1851-1980 (1985)
}

\author{
R. S. Bradley, P. M. Kelly, P. D. Jones, C. M. Goodess, and H. F. Diaz (contributors)
}

For the period 1851 through 1985 , approximately 700 temperature records and 1200 precipitation records for Northern Hemisphere stations were added to the World Weather Records data base with the supplemental data obtained by surveying major libraries, archives, and meteorological data centers and by contacting scientists and meteorological agencies directly. The quality of these supplemental data were assessed when possible by using station-history information. For each addition, the WMO station identification number, station name, country, latitude, longitude, station elevation, beginning year of record, ending year of record, monthly temperature, and monthly precipitation were entered. The data are in two files, one for monthly temperature (6.40 MB) and one for monthly precipitation data (8.06 MB). Because of the size of this data set, it is available only on 9-track magnetic tape.

\section{Volcanic Loading: The Dust Veil Index} (1985)

\section{H. H. Lamb (contributor)}

Lamb's Dust Veil Index (DVI) is a numerical index that quantifies the impact of a particular volcanic eruption's release of dust and aerosols over the years following the event, especially the impact on the Earth's energy balance. DVIs have been calculated for eruptions occurring from 1500 through 1983. The methods used to calculate the DVI have been intercalibrated to give a DVI of 1000 for the eruption of Krakatoa in 1883. The DVI for any volcanic eruption is based on a review of the observational, empirical, and theoretical studies of the possible impact on climate of volcanic dust veils. The DVI allows one to compare volcanic eruptions by a single numerical index. The data base includes the name of the erupting volcano, year of eruption, volcano latitude and longitude, maximum extent of the dust veil, veil duration, DVI for the entire globe, DVI for the Northern Hemisphere, and DVI for the Southern Hemisphere. The data are in one file $(22.6 \mathrm{kB})$. 


\author{
Solar Records: The Wolf Sunspot Index and Umbral/Penumbral \\ Ratio \\ (1985) \\ D. V. Hoyt (contributor)
}

These data from observations of sunspot activity cover the period 1875 through 1981; reconstructions are possible back to 1832 . Available sunspot models and the theory of mixing length indicate that the observed changes in the umbral/penumbral (U/P) ratio may be equivalent to changes in the solar constant. The U/P ratio is calculated from measurements of solar activity and has been shown to be in good agreement with the Northern Hemisphere temperature record. The data consist of year, number of sunspot groups, Wolf sunspot number, umbra area, whole area, penumbral area, and umbral/penumbral ratio. The data are in one file $(3.3 \mathrm{kB})$.

NDP-015

\title{
Surface Air Temperature Anomalies for the Northern Hemisphere: The Russian Dataset (1985)
}

\author{
A. Robock, I. I. Borzenkova, G. V. Gruza, and K. Ya. Vinnikov (contributors) \\ These Northern Hemisphere surface-temperature anomalies cover the period from 1891 \\ through 1980 and were derived from maps compiled at the Main Geophysical Observatory \\ (Leningrad) and maps appearing in the Synoptic Bulletin of the State Hydrometeorological \\ Committee. The data include the year, month, and monthly surface-air-temperature anomaly \\ (relative to a reference period mean in degrees Celsius). They may be compared with other \\ Northern Hemisphere surface-air-temperature-anomaly data sets and used for studies \\ attempting to detect carbon-induced climate change. The data are in seven files (three of \\ monthly surface air temperature anomalies, three of monthly average temperature norms, and \\ one of grid points' altitudes above sea level) that range from $5 \mathrm{kB}$ to $1.46 \mathrm{MB}$ and are \\ available on 9-track magnetic tape only.
}

NDP-016 Climatic Data for Selected U.S. and Canadian Stations, 1941-1980 (1985)

\section{T. R. Karl, and F. T. Quinlan (contributors)}

For 1941 through 1980, monthly temperature and precipitation data were recorded for 130 nonurban stations in the U.S. and Canada. These stations were selected because they provide reasonably uniform spatial coverage of that area; consist of nonurban stations; have few missing daily and monthly data; have experienced few station relocations; and have undergone little change in observation times. These data were obtained from the archives of the National Climatic Data Center and the Canadian Climate Centre. Included in the data are the station identification number, station name, state abbreviation, province code, country code, station latitude and longitude, station population (1940,1960, and 1980), name of observer, observing schedule code, time of observation bias codes, year, monthly precipitation, mean temperatures, mean daily maximum temperatures, mean daily 
minimum temperatures, and difference between the monthly mean daily maximum and minimum temperatures. The data are in eight files [five data files $(530 \mathrm{kB}$ each), one station history file $(56 \mathrm{kB})$, one station inventory file $(11.7 \mathrm{kB})$, and one file that lists the Canadian observers $(7.9 \mathrm{kB})]$ and are available on 9-track magnetic tape only.

\title{
Major World Ecosystem Complexes Ranked by Carbon in Live Vegetation: A Database (1985)
}

\section{J. S. Olson, J. A. Watts, and L. J. Allison (contributors)}

In 1980, this data base and the corresponding map were completed after more than 20 years of field investigations, consultations, and analyses of published literature. They characterize the use and vegetative cover of the Earth's land surface with a $0.5^{\circ} \times 0.5^{\circ}$ grid. The data include latitude, longitude, and vegetation code. This world-ecosystem-complex data set and the accompanying map provide a current reference base for interpreting the role of vegetation in the global cycling of $\mathrm{CO}_{2}$ and other gases and a basis for improved estimates of vegetation and soil carbon, of natural exchanges of $\mathrm{CO}_{2}$, and of net historic shifts of carbon between the biosphere and the atmosphere. The data are in one file of $109 \mathrm{kB}$.

\section{Worldwide Organic Soil Carbon and Nitrogen Data} (1986)

\author{
P. J. Zinke, A. G. Stangenberger, W. M. Post, W. R. Emanuel, and J. S. Olson \\ (contributors)
}

This data base was begun with the collection and analysis of soil samples from California. Additional data came from soil surveys of Italy, Greece, Iran, Thailand, Vietnam, various tropical Amazonian areas, and U.S. forests and from the soil-survey literature. The analyzed samples were collected at uniform soil-depth increments and included bulk-density determinations. The data on each sample are soil profile number; soil profile carbon content; soil profile nitrogen content; sampling site latitude and longitude; site elevation; profile literature reference source; and soil profile codes for Holdridge life zone, Olson ecosystem type, and parent material. These data may be used to estimate the size of the soil organic carbon and nitrogen pools at equilibrium with natural soil-forming factors. The data are in one file of $323 \mathrm{kB}$.

\section{United States Historical Climatology Network (HCN) Serial Temperature and Precipitation Data} (revised 1990)

\author{
T. R. Karl, C. N. Williams, Jr., and F. T. Quinlan, (contributors)
}

Extending through 1987 , this data base contains monthly total precipitation and temperature data from 1219 stations in the contiguous U.S. To be included in the Historical Climatology 
Network (HCN), a station had to be currently active (1987), have at least 80 years of monthly temperature and precipitation data, and have experienced few station changes. These data were derived from a variety of sources including the Nationa! Climatic Data Center archives, state climatologists, and published literature. The data base contains several hundred variables, including state number; station number; monthly temperatures (minimum, maximum, and mean); total monthly precipitation; and time of observation. This is probably the best monthly temperature and precipitation data set available for the contiguous U.S. because station moves, instrument changes, urbanization effects, and time-of-observation differences have been considered and, where necessary, the data have been corrected. The data are in 13 files [one station inven.งry file, one station history file, six temperature files, one precipitation file, one time-of-observation correction file, and two quality-assessment files]. The file sizes range from $5 \mathrm{kB}$ to approximately $50 \mathrm{MB}$ and are available on 9-track magnetic tape only.

\title{
NDP-020/R1 An Updated Global Grid Point Surface Air Temperature Anomaly Data Set: 1851-1990
} (revised 1991)

\author{
P. D. Jones, S. C. B. Raper, B. S. G. Cherry, C. M. Goodess, T. M. L. Wigley, \\ B. Santer, P. M. Kelly, R. S. Bradley, and H. F. Diaz (contributors)
}

This NDP presents land-based monthly surface-air-temperature anomalies (departures from a 1951-1970 reference period mean) on a $5^{\circ}$ latitude by $10^{\circ}$ longitude global grid. Monthly surface-air-temperature anomalies (departures from a 1957-1975 reference period mean) for the Antarctic (grid points from $65^{\circ} \mathrm{S}$ to $85^{\circ} \mathrm{S}$ ) are presented in a similar way as a separate data set. The data were derived primarily from the World Weather Records and from the archives of the United Kingdom Meteorological Office. This long-term record of temperature anomalies may be used in studies addressing possible greenhouse-gas-induced climate changes. To date, the data have been employed in producing regional, hemispheric, and global time series for determining whether recent (i.e., post-1900) warming trends have taken place.

The present updated version of this data set is identical to the earlier version for all records from 1851-1978 except for the addition of the Antarctic surface-air-temperature anomalies beginning in 1957. Beginning with the 1979 data, this package differs from the earlier version in several ways. Erroneous data for some sites have been corrected after a review of the actual station temperature data, and inconsistencies in the representation of missing values have been removed. For some grid locations, data have been added from stations that had not contributed to the original set. Data from satellites have also been used to correct station records where large discrepancies were evident. The present package also extends the record by adding monihly surface-air-temperature anomalies for the Northern (grid points from $85^{\circ} \mathrm{N}$ to $0^{\circ}$ ) and Southern (grid points from $5^{\circ} \mathrm{S}$ to $60^{\circ} \mathrm{S}$ ) Hemispheres for 1985-1990. In addition, this updated package presents the monthly-mean-temperature records for the individual stations that were used to produce the set of gridded anomalies. The periods of record vary by station. Northern Hemisphere data have been corrected for inhomogeneities, while Southern Hemisphere data are presented in uncorrected form. 
The NDP consists of a written report and a 9-track magnetic tape (data are also available on CD-ROM or via FTP) containing 14 files, including five ASCII data files, eight FORTRAN and SAS retrieval routines, and a descriptive file. The data files range in size from $2 \mathrm{kB}$ to $20 \mathrm{MB}$. Because of the size of the data files, it is not feasible to distribute these data on floppy diskettes, even as compressed files.

\section{Historical Sunshine and Cloud Data in the United States} (revised 1991)

\section{P. M. Steurer, and T. R. Karl (contributors)}

This data base presents monthly sunshine data from 240 U.S. stations (including Puerto Rico and nine Pacific Islands) and monthly cloud amount data from 197 U.S. stations. The longest periods of record are 1891 through 1987 for the sunshine data and 1871 through 1987 for the cloud data. The sunshine data were derived from measurements taken by a variety of sunshinerecording instruments. The cloud data were derived from land-based estimates of fractional cloud amount, which were made with observation practices that have varied during the period of record. Station number, station name, latitude, and longitude are given for all stations in each network. The sunshine data include monthly and annual total hours of recorded sunshine, monthly and annual maximum possible hours of sunshine, monthly and annual percentages of possible sunshine (hours recorded/hours possible), and dates of use for specific types of sunshine recorders at each station. The cloud data contain monthly and annual cloud amount (in percent of sky cover). The sunshine data are in four files: one station inventory $(34.1 \mathrm{kB})$, one monthly and annual hours of measured sunshine (1.6 MB), one monthly and annual maximum possible hours of sunshine $(21.5 \mathrm{kB})$, and one monthly and annual percentage of possible sunshine (2.1 MB). The cloud data are in two files: one station inventory $(20.4 \mathrm{kB})$ and one monthly and annual cloud amount (2.4 MB). The data are available on 9-track magnetic tape only.

\section{Global and Hemispheric Annual Temperature Variations Between 1861 and 1988 \\ (revised 1990)}

\section{P. D. Jones, T. M. L. Wigley, and P. B. Wright (contributors)}

This data set contains estimates of global and hemispheric annual temperature variations, relative to a 1950 through 1979 reference period, for 1861 through 1988. The estimates are based on corrected land and ocean data. Land data were derived from meteorological data and fixed-position weather-ship data that were corrected for nonclimatic errors, such as station shifts and/or instrument changes. The marine data used were those in the Comprehensive Ocean-Atmosphere Data Set (COADS) compilation, which with updates covers to 1986. Updates to 1988 were made with hemispheric sea-surface temperature estimates produced by the U.K. Meteorological Office. Each record includes year and six annual temperature variations: one estimate each for the globe, the Northern Hemisphere, and the Southern Hemisphere and another estimate each that reflects an adjustment to account for the influence of El Niño/Southern Oscillation events. The data are in one file of $13 \mathrm{kB}$. 


\title{
NDP-023/R1 Annual and Seasonal Global Variation in Total Ozone and Layer-Mean Ozone, 1958-1989 \\ (revised 1992)
}

\author{
J. K. Angell, J. Korshover, and W. (i. Planet (contributors)
}

For 1958 through 1989, this data base presents total 0\%one variations and layer mean ozone variations expressed as percent deviations from the 1958 to 1977 mean. The total ozone variations were derived from mean $m$ onthly ozone values published in ()zone Data for the World by the Atmospheric Environment Service in cooperation with the World Meteorological Organization. The layer mean ozone variations are derived from ozonesonde and Umkehr observations. The data records include year, seasonal and annual total ozone variations, and seasonal and annual layer mean ozone variations. The total ozone data are for four regie is (Soviet Union, Europe, North America, and Asia); five climatic zones (north and south polar, north and south temperate, and tropical); both hemispheres; and the world. Layer mean ozone data are for four climatic zones (north and south temperate and north and south polar) and for the stratosphere, troposphere, and tropopause layers. The data are in two files [seasonal and year-average total ozone $(13.4 \mathrm{kB})$ and layer mean ozone variations $(24.2 \mathrm{kB})$ ].

\section{NDP-025}

\section{Monthly Mean Pressure Reconstructions for Europe (1780-1980) and North America (1858-1980) \\ (1987)}

\author{
P. D. Jones, T. M. L. Wigley, and K. R. Briffa (contributors)
}

Real and reconstructed measurements of monthly mean pressure data have been constructed for Europe for 1780 through 1980 and North America for 1858 through 1980. The reconstructions use early pressure, temperature, and precipitation data from a variety of sources including World Weather Records, meteorological and national archives, circulation maps, and daily chart series. Each record contains the year, monthly mean pressure, quality code, and annual mean pressure. These reconstructed gridded monthly pressures provide a reliable historical record of mean sea-level pressures for Europe and North America. The data are in two files: pressure reconstructions for Europe (1.47 MB) and for North America $(0.72 \mathrm{MB})$.

\section{NDP-026 Climatological Data for Clouds Over the Globe from Surface Observations (1988)}

\section{J. Hahn, S. G. Warren, J. London, R. L. Jenne, and R. M. Chervin (contributors)}

With some data from as early as 1930 , global long-term monthly and/or seasonal total cloud cover, cloud type amounts and frequencies of occurrence, low cloud base heights, harmonic analyses of annual and diurnal cycles, interannual variations and trends, and cloud type co-occurrences have been compiled and presented in two atlases (Warren et al. 1988, 1990). These data were derived from land and ship synoptic weather reports from the "SPOT" archive of the Fleet Numerical Oceanography Center (FNOC) and from Release $I$ of the 
Comprehensive Ocean-Atmosphere Data Set (COADS) for the years 1930 1979. The data are in 12 files (one containing latitude, longitude, land-fraction, and number of land stations for grid boxes; four containing total cloud, cloud types, harmonic analyses, and interannual variations and trends for land; four containing total cloud, cloud types, harmonic analyses, and interannual variations and trends for oceans; one containing first cloud analyses for the first year of the GARP Global Experiment (FGGE); one containing cloud-type co-occurrences for land and oceans; and one containing a FORTRAN program to read and produce maps). These files range in size from $12.5 \mathrm{kB}$ to $5.67 \mathrm{MB}$ and are available on 9-track magnetic tape only.

\section{GEOSECS Atlantic, Pacific, Indian, and Mediterranean Radiocarbon Data (1988)}

\section{H. G. Östlund, and M. Stuiver (contributors)}

Radiocarbon data for the Atlantic, Pacific, and Indian oceans were obtained between 1972 and 1977 as part of the Geochemical Ocean Section Sth.dy (GEOSECS) cruises during which more than 2200 water samples were collected. Some Mediterranean Sea data were also collected. Samples for ${ }^{14} \mathrm{C}$ were collected at 124 stations, and approximately 18 samples were collected at each station from intervals throughout the water column. The data included in the data base are ship position (latitude and longitude), sample number, depth, potential temperature, salinity, and delta ${ }^{14} \mathrm{C}$. The GEOSECS data sets allow a betier understanding of large-scale oceanic transport and mixing and the establishment of the gross rate of deep-ocean circulation. The data are in three files (radiocarbon data for the Atlantic, Pacific, and Indian Oceans) ranging in size from 39.9 to $50.4 \mathrm{kB}$.

\section{Carbonate Chemistry of the Weddell Sea} (1988)

\section{C.-T. A. Chen (contributor)}

In the late austral winter of 1981 , carbonate data were obtained from the Weddell Sea as part of the U.S.-U.S.S.R. Weddell Polynya Expedition (WEPOLEX-81). Both surface samples and vertical-station samples were taken. The data include ship position (latitude and longitude), date, station number, sample depth, salinity, water temperature, $\mathrm{pH}$, normalized surface total alkalinity, and calcium. These data represent the first comprehensive carbonate data obtained in the Weddell Sea during late winter. Because of the importance of the Weddell Sea as a source of deep water for the world's oceans, these data have improved the understanding " the oceanic circulation of excess $\mathrm{CO}_{2}$ in the carbon cycle. The data are in two files [ for data from surface stations $(15.5 \mathrm{kB})$ and one for data from vertical stations $(5.9 \mathrm{kB})$ ]. 
NDP-029 Carbonate Chemistry of the North Pacific Ocean (1988)

C.-T. A. Chen, M. R. Rodman, C.-L. Wei, E. J. Olson, R. A. Feely, and

J. F. Gendron (contributors)

Carbonate chemistry data from 41 stations in the North Pacific Ocean were obtained during two NOAA CO 2 Dynamics Cruises (June-July 1981 and May-June 1982) and two legs of the NORPAX Hawaii-Tahiti Shuttle Experiment (April 1979 and March-April 1980). The data for each sample include ship position (latitude and longitude), date, station number, sample depth, salinity, water temperature, $\mathrm{pH}$, normalized total alkalinity, and normalized calcium. The data from each of the three cruises are in separate files ranging in size from $7.1 \mathrm{kB}$ to $10.1 \mathrm{kB}$.

\section{NDP-030/R5 Global, Regional, and National $\mathrm{CO}_{2}$ Emission Estimates from (WDC-A) Fossil Fuel Burning, Cement Production, and Gas Flaring: 1950-1991 \\ (revised 1994)}

\section{G. Marland, R. J. Andres, and T. A. Boden (contributors)}

For 1950 through 1991, global, regional, and national annual estimates of $\mathrm{CO}_{2}$ emissions from fossil fuel burning, cement production, and gas flaring were calculated. These estimates, derived primarily from energy statistics published by the United Nations, were calculated using the methods of Marland and Rotty (1984). Cement production estimates from the U.S. Department of Interior's Bureau of Mines were used to estimate $\mathrm{CO}_{2}$ emitted during cement production. Emissions from gas flaring were derived primarily from U.N. data but were supplemented with data from the U.S. Department of Energy's Energy Information Administration, Rotty (1974), and with a few national estimates provided by G. Marland. The resulting database contains $\mathrm{CO}_{2}$ emission estimates (total emissions; emissions from solid, liquid, and gas fuels; emissions from cement production; emissions from gas flaring; and per capita emissions) and the statistics used to calculate them. The data are in nine files (three for the U.N. energy statistics; one for the Bureau of Mines cement production data; one for gas flaring estimates; one file that contains factors to convert solid fuel energy statistics into mass units; and three files containing the global, regional, and national $\mathrm{CO}_{2}$ emissions). Collectively these files require approximately $15 \mathrm{MB}$ of space with the largest single data file being approximately $8 \mathrm{MB}$.

\section{NDP-031 Average Total Snowfall Data for Selected U.S. Stations} (1989)

\section{National Climatic Data Center}

From 1868 through 1986, the average monthly snowfalls for 286 U.S. stations were extracted from the Local Climatological Data Annual Summary. Only stations operating in 1986 and having a minimum of 3 years data and at least one month on record with snowfall greater than a trace $(>0.05$ in.) were included in the record. The data contain the station name, 
number of years of data used to estimate the average monthly snowfall, average monthly snowfall, and annual snowfall. The monthly average snowfall data for 286 U.S. stations are in one 46.4-kB file.

\section{Antarctic Surface Temperature and Pressure Data (1989)}

\section{P. D. Jones, and D. W. S. Limbert (contributors)}

Monthly mean surface temperature and pressure data for 30 Antarctic stations (the earliest beginning in 1903 and all extending through 1988) were assembled primarily from World Weather Records and Monthly Climatic Data for the World. The data were assessed for quality and long-term homogeneity. The data presented are station name, station latitude and longitude, station elevation, first and final year of data record, year, mean monthly sea-level or station-level pressure, and mean monthly surface temperature. The data are in four files (two temperature and two pressure data files) ranging in size from 25 to $43 \mathrm{kB}$.

\section{Atmospheri: $\mathrm{CO}_{2}$ Concentrations Derived from Flask Samples Collected at U.S.S.R.-Operated Sampling Sites (1991)}

\section{A. M. Brounshtein, E. V. Faber, and A. A. Shashkov (contributors)}

This NDP represents the first CDIAC data package to result from our involvement with Soviet scientists as part of Working Group (WG) VIII of the U.S.-U.S.S.R. Joint Committee on Cooperation in the Field of Environmental Protection. The U.S.-U.S.S.R. Agreement on Protection of the Environment, established in 1972, covers a wide variety of areas, including environmental pollution, the urban environment, nature preserves, arctic and subarctic ecological systems, earthquake prediction, and institutional measures for environmental protection. WG VIII is concerned with the influence of environmental changes on climate. CDIAC's activities have been conducted under the auspices of WG VIII's "Data Exchange Management" project. (The four other WG VIII projects deal with climate change, atmospheric composition, clouds and radiation fluxes, and stratospheric ozone.) In addition to the Main Geophysical Observatory, other Soviet institutions that have been cooperating with CDIAC in the exchange of $\mathrm{CO}_{2}$ and climate-related data include the All-Union Research Institute of Hydrometeorological Information (Obninsk) and the State Hydrological Institute (St. Petersburg).

NDP-033 presents daily atmospheric $\mathrm{CO}_{2}$ concentrations from four U.S.S.R.-operated sampling sites [Teriberka Station $\left(69^{\circ} 12^{\prime} \mathrm{N}, 35^{\circ} 06^{\prime} \mathrm{E}\right)$, Ocean Station Charlie $\left(52^{\circ} 45^{\prime} \mathrm{N}, 35^{\circ} 30^{\prime} \mathrm{W}\right)$, Bering Island $\left(55^{\circ} 12^{\prime} \mathrm{N}, 165^{\circ} 59^{\prime} \mathrm{E}\right)$, and Kotelny Island $\left.\left(76^{\circ} 06^{\prime} \mathrm{N}, 137^{\circ} 54^{\prime} \mathrm{E}\right)\right]$. The period of record varies by station, with the earliest measurements dating back to 1983 and recent estimates from early 1991. These $\mathrm{CO}_{2}$ concentrations are derived from air samples collected in 1.5-L stainless steel electropolished flasks and later analyzed at the Main Geophysical Observatory (St. Petersburg, U.S.S.R.) with a nondispersive infrared gas analyzer. Measurements not meeting wind direction, wind speed, interflask agreement, and climatecondition criteria were either discarded or flagged. All measurements have been corrected for drift biases introduced during flask storage. 

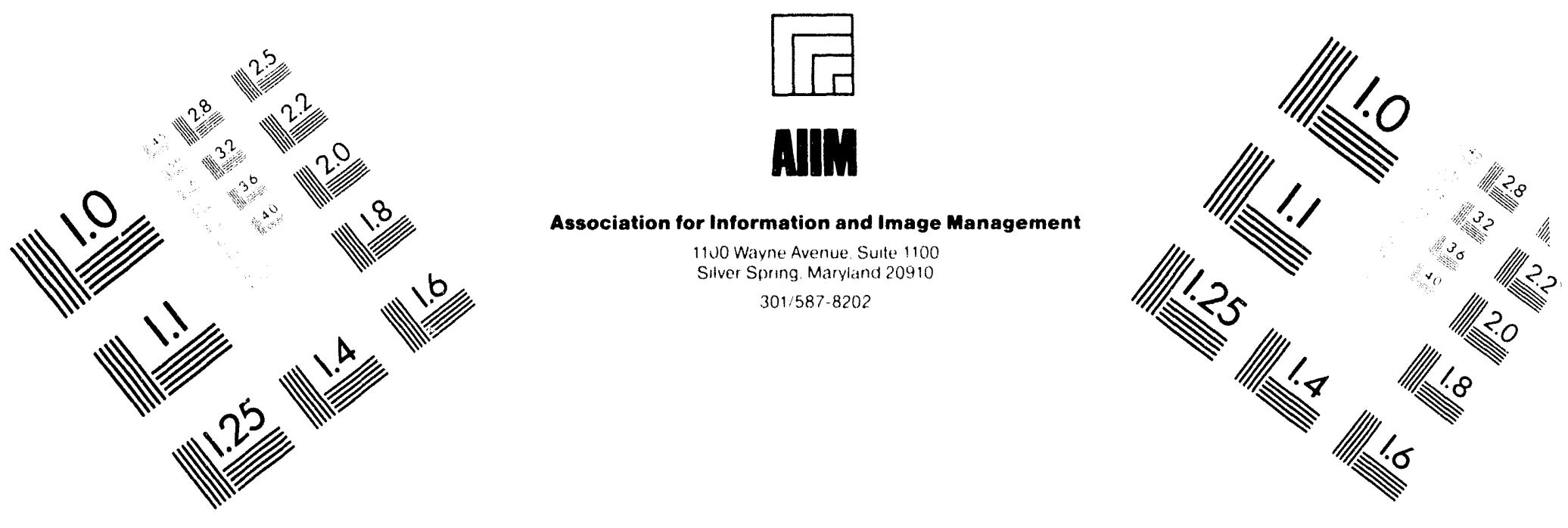

\section{Centimeter}

1

Inches
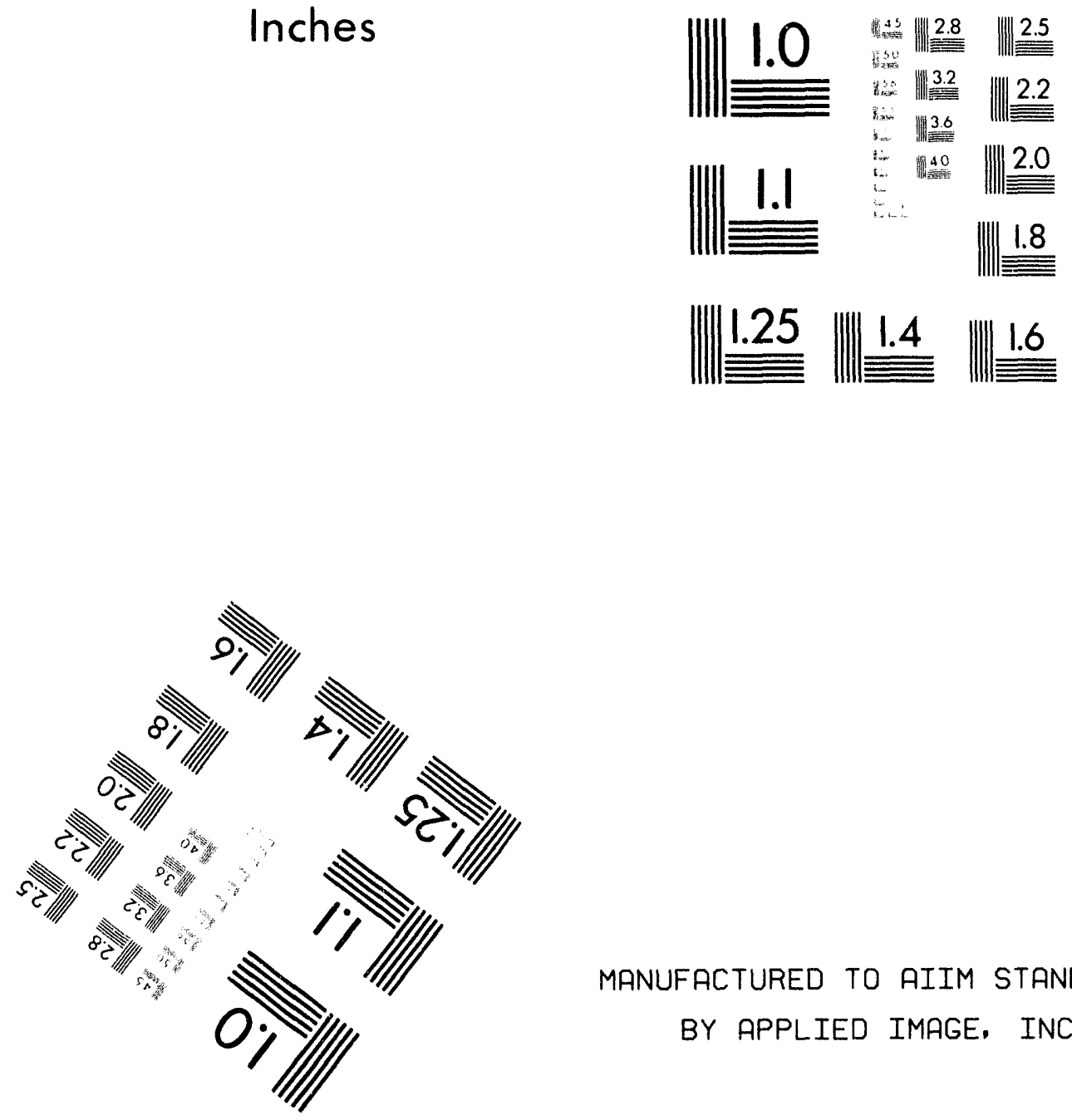

MANUFACTURED TO AIIM STANDARDS

BY APPLIED IMAGE, INC.

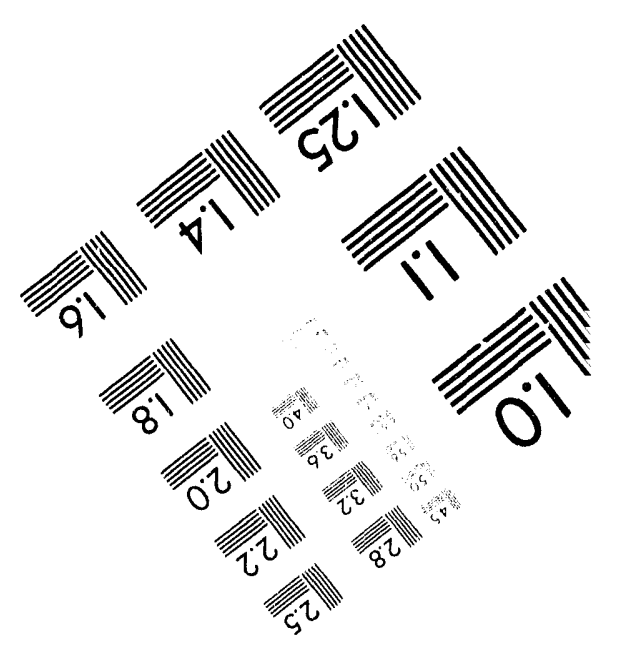



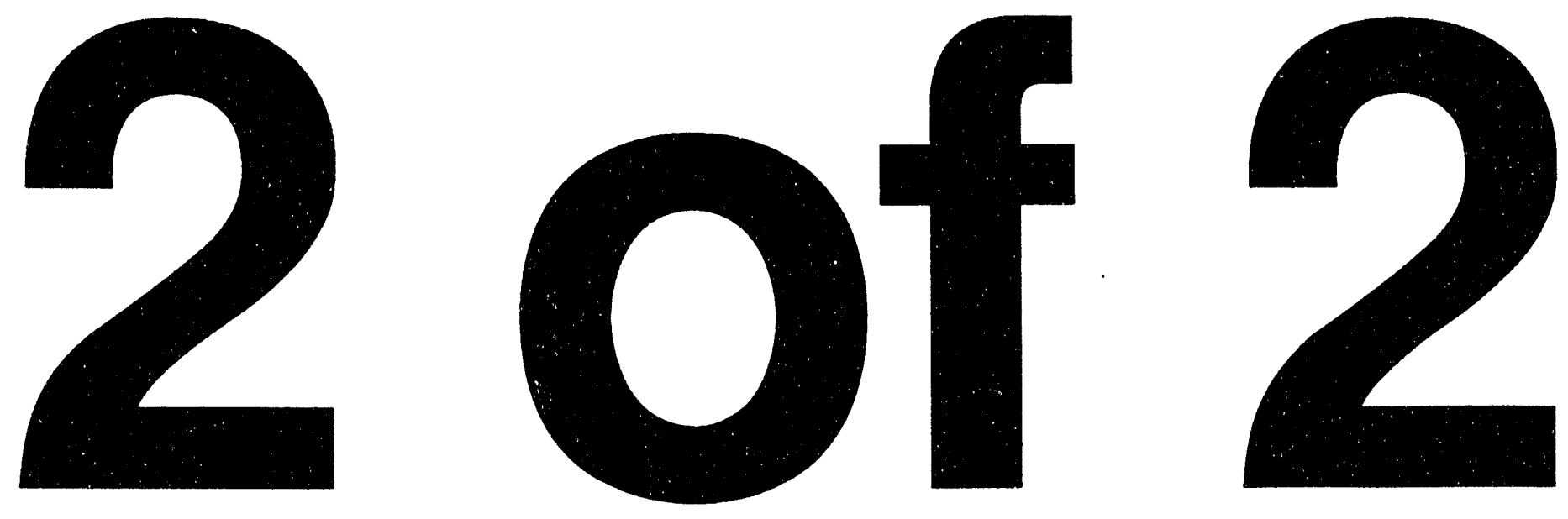
These atmospheric ( ()$_{2}$ concentrations are considered indicative of regional background air conditions and are directly traceable to the World Meteorological ( )rganization's primary $\mathrm{C}_{2} \mathrm{O}_{2}$ standards. These measurements support the rising trend in atmospheric ( ()$_{2}$ concentrations measured at other monitoring sites around the world and may be compared with similar measurements made by various monitoring programs at other northern-latitude sites.

Annual mean atmospheric $\mathrm{CO}_{2}$ concentrations, calculated from available individual flask measurements for the four sites, have increased from 352.38 parts per million by volume (ppmv) in 1988 to $354.97 \mathrm{ppmv}$ in 1990 for Teriberka Station, $343.52 \mathrm{ppmv}$ in 1983 to $355.68 \mathrm{ppmv}$ in 1990 for Ocean Station Charlie, $345.19 \mathrm{ppmv}$ in 1986 to $354.93 \mathrm{ppmv}$ in 1990 for Bering island, and $351.96 \mathrm{ppmv}$ in 1987 to $356.05 \mathrm{ppmv}$ in 1990 for Kotelny Island. The atmospheric $\mathrm{CO}_{2}$ measurements from each site show a pronounced annual seasonal oscillation caused by photosynthetic depletion during the northern growing season. The amplitudes of these seasonal oscillations are quite large (10 to $30 \mathrm{ppmv}$ ) and are consistent with measurement records from other northern-latitude locations.

The NDP consists of a written document and a magnetic tape containing seven files: four data files (one for each station) that provide the atmospheric $\mathrm{CO}_{2}$ concentrations from individual flask measurements, a descriptive file, and FORTRAN and SAS computer codes to access the data files. The written document presents the atmospheric $\mathrm{CO}_{2}$ concentrations in graphic and tabular form, describes the sampling methods, defines limitations and restrictions of the data, and describes the information on the magnetic media. The data files range in size from 0.97 to $20.01 \mathrm{kB}$. These data are also available on CD-ROM or via l'TP. For those wishing to receive these data on floppy diskette, the same files are available on IBMformatted, high- or low-density, 5.25- or 3.5-inch floppy diskettes as DOS ASCII text files.

NDP-034 (WDC-A)

\section{Atmospheric $\mathrm{CO}_{2}$ Concentrations-The Canadian Background Air Pollution Monitoring Network} (1989)

\section{N. B. A. Trivett (contributor)}

Flask air samples collected at roughly weekly intervals at three Canadian sites [Alert, Northwest Territories (July 1975 through October 1987); Sable Isiand, Nova Scotia (June 1975 through October 1987); and Cape St. James, British Columbia (May 1979 through October 1987)] were analyzed for $\mathrm{CO}_{2}$ concentration with the measurements directly traceable to the WMO primary $\mathrm{CO}_{2}$ standards. Each record includes the date, atmospheric $\mathrm{CO}_{2}$ concentration, and flask classification code.

They provide an accurate record of $\mathrm{CO}_{2}$ concentration levels in Canada during the past decade. Because these data are directly traceable to WMO standards, this record may be compared with records from other Background Air Pollution Monitoring Network (BAPMoN) stations. The data are in three files (one for each of the monitoring stations) ranging in size from 3.2 to $12.8 \mathrm{kB}$. 


\title{
Global Geographic Information System Data Base of Storm Occurrences and Other Climatic Phenomena Affecting Coastal Zones
}

(1991)

\author{
K. R. Birdwell, and R. C. Daniels (contributors)
}

This NDP quantifies the occurrence of synoptic storms and other climatological factors that affect coastlines (e.g.. induce erosion or contribute to coastal inundation). This NDP is unique in that it represents CDIAC's first offering of ARC/INFO export data files and equivalent flat ASCII data files that may be used by raster or vector geographic information systems (GISs). The data set contains 61 variables, including information on tropical storms, hurricanes, super typhoons, extratropical cyclogeneses, polar lows, cyclonicity, influence of winds in monsoon regions, and sea-ice concentrations. Increased availability of source data has made it possible to extend the area of these data variables to regional or global coverages. All data variables except five are referenced to $1^{\circ} \cdot 1^{\circ}$ or $5^{\circ} \cdot 5^{\circ}$ grid cells of latitude and longitude. These data help meet the demand for new and improved climatologies of storm events and may be used in climate research studies, including the verification of general circulation models and the calculation of storm-recurrence intervals.

The NDP consists of a written report and a 9-track magnetic tape containing 34 files, including eight ARC/INFO files, flat ASCII files, and FORTRAN and SAS retrieval routines; a vector coordinate file; and a descriptive file. The data files range in size from $0.1 \mathrm{kB}$ to $5.31 \mathrm{MB}$. The data are also available on CD-ROM or via FTP. For those wishing to receive these data on floppy diskettes, CDIAC will provide all except the ARC/INFO files on IBM-format, high-density 5.25 - or 3.5-in. diskettes.

\section{Indian Ocean Radiocarbon: Data from the INDIGO 1, 2, and 3 Cruises NDP-036 (1991)}

\section{H. Göte Östlund, and C. Grall (contributors)}

This data set presents ${ }^{14} \mathrm{C}$ activities from water samples taken at various locations and depths in the Indian and Southern oceans through the Indien Gaz Ocean (INDIGO) project. These data were collected as part of the INDIGO 1, INDIGO 2, and INDIGO 3 cruises, which took place during the years 1985, 1986, and 1987, respectively. These data have been used to estimate the penetration of anthropogenic $\mathrm{CO}_{2}$ in the Indian and Southern oceans. The records include the station, date, ocean bottom depth, latitude and longitude, sampling depth, potential temperature, salinity, density, total $\mathrm{CO}_{2},{ }^{13} \mathrm{C}$, and ${ }^{14} \mathrm{C}$ activity. The data are in one file of $25 \mathrm{kB}$. 
NDP-037 (WDC-A)
NDP-038 (WDC-A)

\section{Carbon Dioxide Enrichment: Data on the Response of Cotton to Varying $\mathrm{CO}_{2}$ Irrigation, and Nitrogen (1992)}

B. A. Kimball, J. R. Mauney, R. L. La Morte, G. Guinn, F. S. Nakayama, J. W. Radin, E. A. Lakatos, S. T. Michell, L. L. Parker, G. J. Peresta, P. E. Nixon III, B. Savoy, S. M. Harris, R. MacDonald, H. Pros, and J. Martinez (contributors)

This NDP presents data on the effects of continuous $\mathrm{CO}_{2}$ enrichment of cotton during five consecutive growing seasons, 1983 to 1987, under both optimal and limiting levels of water and nitrogen. Unlike many prior $\mathrm{CO}_{2}$-enrichment experiments in growth chambers or greenhouses, these studies were conducted on field-planted cotton at close to natural conditions with open-top chambers. Measurements were made on a variety of crop-response variables during the growing season and upon crop harvest. The initial experiment examined the effects of varying $\mathrm{CO}_{2}$ concentration only. During the following two seasons, the interactive effects of $\mathrm{CO}_{2}$ concentration and water availability were studied. During the final two seasons, the interactions among $\mathrm{CO}_{2}$ concentration, water availability, and nitrogen fertility were investigated.

The data include identification variables (such as year, institution and site codes, and treatment regimens), intermediate growth measurements (such as plant height, leaf-area index, number of flowers, and dry weight of leaves) taken at various times during the growing season, and crop-harvest results (such as lint yield, seed yield, and total aboveground dry biomass). These data will be useful in studying the possible future effects on crop production of a doubling of global atmospheric $\mathrm{CO}_{2}$ concentrations and for validating crop-growth models designed to predict the effects of elevated $\mathrm{CO}_{2}$ on cotton growth. The data show that, for all five growing seasons and all experimental treatments, cotton yields and plant dry weights were increased significantly by $\mathrm{CO}_{2}$ enrichment.

The NDP inclides a 48.4-kB ASCII data file, FORTRAN and SAS computer codes for accessing the data, a descriptive file, and written documentation. The documentation includes a supplemental text that describes and presents data for many other parameters, including daily weather, soil profile properties (e.g., initial soil moisture and nitrogen conditions), and irrigation and fertilizer treatments. These additional data are available from CDIAC on magnetic media upon request.

\section{Atmospheric Methane Concentrations-The NOAA/CMDL Global Cooperative Flask Sampling Network, 1983-1988 (1991)}

\section{P. Steel, and P. M. Lang (contributors)}

This data set presents monthly averages and sampling statistics for atmospheric methane concentrations from measurements made by the global cooperative flask sampling network of the National Oceanic and Atmospheric Administration/Climate Monitoring and Diagnostics Laboratory (NOAA/CMDL) from 1983 through 1988. The data are derived from a network of 30 stations (26 of which were still active at the end of 1988), which collected flask air samples approximately once per week for measurement of both methane and $\mathrm{CO}_{2}$. The samples were analyzed for atmospheric methane concentration on a gas chromatograph 
(fitted with a flame ionization detector) at the NOAA/CMDL laboratory in Boulder, Colorado. The data consist of station identification code; year; and mean monthly methane concentration, standard deviation, and number of samples contributing to the mean for each month. The data are in one file of $66.5 \mathrm{kB}$.

\section{Two Long-Term Instrumental Climatic Data Bases of the People's Republic of China (1991)}

\section{S. Tao, C. Fu, Z. Zeng, and Q. Zhang (contributors)}

Two long-term instrumental data bases containing meteorological observations from the People's Republic of China (PRC) are presented in this NDP. These data sets were compiled in accordance with a joint research agreement signed by the U.S. Department of Energy and the PRC Chinese Academy of Sciences (CAS) on Aug. 19, 1987. CAS has provided records from 265 stations, partitioned into two networks of 60 and 205 stations, each providing good geographical coverage of the PRC.

The 60-station-network data contain monthly means, extremes, or totals of barometric pressure, air temperature, precipitation amount, relative humidity, sunshine duration, cloud amount, dominant wind direction and frequency, wind speed, and number of days with snow cover. Detailed station histories are presented for all 60 stations.

The 205-station-network data contain monthly mean temperatures and monthly precipitation totals; however, station histories are not currently available. Sixteen stations from these data sets ( 13 from the 60 -station, 3 from the 205 -station) have temperature and/or precipitation records beginning before 1900 , whereas the remaining stations began observing in the early to mid-1900s. Records from 262 stations extend through 1988; the remaining three station records extend through the early 1980s.

The data are contained in five files [one station-inventory file for each of the networks ( $3.2 \mathrm{kB}$ for the 60 -station; $13.7 \mathrm{kB}$ for the 205 -station), one data file for the 60 -station network (6.5 MB), one temperature data file for the 205-station network ( $1 \mathrm{MB}$ ), and one precipitation data file for the 205-station network (1 MB)].

\section{Daily Temperature and Precipitation Data for 223 U.S.S.R. Stations (1993)}

\section{N. Razuvayev, E. G. Apasova, and R. A. Martuganov (contributors)}

Under an international agreement, the National Climatic Data Center (NCDC) in Asheville, N.C., is exchanging climatological information with the Research Institute of Hydrometeorological Information in Obninsk, Russia. To expedite the dissemination of these data, CDIAC, with funding provided by NCDC, is distributing one of the more useful archives acquired through this exchange: a 223-station daily data set covering from 1881 to 1989 . The 
data sel contains (1) minimum. mean, and maximum daily temperatures; (2) daily precipitation: (3) station inventory information (i.e., WMO number, name, coordinates, and elevation); (4) station history (i.e., station relocation and ratin-gage replacement information); and (5) quality-alssurance information (i.e., Mage codes that were assigned as a result of various data checks). The data are in 18 files.

NDP-041

The Global Historical Climatology Network: Long-Term Monthly Temperature, Precipitation, Sea Level Pressure, and Station Pressure Data

(1992)

R. S. Vose, R. L. Schmoyer, P. M. Steurer, T. C. Peterson, R. Heim, T. R. Karl, and J. K. Eischeid (contributors)

This NDP contains monthly temperature, precipitation, sea-level pressure, and stationpressure data for thousands of meteorological stations worldwide. The database was compiled from pre-existing national, regional, and global collections of data as part of the Global Historical Climatology Network (GHCN) project. It contains data from roughly 6000 temperature stations, 7500 precipitation stations, 1800 sea level pressure stations, and 1800 station pressure stations. Each station has at least 10 years of data, $40 \%$ have more than 50 years of data. Spatial coverage is good over most of the globe, particularly for the United States and Europe. Data gaps are evident over the Amazon rainforest, the Sahara desert, Greenland, and Antarctica.

A detailed analysis has revealed that most stations ( $95 \%$ for temperature and precipitation: $75 \%$ for pressure) contain high-quality data. However, gross data-processing errors (e.g., keypunch problems) and discontinuous inhomogeneities (e.g., station relocations and instrumentation changes) do characterize a small number of stations. All major data processing problems have been flagged (or corrected, when possible). Similarly, all major inhomogeneities have been flagged, although no homogeneity corrections were applied.

The NDP consists of a written report, two magnetic tapes of data, and FORTRAN and $\mathrm{SAS}^{\mathrm{TM}}$ data retrieval codes. Because of the size of the data base, the NDP is not available on floppy diskette.

United States Historical Climatology Network Daily Temperature (WDC-A) and Precipitation Data (1991)

\section{P. Y. Hughes, E. H. Mason, T. R. Karl, and W. A. Brower (contributors)}

This package consists of a data base containing daily observations of maximum and minimum temperature and precipitation amounts at 138 U.S. stations. These stations are a specially chosen subset of the 1219-station United States Historical Climatology Network (HCN), which was compiled by the National Climatic Data Center (Asheville, North Carolina) and is contained in NDP-019/R1. The daily data network (referred to as the $\mathrm{HCN} / \mathrm{D}$ ) consists of stations considered to be the best of those in the HCN, selected 
to provide effective coverage of the contiguous U.S. after considering the temporal homogeneity of each station's observing times, instrument positioning, and surroundings. The data for each station extend through 1987, and most station records are complete for at least 80 years. The daily resolution of these data lends maximum flexibility for studies attempting to detect and monitor long-term climatic changes on a regional scale. The data are contained in seven files (one station-inventory file, one station-history file, and five temperature and precipitation data files). The files range in size from $10 \mathrm{kB}$ to approximately $31 \mathrm{MB}$.

\section{A Coastal Hazards Data Base for the U.S. East Coast} (1992)

\section{M. Gornitz, and T. W. White (contributors)}

This NDP presents data on coastal geology, geomorphology, elevation, erosion, wave heights, tide ranges, and sea levels for the U.S. east coast. These data may be used either by nongeographic database management systems or by raster or vector geographic information systems (GISs). The database integrates several data sets (originally obtained as point, line, and polygon data) for the east coast into $0.25^{\circ}$-latitude by $0.25^{\circ}$-longitude grid cells. Each coastal grid cell contains 28 data variables.

This NDP may be used to predict the response of coastal zones on the U.S. east coast to changes in local or global sea levels. Information on the geologic, geomorphic, and erosional states of the coast provides the basic data needed to predict the behavior of the coastal zone into the far future. Thus, these data may be seen as providing a baseline for the calculation of the relative vulnerability of the east coast to projected sea-level rises. This data will also be useful to research, educational, governmental, and private organizations interested in the present and future vulnerability of coastal areas to erosion and inundation.

The data are in 13 files, the largest of which is $1.42 \mathrm{MB}$; the entire data base takes up $3.29 \mathrm{MB}$, excluding the ARC/INFO' ${ }^{\text {rM }}$ files.

\section{A Coastal Hazards Data Base for the U.S. Gulf Coast (1993)}

\section{M. Gornitz, and T. W. White (contributors)}

This document describes the contents of a digital data base that may be used to identify coastlines along the U.S. Gulf Coast at risk to sea-level rise. The data base integrates point, line, and polygon data for the U.S. Gulf Coast into $0.25^{\circ}$ latitude by $0.25^{\circ}$ longitude grid cells and into $1: 2,000,000$ digitized line segments that can be used by raster or vector geographic information systems (GIS) as well as by non-GIS data base systems. Each coastal grid cell and line segment contains data on elevations, geology, geomorphology, sea-level trends, shoreline displacement (erosion/accretion), tidal ranges, and wave heights.

To allow for the identification of coastlines at risk from sea level rise, 7 of the 22 original data variables in this data base were classified by vulnerability and used to create 7 relative risk variables. These relative risk variables range in value from 1 to 5 and may be used to calculate a coastal vulnerability index for each grid cell and/or line segment. The data for these
NDP-043A

NDP-043B 
29 variables (i.e., the 22 original variables and 7 risk variables) have been placed into the following data formats:

1. Gridded polygon data for the 22 original data variables. Data include elevations, geology, geomorphology, sea-level trends, shoreline displacement (erosion/accretion), tidal ranges, and wave heights.

2. Gridded polygon data for the seven classified risk variables. The risk variables are classified versions of mean coastal elevation, geology, geomorphology, local subsidence trend, mean shoreline displacement, maximum tidal range, and maximum significant wave height.

3. 1:2,000,000 line segment data containing the 29 data variables (i.e., the 22 original data variables and the 7 classified risk variables).

4. Supplemental point data for the stations used in calculating the sea-level trend and tidal range data sets.

5. Supplemental line segment data containing a 1:2,000,000 digitized coastline of the U.S. Gulf Coast as defined by this numeric data package (NDP).

These data are available as an NDP from the Carbon Dioxide Information Analysis Center (CDIAC). The NDP consists of this document and machine-readable files available on 9track magnetic tape, IBM-formatted floppy diskettes, and CD-ROM and through Internet by means of the File Transfer Protocol (FTP) from CDIAC's anonymous FTP area. This document provides sample listings of the data and detailed descriptions of the file formats; offers FORTRAN and SAS ${ }^{\mathrm{TM}}$ retrieval program listings; describes the methods used in calculating each variable; discusses the sources, restrictions, and limitations of the data; provides five $\mathrm{ARC} / \mathrm{INFO}^{\mathrm{TM}}$ export coverages and flat $\mathrm{ASCII}$ data files containing these data; and provides reprints of pertinent literature.

\section{Surface Water and Atmospheric Carbon Dioxide and Nitrous Oxide Observations by Shipboard Automated Gas Chroma- tography: Results from Expeditions Between 1977 and 1990 (1992)}

\section{R. F. Weiss, F. A. Van Woy, and P. K. Salameh (contributors)}

This NDP presents the results of surface water and atmospheric carbon dioxide $\left(\mathrm{CO}_{2}\right)$ and nitrous oxide $\left(\mathrm{N}_{2} \mathrm{O}\right)$ measurements carried out on shipboard by gas chromatography from 1977 to 1990. These data include results from 41 legs of 11 ocean surveys conducted in the Atlantic, Pacific, Indian, and Southern oceans, as well as the Mediterranean and Red seas.

The measurements were made by an automated high-precision shipboard gas chromatographic system that measures $\mathrm{CO}_{2}$ by flame ionization after quantitative reduction to methane in a stream of hydrogen. Nitrous oxide is measured by a separate electron-capture detector. The chromatographic system measures 196 dry-gas samples 
a day, divided equally among the atmosphere, gas equilibrated with surface water, a low-range gas standard, and a high-range gas standard.

These data constitute one of the most extensive records available of $\mathrm{CO}_{2}$ and, particularly, $\mathrm{N}_{2} \mathrm{O}$ in marine air and surface seowater. The data will be valuable in modeling the ocean's role in the global cycles of carbon and nitrogen, in studies of ocean-atmosphere dynamics, and in evaluations of other methods for determining $\mathrm{pCO}_{2}$. The records include the names of the expedition and research vessel, sample date and time, latitude and longitude, sample type (i.e., marine air or surface seawater), barometric pressure, surface water temperture, and dry-gas mole fractions of $\mathrm{CO}_{2}$ and $\mathrm{N}_{2} \mathrm{O}$. The data are in 82 files totaling $7.1 \mathrm{MB}$.

\section{Historic Land Use and Carbon Estimates for South and Southeast Asia: 1880-1980 (1993)}

\section{J. F. Richards, and E. P. Flint (contributors)}

This digital data base contains estimates of land use change and the carbon content of vegetation for South and Southeast Asia for the years 1880, 1920, 1950, 1970, and 1980. These data were originally collected for climate modelers so they could reduce the uncertainty associated with the magnitude and time course of historical land use change and of carbon release. For this data base, South and Southeast Asia is defined as encompassing nearly $8 \times 10^{6} \mathrm{~km}^{2}$ of the earth's land surface and includes the countries of India, Sri Lanka, Bangladesh, Myanmar (Burma), Thailand, Laos, Kampuchea (Cambodia), Vietnam, Malaysia, Brunei, Singapore, Indonesia, and the Philippines.

The most important change in land use over this 100-year period was the conversion of $107 \times 10^{6}$ ha of forest/woodland to categories with lower biomass. Land thus transformed accounted for $13.5 \%$ of the total area of the study region. The estimated total carbon content of live vegetation in South and Southeast Asia has dropped progressively, from $59 \times 10^{9} \mathrm{Mg}$ in 1880 to $27 \times 10^{9} \mathrm{Mg}$ in 1980 . Throughout the study period, the carbon stock in forests was greater than the carbon content in all other categories combined, although its share of the total declined progressively from $81 \%$ in 1880 to $73 \%$ in 1980 .

The data base was developed in Lotus $1-2-3^{\mathrm{TM}}$ by using a sequential bookkeeping model. The source data were obtained at the local and regional level for each country from official agricultural and economic statistics (e.g., the United Nations Food and Agriculture Organization); historical geographic and demographic texts, reports, and articles; and any other available source. Because of boundary changes through time and disparities between the validity, availability, and scale of the data for each country, the data were aggregated into 94 ecological zones. The resulting data base contains land use and carbon information for 94 ecological zones and national totals for 13 countries.

The data base consists of 90 Lotus $1-2-3^{\mathrm{TM}}$ files, 3 ARC/INFO ${ }^{\mathrm{TM}}$ export files, and 5 ASCII data files. In addition to these, a descriptive file that explains the contents and format of each data file and 4 FORTRAN and SAS ${ }^{\mathrm{TM}}$ retrieval programs for use with the ASCII data files are included. 


\title{
The IEA/ORAU Long-Term Global Energy- $\mathrm{CO}_{2}$ Model
} (1984)

\author{
J. A. Edmonds, and J. M. Reilly (contributors)
}

This mathematical model, written in FORTRAN IV and adapted for use on an $I \mathrm{BM}^{*} 370 / 3033$, makes projections concerning global energy and $\mathrm{CO}_{2}$ emissions at 25-year intervals from 1975 through 2100 based on economic, demographic, and energy interactions. The model separates the world into nine regions, each having four components: demand, supply, energy balance, and $\mathrm{CO}_{2}$ emissions. Energy demand is a function of the population, economic activity, technological change, energy prices, and energy taxes and tariffs existing in each region. Supply is dependent upon resource constraints, behavioral assumptions, and energy prices in a region. Energy balance reconciles the global energy supply and demand for fuels. Emissions are determined by applying appropriate carbon coefficients at the points in the energy flow where carbon is released. The model offers three energy/emission scenarios through 2100 and illustrates the complex relationships between global $\mathrm{CO}_{2}$ emissions, rising populations, and energy parameters. The model is in nine files, three containing the source code and subroutines and one input-data and one output file each for low, mid, and high cases. These files range in size from 45.6 to $422 \mathrm{kB}$ and are available on 9-track magnetic tape only.

CMP-002/PC (WDC-A)

\section{The IEA/ORAU Long-Term Global Energy- $\mathrm{CO}_{2}$ Model: Personal Computer Version A84PC (1984)}

\section{J. A. Edmonds, and J. M. Reilly (contributors)}

The IBM ${ }^{\circledR}$ PC version of the Edmonds-Reilly model reflects considerable refinements and improvements over the mainframe version (see CDIAC CMP-002). It has the capability to calculate both $\mathrm{CO}_{2}$ and $\mathrm{CH}_{4}$ emission estimates by source and region. The basic methodology and features of the PC version are the same as those for the mainframe version. Population, labor productivity, end-use energy efficiency, income effects, price effects, resource base, technological change in energy production, environmental costs of energy production, market-penetration rate of energy-supply technology, solar and biomass energy costs, synfuel costs, and the number of forecast periods may be interactively inspected and altered producing a variety of global and regional $\mathrm{CO}_{2}$ and $\mathrm{CH}_{4}$ emission scenarios for 1975 through 2100 . The executable versions of the model and the source code are contained in 74 files ranging in size from 10 bytes to $292 \mathrm{kB}$.

\section{CDIAC's Numeric Data Package Collection: Selected Data Sets Relevant to Studies of Greenhouse Gases and Climate (April 1993)}

\section{T. A. Boden, and T. R. Nelson (contributors)}

This two-volume CD-RONi provides data files, retrieval codes, and descriptive files for selected NDPs and CMPs, data from selected technical reports, and the data from Trends '91: A Compendium of Data on Global Change. A full listing of NDPs and CMPs is 
available in the CDIAC Catalog of Numeric Data Packages and Computer Model Packages. The CD's data bases are arranged as subdirectories, each subdirectory corresponding to an NDP number (e.g., NDP-001/R3). The first CD-ROM of this two-volume set contains all subdirectories except for NDP-041, NDP-042, and NDP-044. These subdirectories are provided on the second volume.

Within each subdirectory, the user will find a descriptive file (*.DES or README) that outlines the basis contents and formats of the other files in the subdirectory. All the data bases provided on these CD-ROMs are fully documented and are also available on 9-track magnetic tape; IBM-formatted, floppy diskettes; or through CDIAC's anonymous FTP (file transfer protocol) area via Internet. To receive the complete documentation for an NDP, please contact CDIAC. 
Section G

Other Data Sets Distributed by CDIAC 


\section{The ALE/GAGE/AGAGE Network}

R. Prinn, D. Cunnold, P. Fraser, R. Weiss, P. Simmonds, B. Miller, F. Alyea, and

A. Crawford. (contributors)

In the ALE/GAGE/AGAGE global network program, continuous high frequency gas chromatographic measurements of two biogenic anthropogenic gases (methane, $\mathrm{CH}_{4}$; nitrous oxide. $\mathrm{N}_{2} \mathrm{O}$ : and five anthropogenic gases (chlorotluorocarbons $\mathrm{CFCl}_{3}, \mathrm{CF}_{2} \mathrm{Cl}_{2}$, and $\mathrm{CF}_{2} \mathrm{ClCl}_{2} \mathrm{Cl}_{2}$; methyl chloroform, $\mathrm{CH}_{3} \mathrm{CCl}_{3}$; carbon tetrachloride, $\mathrm{CCl}_{4}$ ) are carried out at globally distributed sites. The program, which began in 1978, is conveniently divided into three parts associated with three changes in instrumentation: the Atmospheric Lifetime Experiment (ALE), which utilized Hewlett Packard HP5840 gas chromatographs; the Global Atmospheric Gases Experiment (GAGE), which utilized HP5880 gas chromatographs; and the recently initiated Advanced (AGE (AGAGE). AGAGE uses a new fully automated system from the Scripps Institution of Oceanography containing a custom-designed sample module and HP5890 and Carle Instruments gas chromatographic components.

The current station locations are Cape Grim, Tasmania $\left(41^{\circ} \mathrm{S}, 145^{\circ} \mathrm{E}\right)$. Point Matatula, Amrican Samoa $\left(14^{\circ} \mathrm{S}, 171^{\circ} \mathrm{E}\right)$, Ragged Point, Barbados $\left(13^{\circ} \mathrm{N}, 59^{\circ} \mathrm{W}\right)$, and Mace Head, Ireland $\left(53^{\circ} \mathrm{N}, 10^{\circ} \mathrm{W}\right)$. Stations also previously existed at ('ape Meares, Oregon $\left(45^{\circ} \mathrm{N}, 124^{\circ} \mathrm{W}\right)$, and Adrigole, Ireland $\left(52^{\circ} \mathrm{N}, 10^{\circ} \mathrm{W}\right)$. The current Mace Head station replaced the Adrigole station and a station is planned at Trinidad Head, California $\left(41^{\circ} \mathrm{N}, 124^{\circ} \mathrm{W}\right)$ to replace Cape Meares.

Presently, data from the ALE and GAGE experiments are available. Data from AGAGE are not yet available. Individual measurements (generally made 4 times daily at each site for ALE and 12 times daily at each site for GAGE) and monthly summary averages are provided for each site.

\section{ICRCCM Infrared (Clear-Sky) Line-by Line Radiative Fluxes}

\section{A. Arking, B. Ridgway, T. Clough, M. Iacono, B. Fomin, A. Trotsenko, S. Freidenreich, and D. Schwarzkopf (contributors)}

The intercomparison of Radiation Codes in Climate Models (ICRCCM) study was launched under the auspices of the World Meteorological Organization and with the support of the U.S. Department of Energy to document differences in results obtained with various radiation codes and radiation parameterizations in general circulation models (GCMs). ICRCCM produced benchmark, longwave, line-by-line (L,BL) fluxes that may be compared against each other and against models of lower spectral resolution.

During ICRCCM, infrared fluxes and cooling rates for several standard model atmospheres with varying concentrations of water vapor, carbon dioxide, and ozone were calculated with LBL methods at resolutions of $0.01 \mathrm{~cm}^{-1}$ or higher. For comparison with other models, values were summed for the IR spectrum and given at intervals of 5 or $10 \mathrm{~cm}^{-1}$.

This archive contains fluxes for ICRCCM-prescribed clear-sky cases. Radiative flux and cooling-rate profiles are given for specified atmospheric profiles for temperature, water vapor, and ozone-mixing ratios. The archive contains 328 files, including spectral summaries, 
formatted data files, and a variety of programs (i.e., C-shell scripts, FORTRAN codes, and IDL programs) to read, reformat, and display data. Collectively, these files require approximately 59 $\mathrm{MB}$ of disk space.

\title{
DB1003 A Computer-Based Atlas of Global Instrumental Climate Data
}

\author{
R. S. Bradley, L. G. Ahern, and F. T. Keimig (contributors)
}

Color-shaded and contoured images of global, gridded instrumental data have been produced as a computer-based atlas. Each image simultaneously depicts anomaly maps of surface temperature, sea-level pressure, 500-mbar geopotential heights, and percentages of referenceperiod precipitation. Monthly, seasonal, and annual composites are available in either cylindrical equidistant or northern and southern hemisphere polar projections. Temperature maps are available from 1854 to 1991 , precipitation from 1851 to 1989 , sea-level pressure from 1899 to 1991, and 500-mbar heights from 1946 to 1991. The source of data for the temperature images is Jones et al.'s global gridded temperature anomalies. The precipitation images were derived from Eischeid et al.'s global gridded precipitation percentages. Grids from the Data Support Section, National Center for Atmospheric Research (NCAR) were the sources for the sea-level-pressure and 500-mbar geopotential-height images. All images are in GIF files ( $1024 \times 822$ pixels, 256 colors) and can be displayed on many different computer platforms. Each annual subdirectory contains 141 images, each seasonal subdirectory contains 563 images, and each monthly subdirectory contains 1656 images. The entire atlas requires approximately $340 \mathrm{MB}$ of disk space, but users may retrieve any number of images at one time.

Users should have monitors with the capability of displaying 256 colors (SVGA, 8-bit RGB color) and software for viewing GIF files. The monitor is necessary to take advantage of the high-resolution color images and to display them correctly. For users needing a GIF viewer, three shareware viewers are provided-one for an IBM-compatible PC, one for a Macintosh, and one for a workstation.

A CD-ROM version of the atlas is presently being prepared by the Climatology Lab at the University of Massachusetts and will be distributed by them at a cost of $\$ 30.00$.

\section{DB1004 Alaskan Historical Climatology Network (HCN) Serial Temperature and Precipitation Data}

\author{
T. R. Karl, R. G. Baldwin, M. G. Burgin, D. R. Easterling, R. W. Knight, and \\ P. Y. Hughes (contributors)
}

This database is a companion to the Historical Climatology Network (HCN) database for the contiguous United States (see NDP0/9/RI on page 91). The database contains monthly temperature (minimum. maximum. and mean) and total monthly precipitation data for 47 Alaskan stations. These data were derived from a variety of sources including the National Climatic Data Center archives, the state climatologist for Alaska, and published literature. The period of record varies by station. The longest record is for the Sitka Magnetic Observatory (1828) and most records extend through 1990. Unlike the HCN database for the contiguous U.S., adjustments have not been made to these climate records for time-of-observation differences, instrument changes, or station moves. The data are in three files fone data file that 
contains all four climate variables, one station inventory file, and one station history file]. The file sizes range from $3.5 \mathrm{kB}$ to $1.7 \mathrm{MB}$. 


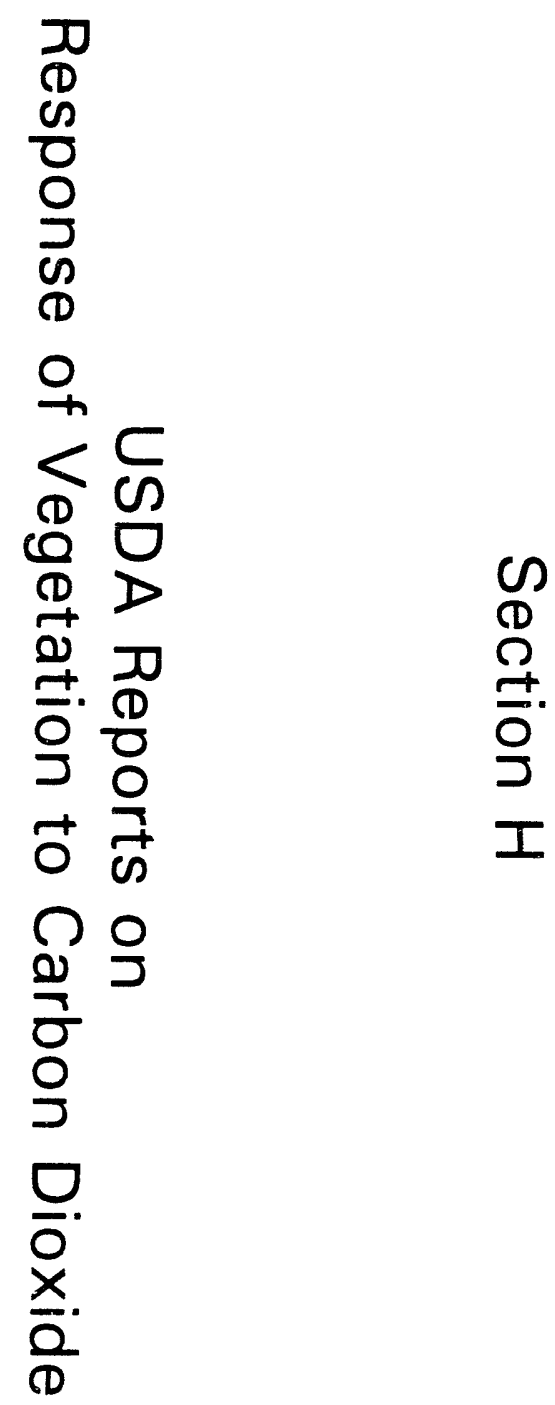


Field Studies of Plant Responses to Elevated Carbon Dioxide Levels, 1980

H. H. Rogers, G. E. Bingham, J. D. Cure, W. W. Heck, A. S. Heagle, D. W. Israel, J. M. Smith, K. A. Surano, and J. F. Thomas

During the summer of 1980 techniques were developed for the generation of large-scale test atmospheres in the field. These methods are applicable to the study of $\mathrm{CO}_{2}$ dose-response relationships of agronomic and forest species. The system performed satisfactorily and its feasibility for the study of responses of field vegetation to $\mathrm{CO}_{2}$ was demonstrated.

\section{Effects of Increased Carbon Dioxide on Photosynthesis and Agricultural Productivity of Soybeans, 1981}

L. H. Allen, Jr., K. J. Boote, J. W. Jones, J. W. Mishoe, P. H. Jones, C. V. Vu, R. Valle, and W. J. Campbell

Part A of this report describes responses of soybean crops that were grown from seeding to final harvest in outdoor, controlled environment chambers, Soil-Plant-Atmosphere- Research (SPAR) units, that were used to conduct experiments at $\mathrm{CO}_{2}$ concentrations from $330 \mathrm{vpm}$ to $800 \mathrm{vpm}$. This report also contains information on plant growth, staging, and components of dry matter at final harvest, as well as preliminary information on leaf RuBP carboxylase. Part B of this report includes laboratory analyses of nonstructural carbohydrates and nitrogen of leaves during diurnal samplings, and of plant components of the final harvest (leaves, stems, petioles, seed).

\section{Field Studies of Sweet Potatoes and Cowpeas in Response to Elevated Carbon Dioxide, 1985}

P. K. Biswas, J. R. Allen, N. C. Bhattacharya, J. Y. Lu, R. D. Pace, H. H. Rogers, K. B. Coleman, J. F. Eatman, P. P. Ghosh, N. Mbikayi, J. N. McCrimmon, and A. Menefee

This report summarizes the results of a study on the physiological and biochemical effects of enriched $\mathrm{CO}_{2}$ on sweet potatoes and cowpeas. The following are the results of the study.

Sweet potatoes grown in the open top chambers, at ambient $\mathrm{CO}_{2}$ concentrations had fewer leaves, less total runner length, and lower fresh and dry weights of shoots, leaves, and tubers as compared with sweet potatoes grown in the open field without chambers. While shoot growth in sweet potatoes increased with increasing $\mathrm{CO}_{2}$, few of the effects were large enough to be significant, but the percentages of nitrogen and protein nitrogen in sweet potato leaves decreased significantly at higher $\mathrm{CO}_{2}$ concentrations. The total fresh weight of tubers increased significantly at the higher levels of $\mathrm{CO}_{2}$, primarily due to an increase in the number of tubers. There were no differences in the density of stomates or in stomatal conductances in sweet potato leaves. Protein, total carotenoids, and insoluble dietary fiber of tubers all decreased with increasing $\mathrm{CO}_{2}$, while dry matter content increased with increasing $\mathrm{CO}_{2}$. 
In phytotron studies with pot-grown sweet potatoes, plants grown at 675 or $1000 \mathrm{ppm} \mathrm{CO}$. showed increases in the length of the main stem, total branch length, the number of branches, and leaf area as compared with those grown in $350 \mathrm{ppm} \mathrm{CO}_{2}$. At each harvest interval the production of total dry matter increased in response to increasing $\mathrm{CO}_{2}$. Specific leaf weight also increased with increased $\mathrm{CO}_{2}$ concentrations. At the final harvest, the dry weights of roots and tubers increased 1.8 and 2.6 times in plants grown at 675 and $1000 \mathrm{ppm} \mathrm{CO}_{2}$, respectively, compared with those grown at $350 \mathrm{ppm} \mathrm{CO}_{2}$. The number and size of tubers increased at high $\mathrm{CO}_{2}$ concentrations. Carbon dioxide enrichment resulted in early tuber maturation in sweet potatoes.

Cowpeas were studied in two experiments in open top chambers. In the row crops study, the fresh and dry weights of cowpea plants grown in chambers at ambient $\mathrm{CO}_{2}$ were slightly lower than in plants grown in the open field, but the differences were statistically insignificant. Within chambers, the fresh and dry weights of plants were significantly greater at 506 and $655 \mathrm{ppm} \mathrm{CO}_{2}$ as compared to plants grown at ambient $\mathrm{CO}_{2}(354 \mathrm{ppm})$. The number of leaves, leaf area, plant height, number of nodules and pods, and the fresh weight of seeds were significantly greater at enriched $\mathrm{CO}_{2}$ levels. Protein nitrogen of seeds increased significantly with increased $\mathrm{CO}_{2}$ concentrations. The number of stomata did not differ among the different chambers. Stomatal conductances were signiticantly greater in plants grown at $506 \mathrm{ppm} \mathrm{CO}_{2}$ than in plants grown in chambers at ambient $\mathrm{CO}_{2}$.

In the cowpea pot study, plants grown at elevated $\mathrm{CO}_{2}$ had greater dry weights of seeds and vegetative parts and produced more leaves than plants grown in a chamber at ambient $\mathrm{CO}_{2}$. but there were not differences in plant height or rate of growth. Differences in the number of nodules and the rate of nitrogen fixation were not significant, but nitrogen fixation rates in plants grown at elevated $\mathrm{CO}_{2}$ were approximately $45 \%$ higher, on a per plant basis, than in plants grown in ambient chambers. In phytotron studies with pot-grown cow peas, the length of the main stem and branches, the number of leaves and leaf area were greater at 675 and $1000 \mathrm{ppm} \mathrm{CO}$ than at $350 \mathrm{ppm} \mathrm{CO}_{2}$. Flowers appeared $10-12$ days earlier in an enriched $\mathrm{CO}_{2}$ atmosphere. Carbon dioxide enrichment hastened pod and seed formation in cowpeas and also caused greater partitioning of biomass into pods than into roots, stems, or leaves. Total seed weight and number of seeds per pod were significantly greater at elevated $\mathrm{CO}_{2}$, but $\mathrm{CO}_{2}$ enrichment did not affect the harvest index of cowpeas. 
Section I

\section{Other Publications}


R. C. Dahlman, T. Gross, L. Machta, W. Elliot, and M. MacCracken

This is a report of progress made by Department of Energy contractors on the carbon dioxide issue during fiscal year 1979. The report is largely limited to questions on the global carbon cycle and the effect of increased carbon dioxide on the global climate system.

\section{A Comprehensive Plan for Carbon Dioxide Effects Research and Assessment. Part I: The Global Carbon Cycle and Climatic Effects of Increasing Carbon Dioxide}

(DOE/EV-0094, August 1980)

Carbon Dioxide and Climate Division, U.S. Department of Energy

This plan outlines, in order of priorities, the first part of an urgently required research effort on carbon dioxide effects. The Department of Energy is guided by this plan in developing its research program and offers it to the governmental and scientific communities as a focus about which the required major national and international effort can be developed.

Workshop on Environmental and Societal Consequences of a Possible $\mathrm{CO}_{2}$-Induced Climate Change (CONF-7904143, October 1980)

Office of Health and Environmental Research, U.S. Department of Energy

This is a report of a workshop held on April 2-6. 1979, at Annapolis, Maryland. This was one of the major events in the development of the Department of Energy's research program on the carbon dioxide issue. The workshop was on the development of the program on the environmental and societal consequences resulting from a climate change and increase in atmospheric concentrations of carbon dioxide.

\section{Proceedings of the Carbon Dioxide and Climate Research Program Conference (CONF-8004110, December 1980)}

\section{E. Schmitt (ed.)}

This is a report of a conference held in Washington, D.C., on April 24-25, 1980, to review research progress through fiscal year 1979 of the DOE's Carbon Dioxide and Assessment Program, and to review a draft update of the Comprehensive Plan, Part I: The Cilobal Carbon Cycle and Climatic Effects of Increasing Carbon Dioxide (subsequently issued as document 008 ) 


\section{Proceedings of the International Meeting on Stable Isotopes in Tree-Ring Research \\ (CONF-790518, December 1980)}

\section{G. Jacoby (ed.)}

This is a report of the proceedings of a meeting held on May 22-25, 1979. at Mohonk Mountain House in New Paltz. New York. The meeting was convened to accelerate the flow of information between scientis's in the relatively new and rapidly developing field of measurements of stable isotopes in tree rings. The report contains most of the papers presented at the meeting.

\section{Some Aspects of the Rule of the Shallow Ocean in Global Carbon Dioxide Uptake (CONF-8003115, January 1981)}

\section{R. M. Garrels, and F. T. Mackenzie (eds.)}

These are the proceedings of a workshop, which was supported jointly by the U.S. Department of Energy and the Gas Research Institute of Chicago, held on March 20-22, in Atlanta, Georgia. The purpose was to assess the role of the oceanic mixed layer. especially the shallow waters of shelves, seas, and estuaries as a sink or source for atmospheric carbon dioxide.

Flux of Organic Carbon by Rivers to the Oceans (CONF-8009140, April 1981)

Committee on Flux of Organic Carbon to the Oceans, National Research Council

The state of knowledge about the role of rivers in the transport, storage, and oxidation of carbon is the subject of this report. It summarizes a workshop of the committee on flux of Organic Carbon to the Ocean. Division of Biological Sciences, National Research Council held at Woods Hole, Massachusetts on September 21-25, 1980.

\section{Workshop on Oceanic $\mathrm{CO}_{2}$ Standardization} (CONF-7911173, February 1982)

H. G. Ostlund, and D. Dyrssen (eds.)

This report contains detailed information or the measurements of carbon dioxide and alkalinity made during the GEOSECS (Geochemical Ocean Section) program. 


\section{Proceedings: Carbon Dioxide Research Conference: Carbon Dioxide, Science and Consensus (CONF-820970, February 1983)}

Institute for Energy Analysis

Oak Ridge Associated Universities

This is a record of the technical papers presented at a conterence held at coolfont. West Virginia on September 19-23, 1982. These papers reviewed the uncertainty on future atmospheric $\mathrm{CO}_{2}$ levels, global and regional climate changes (as measured by temperature. precipitation, cloudiness, etc.), effects of elevated $\mathrm{CO}_{2}$ levels on crops and ecosystems, and the potential impact on the West Antarctic.

Proceedings from the Second Science Team Meeting of the United States of America Clepartment of Energy and the People's Republic of China Academia Sinica Joint Research Program on $\mathrm{CO}_{2}$-Induced Climate Change (CONF-8708252, June 1988)

\section{W.-C. Wang, and M. R. Riches (eds.)}

The Carbon Dioxide Research Division of the U.S. Department of Energy (DOE). brought together 30 Chinese and American scientists at Harper's Ferry, West Virginia, for the second science team meeting of the United States of America Department of Fnergy (USDOV) and the People's Republic of ('hina Academia Sinica (PRC CAS) Joint Rescarch Program on ( $\mathrm{O}_{2}$ Induced Climate Change. The purpose of the conference was to review recent progress and to sel new goals for cooperative research and the exchange of data regarding carbon dioxide research Six papers are presented as Proceedings of the August 1987 PR( CAS and USA D)( ) Joint Carbon Dioxide Research Conterence investigating the influence of carbon dioxide upon world climate and are examples of research progress during the last wo years. Fach of the four task areas set forth are represented: Climate Modeling. Data Preparation. Data Analysis, and Methane Studies.

"A Description of IAP Two-Level Atmospheric General Circulation Model" is documentation of the first numerical climate simulation model developed by the Institute of Atmospheric Physics (IAP) in Beijing. This paper is presented by $X$. Zhang and $X$. Liang of CAS IAP, now visiting scholars at the Laboratory for Plantary Atmosphere Research, State University of New York at Stony Brook.

The category of Task II. Data Preparation, is represented by two papers from the National Oceanic and Atmospheric Administration's National Climatic Data Center at Asheville, North Carolina. These papers, "Historical Sunshine Data in the United States" ( $P$. J. Young. F. T. Quinlan, and T. R. Karl) and "United States Historical Climatology Network (HCN) Serial Temperature and Precipitation Data" (F. T. Quinlan, T. R. Karl, and C. N. Williams, Ir.), demonstrate the work being done on the United States Historical Climatology Network data (the time series of temperature, precipitation, and sunshine) in the United States. These two papers have been published previously; accordingly, we present them here in that format. 
"Climate Patlerns in China and II.S." by W.-C. Wang, B. Ronberg, and D. Portman of Amospheric and lenvironmental Research, Ine., speaks of climate variability on a regional scale being much larger than that hased on averages of global-wide data and therefore being more difficult to predict. The (hina Precipitation Proxy Index covers a period of 510 years. This permits comparison of contemporary climate patterns (i.e. the last 100 years) with the period of the little lee Age, when the mean lemperature over (hina was 2 " colder than present. "The Shift of the climate /one and Boundaries of Animals and Plants in (hina During Ilistorical limes," by (ioola ciong, P. Khang, and J. Khang, is fascinating documentation of the effects of elimate change upon the wild elephant whose habitat has shifted from as far north as Beijing in historical times to its current habitat, a small, sequestered section in the southwest cormer of the country.

The final paper of this series, "( 11 , Flux from Biogas (ienerators and Rice Paddies as Measured in Sichuan, (hina," is the joint work of the Institute of Atmospheric Physics of Beijing and the lnstitute of Amospheric Physics at the oregon (iraduate (enter all Beaverton, Oregon (M. X. Wang $\mid(\wedge S|A P|, H . \wedge . K$. Khalil, and R. A. Rasmussen) and demonstrates the pragmatic exchange of both data and technical assistance between the two countries.

\section{Workshop on Sea Level Rise and Coastal Processes} (1)OE/NBB-0086, March 1989)

\section{A. J. Mchta, and R. M. Cushman (eds.)}

The possibility in the coming decaldes of a higher rate of relative sea-level rise globally is now thought to be sufticiently great to warrant serious consideration for its potential implications to human populations. However, the complexities of shoreline response to sea-level rise are contingent on a wide range of interelationships between physical and ecological lactors. The question of how shorelines and shore environments will change with sea-level rise must ultimately focus on our capability to predict such changes, which in turn requires an understanding of the processes involved and availability of data.

As a lirst step, the liniversity of lilorida (LF) undertook a study during the summer of 1987 , which resulted in a report, "Some considerations on Coastal Processes Relevant to Sea Level Rise," by Ashish Mehta, Robert Dean, William Dally. and (lay Montague. In this report, the effects of potential sea-level rise on the shoreline and shore environment were brictly examined by considering the interactions between sea-level rise and coastal processes.

Considerations amply demonstrated the complexities of the interaction between sea-level change and loose-boundary shoreline, their site-specificity, and the inadequacy of inundation models. It was concluded that, with some minor exceptions, the basic knowledge of coastal processes including hydrodynamics, sedimentary processes, and their interaction, and the available data base are inadequate fore predictive modeling. Apart from difficulties in modeling boundary layer turbulence and associated mixing processes. sediment transport formulations recpuire knowledge of a host of free coefficients that tend to be highly site-specific and, therefore, difficult to evaluate in the complex coastal enviromment. Besides further improvements in theory, and the need for better definition of wave forcing through adequate long-term monitoring of the coastal wave field via field measurement is emphasized. 
To critique the conclusions of the UF report and to reach a broader agreement on research needs to vastly improve the capability to predict shoreline response, the "Workshop on Sea Level Rise and Coastal Processes" was held at Palm Coast, Florida. on March 9-11, 1988. The report on the workshop includes a version of the UF report (modified by its authors after the workshop) and an appendix. The appendix contains comments by workshop participants, excluding the authors of the UF report. In addition. the appendix includes the comments of John de Ronde, who was invited to the workshop to present his view of the Dutch experience. which provide in ight into what higher relative sea level might mean worldwide.

Participants comments largely reinforce the conclusions of the UF report through additional illustrative examples, clarifications, and qualifications, in some cases.

\section{$\mathrm{CO}_{2}$ Symposium}

\section{Published by the American Geophysical Union}

This report presents papers given at the symposium held September 14-18, 1981, at the University of Bern. Switzerland. The participants were scientists directly responsible for making atmospheric carbon dioxide measurements or were involved in interpreting these measurements. A large body of new atmospheric $\mathrm{CO}_{2}$ data, supplemented by isotopic and oceanic measurements, were presented at the conference.

\section{Proceedings of the International Conference on Global and Regional Environmental Atmospheric Chemistry} (May 1989)

\section{Newman. W. Wang, and C. S. Kiang (eds.)}

Today, the economy of the People's Republic of China stands at an important turning point because of the open-door policy adopted by that country in 1978. The changes in infrastructure and in attitude toward socialistic modernization that resulted from that shift in policy are having far-reaching consequences on the industrial and agricultural output and the local, regional, and global atmospheric environment. During the past four decades in China, annual grain production (about half of it rice) has increased by a factor of 3 , annual production of coal by a factor of 30 , and annual production of crude oil by a factor of about 900 . These changes have an inescapable influence on the atmosphere, both regional and global. Moreover, the great deserts in western China produce dusts that blow over the Pacific Ocean and may alter the chemistry and radiative processes in the troposphere. This conference, attended by more than 250 scientists and presenting more than 170 papers, was held because China has become such an important source region to the global atmosphere.

Topics covered at this conference include atmospheric chemistry; the greenhouse effect; sea-level rise; atmospheric dynamics and transport; modelling techniques; the biogeochemical cycles of carbon, sulfur, nitrogen, halogens, and trace element $\%$; the effects of sulfur and nitrogen on climate; the ecological effects of airborne chemicals; acid precipitation and deposition processes, detection, and effects; methane sources; polar ozone depletion; atmospheric aerosols; particulate air pollutants; and sandstorms. 
CONF930285

\title{
A Report from the Second U.S.IJapan Workshop on Global Change Research: Environmental Response Technologies (Mitigation and Adaptation)
}

(February 1993)

\author{
Sylvia Edgerton, National Science Foundation
}

Tateki Mizuno, National Institute for Resources and Environment (Japan)

The second U.S.Japan Workshop on Global Change was planned and organized under the aegis of the U.S./Japan Science and Technology (UJST) Agreement. The High-Level Committee for the UJST decided in 1989 to support the conduct of U.S./Japan workshops to encourage joint research on high-priority scientific and technical questions related to global change. The second global change workshop under UJST was hosted by the U.S. Committee on Earth and Environmental Sciences (CEES) on February 1-3, 1993, and held at the EastWest Center, in Honolulu, Hawaii. The subject of the workshop was Environmental Response Technologies (Mitigation and Adaptation).

\section{CONF- 8608144 \\ Proceedings of the International Symposium on Ecological Aspects of Tree Ring Analysis (April 1987)}

G. C. Jacoby, Jr., and J. W. Hornbeck (eds.)

The objective of this proceedings of the meeting is to aid communications within the field of tree-ring analysis, stimulate others to see the potential for even more applications, and serve as a resource for those entering the field.

CONF9006134

\section{Global Climate Feedbacks: Proceedings of the Brookhaven National Laboratory Workshop (June 1990)}

\section{B. Manowitz (ed.)}

The present General Circulation Models (GCMs) do not model important feedbacks, including those from clouds, oceans, and land processes. The purpose of this workshop was to identify such potential feedbacks, to evaluate the uncertainties in the feedback processes (and, if possible, to parameterize the feedback processes so that they can be treated in a GCM), and to recommend research programs that will reduce the uncertainties in important feedback processes.

The following papers were presented:

"Observational Determination of the Greenhouse Effect," A. Raval and V. Ramanathan

"Interpretation of Cloud-Climate Feedback as Produced by 14 Atmospheric General Circulation Models," R. D. Cess

"Cloud Parameterization," D. A. Randall

"Comments on Atmospheric Feedbacks," A. Heymsfield 
"Atmospheric Feedbacks: Comments," S. E. Schwartz.

"Ocean Thermal Transients: A Program of Data Analysis, Modeling and Monitoring of the

Atlantic Ocean Thermohaline Circulation," $K$. Bryan

"Paleo Deep Water Variability: Magnitude and Rapidity," E. A. Boyle

"Role of the Ocean Carbon Cycle in Determining Atmospheric pCO.." J. L. Sarmiento

"Comments on the Problem of Ocean Circulation," C. Wunsch

"Elements of Oceanic $\mathrm{CO}_{2}$ Feedback in Response to Climate Change," T. Takahashi

"Terrestrial Ecosystems and Climatic Change," W. R. Emanuel and D. S. Schimel

"The Response of Ecosystems to Global Change: Research Agenda." F. A. Bazzaz.

"Sea Ice Response to Globai Climate Change," W. D. Hibler III

"Commentary on Sea Ice Feedbacks." R. E. Moritz

\section{Atlas of Simultaneous Occurrence of Different Cloud Types Over the Ocean}

(November 1982) (Reprinted 1990)

\section{J. Hahn, Cooperative Institute for Research in Environmental Sciences}

\section{S. G. Warren, University of Washington}

\section{J. London, University of Colorado}

\section{R. M. Chervin, and R. Jenne, National Center for Atmospheric Research}

The importance of clouds for the earth's radiation budget is receiving a great deal of attention in current atmospheric research. This includes both studies of the mechanisms of cloud formation and theoretical and experimental work on radiative properties of clouds. Recognition of the importance of clouds for global and regional climate has led to the plan for the International Satellite Cloud Climatology Project (ISCCP). Preparation for the five-year project is now under way, in that the methods for obtaining cloud information from satellite radiation ohservations are being developed. This atlas of co-occurrence of different cloud types over the ocean is expected to aid in the development of these methods by providing ground-based data for comparison with satellite observations. It should also assist the development of cloudgeneration schemes in climate models.

Cloud observations from ships are used to investigate the co-occurrence of different cloud types and the geographical and seasonal variation of these co-occurrences. Ground-based observations are used because they provide a more definitive identification of clouds by type than do satellite observations. The clouds are grouped into six types (cirrus-type clouds, altostratus + altocumulus, nimbostratus, cumulus, stratus + stratocumulus, and cumulonimbus). The results are expressed as contingency probabilities; that is, given that one cloud type is present, the probability that another particular type is also present is computed. Since higher clouds are detectable only when the lower clouds are not overcast, a procedure is developed to remove the resulting bias is computing the co-occurrence probabilities. Thus both upward-directed (e.g., cumulus implies cirrus) and downward-directed (e.g., cirrus implies cumulus) contingency probabilities should be reasonably accurate. Maps of these quantities, as well as of the overall frequency of occurrence of each cloud type, of fog, and of clear sky, are presented at $15^{\circ}$ latitude by $30^{\circ}$ longitude resolution. These contingency probabilities should be useful for testing cloud-generation algorithms in general circulation models and for interpretation of cloud observations from satellites. 


\title{
NCAR/TN- Atlas of Simultaneous Occurrence of Different Cloud Types Over $241+$ STR Land
}

(August 1984) (Reprinted 1990)

\section{J. Hahn, Cooperative Institute for Research in Environmental Sciences}

\author{
S. G. Warren, University of Washington
}

\section{J. London, University of Colorado}

R. M. Chervin, and R. Jenne, National Center for Atmospheric Research

This is the second of a series of atlases to be published as part of an extensive study of the global cloud climatology from ground-based observations. This first atlas, published as NCAR/TN-201 + STR, described the observed simultaneous occurrence of different cloud types over the oceans. The prestnt atlas covers a similar analysis of cloud observations over the land. The classification and grouping of cloud types, and the general methodology of determining different cloud type co-occurrences was discussed in the first atlas, and the reader is referred to that atlas for details of the procedures used. Additional discussion is contained in the present atlas to describe those cases where a different procedure was followed either as an improvement, or to fit the different circumstances under which land-based cloud observations are made.

The current cloud climatology study is part of the International Satellite Cloud Climatology Program (ISCCP) and will provide a complementary data set for evaluating and validating results from the First ISCCP Regional Experiment (FIRE) and subsequent field experiments.

\section{The Global Carbon Cycle (January 1991)}

\section{Carbon Dioxide Research Program, U.S. Department of Energy}

This reprint from the Canadian Journal of Forest Research features research directed through Oak Ridge National Laboratory's Center for Global Environmental Studies, Environmental Sciences Division.

Featured articles and contributing researchers include:

"Estimating the effects of land-use change on global atmospheric $\mathrm{CO}_{2}$ concentrations," by V. H. Dale, R. A. Houghton, and C. A. S. Hall;

"Historical analysis of changes in land use and carbon stock of vegetation in south and southeast Asia," by E. P. Flint and J. F. Richards;

"Biomass of tropical forests of south and southeast Asia," by S. Brown, A. J. R. Gillespie, and A. E. Lugo;

"Refining estimates of carbon released from tropical land-use change," by C. A. S. Hall and J. Uhlig; and

"Releases of carbon to the atmosphere from degradation of forests in tropical Asia," by R. A. Houghton. 


\section{Our Changing Planet: The FY 1991 Research Plan (October 1990)}

\section{Committee on Earth and Environmental Sciences Office of Science and Technology Policy}

The scientific objectives of the research plan are to observe, understand, and ultimately predict global change. The report outlines a priority framework for coordinating and integrating the agency research efforts to ensure that they meet these objectives. This priority framework was derived from numerous research outlines developed in both the United States. and international communities. It emphasizes research areas where improved understanding of both natural and human-induced global changes is of greatest importance. The scope of the plan, as outlined in this document, reflects the magnitude and nature of the strong U.S. commitment to contributing to the scientific basis for the challenging and vital decisions required for responsible global stewardship.

\section{Our Changing Planet: The FY 1993 U.S. Global Change Research Program}

\section{Committee on Earth and Environmental Sciences \\ Office of Science and Technology Policy}

- World leaders continue to debate the economic and social implications of global environmental changes, both natural and human-induced.

- An improved predictive understanding of the integrated Earth system, including human interactions, will provide direct benefits by anticipating and planning for possible impacts on commerce, agriculture, energy, resource utilization, human safety, and environmental quality.

- The central goal of the U.S. Global Change Research Program (USGCRP) is to help establish the scientific understanding and the basis for national and international policymaking related to natural and human-induced changes in the global Earth system by

- establishing an integrated, comprehensive, long-term program of documenting the Earth system on a global scale;

- conducting a program of focused studies to improve our understanding of the physical, geological, chemical, biological, and social processes that influence Earth system processes; and

- developing integrated conceptual and predictive Earth system models.

- The highest priority near-term scientific and policy-related issue for the USGCRP is whether, and to what extent, human activities are changing, or will change, the global climate system.

- The President's FY 1993 Budget requests $\$ 1372.4$ million for the USGCRP. This represents and increase of $\$ 262.6$ million, or $24 \%$, over the FY 1992 level. 
- Responding to the most critical scientific uncertainties identified by the Scientific and Impacts Working Groups of the Intergovernmental Panel on Climate Change (IPCC) as the highest priority near-term foci, the FY 1993 USGCRP continues the strategy of using the following four high-priority integrating themes:

Climate Modeling and Prediction

Global Water and Energy Cycles

Global Carbon Cycle

Ecological Systems and Population Dynamics

In addition, the USGCRP continues to support economics research related to global change.

- The FY 1993 USGCRP reflects a restructured Earth Observing System (EOS) consistent with the recommendations of the EOS Engineering Review Committee and includes a small satellite and remotely piloted aircraft effort supported by the Committee on Earth and Environmental Sciences (CEES) agencies.

- The USGCRP also continues support for investigations in stratospheric ozone, human interactions, solid Earth processes, and solar influences.

- The USGCRP has been developed by the CEES of the Federal Coordinating Council for Science, Engineering, and Technology (FCCSET). The CEES has been established in cooperation with the U.S. and international scientific communities through the National Academy of Sciences and the International Council of Scientific Unions, and is linked internationally to other government agencies, to the relevant intergovernmental organizations of the United Nations, and to other governmental and nongovernmental organizations.

\section{Natural Sinks of $\mathrm{CO}_{2}$}

\section{J. Wisniewski, Wisniewski \& Associates, Inc.}

\section{A. E. Lugo, Institute of Tropical Forestry}

Environmental, energy-related and socioeconomic issues associated with carbon dioxide $\left(\mathrm{CO}_{2}\right)$ and other "greenhouse" gases have been debated intensely in political arenas and the scientific community as a result of recent concerns over potential for human-induced changes in the Earth's climate. Because of the complexity of the Earth's systems, the current and long-term interactions between atmospheric $\mathrm{CO}_{2}$ and the complete carbon cycle have yet to be examined in an integrated manner. To evaluate the global carbon budget and the potential for managing the Earth's carbon sinks, a workshop of leading scientists was convened in Palmas Del Mar, Puerto Rico, in February 1992.

The workshop as motivated by needs to (1) understand properties, processes and magnitudes of natural sinks of atmospheric $\mathrm{CO}_{2} ;(2)$ expand the scope of measurements and models to provide a truly interdisciplinary analysis of the global carbon cycle; (3) encourage broad participation (academic, government and private sector) in research that offers solutions to increasing atmospheric $\mathrm{CO}_{2}$; and (4) balance the carbon budget as a basis for better policy making. 
This statement is a synopsis of findings presented at the workshop. New information was presented at the workshop that indicated substantial potential exists for capturing and sequestering carbon in land and water environments. Carbon is being absorbed by natural sinks, and it is economically feasible to manage additional land, soil, and coastal ecosystems with the objective of building carbon stocks.

Note: This is a promotional/descriptive flyer for Kluwer Academic Publishers, publishers of the proceedings of this workshop. This is a summary and should not be construed as an endorsement.

\section{CDIAC Fact Sheets}

\section{Compiled by F. W. Stoss}

Fact sheets are short, descriptive materials promoting the availability of specific information products or services. Fact sheets appearing on this list are periodically updated and new fact sheets are added in response to request-response activities. An order form is provided to request future editions.

ARM Outreach Factsheet gives a brief description of the research and program activities of the U.S. Department of Energy's Atmospheric Radiation Measurement Program. An order form is provided to request future issues. (see p. 13?).

Carbon Dioxide Information Analysis Center (CDIAC) Factsheet gives a brief history and description of CDIAC activities.

CDIAC Communications Factsheet gives a brief description of the newsletter and has an order form to request future issues. (see p. 132).

DOE Research Summary: A Synopsis of DOE-Sponsored Research Factsheet describes the 4-page newsletter that highlights current research funded by DOE's Global Change Research Program. An order form is provided to request future issues. (see p. 132).

Environmental Policy and Impacts to International Commerce and Trade-Selected Resources Factsheet lists publications and organizations for further environmental information.

Glossary: Carbon Dioxide and Climate Factsheet briefly describes the glossary of selected $\mathrm{CO}_{2}$ terms available from CDIAC. (see p. 77 ).

Office of Scientific and Technical Information (OSTI) Factsheet describes a number of information management tools available from them. An order form is provided.

Specialty Newsletters: Global Studies and Climate Change Factsheet is a compilation of newsletters that cover the issues of global change. An order form is provided.

Technical Assistance for Developing Regions Factsheet gives information about two programs established to assist developing regions resolve global environmental problems.

Trends Factsheet describes data in Trends issues from the 1990 inaugural issue to the latest version Trends '91: A Compendium of Data on Global Change. (see p. 78). 


\section{Newsletters}

CDIAC produces and distributes newsletters specific to global change interests. CDIAC maintains a small inventory of back issues primarily for archival purposes. Back issues are available as the supply lasts. New subscriptions to these periodicals can be made by indicating your choice on the order form in this catalog.

CDIAC Communications describes the activities, services, information products, and publications of CDIAC and those related to the DOE GCRP. The first public announcements of CDIAC's NDPs, CMPs, and other publications is made in this newsletter. Eash issue includes an update of the DOE-sponsored CHAMMP program. (see Factsheet p. 131).

DOE Research Summary is a four-page description of a single DOE-sponsored research project. These newsletters are written by the principle investigators for research projects in progress or near completion. (see Factsheet p. 131).

Arm Outreach provides an overview and update of services and products of the ARM Program. (see Factsheet p. 131). 
Author Index 
Page

32 The Impact of Climate Change from Increased Atmospheric

Achutuni, R.

Carbon Dioxide on American Agriculture

43 The Use of Statistical Climate-Crop Models for Simulating

Yield to Project the Impacts of $\mathrm{CO}$. Induced Climate Change

112 A Computer-Based Atlas of Global Instrumental Climate Data

Ahern, L. G.

115 Field Studies of Sweet Potatoes and Cowpeas in Response to Elevated Carbon Dioxide, 1985

Allen, J. R.

46 Effects of Air Temperature on Atmospheric $\mathrm{CO}_{2}$-Plant (irowth Relationships

Allen, L. H., Jr.

115 Effects of Increased Carbon Dioxide on Photosynthesis and Agricultural Productivity of Soybeans, 1981

46 Effects of Air Temperature on Almospheric $\mathrm{CO}_{2}-$ Plant Growth Relationships

Allen, S. G.

14 Carbon in Live Vegetation of Major World Ecosystems

Allison, L. J.

76 Environmental Atlas of the lowa-Kansas-Missouri-Nebraska

Climate-Change Study Region

91 Major World Ecosystem Complexes Ranked by Carbon in live Vegetation: A Database

111 The ALE/GAGE/AGAGE Network

Alyea, $\mathrm{F}$.

$123 \quad \mathrm{CO}_{2}$ Symposium

American

60 Intercomparison of Radiation Codes in Climate Models Geophysical Union

46 Effects of Air Temperature on Atmospheric $\mathrm{CO}_{2}$-Plant Growth Relationships

Anderson, M. G.

96 Global, Regional, and National $\mathrm{CO}_{2}$ Emission Estimates from

Fossil Fuel Burning, Cement Production, and Gas Flaring: 1950 1991

Andres, $\mathrm{R}$.

87 Annual and Seasonal Global Temperature Anomalies

in the Troposphere and Low Stratosphere, 1958-1992

Angell, J. K.

94 Annual and Seasonal Global Variation in Total Ozone and Layer-Mean Ozone, 1958-1986

101 Daily Temperature and Precipitation Data for 223 U.S.S.R. Stations

Apasova, E. G. 
Page

47 Modeling $\mathrm{pCO}_{2}$ in the Upper Ocean: A Review of Relevant Physical,

Archer, D.

Chemical, and Biological Processes

III ICRCCM Infrared (Clear-Sky) Line-by-Line Radiative Fluxes

Arking, A.

45 A Preliminary Analysis of U.S. $\mathrm{CO}_{2}$ Emissions Reduction

Ashton, W. B. Potential from Energy Conservation and the Substitution of Natural Gas for Coal in the Period to 2010

57 Atmospheric Radiation Measurement Program Plan

57 Atmospheric Radiation Measurement Program Plan Executive Summary

67 Building an Advanced Climate Model (Program plan for the CHAMMP Climate Modeling Program)

58 Identification, Recommendation, and Justification of Potential Locales for ARM Sites

57 Identification, Recommendation, and Justification of Potential Locales for ARM Sites, Executive Summary

24 A Two Dimensional $\mathrm{CO}_{2}$-Ocean Model Including the Biological Processes

46 Effects of Air Temperature on Atmospheric $\mathrm{CO}_{2}$-Plant Growth Relationships

12 Alaskan Historical Climatology Network (HCN) Serial Temperature and Precipitation Data

Baldwin, R. G.

18 Historical Carbon Dioxide: Abundances Derived from the Sinithsonian Spectrobolograms

Barnard, J. C

33 High Accuracy Standards and Reference Methodology for Carbon Dioxide in the Air

Barnes, I. L.

45 An Evaluation of the Relationship between the Production

Barns, D. W. and Use of Energy and Atmospheric Methane Emissions

13 On Possible Changes in Global Sea Level and Their Potential Causes

Barnett, T. P.

73 Bibliography on Tropical Rain Forests and the Global Carbon Cycle. Vol. I. An Introduction to the Literature

Barshaw, D.

25 The Effect of Elevated Atmospheric $\mathrm{CO}_{2}$ on Plant Communities

Bazzaz, F. A. 
Page

87 Atmospheric $\mathrm{CO}_{2}$ Concentrations The CSIRO (Australia)

Beardsmore, D. J

Monitoring Program from Aircraft for 1972.1981

88 Atmospheric CO. Concentrations The (SIKO Monitoring

Program: Surface Data for Cape (irim. Tasmania

30 Eifects of Energy Technology on (ilobal $\mathrm{CO}_{2}$ Emissions

Beller, M

115 Ficld Studies of Sweet Potatoes and Cowpeas in Response

to Hevated Carbon Dioxide, 1985

Bhattacharya, N. C.

115 Field Studies of Plant Responses to Lilevated Carbon Dioxide

Levels, 1980

Bingham, G. E

99 Gilobai (ieographic Information System Data Base of

Birdwell, K. R.

Storm Occurrences and Other Climatic Phenomena

Affecting Coastal Zones

115 Field Studies of Sweet Potatoes and Cowpeas in Response

to Klevated Carbon Dioxide, 1985

Biswas, P. K.

16 Response of the North American Corn Belt to Climate Warming

Blasing, T. J.

85 Tree Ring Chronology Indexes and Reconstructions of

Precipitation in Central lowa, USA

106 CDIAC"s Numeric Data Package Collection: Selected Data Sets

Boden, T. A.

Relevant to Studies of Greenhouse Gases and Climate (CD-ROM)

96 Global, Regional, and National $\mathrm{CO}_{2}$ Emission listimates from

Fossil Fuel Burning, Cement Production, and Gas Flaring: 1950-1991

78 Trends '9/: A Compendium of Data on Global Change

78 Trends '9/: A Compendium of Data on Gilobal Change -..Highlights

81 CDIAC Catalog - Numeric Data Packages and Computer

Model Packages

73 Bibliography on Tropical Rain Forests and the Global Carbon Cycle

Vol. 1. An Introduction to the Literature

Bogdonoff, P. B.

115 Effects of Increased Carbon Dioxide on Photosynthesis and

Agricultural Productivity of Soybeans, 1981

Boote, K. J.

90 Surface Air Temperature Anomalies for the Northern Hemisphere:

The Russian Dataset

Borzenkova, I. I. 
Page

50 Processes for Identifying Regional Influences of and Responses

Bowes, M. to Increasing Atmospheric $\mathrm{CO}_{2}$ and (limate (hange

The MINK Project. Repont I Background and Baselines

51 Processes for Identifying Regional Influences of and Responses to Increasing Atmospheric $\mathrm{CO}_{2}$ and (limate Change

The MINK Project. Report III Forest Resources

52 Processes for Identifying Regional Influences of and Responses to Increasing Atmospheric $\mathrm{CO}_{2}$ and Climate Change The MINK Project. Report VI-Consequences of Climate Change for the MINK Economy: Impacts and Responses

22 A Climatic Data Bank for Northern Hemisphere Iand Areas, 185/-1980

Bradley, R. S

89 Climatic Data for Northern Hemisphere Land Areas, 1851-1980

49 A Comprehensive Precipitation Data Set for Cilobal land Areas

112 A Computer-Based Atlas of Global Instrumental Climate Data

85 Global Surface Air Temperature Variations: 1851-1984

25 A Grid Point Surface Air Temperature Data Set for the Northern Hemisphere

92 An Updated Global Grid Point Surtace Air Temperature Anomaly Data Set: $1851-1990$

36 Uncertainty in Future Global Energy Use and Fossil Fuel CO. Emissions 1975 to 2075

86 Transient Tracers in the Oceans (TTO) Hydrographic Data and Carbon Dioxide Systems With Revised (arbon Chemistry Data

Brewer, P. G

37 Monthly Mean Pressure Reconstructions for Lurope (Back to 1780) and North America (To 18.58)

Briffa, K. R

94 Monthly Mean Pressure Reconstructions for Europe (1780 1980) and North America (1858 1980)

23 Carbon Dynamics of Northern Hardwood Forests: Gas Exchange Characteristics

Briggs, G. M

24 Recunstruction of Past Atmospheric $\mathrm{CO}$. Contents from the Chemistry of the Contemporary Ocean: An Evaluation

Broecker, W. S.

97 Atmospheric $\mathrm{CO}_{2}$ Concentrations Derived from Flask Samples Collected at U.S.S.R-Operated Sampling Sites

Brounshtein, A. M. 
Page

102 United States Mistorical Climatolog! Notwork Daily

Brower, W. A

Temperature and Precipitation Data

Brown, S

73 Bibliography on Tropical Rain Forests and the Global Carbon

Cycle. Vol. I. An Introduction to the literature

112 Alaskan Historical Climatology Network (HCN) Serial

Temperature and Precipitation Data

Burgin, M. G

81 Selected Translated Abstracts of Russian-Language Climatc-

Burtis, M. D

Change Publications. I. Surface Energy Budget

82 Selected Translated Abstracts of Russian-l anguage

Climate-Change Publications. II. Clouds

115 Effects of Increased Carbon Dioxide on Photosynthesis and

Campbell, W. J

Agricultural Productivity of Soybeans, 1981

119 A Comprehensive Plan for Carbon Dioxide Effects. Research and Assessment-Part 1: The Global Carbon Cycle and Climatic Effects of Increasing Carbon Dioxide

76 Catalog of Data Bases and Reports

Carbon Dioxide Information

77 Glossary: Carbon Dioxide and Climate

Analysis Center

$132 \quad$ Newsletters

3 The Carbon Dioxide Research Plan: A Summary

Carbon Dioxide

Research Division

4 Carbon Dioxide and Climate: Summaries of Research

in FY 1983 and FY 1984

4 Carbon Dioxide and Climate: Summaries of Research in FY 1985

4 Carbon Dioxide and Climate: Summaries of Research in FY 1986

4 Carbon Dioxide and Climate: Summaries of Research in FY 1987

5 Carbon Dioxide and Climate: Summaries of Research in FY 1988

5 Carbon Dioxide and Climate: Summaries of Research in FY 1989

Carbon Dioxide

5 Carbon Dioxide and Climate: Summaries of Research in FY 1990

Research Program

5 Carbon Dioxide and Climate: Summaries of Research in FY 1991 
Page

66 Atmospheric Carbon Dioxide and the Greenhouse Effect

126 The Global Carbon Cycle

Research Program

(continued)

79 Climate Change and Water Supply, Management

Chang, L. H. and Use: Literature Review

59 Quantifying and Minimizing Uncertainty of Climate Forcing

Charlson, R. J. by Anthropogenic Aerosols

27 Carbonate Chemistry of the Bering Sea

Chen, C.-T. A.

34. Carbonate Chemistry of the North Pacific Ocean

96

17. Carbonate Chemistry of the Weddell Sea

95

29 Preliminary Data Report for the INDIVAT Number $I$ and INDIGO I/INDIVAT 3 Cruises in the Indian Ocean

53 Modeling the Response of Plants and Ecosystems to Elevated Chen, J $\mathrm{CO}_{2}$ and Climate Change

43 Documentation of IAP Two-Level Atmospheric General Circulation Model

30 Effects of Energy Technology on Global $\mathrm{CO}_{2}$ Emissions

Cheng, H. C

21 A Systems Study for the Removal, Recovery and Disposal of Carbon Dioxide from Fossil Fuel Power Plants in the U.S.

45 A Preliminary Analy'sis of U.S. CO, Emissions Reduction Potential from Energy Conservation and the Substitution of Natural Gas for Coal in the Period to 2010

25 A Grid Point Surface Air Temperature Data Set for the Northern Hemisphere

Cherry, B. S. G

27 A Grid-Point Surface Air Temperature Data Set for the Southern Hemisphere

92 An Updated Global Grid Point Surface Air Temperature Anomaly Data Set: 1851-1990 
Page

126 Atlas of Simultaneous Occurrence of Different Cloud Types Over Land

Chervin, R. M.

125 Atlas of Simultaneous Occurrence of Different Cioud Types Over the Ocean

94 Climatological Data for Clouds Over the Globe from Surface Observations

64 Global Distribution of Total Cloud Cover and Cloud Type Amounts Over Land

66 Global Distribution of Total Cloud Cover and Cloud Type Amounts Over the Ocean

68 Review of Carbon Dioxide Research Staffing and Academic Support

Clark, S. B.

111 ICRCCM Infrared (Clear-Sky) Line-by-Line Radiative Fluxes

115 Field Studies of Sweet Potatoes and Cowpeas in Response to Elevated Carbon Dioxide, 1985

Clough, T.

Coleman, K. B.

127 Our Changing Planet: The FY 1991 Research Plan

127 Our Changing Planet: The FY 1993 U.S. Global Change Research Program

86 Atmospheric $\mathrm{CO}_{2}$ Concentrations-The NOAA/GMCC Flask and Continuous Sampling Network

\section{Committee on Earth and Environmental Sciences}

111 The ALE/GAGE/AGAGE Network

Crawford, A.

49 Processes for Identifying Regional Influences of and Responses to Increasing Atmospheric $\mathrm{CO}_{2}$ and Climate Change-The MINK

Crosson, P. R. Project. An Overview

50 Processes for Identifying Regional Influences of and Responses to Increasing Atmospheric $\mathrm{CO}_{2}$ and Climate Change--The MINK Project. Report I-Background and Baselines

50 Processes for Identifying Regional Influences of and Responses to Increasing Atmospheric $\mathrm{CO}_{2}$ and Climate Change-The MINK Project. Report IIA-Agricultural Production and Resource Use in the MINK Region Without and With Climate Change 
Page

52 Processes for Identifying Regional Influences of and Responses to Increasing Atmospheric $\mathrm{CO}_{2}$ and Climate Change-The MINK

Crosson, P.R. (continued) Project. Report VI--Consequences of Climate Change for the MINK Economy: Impacts and Responses

111 The ALE/GAGE/AGAGE Network

Cunnold, D.

63 Direct Effects of Increasing Carbon Dioxide on Vegetation Field Studies of Plant Responses to Elevated Carbon Dioxide Levels, 1980

Cure, J. D.

115 Field Studies of Plant Responses to Elevated Carbon Dioxide Levels, 1980

80 Adapting to Sea-Level Rise in the U.S. Southeast:

Cushman, R. M. The Influence of Built Infrastructure and Biophysical Factors on the Inundation of Coastal Areas

Environmental Atlas of the lowa-Kansas-Missouri-Nebraska ClimateChange Study Region

Environmental Consequences of $\mathrm{CO}_{2}$-Climate Interactions:

The Need for Integrated Resource Analysis

122 Workshop on Sea Level Rise and Coastal Processes

3 Carbon Cycle Research Plan

Dahlman, R. C.

119 Carbon Dioxide Research Progress Report

3 Vegetation Response to Carbon Dioxide Research Plan

80 Adapting to Sea-Level Rise in the U.S. Southeast:

Daniels, R. C. The Influence of Built Infrastructure and Biophysical Factors on the Inundation of Coastal Areas

99 Global Geographic Information System Data Base of Storm Occurrences and Other Climatic Phenomena Affecting Coastal Zones

50 Processes for Identifying Regional Influences of and Responses to Increasing Atmospheric $\mathrm{CO}_{2}$ and Climate Change-The MINK Project Report I--Background and Baselines

51 Processes for Identifying Regional Influences of and Responses to Increasing Atmospheric $\mathrm{CO}_{2}$ and Climate Change-The MINK Project Report $\mathrm{V}$-Energy 
Page

32 The Impact of Climate Change from Increased Atmospheric Carbon Dioxide on American Agriculture

Decker, W. L.

43 The Use of Statistical Climate-Crop Models for Simulating

Yield to Project the Impacts of $\mathrm{CO}_{2}$ Induced Climate Change

22 A Climatic Data Bank for Northern Hemisphere Land Areas, 1851-1980

Diaz, H. F.

89 Climatic Data for Northern Hemisphere Land Areas, 1851-1980

49 A Comprehensive Precipitation Data Set for Global Land Areas

85 Global Surface Air Temperature Variations: 1851-1984

25 A Grid Point Surface Air Temperature Data Set for the Northern Hemisphere

92 An Updated Global Grid Point Surface Air Temperature Anomaly Data Set: 1851-1990

52 The Determination of Total Dissolved Inorganic Carbon in Sea Water Using Extraction/Coulometry: The First Stage of a Collaborative Study

68 International Carbon Dioxide-Related Activities: The International Organizations Involved and U.S. Bilateral Arrangements

67 Computer Hardware, Advanced Mathematics and Model Physics (CHAMMP) Pilot Project Final Report

Dickson, A. G.

Dougher, $\mathrm{R}$.

Drake, J.

79 Climate Change and Water Supply, Management

Draves, J. D. and Use: Literature Review

76 Environmental Atlas of the Iowa-Kansas-Missouri-Nebraska Climate-Change Study Region

85 Tree Ring Chronology Indexes and Reconstructions of Precipitation in Central lowa, USA

Duvick, D. N.

120 Workshop on Oceanic $\mathrm{CO}_{2}$ Standardization

Dyrssen, D.

112 Alaskan Historical Climatology Network (HCN) Serial Temperature and Precipitation Data

Easterling, W. E. III 
Page

50 Processes for Identifying Regional Influences of and Responses to Increasing Atmospheric $\mathrm{CO}_{2}$ and Climate Change-The

MINK Project. Report I-Background and Baselines

50 Processes for Ideritifying Regional Influences of and Response to Increasing Atmospheric $\mathrm{CO}_{2}$ and Climate Change-The MINK Project. Report IIB-A Farm-Level Simulation of the Effects of Climate Change on Crop Production in the MINK Region

115 Field Studies of Sweet Potatoes and Cowpeas in Response to Elevated Carbon Dioxide, 1985

Eatman, J. F.

124 A Report from the Second U.S./Japan Workshop on Global Change Research: Environmental Response Technologies (Mitigation and Adaptation)

20 An Analysis of Possible Future Atmospheric Retention of Fossil Fuel $\mathrm{CO}_{2}$

Edmonds, J. A.

45 An Evaluation of the Relationship between the Production and Use of Energy and Atmospheric Methane Emissions

106 The IEA/ORAU Long-Term Global Energy $\mathrm{CO}_{2}$ Model

106 The IEA/ORAU Long-Term Global Energy $\mathrm{CO}_{2}$ Model: Personal Computer Version A84PC

45 A Preliminary Analysis of U.S. $\mathrm{CO}_{2}$ Emissions Reduction Potential Conservation and the Substitution of Natural Gas for Coal in the Period to 2010

39 A Primer on Greenhouse Gases

36 Uncertainty in Future Global Energy Use and Fossil Fuel $\mathrm{CO}_{2}$ Emissions 1975 to 2075

49 A Comprehensive Precipitation Data Set for Global Land Areas

Eischeid, J. K.

102 The Global Historical Climatology Network: Long-Term Monthly Temperature, Precipitation, Sea Level Pressure, and Station Pressure Data

33 High Accuracy Standarus and Reference Methodology for Carbon Dioxide in the Air

Elkins, J.W.

119 Carbon Dioxide Research Progress Report

Elliot, W. 
Page

88 Growth and Chemical Responses to $\mathrm{CO}_{2}$ Enrichment-Virginia Pine (Pinus Virginiana Mill.)

18 Computer Implementation of a Globally Averaged Model of the World Carbon Cycle

91 Worldwide Organic Soil Carbon and Nitrogen Data

8 Atmospheric Chemistry Program-Program Operation Plan

7 Atmospheric Sciences Program Summaries of Research in FY 1992

9 Atmospheric Sciences Program Summaries of Research in FY 1993

6 Global Change Research: Summaries of Research in FY 1992

9 Global Change Research: Summaries of Research in FY 1993

$5 \quad$ Multi-Year Strategic Plan for the Atmospheric Studies in Complex Terrain (ASCOT) Program

8 Overview of the DOE Atmospheric Chemistry Program's Ozone Project

58 The Possible Direct Use of Satellite Radiance Measurements by the Atmospheric Radiation Measurement Program

58 Proceedings of the Second Atmospheric Radiation Measurement (ARM) Science Team Meeting

97 Atmospheric $\mathrm{CO}_{2}$ Concentrations Derived from Flask Samples Collected at U.S.S.R-Operated Sampling Sites

64 Master Index for the Carbon Dioxide Research State-of-the-Art Report Series

75 Environmental Consequences of $\mathrm{CO}_{2}$-Climate Interactions: The Need for Integrated Resource Analysis

34, Carbonate Chemistry of the North Pacific Ocean

96
Ells, J. M.

Emanuel, W. R.

Environmental Sciences

Division, U.S. DOE
Farber, E. V.

Farrell, M. P.

Feely, R. A. 
Page

74 Bibliography on Tropical Rain Forests and the Global Carbon Flint, E. P. Cycle. Vol. 2. South Asia

105 Historic Land Use and Carbon Estimates for South and Southeast Asia: 1880-1980

111 ICRCCM Infrared (Clear-Sky) Line-by-Line Radiative Fluxes

Fomin, B.

67 Computer Hardware, Advanced Mathematics and Model Physics

Foster, 1 (CHAMMP) Pilot Project Final Report

111 The ALE/GAGE/AGAGE Network

Fraser, $P$.

50 Processes for Identifying Regional Influences of and Responses to Frederick, K. D. Increasing Atmospheric $\mathrm{CO}_{2}$ and Climate Change-The MINK Project Report I-Background and Baselines

51 Processes for Identifying Regional Influences of and Responses to Increasing Atmospheric $\mathrm{CO}_{2}$ and Climate Change--The MINK Project Report IV-Water Resources

111 ICRCCM Infrared (Clear-Sky) Line-by-Line Radiative Fluxes

Freidenreich, S.

53 Climate Data Bases of the People's Republic of China 1841-1988

Fu, C.

101 Two Long-Term Instrumental Climatic Data Bases of the People's Republic of China

25 The Effect of Elevated Atmospheric $\mathrm{CO}_{2}$ on Plant Communities

Garbutt, K.

26 Methods of Uncertainty Analysis for a Global Carbon Dioxide Model

Gardner, R. H.

36 Uncertainty in Future Global Energy Use and Fossil Fuel $\mathrm{CO}_{2}$

Emissions 1975 to 2075

120 Some Aspects of the Role of the Shallow Ocean in Global Carbon

Garrels, R. M. Dioxide Uptake

23 Carbon Dynamics of Northern Hardwood Forests: Gas Exchange Characteristics

Gates, D. M.

34, Carbonate Chemistry of the North Pacific Ocean

Gendron, J. F. 96

115 Field Studies of Sweet Potatoes and Cowpeas in Response to Elevated Ghosh, P. P. Carbon Dioxide, 1985 
22 A Climatic Data Bank for Northern Hemisphere Land Areas, 1851-1980

Goodess, C. M.

89 Climatic Data for Northern Hemisphere Land Areas, 1851-1980

25 A Grid Point Surface Air Temperature Data Set for the Northern Hemisphere

27 A Grid-Point Surface Air Temperature Data Set for the Southern Hemisphere

92 An Updated Global Grid Point Surface Air Temperature Anomaly Data Set: 1851-1984

80 Adapting to Sea-Level Rise in the U.S. Southeast: The Influence

Gornitz, V. M. of Built Infrastructure and Biophysical Factors on the Inundation of Coastal Areas

103 A Coastal Hazards Data Base for the U.S. East Coast

103 A Coastal Hazards Data Base for the U.S. Gulf Coast

29 Preliminary Data Report for the INDIVAT Number 1 and INDIGO $1 /$

INDIVAT 3 Cruises in the Indian Ocean

Goyet, C.

99 Indian Ocean Radiocarbon: Data from the INDIGO 1, 2, and 3 Cruises

Grall, C.

119 Carbon Dioxide Research Progress Report

Gross, T.

28 Definition and Characterization of Data Needs to Describe the

Grosse, D. J.

Potential Effects of Increased Atmospheric $\mathrm{CO}_{2}$ on Marine

Fisheries from the Northeast Pacific Ocean

40 Regional Intercomparisons of General Circulation Model

Predictions and Historical Climate Data

Grotch, S. L.

Surface Air Temperature Anomalies for the Northern Hemisphere:

The Russian Dataset

Gruza, G. V.

100 Carbon Dioxide Enrichment: Data on the Response of Cotton to Varying $\mathrm{CO}_{2}$, Irrigation, and Nitrogen

Guinn, G.

47 Simulating Climate with Two Different Numerical Schemes

Gutowski, W. J.

41 Surface Energy Balance of Three General Circulation Models:

Current Climate and Response to Increasing Atmospheric $\mathrm{CO}_{2}$

41 Surface Energy Balance of Three General Circulation Models:

Gutzler, D. S. Current Climate and Response to Increasing Atmospheric $\mathrm{CO}_{2}$ 
Page

59 Quantifying and Minimizing Uncertainty of Climate Forcing

Hales, J. M. by Anthropogenic Aerosols

126 Atlas of Simultaneous Occurrence of Different Cloud Types Over Land

Hahn, C. J.

125 Atlas of Simultaneous Occurrence of Different Cloud Types Over the Ocean

94 Climatological Data for Clouds Over the Globe from Surface Observations

64 Global Distribution of Total Cloud Cover and Cloud Type Amounts Over Land

66 Global Distribution of Total Cloud Cover and Cloud Type Amounts Over the Ocean

32 A Comparison of Tropical Forest Surveys

Hall, C. A. S.

73 Bibliography on Tropical Rain Forests and the Global Carbon Cycle. Vol. I. An Introduction to the Literature

53 Modeling the Response of Plants and Ecosystems to Elevated $\mathrm{CO}_{2}$ and Climate Change

Harley, P. C.

100 Carbon Dioxide Enrichment: Data on the Response of Cotton to Varying $\mathrm{CO}_{2}$, Irrigation, and Nitrogen

Harris, S. M.

45 Global Lake-Level Variations from 18,000 to 0 Years Ago:

A Palaeoclimatic Analysis

Harrison, S. P.

35 An Annotated Inventory of Climatic Indices and Data Sets

Hattemer-Frey, H. A.

115 Field Studies of Plant Responses to Elevated Carbon Dioxide Levels, 1980

Heagle, A. S.

115 Field Studies of Plant Responses to Elevated Carbon Dioxide Levels, 1980

Heck, W. W.

102 The Global Historical Climatology Network: Long-Term

Heim, R. Monthly Temperature, Precipitation, Sea Level Pressure, and Station Pressure Data

53 Modeling the Response of Plants and Ecosystems to Elevated $\mathrm{CO}_{2}$ and Climate Change

Hilbert, D. W.

Hobbie, J. E. 
Page

21 A Systems Study for the Removal, Recovery and Disposal of Carbon Horn, $F$ Dioxide from Fossil Fuel Power Plants in the U.S.

124 Proceedings of the International Symposium on Ecological Aspects of Tree Ring Analysis

Hornbeck, J.W.

15 Deforestation Measured by LANDSAT: Steps Toward a Method

Houghton, R. A.

68 Review of Carbon Dioxide Research Staffing and Academic Support

Howard, L.

90 Solar Records: The Wolf Sunspot Index and Umbral/Penumbral Ratio

Hoyt, D. V.

33 High Accuracy Standards and Reference Methodology for Carbon

Dioxide in the Air

112 Alaskan Historical Climatology Network (HCN) Serial

Temperature and Precipitation Data

Hughes, P. Y

102 United States Historical Climatology Network Daily

Temperature and Precipitation Data

79 Climate Change and Water Supply, Management and Use: Literature Review

Hunsaker, C. T.

76 Environmental Atlas of the lowa-Kansas-Missouri-Nebraska ClimateChange Study Region

47 Simulating Climate with Two Different Numerical Schemes

lacono, M. J.

111 ICRCCM Infrared (Clear-Sky) Line-by-Line Radiative Fluxes

46 Effects of Air Temperature on Atmospheric $\mathrm{CO}_{2}$-Plant Growth Relationships

121 Proceedings: Carbon Dioxide Research Analysis Conference: Carbon Dioxide, Science, and Consensus

Institute for Energy Analysis

115 Field Studies of Plant Responses to Elevated Carbon Dioxide Levels, 1980

Israel, D. W.

120 Proceedings of the International Meeting on Stable Isotopes in Tree-Ring Research

Jacoby, G.

124 Proceedings of the International Symposium on Ecological Aspects of Tree Ring Analysis

Jacoby, G. C.

77 Documentation and Analysis of a Global $\mathrm{CO}_{2}$ Model Developed by Peng et al.

Jager, H. I. 
Page

126 Atlas of Simultaneous Occurrence of Different Cloud Types

Jenne, R. L. Over Land

125 Atlas of Simultaneous Occurrence of Different Cloud Types Over the Ocean

94 Climatological Data for Clouds over the Globe from Surface Observations

64 Global Distribution of Total Cloud Cover and Cloud Type Amounts Over Land

66 Global Distribution of Total Cloud Cover and Cloud Type Amounts Over the Ocean

65 Antarctic Surges-A Clear and Present Danger?

Jenssen, D.

115 Effects of Increased Carbon Dioxide on Photosynthesis Jones, J.W. and Agricultural Productivity of Soybeans, 1981

97 Antarctic Surface Temperature and Pressure Data Jones, P. D

22 A Climatic Data Bank for Northern Hemisphere Land Areas, 1851-1980

89 Climatic Data for Northern Hemisphere Land Areas, 1851-1980

49 A Comprehensive Precipitation Data Set for Global Land Areas

38 Data Bank of Antarctic Surface Temperature and Pressure Data

85 Global Surface Air Temperature Variations: 1851-1984

93 Global and Hemispheric Annual Temperature Variations Between 1861 and 1988

25 A Grid Point Surface Air Temperature Data Set for the Northern Hemisphere

27 A Grid-Point Surface Air Temperature Data Set for the Southern Hemisphere

37 Monthly Mean Pressure Reconstructions for Europe (back to 1780) and North America (to 1858)

94 Monthly Mean Pressure Reconstructions for Europe (1780-198i) and North America (1858-1980)

92 An Updated Global Grid Point Surface Air Temperature Anomaly Data Set: $1851-1990$ 
Page

115 Effects of Increased Carbon Dioxide on Photos!nthesis and

Jones, P. H

Agricultural Productivity of Soybeans, 1981

32 The Impact of Climate Change from Increased Amospheric

Jones, V. K

Carbon Dioxide on American Agriculture

23 Carbon Dynamics of Northern Hardwood Forests: Gas Exchange

Jurik, T. W

Characteristics

53 Climate Data Bases of the People's Republic of China

Kaiser, D $1841 \ldots 1988$

112 Alaskan Historical Climatology Network (HCN) Serial

Temperature and Precipitation Data

Karl, T. R

35 An Annotated Inventory of Climatic Indices and Data Sets

53 Climate Data Bases of the People's Republic of China

$1841-1988$

90

Climatic Data for Selected U.S. and Canadian Stations, 1941-1980

102 The Global Historical Climatology Network: L.ong-Term

Monthly Temperature, Precipitation, Sea Level Pressure,

and Station Pressure Data

93 Historical Sunshine and Cloud Data in the United States

91 United States Historical Climatology Network (HCN) Serial

Temperature and Precipitation Data

102 United States Historical Climatology Network Daily

Temperature and Precipitation Data

Processes for Identifying Regional Influences of and Responses to

Katz, L. A. Increasing Atmospheric $\mathrm{CO}_{2}$ and Climate Change-The MINK

Project Report I--Background and Baselines

50 Processes for Identifying Regional Influences of and Responses to Increasing Atmospheric $\mathrm{CO}_{2}$ and Climate Change-The MINK

Project Report IIA-Agricultural Production and Resource Use in the MINK Region Without and With Climate Change

73 Bibliography on Tropical Rain Forests and the Global Carbon

Kaufman, E. Cycle. Vol. I. An Introduction to the Literature

85 Atmospheric $\mathrm{CO}_{2}$ Concentrations-Mauna Loa Observatory, Hawaii, 1958-1986.

Keeling, C. D. 
Page

112 A Computer-Based Atlas of Global Instrumental Climate Data

Keimig, F. T.

22 A Climatic Data Bank for Northern Hemisphere Land Areas. $1851 \quad 1980$

Kelly, P. M.

89 Climatic Data for Northern Hemisphere Land Areas, $1851 \quad 1980$

25 A Grid Point Surface Air Temperature Data Set for the Northern Hemisphere

85 Global Surface Air Temperature Variations: $1851 \quad 1984$

92 An Updated Global Grid Point Surface Air Temperature Anomaly Data Set: $1851-1990$

53 Modeling the Response of Plants and Ecosystems to Flevated $\mathrm{CO}_{2}$ and Climate Change

Kemp, P. R.

123 Proceedings of the International Conference on Global

Kiang, C. S. and Regional Environmental Atmospheric Chemistry

Killough, G. G.

18 Computer Implementation of a Globally Averaged Model of the World Carbon Cycle

24 A Two Dimensional $\mathrm{CO}_{2}$-Ocean Model Including the Biological Processes

100 Carbon Dioxide Enrichment: Data on the Response of Cotton to Varying $\mathrm{CO}_{2}$, Irrigation, and Nitrogen

Kimball, B. A.

46 Effects of Air Temperature on Atmospheric $\mathrm{CO}_{2}$-Plant Growth Relationships

Kimball, B. A.

77 Documentation and Analysis of a Global $\mathrm{CO}_{2}$ Model Developed by Peng et al.

King, A. W.

75 A Plan for Intermodel Comparison of Almospheric $\mathrm{CO}_{2}$ Projections with Uncertainty Analysis

112 Alaskan Historical Climatology Network (HCN) Serial Temperature and Precipitation Data

Knight, R. W.

87 Annual and Seasonal Global Temperature Anomalies in the Troposphere

Korshover, J. and Low Stratosphere, $1958-1989$

94 Annual and Seasonal Global Variation in Total Ozone and Layer Mean Ozone, 1958-1989 
Page

100 Carbon Dioxide Enrichment: Data on the Response of Colton

Lakatos, E.A. to Varying $\mathrm{CO}_{2}$. Irrigation, and Nitrogen

Lamb, H. H.

89 Volcanic loading: The Dust Veil Index

LaMorte, R. L.

to Varying $\mathrm{CO}_{2}$, Irrigation, and Nitrogen

100 Amospheric Methane Concentrations The NOAA CMDI

Global Cooperative Flask Sampling Network. 1983 1988

Lang. P. M.

59 Quantifying and Minimizing Uncertainty of Climate Forcing

Laulainen, $\mathrm{N}$. by Anthropogenic Aerosols

53 Modeling the Response of Plants and Ecosystems to

Leadley, P. W. Elevated $\mathrm{CO}_{2}$ and Climate Change

80 Adapting to Sea-Level Rise in the U.S. Southeast:

Lee, S.-C

The Influence of Built Infrastructure and Biophysical

Factors on the Inundation of Coastal Areas

59 Quantifying and Minimizing Uncertainty of Climate Forcing by Anthropogenic Aerosols

Leifer, $R$.

50 Processes for Identifying Regional Influences of and Responses

Lemon, K. M. to Increasing Atmospheric $\mathrm{CO}_{2}$ and Climate Change - The MINK

Project. Report I-Background and Baselines

50 Processes for Identifying Regional Influences of and Responses to Increasing Atmospheric $\mathrm{CO}$, and Climate Change-The MINK Project. Report IIB-A Farm-Level Simulation of the Effects of Climate Change on Crop Production in the MINK Region

43 Documentation of IAP Two-Level Atmospheric General Circulation Model

Liang, X.-Z.

47 Simulating Climate with Two Different Numerical Schemes

38 A Data Bank of Antarctic Surface Temperature and Pressure Data

Limbert, D. W. S

97 Antarctic Surface Temperature and Pressure Data

126 Atlas of Simultaneous Occurrence of Different Cloud Types Over Land

London, J.

Atlas of Simultaneous Occurrence of Different Cloud Types Over the Ocean 
Page

94 Climatological Data for Clouds over the (ilobe from Surface

London, J. Observations

(continued)

64 Global Distribution of Total Cloud Cover and Cloud Type Amounts Over Land

66

Global Distribution of Total Cloud Cover and Cloud Type Amounts

Over the Ocean

17 Seasonal Climate Scenarios for Europe and North America

in a High- $\mathrm{CO}_{2}$, Warmer World

Lough, J. M.

115 Field Studies of Sweet Potatoes and Cowpeas in Response to Elevated Carbon Dioxide, 1985

LU, J. Y.

$128 \quad$ Natural Sinks of $\mathrm{CO}_{2}$

Lugo, A. E.

63 Detecting the Climatic Effects of Increasing Carbon Dioxide

Luther, F. M.

63 Projecting the Climatic Effects of Increasing Carbon Dioxide

21 A Proposed Reference Set of Scenarios for Radiatively

Active Atmospheric Constituents

88 Growth and Chemical Responses to $\mathrm{CO}$, Enrichment ... Virginia

Luxmoore, R. J.

Pine (Pinus Virginiana Mill.)

119 Carbon Dioxide Research Progress Report

MacCracken, M. C.

63 Detecting the Climatic Effects of Increasing Carbon Dioxide

63 Projecting the Climatic liffects of Increasing Carbon Dioxide

21 A Proposed Reference Set of Scenarios for Radiatively Active Atmospheric Constituents

100 Carbon Dioxide Enrichment: Data on the Response of Cotton to Varying $\mathrm{CO}_{2}$, Irrigation, and Nitrogen

MacDonald, $R$.

119 Carbon Dioxide Research Progress Report

Machta, L.

120 Some Aspects of the Role of the Shallow Ocean in Cilobal Carbon Dioxide Uptake

Mackenzie, F. T.

124 Global Climate Feedbacks: Proceedings of the Brookhaven National Laboratory Workshop

Manowitz, B.

45 Global Lake-Level Variations from 18,000 to 0 Years Ago: A Palaeoclimatic Analysis

Marchand, D. S. 
Page

14 Carbon Dioxide Emissions from Fossil Fuels: A Procedure

Marland, G.

for Estimation and Results for 1950-1981

20 The Changing Pattern of Fossil Fuel $\mathrm{CO}_{2}$ Emissions

96 Global, Regional, and National $\mathrm{CO}_{2}$ Emission Estimates from

Fossil Fuel Burning, Cement Production, and Gas Flaring: 1950 1991

86 Production of $\mathrm{CO}_{2}$ from Fossil Fuel Burning by Fuel Type, 1860-1982.

38 The Prospect of Solving the $\mathrm{CO}_{2}$ Problem Through Global Reforestation

100 Carbon Dioxide Enrichment: Data on the Response of Cotton

Martinez, J. to Varying $\mathrm{CO}_{2}$, Irrigation, and Nitrogen

101 Daily Temperature and Precipitation Data for 223 U.S.S.R. Stations

Martuganov, R. A.

102 United States Historical Climatology Network Daily

Mason, E. H.

Temperature and Precipitation Data

100 Carbon Dioxide Enrichment: Data on the Response of Cotton

to Varying $\mathrm{CO}_{2}$, Irrigation, and Nitrogen

Mauney, J. R.

46 Effects of Air Temperature on Atmospheric $\mathrm{CO}_{2}-$ Plant

Growth Relationships

115 Field Studies of Sweet Potatoes and Cowpeas in Response

to Elevated Carbon Dioxide, 1985

Mbikayi, $N$.

115 Field Studies of Sweet Potatoes and Cowpeas in Response to Elevated Carbon Dioxide, 1985

McCrimmon, J. N.

65 Antarctic Surges-A Clear and Present Danger?

Mclnnes, B.

50 Processes for Identifying Regional Influences of and Responses to Increasing Atmospheric $\mathrm{CO}_{2}$ and Climate Change-The MINK

McKennney, M. S. Project. Report 1-Background and Baselines

50 Processes for Identifying Regional Influences of and Responses to Increasing Atmospheric $\mathrm{CO}_{2}$ and Climate Change-The MINK Project. Report IIB-A Farm-Level Simulation of the Effects of Climate Change on Crop Production in the MINK Region 
Page

80 Adapting to Sea-Level Rise in the U.S. Southeast:

Mehta, A. J.

The Influence of Built Infrastructure and Biophysical

Factors on the Inundation of Coastal Areas

122 Workshop on Sea Level Rise and Coastal Processes

15 Deforestation Measured by LANDSAT: Steps Toward a Method

Melillo, J. M.

115 Field Studies of Sweet Potatoes and Cowpeas in Response to

Menefee, A.

Elevated Carbon Dioxide, 1985

100 Carbon Dioxide Enrichment: Data on the Response of Cotton

Michell, S. T. to Varying $\mathrm{CO}_{2}$, Irrigation, and Nitrogen

73 Graduate Student Theses Supported by Carbon Dioxide Research Division Office of Basic Energy Sciences,

Millemann, R. E.

U.S. Department of Energy

111 The ALE/GAGE/AGAGE Network

Miller, B.

115 Effects of Increased Carbon Dioxide on Photosynthesis and Agricultural Productivity of Soybeans, 1981

Mishoe, J. W.

Mizuno, $T$.

124 A Report from the Second U.S./Japan Workshop on Global Change Research: Environmental Response Technologies (Mitigation and Adaptation)

A Comparison of Tropical Forest Surveys

Molofsky, J.

15 Deforestation Measured by LANDSAT: Steps 'Toward a Method

Moore, B.

32 A Comparison of Tropical Forest Surveys

Myers, N.

100 Carbon Dioxide Enrichment: Data on the Response of Cotton to Varying $\mathrm{CO}_{2}$, Irrigation, and Nitrogen

Average Total Snowfall Data For Selected U.S. Stations

National Climatic

Data Center

Flux of Organic Carbon by Rivers to the Oceans

National Research

Council

Sets Relevant to Studies of Greenhouse Gases and

Climate (CD-ROM)

Proceedings of the International Conference on Global

Newman, L. and Regional Environmental Atmospheric Chemistry 
Page

100 Carbon Dioxide Enrichment: Data on the Response of Cotton to Varying $\mathrm{CO}_{2}$, Irrigation, and Nitrogen

Nixon, P. E. III

88 Growth and Chemical Responses to $\mathrm{CO}_{2}$ Enrichment-Virginia Pine (Pinus Virginiana Mill.)

59 Quantifying and Minimizing Uncertainty of Climate Forcing by Anthropogenic Aerosols

88 Atmospheric $\mathrm{CO}_{2}$ Concentrations--The CSIRO Monitoring Program: Surface Data for Cape Grim, Tasmania

69 Global Climate Trends and Greenhouse Gas Data: Federal Activities in Data Collection, Archiving, and Dissemination. Report to the Congress of the United States Norby, R. J. Novakov, T. O'Brien, R. C. Workshop on Environmental and Societal Consequences of a Possible $\mathrm{CO}_{2}$-Induced Climate Change

Office of Health and Environmental Research, U.S. DOE

59 Quantifying and Minimizing Uncertainty of Climate Forcing by Anthropogenic Aerosols

Ogren, J.

73 Bibliography on Tropical Rain Forests and the Global Carbon Cycle. Vol. I. An Introduction to the Literature

O'Hara, F. M. Jr.

81 CDIAC Catalog-Numeric Data Packages and Computer Model Packages

34, Carbonate Chemistry of the North Pacific Ocean

Olson, E. J.

14 Carbon in Live Vegetation of Major World Ecosystems

Olson, J. S.

91 Major World Ecosystem Complexes Ranked by Carbon in Live Vegetation: A Database

91 Worldwide Organic Soil Carbon and Nitrogen Data

88 Growth and Chemical Responses to $\mathrm{CO}_{2}$ Enrichment-Virginia Pine (Pinus Virginiana Mill.)

95 GEOSECS Atlantic, Pacific, Indian, and Mediterranean Radiocarbon Data

Östlund, H. G.

99 Indian Ocean Radiocarbon: Data from the INDIGO 1, 2, and 3 Cruises

120 Workshop on Oceanic $\mathrm{CO}_{2}$ Standardization 
Page

28 Definition and Characterization of Data Needs to Describe

Ostrander, G. K. the Potential Effects of Increased Atmospheric $\mathrm{CO}_{2}$ on Marine Fisheries from the Northeast Pacific Ocean

115 Field Studies of Sweet Potatoes and Cowpeas in Response to

Pace, R. D. Elevated Carbon Dioxide, 1985

17 Seasonal Climate Scenarios for Europe and North America in a High- $\mathrm{CO}_{2}$, W'armer World

Palutikof, J.P.

15 Deforestation Measured by LANDSAT: Steps Toward a Method

Park, A. B.

100 Carbon Dioxide Enrichment: Data on the Response of Cotton to Varying $\mathrm{CO}_{2}$, Irrigation, and Nitrogen

Parker, L. L.

87 Atmospheric $\mathrm{CO}_{2}$ Concentrations-The CSIRO (Australia)

Pearman, G. I. Monitoring Program From Aircraft for 1972-1981

88 Atmospheric $\mathrm{CO}_{2}$ Concentrations--The CSIRO Monitoring Program: Surface Data for Cape Grim, Tasmania

18 Historical Carbon Dioxide: Abundances Derived from the Smithsonian Spectrobolograms

Pearson, E. W.

77 Documentation and Analysis of a Global $\mathrm{CO}_{2}$ Model Developed by Peng et al.

Peng, T.-H.

24 Reconstruction of Past Atmospheric $\mathrm{CO}_{2}$ Contents from the Chemistry of the Contemporary Ocean: An Evaluation

59 Quantifying and Minimizing Uncertainty of Climate Forcing by Anthropogenic Aerosols

Penner, J. E.

100 Carbon Dioxide Enrichment: Data on the Response of Cotton to Varying $\mathrm{CO}_{2}$, Irrigation, and Nitrogen

Peresta, G. J.

15 Deforestation Measured by LANDSAT: Steps Toward a Method

Peterson, B. J.

102 The Global Historical Climatology Network: Long-Term

Peterson, T. C. Monthly Temperature, Precipitation. Sea Level Pressure. and Station Pressure Data

94 Annual and Seasonal Global Variation in Total Ozone and LayerMean Ozone, 1958-1989

Planet, W. G.

29 Preliminary Data Report for the INDIVAT Number 1 and

Poisson, $\mathrm{A}$. INDIGO I/INDIVAT 3 Cruises in the Indian Ocean 
Page

68 Glaciers, Ice Sheets, and Sea Level: National Res. Council Effect

Polar Research

of a $\mathrm{CO}_{2}$-Induced Climatic Change

Board

41 Surface Energy Balance of Three General Circulation Models:

Portman, D.

Current Climate and and Response to Increasing Atmospheric $\mathrm{CO}_{2}$

18 Computer Implementation of a Globally Averaged Model of the

Post, W. M.

World Carbon Cycle

91 Worldwide Organic Soil Carbon and Nitrogen Data

26 The Stability of Low-Latitude Sea Surface Temperatures:

An Evaluation of the CLIMAP Reconstruction with Emphasis on the Positive SST Anomalies

111 The ALE/GAGE/AGAGE Network

Prinn, $\mathrm{R}$.

Pros, $\mathrm{H}$.

100 Carbon Dioxide Enrichment: Data on the Response of Cotton to Varying $\mathrm{CO}_{2}$, Irrigation, and Nitrogen

35 An Annotated Inventory of Climatic Indices and Data Sets

Quinlan, F. T.

90 Climatic Data for Selected U.S. and Canadian Stations, 1941-1980

$91 \quad$ United States Historical Climatology Network (HCN) Serial

Temperature and Precipitation Data

100 Carbon Dioxide Enrichment: Data on the Response of Cotton

to Varying $\mathrm{CO}_{2}$, Irrigation, and Nitrogen

Radin, J. W.

46 Effects of Air Temperature on Atmospheric $\mathrm{CO}_{2}$-Plant Growth

Relationships

59 Quantifying and Minimizing Uncertainty of Climate Forcing by Anthropogenic Aerosols

Radke, L. F.

65 Antarctic Surges-A Clear and Present Danger?

Radok, U.

85 Global Surface Air Temperture Variations: 1851-1984

Raper, S. C. B.

25 A Grid Point Surface Air Temperature Data Set for the Northern Hemisphere

27 A Grid-Point Surface Air Temperature Data Set for the Southern Hemisphere

92 An Updated Global Grid Point Surface Air Temperature Anomaly Data Set: $1851-1990$ 
Page

81 Selected Translated Abstracts of Russian-Language Climate-Change

Ravina, C. B. Publications. I. Surface Energy Budget

82 Selected Translated Abstracts of Russian-Language Climate-Change Climate-Change Publications. II. Clouds

101 Daily Temperature and Precipitation Data for 223 U.S.S.R. Stations

Razuvayev, V. N.

20 An Analysis of Possible Future Atmospheric Retention of Fossil Fuel $\mathrm{CO}_{2}$

Reichle, D. E.

20 An Analysis of Possible Future Atmospheric Retention of Fossil Fuel $\mathrm{CO}_{2}$

Reilly, J. M.

106 The IEA/ORAU Long-Term Global Energy- $\mathrm{CO}_{2}$ Model

106 The IEA/ORAU Long-Term Global Energy- $\mathrm{CO}_{2}$ Model: Personal Computer Version A84PC

36 Uncertainty in Future Global Energy Use and Fossil Fuel $\mathrm{CO}_{2}$ Emissions 1975 to 2075

53 Modeling the Response of Plants and Ecosystems to Elevated $\mathrm{CO}_{2}$ and Climate Change

Reynolds, J. F.

74 Bibliography on Tropical Rain Forests and the Global Carbon Cycle. Vol. 2. South Asia

Richards, J.F.

105 Historic Land Use and Carbon Estimates for South and Southeast Asia: 1880-1980

$3 \mathrm{CO}_{2}$ Climate Research Plan

Riches, M. R.

121 Proceedings from the Second Science Team Meeting of the United States of America Department of Energy and the People's Republic of China Academia Sinica Joint Research Program on $\mathrm{CO}_{2}$-Induced Climate Change

111 ICRCCM Infrared (Clear-Sky) Line-by-Line Radiative Fluxes

Ridgway, B.

45 Global Lake-Level Variations from 18,000 to 0 Years Ago:

A Palaeoclimatic Analysis

Roberts, N.

90 Surface Air Temperature Anomalies for the Northern Hemisphere: The Russian Dataset

Robock, A. 
Page

27 Carbonate Chemistry of the Bering Sea

Rodman, M. R.

34. Carbonate Chemistry of the North Pacific

96

115 Field Studies of Plant Responses to Elevated Carbon Dioxide

Rogers, H. H.

Levels, 1980

115 Field Studies of Sweet Potatoes and Cowpeas in Response to

Elevated Carbon Dioxide, 1985

Growth and Chemical Responses to $\mathrm{CO}_{2}$ Enrichment--Virginia

Pine (Pinus lïrginiana Mill.)

High Accuracy Standards and Reference Methodology for Carbon Dioxide in the Air

Processes for Identifying Regional Influences of and Responses to Increasing Atmospheric $\mathrm{CO}_{2}$ and Climate Change-The MINK Project. An Overview

50 Processes for Identifying Regional Influences of and Responses to Increasing Atmospheric $\mathrm{CO}_{2}$ and Climate Change---The MINK Project. Report I--Background and Baselines

50 Processes for Identifying Regional Influences of and Responses to Increasing Atmospheric $\mathrm{CO}_{2}$ and Climate Change-The MINK Project. Report IIB-A Farm-Level Simulation of the Effects of Climate Change on Crop Production in the MINK Region

14 Carbon Dioxide Emissions from Fossil Fuels: A Procedure for Estimation and Results for 1950-198,

The Changing Pattern of Fossil Fuel $\mathrm{CO}_{2}$ Emissions

Production of $\mathrm{CO}_{2}$ From Fossil Fuel Burning by Fuel Type, 1860-1982

104 Surface Water and Atmospheric Carbon Dioxide and Nitrous Oxide Observations by Shipboard Automated Gas Chromatography: Results From Expeditions Between 1977 and 1990

A Plan for Intermodel Comparison of Atmospheric $\mathrm{CO}_{2}$ Projections with Uncertainty Analysis 
Page

25 A Grid Point Surface Air Temperature Data Set for the Northern Hemisphere

Santer, B.

92 An Updated Global Grid Point Surface Air Temperature Anomaly Data Set: $1851-1990$

100 Carbon Dioxide Enrichment: Data on the Response of Cotton to Varying $\mathrm{CO}_{2}$, Irrigation, and Nitrogen

Savoy, B.

119 Proceedings of the Carbon Dioxide and Climate Research Program Conference

Schmitt, L. E.

102 The Global Historical Climatology Network: Long-Term Monthly Temperature, Precipitation, Sea Level Pressure, and Station Pressure Data by Anthropogenic Aerosols

Schwartz, W. E.

111 ICRCCM Infrared (Clear-Sky) Line-by-Line Radiative Fluxes

50 Processes for Identifying Regional Influences of and Responses to Increasing Atmospheric $\mathrm{CO}_{2}$ and Climate Change-The MINK Project Report 1-Background and Baselines

51 Processes for Identifying Regional Influences of and Responses to Increasing Atmospheric $\mathrm{CO}_{2}$ and Climate Change-The MINK Project Report III-Forest Resources

Trends '91: A Compendium of Data on Global Change--Highlights

Atmospheric $\mathrm{CO}_{2}$ Concentrations Derived from Flask Samples

Flask Samples Collected at U.S.S.R-Operated Sampling Sites

Definition and Characterization of Data Needs to Describe the Potential Effects of Increased Atmospheric $\mathrm{CO}_{2}$ on Marine Fisheries from the Northeast Pacific Ocean

Schwarzkopf, D. Sedjo, R. A.
Shaver, G. R. Shugart, H. H. Sibley, T. H. Simmonds, $\mathrm{P}$. 
Page

115 Field Studies of Plant Responses to Elevated Carbon Dioxide Levels, 1980

Smith, J. M

16 Response of the North American Corn Belt to Climate Warming

Solomon, A. M

17 Response of Unmanaged Forests to $\mathrm{CO}_{2}$-Induced Climate Change: Available Information. Initial Tests, and Data Requirements

91 Worldwide Organic Soil Carbon and Nitrogen Data

Stangenberger, A. G.

100 Atmospheric Methane Concentrations- The NOAA CMDI.

Global Cooperative Flask Sampling Network, 1983 1988

Steel, L. P

17 An Analysis of Concepts for Controlling Atmospheric Carbon Dioxide

Steinberg, M.

30 Effects of Energy Technology on Global $\mathrm{CO}_{2}$ Emissions

45 A Preliminary Analysis of U.S. $\mathrm{CO}_{2}$ Emissions Reduction Potential from Energy Conservation and the Substitution of Natural Gas for Coal in the Period to 2010

21 A Systems Study for the Removal, Recovery and Disposal of Carbon Dioxide from Fossil Fuel Power Plants in the U.S.

102 The Global Historical Climatology Network: Long-Term Monthly Temperature, Precipitation, Sea Level Pressure, and Station Pressure Data

93 Historical Sunshine and Cloud Data in the United States

18 Computer Implementation of a Globally Averaged Model of the World Carbon Cycle

Stevenson, M. P.

68 Review of Carbon Dioxide Research Staffing and Academic Support

Steurer, P. M

18 Historical Carbon Dioxide: Abundances Derived from the Smithsonian Spectrobolograms

Stokes, G. M.

15 Deforestation Measured by LANDSAT: Steps Toward a Method

Stone, T. A.

81 CDIAC Catalog-Numeric Data Packages and Computer Model Model Packages

Stevenson, W.

CDIAC Fact Sheets 
Page

78 Trends '91: A Compendium of Data on Global Change

Stoss, F. W.

(continued)

78 Trends '91: A Compendium of Data on Global Change Highlights

63 Direct Effects of Increasing Carbon Dioxide on Vegetation

Strain, B. R.

45 Global Lake-Level Variations from 18,000 to 0 Years Ago:

A Palaeoclimatic Analysis

Street-Perrott, F. A.

28 Definition and Characterization of Data Needs to Describe the

Potential Effects of Increased Atmospheric $\mathrm{CO}_{2}$ on Marine

Fisheries from the Northeast Pacific Ocean

28 Definition and Characterization of Data Needs to Describe the

Stubin, A. I.

Potential Effects of Increased Atmospheric $\mathrm{CO}_{2}$ on Marine

Fisheries from the Northeast Pacific Ocean

95 GEOSECS Atlantic, Pacific, Indian, and Mediterranean Radiocarbon

Stuiver, $M$ Data

115 Field Studies of Plant Responses to Elevated Carbon Dioxide Levels, 1980

67 Computer Hardware. Advanced Mathematics and Model Physics (CHAMMP) Pilot Project Final Report

Strickland, R. M.

4 Reconstruction of Past Atmospheric $\mathrm{CO}_{2}$ Contents from the Chemistry of the Contemporary Ocean: An Evaluation

Surano, K. A.

Swarztrauber, $P$.

Takahashi, T.

Transient Tracers in the Oceans (TTO)-Hydrographic Data and Carbon

Dioxide Systems With Revised Carbon Chemistry Data

Atmospheric $\mathrm{CO}_{2}$ Concentrations-The NOAA/GMCC Flask and

Continuous Sampling Network

Tans, $\mathbf{P}$.

53 Climate Data Bases of the People's Republic of China $1841-1988$

Tao, S.

101 Two Long-Term Instrumental Climatic Data Bases of the

People's Republic of China

17 Response of Unmanaged Forests to $\mathrm{CO}_{2}$-Induced Climate Change:

Available Information, Initial Tests, and Data Requirements

17 Response of Unmanaged Forests to $\mathrm{CO}_{2}$-Induced Climate Change:

Available Information, Initial Tests, and Data Requirements

Taylor, G. E.

Tharp, M. L. 
Page

115 Field Studies of Plant Responses to Elevated Carbon Dioxide

Thomas, J.F. Levels, 1980

20 An Analysis of Possible Future Atmospheric Retention of Fossil Fuel $\mathrm{CO}$ ?

Trabalka, J.R.

64 Atmospheric Carbon Dioxide and the Global Carbon Cycle

26 Methods of Uncertainty Analysis for a Global Carbon Dioxide Model

59 Quantifying and Minimizing Uncertainty of Climate Forcing

by Anthropogenic Aerosols

20 The Changing Pattern of Fossil Fuel $\mathrm{CO}_{2}$ Emissions

68 Review of Carbon Dioxide Research Staffing and Academic Support

17 Response of Unmanaged Forests to $\mathrm{CO}_{2}$-Induced Climate Change:

Available Information, Initial Tests, and Data Requirements

98 Atmospheric $\mathrm{CO}_{2}$ Concentrations--The Canadian Background Air Pollution Monitoring Network

III ICRCCM Infrared (Clear-Sky) Line-by-Line Radiative Fluxes

73 Bibliography on Tropical Rain Forests and the Global Carbon

Cycle. Vol. I. An Introduction to the Literature

Policy Statements on Data Management for Global

Change Research

\section{U.S. Global Change Research Program \\ Valle, $R$.}

115 Effects of Increased Carbon Dioxide on Photosynthesis and Agricultural Productivity of Soybeans, 1981

104 Surface Water and Atmospheric Carbon Dioxide and Nitrous Oxide Observations by Shipboard Automated Gas Chromatography:

Van Woy, F. A. Results From Expeditions Between 1977 and 1990

90 Surface Air Temperature Anomalies for the Northern Hemisphere: The Russian Dataset

Vinnikov, K. Ya.

102 The Global Historical Climatology Network: Long-Term Vose, R. S. Monthly Temperature, Precipitation, Sea Level Pressure, and Station Pressure Data 
Page

115 Effects of Increased Carbon Dioxide on Photosynthesis and Vu, C. V. Agricultural Productivity of Soybeans, 1981

123 Proceedings of the International Conference on Global and Regional Environmental Atmospheric Chemistry

Wang, W.

53 Climate Data Bases of the People's Republic of China $1841-1988$

Wang, W.-C.

13 Effects of Approximate Radiation Treatments Used in the Climate Models on the Clear Sky Thermal Radiation Flux and its Perturbation Due to $\mathrm{CO}_{2}$ Increase

121 Proceedings from the Second Science Team Meeting of the United States of America Department of Energy and the People's Republic of China Academia Sinica Joint Research Program on $\mathrm{CO}_{2}$-Induced Climate Change

47 Simulating Climate with Two Different Numerical Schemes

4 Surface Energy Balance of Three General Circulation Models: Current Climate and Response to Increasing Atmospheric $\mathrm{CO}_{2}$

126 Atlas of Simultaneous Occurrence of Different Cloud Types Over

Warren, S. G. Land

125 Atlas of Simultaneous Occurrence of Different Cloud Types Over the Ocean

94 Climatological Data for Clouds Over the Globe from Surface Observations

64 Global Distribution of Total Cloud Cover and Cloud Type Amounts Over Land

Global Distribution of Total Cloud Cover and Cloud Type Amounts Over the Ocean

75 Environmental Consequences of $\mathrm{CO}_{2}$-Climate Interactions: The Need for Integrated Resource Analysis

Waterhouse, J. C.

14 Carbon in Live Vegetation of Major World Ecosystems

Watts, J. A.

91 Major World Ecosystem Complexes Ranked by Carbon in Live Vegetation: A Database 
Page

17 Response of Unmanaged Forests to $\mathrm{CO}_{2}$ - Induced Climate Change:

Webb, J.W.

Available Information, Initial Tests, and Data Requirements

22 A Global Paleoclimatic Data Base for 6000 Year B.P.

Webb, T. III

88 Global Paleoclimatic Data for 6000 Ýr. B.P.

27 Carbonate Chemistry of the Bering Sea

Wei, C.-L

34. Carbonate Chemistry of the North Pacific Ocean

96

111 The ALE/GAGE/AGAGE Network

Weiss, $\mathrm{R}$.

104 Surface Water and Atmospheric Carbon Dioxide and Nitrous Oxide Observations by Shipboard Automated Gas Chromatography:

Results From Expeditions Between 1977 and 1990

88 Growth and Chemical Responses to $\mathrm{CO}_{2}$ Enrichment-Virginia Pine (Pinus Virginiana Mill.)

17 Response of Unmanaged Forests to $\mathrm{CO}_{2}$-Induced Climate Change: Available Information, Initial Tests, and Data Requirements

Weiss, R. F.

Weller, D. G

West, D. C.

63 Characterization of Information Requirements for Studies of $\mathrm{CO}_{2}$ Effects: Water Resources, Agriculture, Fisheries, Forests, and Human Health

103 A Coastal Hazards Data Base for the U.S. East Coast

White, T. W.

103 A Coastal Hazards Data Base for the U.S. Gulf Coast

76 Environmental Atlas of the lowa-Kansas-Missouri-Nebraska

Climate-Change Study Region

93 Global and Hemispheric Annual Temperature Variations Between 1861 and 1988

Wigley, T. M. L.

85 Global Surface Air Temperature Variations: 1851-1984

25 A Grid Point Surface Air Temperature Data Set for the Northern Hemisphere

27 A Grid-Point Surface Air Temperature Data Set for the Southern Hemisphere 
Page

37 Monthly Mean Pressure Reconstructiuns for Europe (back to 1780) and North America (to 18.58)

Wigley, T. M. L. (continued)

94 Monthly Mean Pressure Reconstructions for Europe (1780 1980) and North America (1858-1980)

19 Seasonal Climate Scenarios for Europe and North America in a High- $\mathrm{CO}_{2}$, Warmer World

92 An Updated Global Grid Point Surface Air Temperature Anomaly Data Set: $1851-1984$

91 United States Historical Climatology Network (HCN) Seriai Temperature and Precipitation Data

Williams, C. N. Jr.

86 Transient Tracers in the Oceans (TTO)-Hydrographic Data and Carbon Dioxide Systems With Revised Carbon Chemistry Data

Williams, R. T.

25 The Effect of Elevated Atmospheric $\mathrm{CO}_{2}$ on Plant Communities

50 Processes for Identifying Regional Influences of and Responses to Increasing Atmospheric $\mathrm{CO}_{2}$ and Climate Change--The MINK Project Report IIA--Agricultural Production and Resource Use in the MINK Region Without and With Climate Change

128 Natural Sinks of $\mathrm{CO}_{2}$

Wisniewski, J.

15 Deforestation Measured by LANDSAT: Steps Toward a Method

93 Global and Hemispheric Annual Temperature Variations Between 1861 and 1988

Williams, W. E.

Wingard, J.

Woodwell, G. M.

Wright, P. B.

39 A Primer on Greenhouse Gases

Wuebbles, D. J.

21 A Proposed Reference Set of Scenarios for Radiatively Active Atmospheric Constituents

43 Documentation of IAP Two-Level Atmospheric General Circulation Model

Yuan, C.-G.

43 Documentation of IAP Two-Level Atmospheric General Circulation Model

Zeng, Q.-C.

101 Two Long-Term Instrumental Climatic Data Bases of the People's Republic of China

Zeng, $Z$. 
Page

53 Climate Data Bases of the People's Republic of China

Zhang, Q. 1841-1988

101 Two Long-Term Instrumental Climatic Data Bases of the

People's Republic of China

43 Documentation of IAP Two-Level Atmospheric General Circulation

Zhang, X.-H. Model

33 High Accuracy Standards and Reference Methodology for Carbon Dioxide in the Air

Zielinski, W. L. Jr.

91 Worldwide Organic Soil Carbon and Nitrogen Data

Zinke, P. J. 


$$
\begin{aligned}
& \frac{1}{7} \\
& \frac{1}{7} \\
& \frac{2}{8} \\
& \times
\end{aligned}
$$


Adapting to Sea-Level Rise in the U.S. Southeast: The Influence of Built Infrastructure and Biophysical Factors on the Inundation of Coastal Areas

Alaskan Historical Climatology Network (HCN) Serial Temperature and Precipitation Data

The ALE/GAGE/AGAGE Network

An Analysis of Concepts for Controlling Atmospheric Carbon Dioxide

An Analysis of Possible Future Atmospheric Retention of Fossil Fuel $\mathrm{CO}_{2}$

An Annotated Inventory of Climatic Indices and Data Sets

Annual and Seasonal Global Temperature Anomalies in the Troposphere and Low Stratosphere, 1958-1992

Annual and Seasonal Global Variation In Total Ozone and Layer-Mean Ozone, 1958-1989

Antarctic Surface Temperature and Pressure Data Antarctic Surges-A Clear and Present Danger?
Daniels, R. C.

V. M. Gornitz
A. J. Mehta
S.-C. Lee
R. M. Cushman

Karl, T, R.

112

R. G. Baldwin

M. G. Burgin

D. R. Easterling

R. W. Knight

P. Y. Hughes

Prinn, R.
D. Cunnold
P. Fraser
R. Weiss
P. Simmonds
B. Miller
F. Alyea
A. Crawford

Steinberg, M.

Edmonds, J. A.

J. Reilly

J. R. Trabalka

D. E. Reichle

Hattemer-Frey, H. A.

T. R. Karl

F. T. Quinlan

Angell, J. K.

J. Korshover

Angell, J. K.

J. Korshover

W. G. Planet

Jones, P. D.

97

D. W. S. Limbert

Radok, U.

D. Jenssen

B. Mclnnes

111 
Atlas of Simultane
Types Over Land

Atlas of Simultaneous Occurrence of Different Cloud Types Over the Ocean

Atmospheric Carbon Dioxide and the Global Carbon Cycle

Atmospheric Carbon Dioxide and the Greenhouse Effect

Atmospheric $\mathrm{CO}_{2}$ Concentrations-The Canadian Background Air Pollution Monitoring Network

Atmospheric $\mathrm{CO}_{2}$ Concentrations-The CSIRO (Australia) Monitoring Program from Aircraft for 1972-1981

Atmospheric $\mathrm{CO}_{2}$ Concentrations-The CSIRO Monitoring Program: Surface Data for Cape Grim, Tasmania

Atmospheric $\mathrm{CO}_{2}$ Concentrations Derived from Flask Samples Collected at U.S.S.R.Operated Sampling Sites

Atmospheric $\mathrm{CO}_{2}$ Concentrations-Mauna Loa Observatory, Hawaii 1958-1991

Atmospheric $\mathrm{CO}_{2}$ Concentrations-The NOAA/GMCC Flask and Continuous Sampling Network

Atmospheric Chemistry Program. Program Operation Plan

Atmospheric Methane Concentrations-The NOAA/CMDL Global Cooperative Flask

Sampling Network, 1983-1988
Hahn, C. J.

S. G. Warren

J. London

R. M. Chervin

R. Jenne

Hahn, C. J.

S. G. Warren

J. London

R. M. Chervin

R. Jenne

Trabalka, J. R.

Carbon Dioxide Research

Program, U.S. DOE

Trivett, N. B. A.

Beardsmore, D. I.

(j. 1. Pearman

Beardsmore, D. J.

G. I. Pearman

R. C. O'Brien

Brounshtein, A. M.

E. V. Faber

A. A. Shashkov

Keeling, C. D.

Conway, T.J.

86

P. Tans

Environmental Sciences

8

Division, U.S. DOE:

Steel, L. P.

25

4

4

( 
Atmospheric Radiation Measurement Program Plan

Atmospheric Radiation Measurement Program Plan, Executive Summary

Atmospheric Sciences Program Summaries of Research in FY 1992

Atmospheric Sciences Program. Summaries of Research in FY 1993

Average Total Snowfall Data For Selected U.S. Stations

Bibliography on Tropical Rain Forests and the Global Carbon Cycle. Vol. I. An Introduction to the Literature

Bibliography on Tropical Rain Forests and the Global Carbon Cycle. Vol. 2. South Asia

Building an Advanced Climate Model Program Plan for the CHAMMP Climate Modeling Program

Carbonate Chemistry of the Bering Sea

Carbonate Chemistry of the North Pacific Ocean

Carbonate Chemistry of the Weddell Sea

Carbon Cycle Research Plan
Office of Health and

Page

Environmental Research.

U.S. DOE

Office of Health and

57

Environmental Research.

U.S. DOE

Environmental Sciences

Division, U.S. DOI:

Environmental Sciences

Division, U.S. DOE:

National Climatic Data Center

Hall, C. A. S.

S. Brown

F. M. O'Hara, Jr.

P. B. Bogdonoff

D. Barshaw, E. Kaufman

S. Underhill

Flint, E. P.

J. F. Richards

Atmospheric and Climate Research Division, U.S. DOE

Chen, C.-T. A.

C.-L. Wei

M. R. Rodman

Chen, C.-T. A.

34 ,

M. R. Rodman

96

C.-L. We

E. J. Olson

R. A. Feely

J. F. Gendron

Chen, C.-T. A.

15 ,

Dahlman, R. C. 
The Carbon Dioxide Research Plan: A Summary

Carbon Dioxide and Climate: Summaries of Research in FY 1983 and FY 1984

Carbon Dioxide and Climate: Summaries of Research in FY 1985

Carbon Dioxide and Climate: Summaries of Research in FY 1986

Carbon Dioxide and Climate: Summaries of Research in FY 1987

Carbon Dioxide and Climate: Summaries of Research in FY 1988

Carbon Dioxide and Climate: Summaries of Research in FY 1989

Carbon Dioxide and Climate: Summaries of Research in FY 1990

Carbon Dioxide and Climate: Summaries of Research in FY 1991

Carbon Dioxide Emissions from Fossil Fuels: A Procedure for Estimation and Results for 1950-1981

Carbon Dioxide Enrichment: Data on the Response of Cotton to Varying $\mathrm{CO}_{2}$ Irrigation, and Nitrogen
Page

Carbon Dioxide Research

3

Division, U.S. DOE

Marland, G.

R. M. Rotty

Kimball, B. A.

100

J. R. Mauney

R. L. LaMorte

G. Guinn

F. S. Nakayama

J. W. Radin

E. A. Lakatos

S. T. Michell

L. L. Parker

G. J. Peresta

P. E. Nixon III

B. Savoy

S. M. Harris

R. MacDonald

H. Pros

J. Martinez 
Carbon Dioxide Research Progress Report

Carbon Dynamics of Northern Hardwood Forests:

Gas Exchange Characteristics

Carbon in Live Vegetation of Major World Ecosystems

Catalog of Data Bases and Reports

CDIAC Catalog-Numeric Data Packages and

Computer Model Packages

CDIAC's Numeric Data Package Collection:

Selected Data Sets Relevant to Studies of

Greenhouse Gases and Climate (CD-ROM)

The Changing Pattern of Fossil Fuel $\mathrm{CO}_{2}$ Emissions

Characterization of Information Requirements for Studies of $\mathrm{CO}_{2}$ Effects: Water Resources, Agriculture, Fisheries, Forests, and Human Health

Climate Change and Water Supply, Management and Use: Literature Review

Climate Data Bases of the People's Republic of China 1841-1988
Dahlman, R. C.

T. J. Gross

L. Machta

W. Elliot

M. MacCracken

Jurik, T. W.

G. M. Briggs

D. M. Gates

Olson, J. S.

J. A. Watts

L. J. Allison

Carbon Dioxide Information

76

Analysis Center

Boden, T. A.

F. A. O'Hara, Jr.

F. W. Stoss

Nelson, T. R.

106

T. A. Boden

Rotty, R. M.

G. Marland

N. Treat

White, M. R.

Chang, L. H.

J. D. Draves

C. T. Hunsaker

Kaiser, D.

S. Tao

C. Fu

Q. Zhang

W.-C. Wang

T. Karl 
A Climatic Data Bank for Northern Hemisphere Land Areas, 1851-1980

Climatic Data for Northern Hemisphere Land

Areas, 1851-1980

Climatic Data for Selected U.S. and Canadian

Stations, 1941-1980

Climatological Data for Clouds Over the Globe from Surface Observations

A Coastal Hazards Data Base for the U.S. East Coast

A Coastal Hazards Data Base for the U.S. Gulf Coast

$\mathrm{CO}_{2}$ Climate Research Plan

$\mathrm{CO}_{2}$ Symposium

A Comparison of Tropical Forest Surveys

A Comprehensive Plan for Carbon Dioxide Effects and Assessment. Part 1: The Global Carbon Cycle and Climatic Effects of Increasing Carbon Dioxide

A Comprehensive Precipitation Data Set for Global Land Areas

A Computer-Based Atlas of Global Instrumental Climate Data
Page

Bradley, R. S.

P. M. Kelly

P. D. Jones

C. M. Goodess

H. F. Diaz

Bradley, R. S.

P. M. Kelly

P. D. Jones

C. M. Goodess

H. F. Diaz

Kari, T. R.

F. T. Quinlan

Hahn, C. J.

S. G. Warren

J. London

R. L. Jenne

R. M. Chervin

Gornitz, V. M.

T. W. White

103

Gornitz, V'. M.

T. W'. White

American Geophysical

Union

Molofsky, J.

C. A. S. Hall

N. Myers

Carbon Dioxide and

Climate Division,

U.S. DOE

Eischeid, J. K.

H. F. Diaz

R. S. Bradley

P. D. Jones

Bradley, R. S.

L. G. Ahern

F. T. Keimig 
Computer Hardware, Advanced Mathematics and Model Physics (CHAMMP) Pilot Project Final Report

Computer Implementation of a Globally Averaged Model of the World Carbon Cycle

Daily Temperature and Precipitation Data for 223 U.S.S.R. Stations

A Data Bank of Antarctic Surface Temperature and Pressure Data

Definition and Characterization of Data Needs to Describe the Potential Effects of Increased Atmospheric $\mathrm{CO}_{2}$ on Marine Fisheries from the Northeast Pacific Ocean

Deforestation Measured by LANDSAT: Steps Toward a Method

Detecting the Climatic Effects of Increasing Carbon Dioxide

The Determination of Total Dissolved Inorganic Carbon in Sea Water Using Extraction/Coulometry: The First Stage of a Collaborative Study

Direct Effects of Increasing Carbon Dioxide on Vegetation

Documentation and Analysis of a Global $\mathrm{CO}_{2}$ Model Developed by Peng et al.
Drake. J.

I. Foster

P. Swarztrauber

Emanuel, W. R.

G. G. K'illough

W. M. Post

H. H. Shugart

M. P. Stevenson

Razuvayev, V. N.

E. G. Apasova

R. A. Martuganov

Jones, P. D.

D. W. S. Limbert

Strickland, R. M.

D. J. Gosse

A. I. Stubin

G. K. Ostrander

T. H. Sibley

Woodwell, G. M.

J. E. Hobbie

R. A. Houghton

J. M. Melillo

B. J. Peterson

G. R. Shaver

T. A. Stone

B. Moore

A. B. Park

MacCracken, M. C

63

F. M. Luther

Dickson, A. G.

52

Strain, B. R.

J. D. Cure

Jager, H. I.
A. W. King

M. J. Sale 
Documentation of IAP Two-Level Atmospheric General Circulation Model

The Effect of Elevated Atmospheric $\mathrm{CO}_{2}$ on Plant Communities

Effects of Air Temperature on Atmospheric $\mathrm{CO}_{2}$-Plant Growth Relationships

Effects of Approximate Radiation Treatments Used in the Climate Models on the Clear Sky Thermal

Radiation Flux and its Perturbation Due to $\mathrm{CO}_{2}$ Increase

Effects of Energy Technology on Global $\mathrm{CO}_{2}$ Emissions

Effects of Increased Carbon Dioxide on Photosynthesis and Agricultural Productivity of Soybeans, 1981

Environmental Atlas of the lowa-Kansas-MissouriNebraska Climate-Change Study Region

Environmental Consequences of $\mathrm{CO}_{2}$-Climate Interactions: The Need for Integrated Resource Analysis
Page

Zeng, Q.-C.

$X$. H. Zhang

$X .-Z$. Liang

C.-G. Yuan

S.-F. Chen

Bazzaz, F. A.

K. Garbutt

W. E. Williams

Allen, S. G.

46

S. B. Idso

B. A. Kimball

J. T. Baker

L. H. Allen Jr.

J. R. Mauney

J. W. Radin

M. G. Anderson

Wang, W.-C.

13

Cheng, H. C.

M. Steinberg

M. Beller

Allen, L. H., Jr.

K. J. Boote

J. W. Jones

J. W. Mishoe

P. H. Jones, C. V. Vu

R. Valle

W. J. Carnpbell

Allison, L. J.

C. T. Hunsaker

R. M. Cushman

T. W. White

J. D. Draves

Cushman, R. M.

75

J. C. Waterhouse

M. P. Farrell 
An Evaluation of the Relationship Between the Production and Use of Energy and Atmospheric Methane Emissions

Field Studies of Plant Responses to Elevated Carbon Dioxide Levels, 1980
Barns, D. W.

J. A. Edmonds

Rogers. H. H.

G. E. Bingham

J. D. Cure

W'. W. Heck

A. S. Heagle

D. W. Isracl

J. M. Smith

K. A. Surano

J. F. Thomas

Biswas, P. K

115

Field Studies of Sweet Potatoes and Cowpeas

in Response to Elevated Dioxide, 1985

Flux of Organic Carbon by Rivers to the Oceans

GEOSECS Atlantic, Pacific, Indian, and Mediterranean

Radiocarbon Data

Glaciers, Ice Sheets, and Sea Level: Effect of a

$\mathrm{CO}_{2}$-Induced Climatic Change

J. R. Allen

N. C. Bhattacharya

J. Y. Lu, R. D. Pace

H. H. Rogers

K. B. Coleman

J. F. Eatman

P. P. Ghosh

N. Mbikayi

J. N. McCrimmon

A. Menefee

National Research

Council

120

Östlund, H. G.

95

M. Stuiver

Polar Research Board

National Res. Council

Carbon Dioxide Research

Program, U.S. DOE

Environmental Sciences

Division, U.S. DOE

Environmental Sciences

Division, U.S. DOE

Manowitz, B. 
Global Climate Trends and Greenhouse Gas Data: Federal Activities in Data Collection, Archiving. and Dissemination. A report to the Congress of the United States

Global Distribution of Total Cloud Cover and Cloud Type Amounts Over Land

Global Distribution of Total Cloud Cover and Cloud Type Amounts Over the Ocean

Global Geographic Information System Data Base of Storm Occurrences and Other Climatic Phenomena Affecting Coastal Zones

Global and Hemispheric Annual Temperature Variations Between 1861 and 1988

The Global Historical Climatology Network: Long-Term Monthly Temperature, Precipitation, Sea Level Pressure, and Station Pressure Data

Global Lake-Level Variations from 18,000 to 0 Years Ago: A Palaeoclimatic Analysis

Global Paleoclimatic Data for 6000 Yr. B.P.

A Global Paleoclimatic Data Base for 6000 Year B.P

Global, Regional, and National $\mathrm{CO}_{2}$ Emission Estimates from Fossil Fuel Burning, Cement Production, and Gas Flaring: $1950-1991$
Office of Environmental Analysis, (I.S. 1)O :

Warren, S. (j.

C. J. Hahn

J. London

R. M. Chervin

R. I. Jenne

Warren, S. G.

C. J. Hahn

J. London

R. M. Chervin

R. L. Jenne

Birdwell, K. R.

R. C. Danicls

Jones, P. D.

T. M. L. Wigley

P. B. Wright

Vose, R. S

102

R. L. Schmoyer

P. Mi. Steurer

i. C. Peterson

R. Heim

T. R. Karl

J. K. Eischeid

Street-Perroll, F. A.

D. S. Marchand

N. Roberts

S. P. Harrison

Webb, T. III

88

Webb, T. III

22

Marland, G.

96 
Global Surface Air Temperature Variations: $1851-1984$

Glossary: Carbon Dioxide and Climate

Graduate Student Theses Supported by Carbon Dioxide Research Division Office of Basic Energy Sciences, U.S. Department of Energy

A Grid-Point Surface Air Temperature Data Set for the Northern Hemisphere

A Grid-Point Surface Air Temperature Data Set for the Southern Hemisphere

Growth and Chemical Responses to $\mathrm{CO}_{2}$ Enrichment-Virginia Pine (Pinus Virginiana Mill.)

High Accuracy Standards and Reference Methodology for Carbon Dioxide in the Air

Historical Carbon Dioxide: Abundances Derived from the Smithsonian Spectrobolograms
Page

Jonces, P. I). 85

S. C. B. Raper

T. M. I. Wigley

R. S. Bradley

P. M. Kelly

II. F. Diak

Carbon Dioxide Intormation

77 Analy sis Center

Millemann, R. L:.

73

Jones, P. D.

25

S. C. B. Raper

B. Santer

B. S. Ci. Cherry

C. Goodess

P. M. Kelly

T. M. L. Wigley

R. S. Bradley

H. F. Diaz

Jones, P. D.

S. C. B. Raper

C. M. Goodess

B. S. G. Cherry

T. M. L. Wigley

Luxmoore, R. J.

88

R. J. Norby

E. G. O'Neill

D. G. Weller

J. M. Ells

H. H. Rogers

Zielinski, W. L.

E. E. Hughes

1. L. Barnes

J. W. Elkins

H. L. Rook

Stokes, G. M.

18

J. C. Barnard

E. W. Pearson 
ICRCCM Infrared (Clear-Sky) Line-by-Line

Radiative Fluxes

Historical Sunshine and Cloud Data in the United States

Historic Land Use and Carbon Estimates for South Southeast Asia: 1880-1980

Identification, Recommendation, and Justification of Potential Locales for ARM Sites

Identification, Recommendation, and Justification of Justification of Putential Locales for ARM Sites,

Executive Summary

The IEA/ORAU Long-Term Global Energy $\mathrm{CO}_{2}$ Model

The IEA/ORAU Long-Term Global Energy $\mathrm{CO}_{2}$ Model: Personal Computer Version A84PC

The Impact of Climate Change from Increased Atmospheric Carbon Dioxide on American Agriculture

Indian Ocean Radiocarbon: Data from the INDIGO 1, 2, and 3 Cruises

Intercomparison of Radiation Codes in Climate Models

International Carbon Dioxide-Related Activities:

The International Organizations Involved and U.S. Bilateral Arrangements

Major World Ecosystem Complexes Ranked by by Carbon in Live Vegetation: A Database
Page

Arking, A.

111

B. Ridgway

T. Clough

M. lacono

B. Fomin

A. Trotsenko

S. Freidenreich

D. Schwarzkopf

Steurer, P. M.

T. R. Karl

Richards, J. F.

E. P. Flint

105

Atmospheric and Climate

Research Division.

U.S. DOE

Atmospheric and Climate Research Division,

U.S. DOE

Edmonds, J. A. J. M. Reilly

Edmonds, J. A. J. M. Reilly

Decker, W. L. V. K. Jones

R. Achutuni

Östlund, H. G.

C. Grall

American Geophysical Union

Dougher, $R$.

Olson, J. S.
J. A. Watts
L. J. Allison 
Master Index for the Carbon Dioxide Research State-of-the-Art Report Series

Methods of Uncertainty Analysis for a Global Carbon Dioxide Model

Modeling $\mathrm{pCO}_{2}$ in the Upper Ocean: A Review of Relevant Physical, Chemical, and Biological Processes

Modeling the Response of Plants and Ecosystems to Elevated $\mathrm{CO}_{2}$ and Climate Change

Monthly Mean Pressure Reconstructions for Europe (Back to 1780) and North America (To 1858)

Monthly Mean Pressure Reconstructions for Europe (1780-1980) and North America (1858-1980)

Multi-Year Strategic Plan for the Atmospheric Studies in Complex Terrain (ASCOT) Program

Natural Sinks of $\mathrm{CO}_{2}$

Our Changing Planet: The FY 1991 Research Plan

Our Changing Planet: The FY 1993 U.S. Global Change Research Program

Overview of the DOE Atmospheric Chemistry Program's Ozone Project

A Plan for Intermodel Comparison of Atmospheric $\mathrm{CO}_{2}$ Projections with Uncertainty Analysis

Policy Statements on Data Management for Global Change Research

On Possible Changes in Global Sea Level and Their Potential Causes
Farrell, M. P.

64

Gardner, R. H.

20

J. R. Trabalka

Archer, D.

Reynolds, J. F.

D. W. Hilbert

J. Chen

P. C. Harley

P. R. Kemp

P. W. Leadley

Junes, P. D.

T. M. L. Wigley

K. R. Briffa

Jones, P. D.

94

T. M. L. Wigley

K. R. Briffa

linvironmental Sciences

5

Division. U.S. DOE:

Wisniewski, $\mathrm{J}$.

A. E. Lugo

Committee on Earth and Environmental Sciences

Committee on Earth and Environmental Sciences

Environmental Sciences

8 Division, U.S. DOE

King, A. W.

M. J. Sale

U. S. Global Change

69

Research Program

Barnett, T. P. 
The Possible Direct Use of Satellite Radiance
Measurements by the Atmospheric Radiation Measurement Program

A Preliminary Analysis of U.S. $\mathrm{CO}_{2}$ Emissions Reduction Potential from Energy Conservation and the Substitution of Natural Gas for

Coal in the Period to 2010

Preliminary Data Report for the INDIVAT Number 1 and INDIGO 1/INDIVAT 3 Cruises in the Indian Ocean

\section{A Primer on Greenhouse Gases}

Proceedings of the Carbon Dioxide and Climate Research Program Conference

Proceedings: Carbon Dioxide Research Conference Carbon Dioxide, Science, and Consensus

Proceedings of the International Conference on Global and Regional Environmental Atmospheric Chemistry

Proceedings of the International Meeting on Stable Isotopes in Tree-Ring Research

Proceedings of the International Symposium on Ecological Aspects of Tree Ring Analysis

Proceedings of the Second Atmospheric Radiation Measurement (ARM) Science Team Meeting

Proceedings from the Second Science Team Meeting of the United States of America Department of Energy and the People's Republic of China Academia Sinica Joint Research Program on $\mathrm{CO}_{2}$-Induced Climate Change

Processes for Identifying Regional Influences of and Responses to Increasing Atmospheric $\mathrm{CO}_{2}$ and Climate Change-The MINK Project. An Overview
Page

Envirommental Sciences

Division, U.S. DOI:

Edmonds. J. A.

W. B. Ashton

H. C. Cheng

M. Steinberg

Chen, C.-T. A.

A. Poisson

G. Goyet

Wuebbles, D. I.

J. A. Edmonds

Schmitt, L. E.

Institute for Eneres: Analysis

Newman, L.

W. Wang

C. S. Kiang

Jacoby, G.

Jacoby, G. C.. Ir.

J. W. Hornoech

Environmental Sciches

Division, LS. D(If

Wang, W.-C.

M. R. Riches

Rosenberg, N. J 


\begin{abstract}
Processes for Identifying Regional Influences of and Responses to Increasing Atmospheric $\mathrm{CO}_{2}$ and Climate Change-The MINK Project Report I. Background and Baselines
\end{abstract}

Processes for Identifying Regional Influences of and Responses to Increasing Atmospheric $\mathrm{CO}_{2}$ and Climate Change-The MINK Project Report IIA. Agricultural Production and Resource Use in the MINK Region Without and With Climate Change

Processes for Identifying Regional Influences of and Responses to Increasing Atmospheric $\mathrm{CO}_{2}$ and Climate Change-The MINK Project Report IIB. A Farm-Level Simulation of the Effects of Climate Change on Crop Production in the MINK Region

Processes for Identifying Regional Influences of and Responses to Increasing Atmospheric $\mathrm{CO}_{2}$ and Climate Change-The MINK Project Report III. Forest Resources

Processes for Identifying Regional Influences of and Responses to Increasing Atmospheric $\mathrm{CO}_{2}$ and Climate Change-The MINK Project Repor: IV. Water Resources

Processes for Identifying Regional Influences of and Responses to Increasing Atmospheric $\mathrm{CO}_{2}$ and Climate Change-The MINK Project. Report V. Energy

Processes for Identifying Regional Influences of and Responses to Increasing Atmospheric $\mathrm{CO}_{2}$ and Climate Change-The MINK Project Report VI. Consequences of Climate Change for the MINK Economy: Impacts and Responses

Production of $\mathrm{CO}_{2}$ From Fossil Fuel Burning by Fuel Type, 1860-1982
Page

Rosenberg. N. J.

50

P. R. Crosson

k. D. Frederick

W. E. Easterling III

M. S. McKenney

R. A. Sedjo

M. D. Bowes

J. Darmstadter

L. A. Katz

K. M. Lemon

Crosson, P. R.

50

L. A. Katz

J. Wingard

Easterling, W. E. III

50

M. S. McKenney

N. J. Rosenberg

K. M. Lemon

Bowes, M. D.

R. A. Sedjo

Frederick, K. D.

Darmstadter, J.

51

Bowes, M. D.

52

P. R. Crosson

Rotty, R. M.

86 


\begin{abstract}
A Proposed Reference Set of Scenarios for Radiatively Active Atmospheric Constituents

Projecting the Climatic Effects of Increasing Carbon Dioxide
\end{abstract}

The Prospect of Solving the $\mathrm{CO}_{2}$ Problem Through Global Reforestation

Quantifying and Minimizing Uncertainty of Climate Forcing by Anthropogenic Aerosols

Reconstruction of Past Atmospheric $\mathrm{CO}_{2}$ Contents from the Chemistry of the Contemporary Ocean: An Evaluation

Regional Intercomparisons of General Circulation Model Predictions and Historical Climate Data

A Report from the Second U.S./Japan Workshop on Global Change Research: Environmental

Response Technologies (Mitigation and Adaptation)

Response of the North American Corn Belt to Climate Warming

Response of Unmanaged Forests to $\mathrm{CO}_{2}$-Induced Climate Change: Available Information, Initial Tests, and Data Requirements

Review of Carbon Dioxide Research Staffing and Academic Support

Seasonal Climate Scenarios for Europe and North America in a High- $\mathrm{CO}_{2}$, Warmer World
Page

MacCracken, M. C.

F. M. Luther

Wuebbles, D. J.

M. C. MacCracken

F. M. Luther

Marland, (j.

Penner, J. E.

R. J. Charlson

J. M. Hales, N. Laulainen

R. Leifer, T. Novakov

J. Ogren, L. F. Radke

S. E. Schwartz

L. Travis

Broecker, W. S.

24

T. Takahashi

T.-H. Peng

Grotch, S. L.

Edgerton. S.

T. Mizuno

Blasing, T. J.

16

A. M. Solomon

Solomon, A. M

M. L. Tharp

D. C. West

G. E. Taylor

d. W. Webb

J. L. Trimble

Clark, S. B.

68

L. Howard

W. Stevenson

J. Trice

Palutikof, J. P.

J. M. Lough 
Selected Translated Abstracts of Russian-Language Climate-Change Publications. I. Surface Energy Budget

Selected Translated Abstracts of Russian-Language Climate-Change Publications. II. Clouds

Simulating Climate with Two Different Numerical Schemes

Solar Records: The Wolf Sunspot Index and Umbral/ Penumbral Ratio Budget

Some Aspects of the Role of the Shallow Ocean in Global Carbon Dioxide Uptake

The Stability of Low-Latitude Sea Surface

Temperatures: An Evaluation of the CLIMAP Reconstruction With Emphasis on the Positive SST Anomalies

Surface Air Temperature Anomalies for the Northern Hemisphere: The Rus'sian Dataset

Surface Energy Balance of Three General Circulation Models: Current Climate and

Response to Increasing Atmospheric $\mathrm{CO}_{2}$

Surface Water and Atmospheric Carbon Dioxide and Nitrous Oxide Observations by Shipboard Automated Gas Chromatography: Results From Expeditions Between 1977 and 1990

A Systems Study for the Removal, Recovery and Disposal of Carbon Dioxide from Fossil

Fuel Power Plants in the U.S.

Transient Tracers in the Oceans (TTO)Hydrographic Data and Carbon Dioxide Systems with Revised Carbon Chemistry Data
Ravina, C. B.

M. D. Burtis

Ravina. C. B.

M. D. Burtis

Gutowski, W. J.

M. J. Iacono

X.-Z. Liang

W'-C. Wang

Hoyt. D. V.

90

Garrels, R. M.

F. T. Mackenzie

Prell. W. L.

26

Robock, A.

90

1. I. Borzenkova

G. V. Gruza

K. Ya. Vinnikov

Gutowski, W. J.

D. S. Gutzler

D. Portman

W.-C. Wang

41

Weiss, R. F.

F. A. Van Woy

P. K. Salameh

Steinberg, $M$.

H. C. Cheng

$F$. Horn

Brewer, P. G.

86 
Tree Ring Chronology Indexes and

Reconstructions of Precipitation in Central

lowa, USA

Trends '91: A Compendium of Data on Global Change

Trends '91: A Compendium of Data on Global Change-Highlights

A Two Dimensional $\mathrm{CO}_{2}$-Ocean Model Including the Biological Processes

Two Long-Term Instrumental Climatic Data Bases of the People's Republic of China

Uncertainty in Future Global Energy Use and Fossil Fuel $\mathrm{CO}_{2}$ Emissions 1975 to 2075

United States Historical Climatology Network Daily Temperature and Precipitation Data

United States Historical Climatology

Network (HCN) Serial Temperature and

Precipitation Data

An Updated Global Grid Point Surface Air Temperature Anomaly Data Set: $1851-1990$
Blasing, T. J.

D. N. Duvick

Boden, T. A.

R. J. Sepanski

F. W. Stoss

Boden, T. A.

R. J. Sepanski

F. W. Stoss

Baes, C. F., Jr.

G. G. Killough

Tao, $\mathrm{S}$.

C. $\mathrm{Fu}$

Z. Zeng

Q. Zhang

Edmonds, J. A.

36

J. M. Reilly

R. H. Gardner

A. Brenkert

Hughes, P. Y.

E. H. Mason

T. R. Karl

W. A. Brower

101

Karl, T. R.

91

C. N. Williams Jr.

F. T. Quinlan

Jones, P. D.

92

B. S. G. Cherry

C. M. Goodess

T. M. L. Wigley

B. Santer

P. M. Kelly

R. S. Bradley

H. F. Diaz 
The Use of Statistical Climate-Crop Models for Simulating Yield to Project the Impacts of $\mathrm{CO}_{2}$ Induced Climate Change

Vegetation Response to Carbon Dioxide Research Plan

Volcanic Loading: The Dust Veil Index

Worldwide Organic Soil Carbon and Nitrogen Data

Workshop on Environmental and Societal

Consequences of a Possible $\mathrm{CO}_{2}$-Induced

Climate Change

Workshop on Oceanic $\mathrm{CO}_{2}$ Standardization

Workshop on Sea Level Rise and Coastal Processes
Decker, W. L.

R. Achutuni

43

Dahlman, R. C. 3

Lamb, H. H.

89

Zinke. P. J.
A. G. Stangenberger
W. M. Post
W. R. Emanuel
J. S. Olson

Office of Health and Environmental Research

Östlund, H. G.

D. Dyrssen

120

Mehta, A. J.

122

R. M. Cushman 


\section{Internal Distribution}

$\begin{array}{cl}\text { 1-2. } & \text { A. W. Trivelpiece, 4500N, MS-6255 } \\ \text { 3. } & \text { D. Alvic. UT/EERC } \\ \text { 4. } & \text { L. D. Bates, K-1201, MS-7256 } \\ \text { 5. } & \text { T. A. Boden, 1000, MS-6335 } \\ \text { 6. } & \text { H. L. Boston, 1505, MS-6036 } \\ \text { 7. } & \text { M. D. Burtis, 1000, MS-6335 } \\ \text { 8. } & \text { J. B. Cannon, 4500N, MS-6189 } \\ \text { 9. } & \text { J. H. Cushman, 1503, MS-6352 } \\ \text { 10. } & \text { R. M. Cushman, 1000, MS-6335 } \\ \text { 11. } & \text { R. C. Daniels, 1000, MS-6335 } \\ \text { 12. } & \text { M. P. Farrell, 1505, MS-6038 } \\ \text { 13. } & \text { D. E. Fowler, 1505, MS-6035 } \\ \text { 14. } & \text { C. W. Gehrs, 1505, MS-6036 } \\ \text { 15. } & \text { S. G. Hildebrand, 1505, MS-6037 } \\ \text { 16. } & \text { S. B. Jones, 1000, MS-6335 } \\ \text { 17. } & \text { D. P. Kaiser, 1000, MS-6335 } \\ \text { 18. } & \text { P. Kanciruk, 0907, MS-6490 } \\ \text { 19. } & \text { A. Kozyr, 1000, MS-6335 } \\ \text { 20. } & \text { D. L. Lue, 1000, MS-6335 } \\ \text { 21. } & \text { G. Marland, 1000, MS-6335 } \\ \text { 22. } & \text { L. J. Morris, 1000, MS-6335 }\end{array}$

23. T. R. Nelson, 1000, MS-6335

24. D. E. Reichle, 4500 N, MS-6253

25. R. J. Sepanski, 1000, MS-6335

26. F. E. Sharples, 1505 , MS-6036

27. D. E. Shepherd, 1000, MS-6335

28. D. S. Shriner, $1505, \mathrm{MS}-6036$

29. J. W. Simmons, 2506, MS-6039

30. T. Stamm, UT/EERC

31. F. W. Stoss, 1000, MS-6335

32. S. H. Stow, 1505 , MS-6038

33. P. L. Sullenberger, 1000, MS-6335

34. R. S. Vose, 1000, MS-6335

35. T. W. White, 1000, MS -6335

36. C. T. Woodard, 1000, MS-6335

37-52. ESD Library, 1505, MS-6035

53. Foreign Travel - RC, 4500N, MS-6264

54-55. Laboratory Records Dept., 4500N, MS-6285

56. Laboratory Records Department - RC

57. Lab. Protection Div., 3546, MS-6011

58. ORNL Patent Section, 4500 N, MS-6258

59. ORNL Public Relations, $4500 \mathrm{~N}, \mathrm{MS}-6213$

\section{External Distribution}

60. S. Alexander, Geosiiences Department, Pennsylvania State University, University Park, PA 16802

61. J. H. Allen, National Oceanic and Atmospheric Administration, WDC-A for Solar Terrestrial Physics, National Geophysical Data Center, Code E/GC2, 325 Broadway, Boulder, CO 80303

62. A. Andersen, U.S. Department of Energy, Code El-62, 1000 Independence Ave. SW, Washington. D.C. 20585

63. P. Andre, U.S. Department of Agriculture, National Agricultural Library, 10301 Baltimore Blvd., Beltsville, MD 20705

64. D. C. Bader, Battelle Pacific Northwest Laboratory, 901 D Street SW, Suite 900, Washington, D.C. 20024-2115

65. R. H. Ball, U.S. Department of Energy, Code EH-3, 1000 Independence Ave. SW, Washington, D.C. 20585

66. R. G. Barry, University of Colorado, WDC-A for Glaciology, CIRES, Campus Box 449, University of Colorado, Boulder, CO 80309-0449

67. D. Barth, Director, Harry Reid Center for Environmental Studies, 4505 South Maryland Parkway, University of Nevada, Las Vegas, NV 89154

68. G. Barton, NOAA/NODC, Room 406, 1825 Connecticut Ave. NW, Washington, D.C. 20235

69. iM. Baumgardner, Department of Agronomy, Purdue University, 1220 Potter Drive, West Lafayette, IN 47907

70. D. Bergamaschi, OES-OA/MST, Room 5081, Department of State, Washington, D.C. 20520

71. B. Bernstein, EcoAnalysis, Inc., Arcade Plaza, Suite A, 221 East Matilija, Ojai, CA 93023-0279

72. G. Brasseur, National Center for Atmospheric Research, P.O. Box 3000, Boulder, CO 803007-3000

73. D. A. Bruns, Chair, Department of Earth and Environmental Sciences, Wilkes University, WilkesBarre, PA 18766

74. D. Butler, NASA Headquarters, Mail Code SED, Washington, DC 20546

75. R. Calender, Oceanographer of the Navy, U.S. Naval Observatory, 34th St. and Massachusetts Ave. NW, Washington, D.C. 20392-5101 
76. M. S. Carter, WDC-A for Rotation of the Earth, Time Service Department, U.S. Naval Observatory, Washington, DC 20392-5100

77. M. A. Chinnery, National Oceanic and Atmospheric Administration, National Geophysical Data Center, Code E/GC2, 325 Broadway, Boulder, CO 80303

78. C. Christensen, Department of Interior, Office of Information Resources Management, 1849 C St. NW, MS-5321, Washington, D.C. 20240

79. E. Christian, U.S. Geological Survey, Information Systems Division, Reston, VA 22092

80. D. Collins, Jet Propulsion Laboratory, 4800 Oak Grove Drive, Pasadena, CA 91109

81. P. A. Crowley, Environmental Sciences Division, Office of Health and Environmental Research, ER-74, U.S. Department of Energy, Washington, D.C. 20585

82. H. Croze, Global Environment Monitoring Systems, UNEP, P. O. Box 30552, Nairobi, Kenya

83. R. C. Dahlman, Environmental Sciences Division, Office of Health and Environmental Research, ER-74, U.S. Department of Energy, Washington, D.C. 20585

84. K. Davidson, Deputy Director, National Climatic Data Center, Federal Building, Asheville, NC 28801

85. L. DeMouy, U.S. Department of Energy, Code EI-623, 1000 Independence Ave. SW, Washington, D.C. 20585

86. S. Digby, Jet Propulsion Laboratory, 4800 Oak Grove Drive, Pasadena, CA 91109

87. B. C. Douglas, National Oceanographic Data Center, NOAA, Room 406, Universal Building South. 1825 Connecticut Ave. NW, Washington, DC 20235

88. W. C. Draeger, WDC-A for Land Remotely Sensed Data, EROS Data Center, U.S. Geological Survey, Sioux Falls, SD 57198

89. J. J. Easton, Jr., Assistant Secretary for International Affairs and Energy Emergencies, (IE-1), Department of Energy, Washington, D.C. 20585

90. J. W. Elwood, Environmental Sciences Division, Office of Health and Environmental Research, ER-74, U.S. Department of Energy, Washington, D.C. 20585

91. Energy Library (HR-832.1/GTN), U.S. Department of Energy, Office of Administration and Management, G-034 Germantown, Washington, D.C. 20585

92. Energy Library (HR-832.2/WAS), U.S. Department of Energy, Office of Administration and Management, GA-138 Forrestal Building, Washington, D.C. 20585

93. L. Enomoto, NOAA/NESDIS, FB-4, Room 0110, Washington, D.C. 20233

94. G. Evans, U.S. Department of Agriculture, Global Change Program Office, 1621 N. Kent Street, Room 60LL, Arlington, VA 22209

95. R. N. Farvolden, Professor, Department of Earth Sciences, University of Waterloo, Waterloo, Ontario N2L 3GI Canada

96. J. Fein, National Science Foundation, Atmospheric Science Division, 1800 G St. NW, Washington, D.C. 20550

97. W. Ferrell, U.S. Department of Energy, 1000 Independence Ave. SW, Washington. D.C. 20585

98. J. Filson, WDC-A for Seismology, U.S. Geological Survey, 922 National Center. Reston, VA 22092

99. J. F. Franklin, Bloedel Professor of Ecosystem Analysis, College of Forest Resources. University of Washington, Anderson Hall (AR-10), Seattle. WA 98195

100. D. W. Freckman, Director, College of Natural Resources, 101 Natural Resources Building. Colorado State University, Fort Collins, CO 80523.

101. A. Ghovanlou, Technical Director, Space Systems Division, Mitre Corporation, 7525 Colshire Drive, MS Z650, McLean, VA 22102

102. S. N. Goldstein, National Science Foundation. 1800 G St. NW, Room 416. Washington. D.C. 20550

103. S. Graves, NASA, Code SED, 600 Independence Ave. SW. Washington. D.C. 20546

104. J. L. Green, National Space Science Data Center, NASA Goddard Space Flight Center, Code 630.2. Greenbelt, MD 20771

105. T. J. Gross, Environmental Sciences Division, Office of Health and Environmental Research. ER-74, U.S. Department of Energy, Washington. D.C. 20585

106. K. Hadeen, NOAA National Climatic Data Center, Federal Building, Asheville. NC 28801 
107. R. C. Harriss, Institute for the Study of Earth, Oceans, and Space, Science and Engineering Research Building. University of New Hampshire, Durham. NH 03824.

108. R. Hayes. Oceanographer of the Navy. U.S. Naval Observatory. 34th St. and Massachusetts Ave. NW, Washington, D.C. 20392-5101

109. G. M. Hornberger, Professor, Department of Environmental Sciences, University of Virginia. Charlottesville, VA 22903

110. J. C. Houghton. Environmental Sciences Division, Office of Health and Environmental Research. ER-74, U.S. Department of Energy. Washington. D.C. 20585

111. G. Hunolt, NASA, Code SED, 600 Independence Ave. SW, Washington. D.C. 20546

112. G. Y. Jordy, Director, Office of Program Analysis, Office of Energy Research, ER-30, G-226, U.S. Department of Energy, Washington, D.C. 20545.

113. J. Joyce, National Science Foundation. Atmospheric Science Division, 1800 G St. NW. Washington, D.C. 20550

114. T. R. Karl, National Climatic Data Center, Federal Building, Asheville, NC 28801

115. J. H. King, WDC-A for Rockets and Satellites, National Space Science Data Center, Code 930.2. NASA Goddard Space Flight Center, Greenbelt, MD 20771

116. D. T. Lauer, EROS Data Center, U.S. Geological Survey, Sioux Falls, SD 57198

117. S. Levitus, WDC-A for Oceanography, NOAA/NESDIS, E/OC23, Universal Building, Room 409. 1825 Connecticut Ave. NW, Washington, DC 20235

118. A. M. Linn, Program Officer, BESR, National Academy of Sciences, Harris Building 372, 2101 Constitution Ave. NW, Washington, DC 20418

119. M. S. Loughridge, WDC-A for Marine Geology and Geophysics, National Oceanic and Atmospheric Administration, National Geophysical Data Center, Code E/GC3, 325 Broadway, Boulder, CO 80303

120. G. H. Ludwig, HC 33, Box 641, Winchester, VA 22601

121. P. Lunn, Environmental Sciences Division, Office of Health and Environmental Research, ER-74. U.S. Department of Energy, Washington, D.C. 20585

122. T. H. Mace, U.S. Environmental Protection Agency, Room 1123 West Tower, 401 M St. SW, Washington, D.C. 20460

123. L. McGoldrick, SMSRC, 600 Maryland Ave. SW, Suite 440, Washington, D.C. 20024

124. L. H. Meredith, USRA, 600 Maryland Ave. SW. Suite 440, Washington, D.C. 20024

125. H. Meyers, WDC-A for Solid Earth Geophysics, National Geophysical Data Center, NOAA, E/GC.1, 325 Broadway, Boulder, CO 80303

126. C. Miller, NOAA/NESDIS, 1825 Connecticut Ave. NW, Suite 506, Washington, DC 20235

127. R. E. Munn, University of Toronto, Institute for Environmental Studies, Toronto, Ontario M $5 \mathrm{~S}$ 184, Canada

128. B. Niemann, U.S. Environmental Protection Agency, PM-223X, 401 M St. SW, Washington, D.C. 20460

129. S. Nishioka, Director, Center for Global Environmental Research, National Institute for Environmental Studies, 16-2 Onogawa, Tsukuba, Ibaraki 305, Japan

130. S. Okimasa, Head, WMO World Data Center for Greenhouse Gases, 1-3-4 Otemachi, Chiyoda-ku, Tokyo 100, Japan

131. R. H. Olsen, Vice President for Research, University of Michigan, Medical Science Building II, \#5605, 1301 East Catherine Street, Ann Arbor, MI 48109-0610

132. J. T. Overpeck, National Oceanic and Atmospheric Administration, National Geophysical Data Center, WDC-A for Paleorlimatology, 325 Broadway E/GC, Boulder, CO 80303

133. A. Patrinos, Director, Environmental Sciences Division, Office of Health and Environmental Research, ER-74, U.S. Department of Energy, Washington, D.C. 20585

134. W. Person, National Earthquake Iıformation Center, U.S. Geological Survey, Box 25046, Mail Stop 967, Denver Federal Center, Denver, CO 80225-0046

135. L. Pettinger, National Mapping Division, USGS/DOI, 590 National Center, Reston, VA 22092

136. R. Rand, USDA/NAL/ISD/DAB, 10301 Baltimore Blvd., Beltsville, MD 20705-2351

137. I. Rasool, Lab de Meteorologie, Dynamique, Du C.N.R.S., Ecole Normale Superieure, 24 Rue Lhomond, 75231 Paris, Cedex 05 France 
138. M. R. Riches, Environmental Sciences Division, Office of Health and Environmental Research, ER74, U.S. Department of Energy, Washington, D.C. 20585

139. M. Rodon-Naveira, EPA/ORD, 401 M Street SW, Washington, D.C. 20460

140. E. Russek-Cohen, Department of Animal Sciences, University of Maryland, College Park, MD 20742

141. S. Ruttenberg, University Corporation for Atmospheric Research, CSNET, 3300 Mitchell Lane, Suite 120, Boulder, CO 80301

142. H. H. Shugart, Department of Environmental Sciences, Clark Hall, University of Virginia. Charlottesville, VA 22903

143. A. L. Shumbera, National Oceanic and Atmospheric Administration, WDC-A for Meteorology, National Climatic Data Center, Federal Building, MC E/CC, Asheville, NC 28801

144. S. Sorooshian, Department of Hydrology and Water Resources, University of Arizona, Tucson, AZ 85721

145. P. M. Steurer, National Clinatic Data Center, Database Management Branch, Federal Building, Asheville, NC 28801

146. J. Thieman, NASA/GSFC, Bldg. 26, Room 138, Code 933, Greenbelt, MD 20771

147. R. E. Thompson, Department of Agriculture, National Agricultural Library, 10301 Baltimore Blvd. $/ 5$ th Floor, Beltsville, MD 20705

148. P. F. Uhlir, Assistant Executive Director, Commission on Physical Sciences, Mathematics, and Applications, National Research Council, 2101 Constitution Avenue NW, Washington, D.C. 20418

149. C. Watts, NOAA/Library, 6009 Executive Blvd., Rockville, MD 20852

150. F. Webster, College of Marine Studies, University of Delaware, Lewes, DE 19958

151. G. B. Wiersma, Dean, College of Forest Resources, Maine Agricultural Experiment Station, 202 Nutting Hall, University of Maine, Orono, ME 04469

152. R. Williams, U.S. Department of Agriculture, OIRM - Room 414-W, Washington, D.C. 20250

153. G. Withee, NOAA/NODC, Room 506, 1825 Connecticut Ave. NW, Washington, D.C. 20235

154. F. J. Wobber, Environmental Sciences Division, Office of Health and Environmental Research, ER-74, U.S. Department of Energy, Washington, D.C. 20585

155. L. Wolf, National Academy of Sciences, 2001 Wisconsin Ave. NW, Harris Building 372 , Washington, D.C. 20007

156. J. Young, Commission on Physical Sciences, Mathematics, and Applications, National Research Council, 2101 Constitution Avenue NW, Washington, D.C. 20418

157. Office of Assistant Manager for Energy Research and Development, Oak Ridge Field Office, P.O. Box 2001, U.S. Department of Energy, Oak Ridge. TN 37831-8600

158-59. Office of Scientific and Technical Information. P.O. Box 62. Oak Ridge, TN 37831 


\section{Catalog of Data Bases and Reports Order Form...}

\section{Numeric Data Package (NDP) and Computer Model Package (CMP) request(s):}

$\begin{array}{cc}\text { NDP/CMP } & \text { Documentation } \\ \text { number } & \text { only }\end{array}$

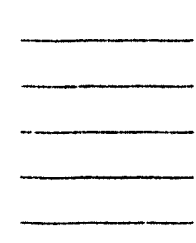

Documentation and floppy diskette*

\author{
Documentation \\ and \\ 9-track tape*
}
Documentation and $8 \mathrm{~mm}$ tape*

The following MUST be specified if a floppy diskette, 9-track magnetic tape, or $8 \mathrm{~mm}$ tape is requested:

\begin{tabular}{|c|c|c|c|c|c|}
\hline \multicolumn{2}{|c|}{ DOS floppy diskette } & \multicolumn{3}{|c|}{ 9-track magnetic tape } & \multirow{2}{*}{$\frac{8 \mathrm{~mm} \text { tape }}{\text { Capacity }}$} \\
\hline Size & Density & Density & Label & Character set & \\
\hline $\begin{array}{l}\text { D. } 51 / 4 " \\
31 / 2 "\end{array}$ & $\begin{array}{l}\square \text { High } \\
\square \text { Low }\end{array}$ & $\begin{array}{l}\square 1600 \mathrm{BPI} \\
\square 6250 \mathrm{BPI}\end{array}$ & $\begin{array}{l}\square \text { Nonlabeled } \\
\square \text { Standard }\end{array}$ & $\begin{array}{l}\square \text { EBCDIC } \\
\square \text { ASCII }\end{array}$ & $\begin{array}{l}\square 2.3 \mathrm{~GB} \\
\square 5 \mathrm{~GB}\end{array}$ \\
\hline
\end{tabular}

C. Numeric data on $150 \mathrm{MB}$ QIC (quarter inch cartridge) tape $\square$ with documentation

$\square$ without documentation

D. CD-ROM: CDIAC's Numeric Duta Package Collection: Selected Duta Sets Relevant to Studies of Greenhouse Gases and Climate

Instructions for accessing CDIAC's numeric data via anonymous FTP files on the Internet or other networks

\section{CDIAC/DOE Technical Reports}

\section{Report}

Number Title (can be tiuncated)

Name

(Last)

(First)

(M.I.)

Organization

Mailing Address

City State ZIP Country 

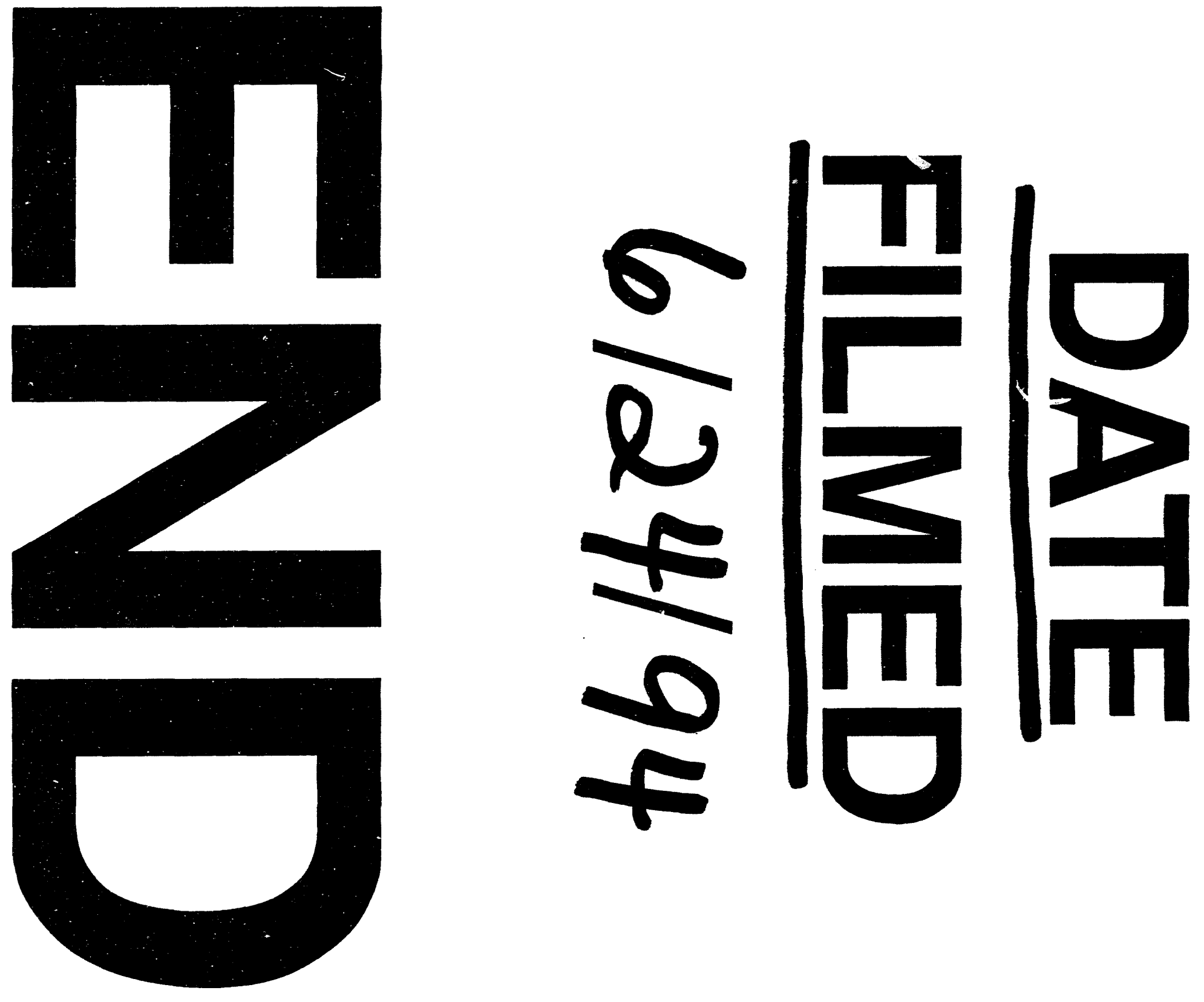
